\title{
WestVirginiaUniversity
}

THE RESEARCH REPOSITORY @ WVU

Graduate Theses, Dissertations, and Problem Reports

2002

\section{Modeling and dynamic stability of distributed generations}

\author{
Zhixin Miao \\ West Virginia University
}

Follow this and additional works at: https://researchrepository.wvu.edu/etd

\section{Recommended Citation}

Miao, Zhixin, "Modeling and dynamic stability of distributed generations" (2002). Graduate Theses, Dissertations, and Problem Reports. 1712.

https://researchrepository.wvu.edu/etd/1712

This Dissertation is protected by copyright and/or related rights. It has been brought to you by the The Research Repository @ WVU with permission from the rights-holder(s). You are free to use this Dissertation in any way that is permitted by the copyright and related rights legislation that applies to your use. For other uses you must obtain permission from the rights-holder(s) directly, unless additional rights are indicated by a Creative Commons license in the record and/ or on the work itself. This Dissertation has been accepted for inclusion in WVU Graduate Theses, Dissertations, and Problem Reports collection by an authorized administrator of The Research Repository @ WVU.

For more information, please contact researchrepository@mail.wvu.edu. 


\title{
Modeling $\lceil$ and Dynamic $\$ Stability of Distributed Generations
}

by

\author{
Zhixin Miao
}

\author{
Dissertation submitted to the \\ College of Engineering and Mineral Resources \\ at West Virginia University \\ in partial fulfillment of the requirements \\ for the degreel of
}

Doctor of Philosophy

in

Electrical Engineering

Professor Ian Christie, Ph.D.

Professor Ali Feliachi, Ph.D.

Professor Powsiri Klinkhachorn, Ph.D.

Professor Muhammad A. Choudhry, Ph.D., Co-Chair

Professor Ronald L. Klein, Ph.D., Chair

Lane Department of Computer Science and Electrical Engineering

Morgantown, West Virginia

2002

Keywords:

distributed generations, dynamic stability, control, power systems

Copyright 2002 Zhixin Miao 


\author{
Abstract \\ Modeling and Dynamic Stability of Distributed Generations \\ by \\ Zhixin Miao \\ Doctor of Philosophy in Electrical Engineering \\ West Virginia University \\ Professor Muhammad A. Choudhry, Ph.D., Co-Chair \\ Professor Ronald L. Klein, Ph.D., Chair
}

The objective of this dissertation is to develop dynamic models for distributed generations (DG), to investigate their impacts on dynamic stability of power distribution systems, and to design controllers for DGs to improve the dynamic stability of the integrated power distribution system.

A two-year distributed generation (DG) project at West Virginia University (WVU) evaluated the impact of various DG sources on actual distribution systems by performing computer simulations. The data is supplied by two regional electric utilities of two actual distribution systems each. In this project several important issues were investigated, including the availability of simulation tools and impacts of DGs connected to a distribution line under a variety of line operating conditions. Based on this preliminary research the further most interesting topics for continued research were raised.

The continued research has focused on deeper investigation, such as, modeling DG sources, evaluating their interaction and impacts, and improving the dynamic stability of the integrated power distribution system. Four specific DGs are studied in this dissertation: fuel cell power plant, wind turbine induction generator, gas turbine synchronous generator and diesel engine synchronous generator.

A full-order synchronous generator model represents the generator models of gas turbine generator and diesel engine generator. A simplified gas turbine model has been chosen to be implemented. A practical diesel engine for emergency use is modeled. The generator model of wind turbine induction generator is represented by a full-order induction generator. The rated power operating regime is considered for impacts evaluations and controller design. Two types of fuel cell models are developed. The first one is a model of already operational phosphoric acid fuel cell (PAFC) obtained through data fitting and the second one is dynamic model of solid oxide fuel cell (SOFC). Since fuel cells are connected to the electric power network via inverters, an inverter model has been developed.

Multi-DG controls are investigated in this dissertation. One DG control is fuel cell control, the other one is wind-turbine control. The control of fuel cell (SOFC) plant is through the inverter to adjust active power injection to the network during the transient time. The control of wind 
turbine generator is through the parallel connected SVC by adjusting reactive power injection to the system. Both control schemes are centralized.

Linear analysis methodologies are utilized in designing the controller. In the fuel cell control design, two pairs of critical modes are screened out using eigenvalue analysis. The participation factors of DGs with respect to the modes are calculated. Two specific lead-lag compensation units are designed to damp each mode separately. The gains of the two compensation units were then obtained via optimal control methodology. In wind turbine DG control design procedure, three rotor speed deviations are used as input signals while the controller outputs are the firing angle for the SVC and the pitch angle for the wind-turbine DG. An output feedback controller is designed. The dynamic load characteristic is also considered by modeling it as a structured uncertainty. $\mu$ analysis is used to evaluate the robust stability of the controllers with respect to the uncertain parameters in the dynamic loads. The IEEE-13 node radial feeder with existing gas turbine and diesel engine DGs is used as a test system to evaluate the multi-DG control. The simulation results demonstrate the effectiveness of the control strategies.

Coordinated operation of all the DGs is investigated. Simulation results show that good configurations within DGs along the system can improve the system stability. Furthermore, the fast acting SVC is very effective in improving damping. Among the DGs investigated in this research, the fuel cell plant control is the best choice for the coordinated operation.

Finally, the approach to model a complete three-phase power distribution system is implemented. The impact of the developed DGs models is evaluated on a three-phase unbalanced distribution system. The three-phase 13-node IEEE system with gas turbine and diesel engine DGs is simulated using MATLAB/Simulink's Power System Blockset (PSB). In the simulation, a three-phase thyristor controlled braking resistor (TCBR) is connected to absorb the surplus energy when the system is subjected to a disturbance. The three-phase dynamic simulation demonstrates the effectiveness of the proposed strategy. 


\section{Acknowledgements}

I am very glad to thank people who helped me during my study to pursue the Ph.D. degree.

To Prof. Ronald Klein, chair of my committee, for his continuous support over the years, his guidance on my research and his patience and kindness. His advice and help make it possible for me to finish the Ph.D. program.

To Prof. Muhammad Choudhry, co-chair of my committee, for his generous help and contribution on my academic progress.

I would like to thank Prof. Feliachi, Prof. Klink and Prof. Christie for serving in my

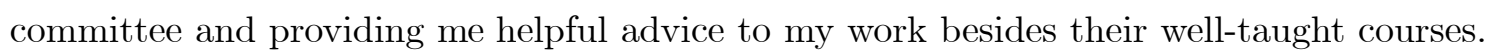

My gratefulness goes to my parents, for they raised me up and continually encourage me to pursue my career.

A special thanks goes to my wife for her love and supporting throughout my study. 


\section{Contents}

Acknowledgements $\square \quad$ iv

List of Figures $\square \quad$ x

List of $\leftarrow$ Tables $\square \quad$ xiv

1 Introduction $\quad 1$

1.1 Problem Description . . . . . . . . . . . . . . . . . . 1

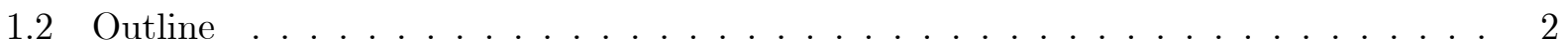

2 Literature Survey 4

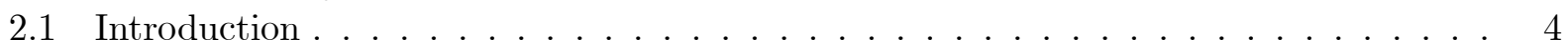

2.2 Models of Distributed Generations _ . . . . . . . . . . . . . . . 4

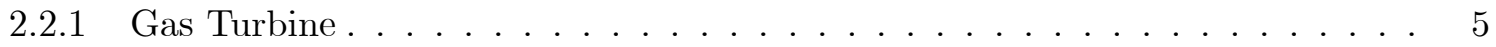

2.2 .2 Diesel Engine . . . . . . . . . . . . . . . . . . . . 6

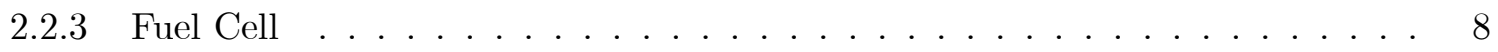

2.2 .4 Wind Turbine . . . . . . . . . . . . . . . . . . . . 9

2.3 Control Strategies for DGs . . . . . . . . . . . . . . . . . . 11

2.3.1 Linear Analysis . . . . . . . . . . . . . . . . . . . . . . 11

2.3.2 Model Reduction . . . . . . . . . . . . . . . . . . . . 11

2.3 .3 Control Schemes . . . . . . . . . . . . . . . . . . . . 12

2.3 .4 Coordinated Control . . . . . . . . . . . . . . . . . . 13

2.3.5 Robust Analysis of the Load Parameter Uncertainty . . . . . . . . . . . . . 13

2.4 Power Electronics Application . . . . . . . . . . . . . . . . . . . 13

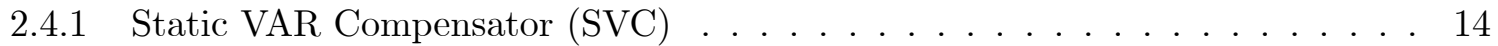

2.4 .2 Current/Voltage Source Inverter (CSI/VSI) . . . . . . . . . . . . . . . 14

2.4.3 Thyristor Controlled Braking Resistor (TCBR) . . . . . . . . . . . . 14

3 Preliminary Research of DGs $\quad 16$

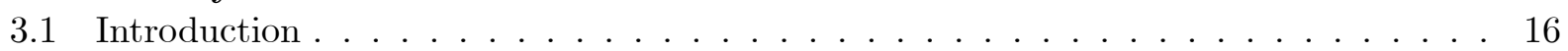

3.2 Models of An Actual Distribution System . . . . . . . . . . . . . . . . 16

3.2 .1 Suburban System I (SI) . . . . . . . . . . . . . . . . . . . 16

3.2 .2 Models . . . . . . . . . . . . . . . . . . . . 17

3.3 Test Cases and Simulation Results . . . . . . . . . . . . . . . . 18 
3.3 .1 Fault Location . . . . . . . . . . . . . . . . . . . . 19

3.3.2 Fault Clearing Time . . . . . . . . . . . . . . . . . . . . 19

3.3.3 Reclosing Time . . . . . . . . . . . . . . . . . . 21

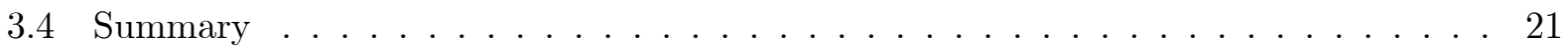

4 DGs Simulation and Linear Analysis with Simulink 24

4.1 Introduction . . . . . . . . . . . . . . . . . . . . . . . . 24

4.2 System Models . . . . . . . . . . . . . . . . . . . . 25

4.2.1 Full-Order Synchronous Generator . . . . . . . . . . . . . . . . 25

4.2 .2 Substation Model . . . . . . . . . . . . . . . . . . 26

4.2 .3 Gas Turbine . . . . . . . . . . . . . . . . . . . 27

4.2 .4 Diesel Engine . . . . . . . . . . . . . . . . . . . . . . 28

4.2.5 Average Model of IEEE-13 Node Feeder . . . . . . . . . . . . . . . . . 28

4.3 Building Synchronous Generator Model using Matrix Concept in Simulink . . . . . . 29

4.4 Models Linearization . . . . . . . . . . . . . . . . . . . . 31

4.4 .1 Linearized Substation Model . . . . . . . . . . . . . . . . 32

4.4.2 Linearized Gas Turbine Synchronous Generator . . . . . . . . . . . . . . . . 32

4.4.3 Linearized Diesel Engine Synchronous Generator . . . . . . . . . . . . . . . 33

4.5 Eigenvalue Analysis . . . . . . . . . . . . . . . . . . . 35

4.5.1 Eigenvalue of the Distribution System with DGs . . . . . . . . . . . . . 35

4.5 .2 Eigenvalue Sensitivity . . . . . . . . . . . . . . . 37

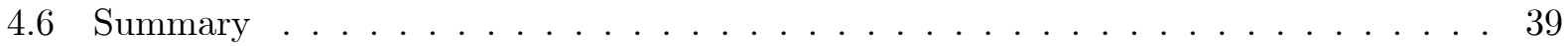

5 A Phosphoric Acid Fuel Cell Model from Data Fitting 40

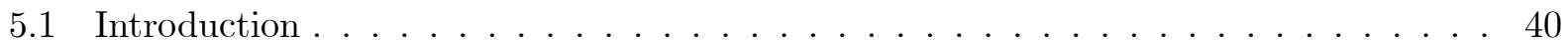

5.2 V-I Characteristics . . . . . . . . . . . . . . . . . . . 41

5.3 Data Fitting . . . . . . . . . . . . . . . . . . . . . . . . . . . . . . . . . .

5.3 .1 Least Squares Optimization Algorithm . . . . . . . . . . . . . . . . . 43

5.3.2 Fuel Cell Transient Output Current Modeling . . . . . . . . . . . . . . . . . . . . . 44

5.3.3 Fuel Cell Transient Output Voltage Modeling . . . . . . . . . . . . . . . . . 46

5.3 .4 Fuel Cell Modeling . . . . . . . . . . . . . . . . . . . . . . 49

5.4 Configuration of Test System with DGs . . . . . . . . . . . . . . . . 49

5.5 Simulation Study . . . . . . . . . . . . . . . . . . . . . 51

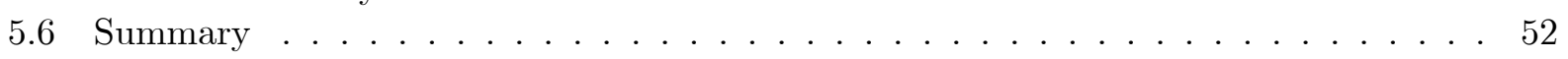

6 Dynamic Modeling of A Solid Oxide Fuel Cell Power Plant 55

6.1 Introduction . . . . . . . . . . . . . . . 55

6.2 Structure of A SOFC Power Plant . . . . . . . . . . . . . . . . 56

6.3 Dynamic Model of Solid Oxide Fuel Cell (SOFC) $\ldots \ldots \ldots$. . . . . . . . 57

6.4 Power Conditioning Unit $(\mathrm{PCU}) \ldots \ldots \ldots \ldots$

6.5 Inverter Control Unit . . . . . . . . . . . . . . . . . . . . . . . . 59

6.6 Model Simulation and Test . . . . . . . . . . . . . . . 61

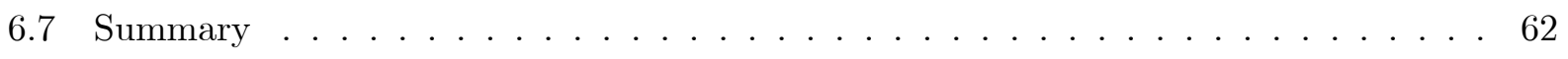


7 Dynamic Stability Control for A SOFC Power Plant 65

7.1 Introduction . . . . . . . . . . . . . . . . . . . 65

7.2 System Configuration _. . . . . . . . . . . . . . . . . 65

7.3 System Linearization . . . . . . . . . . . . . . . . . . . . 66

7.4 Controller Design to Assign Eigenvalues . . . . . . . . . . . . . . . . . . 69

7.4.1 Phase Angle Compensation . . . . . . . . . . . . . . . . 71

7.4.2 Optimal Control Algorithm to Select Gains . . . . . . . . . . . . . . . . . 72

7.5 Simulation Results . . . . . . . . . . . . . . . . . 73

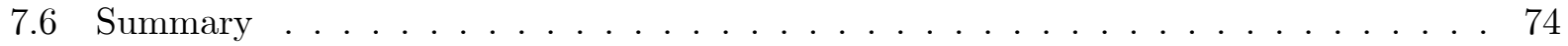

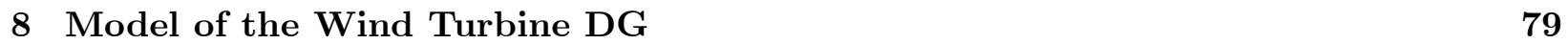

8.1 Introduction . . . . . . . . . . . . . . . . . . . . . 79

8.2 System Models . . . . . . . . . . . . . . . . . . . . . . 80

8.2 .1 Wind Turbine Model . . . . . . . . . . . . . . . . . . . 80

8.2 .2 Induction Generator . . . . . . . . . . . . . . . . . . . . . . . 81

8.2 .3 Static VAR Compensator $(\mathrm{SVC}) \ldots \ldots \ldots \ldots$. . . . . . . . . . . . . . . . . . . . . . . . 81

8.2.4 Static and Dynamic Load Models . . . . . . . . . . . . . . . . . 82

8.3 Control Unit Model . . . . . . . . . . . . . . . . . . . . . . 83

8.4 Induction Machine Simulation . . . . . . . . . . . . . . . . . . . 84

8.4.1 Matrix Concepts Based Induction Machine Model . . . . . . . . . . . . . 85

8.4 .2 Induction Machine Simulink Model . . . . . . . . . . . . . . . . . . . 85

8.4 .3 Initialization of the Induction Machine . . . . . . . . . . . . . . . . . 86

8.4.4 Start-up Procedure and Step Response of Induction Machine . . . . . . . . . 88

8.4.5 Linearized Induction Machine . . . . . . . . . . . . . . . . . . . 88

8.5 Integration of Wind Turbine DG . . . . . . . . . . . . . . . 90

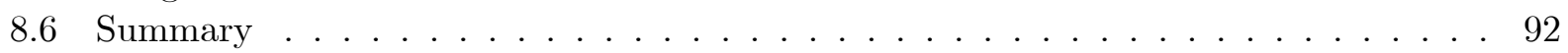

9 Robust Control of Wind Turbine DG $\quad 94$

9.1 Introduction . . . . . . . . . . . . . . . . . . . . . . 94

9.2 System Configuration . . . . . . . . . . . . . . . . . . . 94

9.3 Critical Eigenvalues Identification . . . . . . . . . . . . . . . . 95

9.3.1 Ranking Indices of the Eigenvalues . . . . . . . . . . . . . . . . . 95

9.3 .2 Dominant Eigenvalues Identification . . . . . . . . . . . . . . . . 97

9.4 Controller Design . . . . . . . . . . . . . . . . . . . . . . 98

9.4.1 Multivariable Coordinated Controller . . . . . . . . . . . . . . 98

9.4 .2 Design Results . . . . . . . . . . . . . . . . . . . . 98

9.5 Nonlinear Simulation to Test Controller . . . . . . . . . . . . . . . . . . . . 99

9.6 Controller Robustness Analysis . . . . . . . . . . . . . . . . . . . . . 102

9.6.1 Representing Uncertainty . . . . . . . . . . . . . . . . . . . . . 102

9.6 .2 Parametric Uncertainty . . . . . . . . . . . . . . . . . . . . . . 103

9.6.3 Analyzing Robust Stability . . . . . . . . . . . . . . . . . . . . . 104

9.7 Simulation Results of Robustness Analysis . . . . . . . . . . . . . . . 106

9.8 Summary . . . . . . . . . . . . . . . . . . . . . . . 108 
10 Coordinated Operation of Multiple Types of DGs 111

10.1 Introduction . . . . . . . . . . . . . . . . . . . 111

10.2 Interaction of DGs . . . . . . . . . . . . . . . . . . . 111

10.3 Critical Eigenvalues and Controller Design . . . . . . . . . . . . . . . . 115

10.4 Impacts of Different Real Power Penetrations . . . . . . . . . . . . . . . . . 118

10.5 Summary . . . . . . . . . . . . . . . . . . . . . . . 119

11 Three-Phase Distribution System Study $\quad 120$

11.1 Introduction . . . . . . . . . . . . . . . . . . . . 120

11.2 System Models . . . . . . . . . . . . . . . . . . . . 121

11.2.1 Excitation System Model . . . . . . . . . . . . . . . . . 121

11.2.2 Thyristor Controlled Braking Resistor (TCBR) . . . . . . . . . . . . . 121

11.3 Controller Design . . . . . . . . . . . . . . . . . . . . . . 123

11.3.1 Basic Concepts of Variable Structure Controller . . . . . . . . . . . . . . . . 123

11.3.2 Dynamic Braking Control Strategy . . . . . . . . . . . . . . . . . . 123

11.3.3 Three-Phase Control Strategy . . . . . . . . . . . . . . . . . . . 124

11.4 Test System of TCBR . . . . . . . . . . . . . . . . . . 125

11.5 Dynamic Simulation Results . . . . . . . . . . . . . . . . . 127

11.6 Summary . . . . . . . . . . . . . . . . . . . . . 127

12 Conclusion $\quad 130$

$\begin{array}{ll}\text { References } & 133\end{array}$

$\begin{array}{lr}\text { A Configuration of Models } & 143\end{array}$

A.1 Full-Order Synchronous Generator Model . . . . . . . . . . . . . . . . . . 143

A.2 Simplified Synchronous Generator Model . . . . . . . . . . . . . . . . 146

A.3 Induction Machine . . . . . . . . . . . . . . . . . . 147

A.4 Voltage Source Inverter ． . . . . . . . . . . . . . . . . 149

A.5 Test Systems . . . . . . . . . . . . . . . . . . . . . . . . . . . . 149

A.5.1 IEEE-13 Node Test Feeder . . . . . . . . . . . . . . . . 150

A.5.2 Line Segment Data . . . . . . . . . . . . . . . . . 150

B Parameters for Simulation $\quad 154$

B.1 Parameters for SI system in Chapter $3 \ldots \ldots \ldots$. . . . . . . . . . . . . . . . . . . . . . . . .

B.2 Parameters for the Test System in Chapter $4 \ldots \ldots \ldots$. . . . . . . . . . . . . . . . . . . . . . . . . . .

B.3 Parameters for the SOFC Simulation . . . . . . . . . . . . . . . . . 155

B.4 Parameters for the Wind Turbine DG . . . . . . . . . . . . . 155

B.5 Parameters for TCBR Simulation in Chapter $11 \ldots \ldots \ldots$

$\begin{array}{lr}\text { C Program Structure of Simulation } & 157\end{array}$

C.1 Models . . . . . . . . . . . . . . . . . . . . . 157

C.2 Network . . . . . . . . . . . . . . . . . . . . . . . 159

C.3 Analysis Tools . . . . . . . . . . . . . . . . . . . 161

C.4 Features . . . . . . . . . . . . . . . . . . . . 161 
D Robust Analysis Program 163

Vita

165 


\section{List of Figures}

2.1 General structure of a diesel-engine DG. . . . . . . . . . . . . . . . 6

2.2 Structure of a fuel cell power plant. . . . . . . . . . . . . . . . . . 9

2.3 A wind-synchronous generator with a control loop. . . . . . . . . . . . 10

3.1 One-line diagram of the SI distribution system with DGs. . . . . . . . . . . . . . 17

3.2 Diagram illustrating the procedure used to combine multiple lines and multiple loads into an equivalent single line and single load equivalent circuit. . . . . . . . . . . 18

3.3 Diagram illustrating the procedure for representing three-phase as a single-phase equivalent circuit. . . . . . . . . . . . . . . . . . . 19

3.4 Frequency of DG1 with different fault location (case 9, case 22, case 30). . . . . . 21

3.5 The voltage magnitude of the substation with different fault location (case 20, case

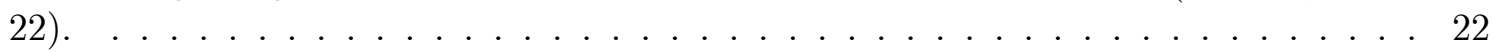

3.6 Frequency of DG1 with different DG1's location (case 22, case 25). . . . . . . . . 22

4.1 Diagram of the substation model of the distribution system. . . . . . . . . . 26

4.2 Diagram of a simplified gas turbine model. . . . . . . . . . . . . . . 28

4.3 Diagram of a diesel engine and a governor model. . . . . . . . . . . . . 28

4.4 IEEE-13 node distribution system with a gas turbine DG and a diesel engine DG. . 29

4.5 Using matrix/vector to represent the synchronous generator model in Simulink. . . . 31

4.6 Diagram of the linearized substation model of the distribution system. . . . . . . . . 32

4.7 Linearized gas-turbine powered synchronous generator. . . . . . . . . . . . . . . . 33

4.8 Linearized diesel engine powered synchronous generator. . . . . . . . . . . . . . 34

5.1 Diagram of a PAFC's generalized schematic. . . . . . . . . . . . . . . . 41

5.2 An equivalent circuit of the PAFC . . . . . . . . . . . . . . . . 41

5.3 I-V characteristics of the PAFC obtained from the recorded data. (X axis: current (A); Y axis: voltage $(\mathrm{V})) \ldots \ldots \ldots \ldots \ldots \ldots$

5.4 A model of the PAFC's DC part. . . . . . . . . . . . . . . . . . . 42

5.5 Diagram of the sampled data of the DFR device. . . . . . . . . . . . . 43

5.6 The recorded data and fitted curve of the PAFC's DC current (Case 1). . . . . . . 45

5.7 The recorded data and fitted curve of the PAFC's DC current (Case 2). . . . . . . 45

5.8 Diagram of the Error vs. polynomial order for the PAFC's DC voltage. . . . . . . . 48

5.9 The recorded data and fitted curve of the PAFC's DC voltage (case 1). (x axis: time $(\mathrm{s})$; y axis: voltage $(\mathrm{v})) \ldots \ldots \ldots \ldots \ldots \ldots$ 
5.10 Diagram of the proposed PAFC's dynamic model. . . . . . . . . . . . . . . . . 49

5.11 The V-I curve of the obtained PAFC's model. (X: current (A); Y: voltage (V)). . . . 50

5.12 The impedance of the obtained PAFC's model vs. time. (X axis: time (s); Y axis:

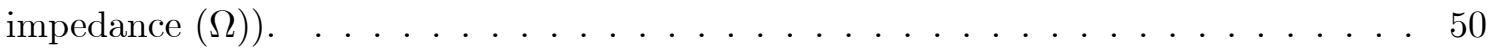

5.13 IEEE-13 node power distribution system with mult-types of DGs. . . . . . . . . . 51

5.14 Real power penetration from the PAFC power plant to IEEE-13 node power distribution system (dotted line: Case I, solid line: Case II) . . . . . . . . . . . . . . 52

5.15 Voltage magnitude of bus 671 during the PAFC's turn-off procedure (dotted line: Case I, solid line: Case II). . . . . . . . . . . . . . . . . . . . . 53

5.16 Rotor speed response of the gas-turbine synchronous generator during the PAFC's turn-off procedure (dotted line: Case I, solid line: Case II) . . . . . . . . . . . . . 53

5.17 Rotor speed response of the diesel-engine synchronous generator during the PAFC's turn-off procedure (dotted line: Case I, solid line: Case II) . . . . . . . . . . . . . . 54

6.1 Diagram of the general structure of a SOFC power plant. . . . . . . . . . 56

6.2 Structure of a fuel cell. . . . . . . . . . . . . . . . . . . 57

6.3 Three-phase CSI-based PCU. . . . . . . . . . . . . . . . . . 58

6.4 Diagram of the current control scheme for the CSI-based PCU. . . . . . . . . . . . 60

6.5 Diagram of an average model of a CSI-based PCU. . . . . . . . . . . . . . . . 61

6.6 Diagram of single fuel cell power plant and infinite bus. . . . . . . . . . . . . . 62

6.7 Real power response of the step change in real power set point. . . . . . . . . . . 63

6.8 Reactive power response of the step change in real power set point. . . . . . . . . 63

6.9 SOFC terminal voltage response of the step change in the real power set point. . . . 64

6.10 SOFC internal Nernst's voltage response of the step change in real power set point. . 64

7.1 IEEE-13 node power distribution system with multi-types of DGs to evaluate the impact of a SOFC power plant. . . . . . . . . . . . . . . 66

7.2 Rotor speeds of DGs $1 \& 2$ as a fault occures at bus 632 without controller. . . . . . . 67

7.3 Real and reactive power of the SOFC power plant as a fault occures at bus 632 without controller. . . . . . . . . . . . . . . . . . 6 67

7.4 Terminal and internal Nernst voltage of SOFC as a fault occures at bus 632 without

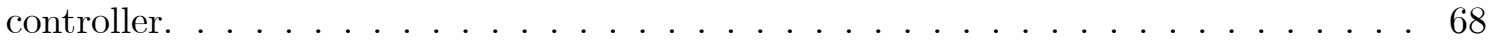

7.5 Structure of the linearized output feedback control. . . . . . . . . . . . . . . . . . 69

7.6 Coordinated control scheme of the SOFC power plant. . . . . . . . . . . 71

7.7 Rotor speed of the gas turbine DG when a fault occurs at bus 634 (Case 1) . . . . . 74

7.8 Rotor speed of the diesel engine DG when a fault occurs at bus 634 (Case 1). . . . . 75

7.9 Terminal voltage of the SOFC when a fault occurs at bus 634 (Case 1). . . . . . . 75

7.10 Rotor speed of the gas turbine DG when a fault occurs at bus 684 (Case 2) . . . . 76

7.11 Rotor speed of the diesel engine DG when a fault occurs at bus 684 (Case 2). . . . 76

7.12 Terminal voltage of the SOFC when a fault occurs at bus 684 (Case 2). $\ldots$. . . . 77

7.13 Rotor speed of the gas turbine DG when a fault occurs at bus 632 (Case 2) . . . . 77

7.14 Rotor speed of the diesel engine DG when a fault occurs at bus 632 (Case 3). . . . 78

7.15 Terminal voltage of the SOFC when a fault occurs at bus 632 (Case 3). . . . . . 78 
8.1 Diagram of a wind turbine DG consisting of a wind turbine, an induction generator

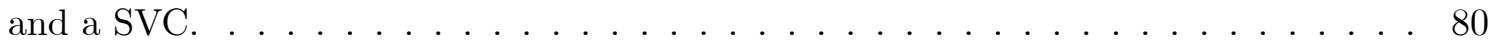

8.2 Diagram of the SVC (FC-TCR) structure . . . . . . . . . . . . . . . 82

8.3 General structure of a wind turbine DG and its control unit. . . . . . . . . . . 83

8.4 Diagram of the SVC's voltage regulator control loop. . . . . . . . . . . . . . . . 84

8.5 Diagram of the blade pitch angle controller of the wind turbine. . . . . . . . . . 84

8.6 State equations of an induction machine represented in Simulink. . . . . . . . . . 86

8.7 Swing equation of an induction machine represented in Simulink. . . . . . . . . . . 86

8.8 Equivalent circuit of an induction machine. . . . . . . . . . . . . . 87

8.9 Diagram of a one-machine infinite bus system to test the induction generator. . . . . 88

8.10 Rotor speed of an induction machine during the start-up and step response procedure. 88

8.11 Electrical torque response of an induction machine during the start-up and step response procedure. . . . . . . . . . . . . . . . . . 89

8.12 State variables of induction machine during the start-up and step response procedure. 89

8.13 Real and reactive power responses of the wind turbine DG to track $P_{\text {wind }}^{*}$ (Case I). . 91

8.14 Terminal voltage response of the wind turbine DG to track $P_{\text {wind }}^{*}$ (Case I). . . . . . 91

8.15 Real/reactive power responses of the wind turbine DG to track the $Q_{\text {wind }}^{*}$ (Case II). 92

8.16 Terminal voltage of the wind turbine DG to track the $Q_{\text {wind }}^{*}$ (Case II). . . . . . . 93

8.17 Rotor speed of the wind turbine DG to track the $Q_{\text {wind }}^{*}$ (Case II). . . . . . . . . 93

9.1 Diagram of IEEE-13 node distribution system with multi-DGs to evaluate the wind turbine DG. . . . . . . . . . . . . . . . . . . . . 95

9.2 Rotor speed of the gas turbine DG with/without a controller of the SVC. . . . . . 100

9.3 Rotor speed of the diesel engine DG with/without a controller of the SVC. . . . . . 100

9.4 Rotor speed of the wind turbine DG with/without a controller of the SVC. . . . . . 101

9.5 Diagram of the susceptance of SVC with controller. . . . . . . . . . . . . . . 101

9.6 Diagram of the interconnected system. . . . . . . . . . . . . . . . . 102

9.7 Diagram of the linear fraction transformation. . . . . . . . . . . . . 103

9.8 Digram of the feedback loop. . . . . . . . . . . . . . . . . . . 104

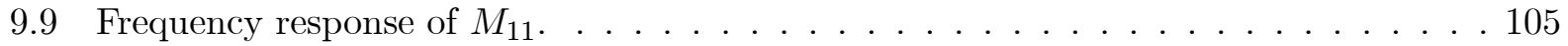

9.10 Diagram of $\mathrm{Mu}(\mu)$ as $r_{s}$ mot has a 0.005 increase. . . . . . . . . . . . . 106

9.11 Diagram of $\mathrm{Mu}(\mu)$ as $r_{s_{-} m o t}$ has a 0.02 increase. . . . . . . . . . . . 107

$9.12 \mu$ upper bound and lower bound of system with the three parameters $\left(r_{s}, r_{r}, X_{M}\right)$ of dynamic loads increasing 0.02pu. (X axis: frequency $(\mathrm{rad} / \mathrm{sec})) \ldots \ldots$. . . . . 107

9.13 Rotor speed of the wind turbine DG with modified parameters of dynamic loads when a fault occurs at bus 632 (dotted line: without controller, solid line: with controller). . . . . . . . . . . . . . . . . . . . 108

9.14 Rotor speed of the gas turbine DG with modified parameters of dynamic loads when a fault occurs at bus 632 (dotted line: without controller, solid line: with controller). 109

9.15 Rotor speed of the diesel engine DG with modified parameters of dynamic loads when a fault occurs at bus 632 (dotted line: without controller, solid line: with controller). 109

9.16 Susceptance of SVC with a controller when a fault occurs at bus $632 \ldots$. . . . . 110

10.1 Diagram of IEEE-13 node power distribution system with multi-type of DGs to investigate the coordinated operation. . . . . . . . . . . . . 112 
10.2 Rotor speed of the gas turbine DG with/without SOFC connected. . . . . . . . . 113

10.3 Rotor speed of the diesel engine DG with/without SOFC connected. . . . . . . . . . 114

10.4 Rotor speed of the wind turbine DG with/without SOFC connected. . . . . . . . . 114

10.5 Rotor speeds of the gas turbine DG with different controllers. . . . . . . . . . . . . 116

10.6 Rotor speed of diesel engine DG with/without coordinated controller. . . . . . . . 117

10.7 Rotor speed of the wind turbine DG with/without coordinated controller. . . . . . . 117

11.1 Diagram of the excitation system . . . . . . . . . . . . . . . . 121

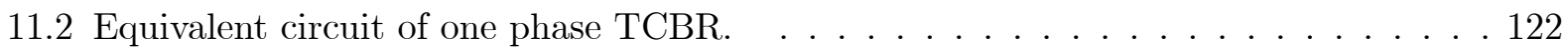

11.3 Diagram of the three-phase TCBR and its control unit. . . . . . . . . . . . 125

11.4 Diagram of IEEE-13 node distribution system with multi-DG and TCBR. . . . . . 126

11.5 Terminal voltage of DG1 as a fault occurs at bus 684 with/without TCBR. . . . . . 127

11.6 Rotor speed deviation of DG1 as a fault occurs at bus 684 with/without TCBR. . . 128

11.7 Terminal voltage of DG2 as a fault occurs at bus 684 with/without TCBR. . . . . . 128

11.8 Stator speed deviation of DG2 as a fault occurs at bus 684 with/without TCBR. . . 129

A.1 Q-axis equivalent circuit of a synchronous generator. . . . . . . . . . . . 144

A.2 D-axis equivalent circuit of a synchronous generator. . . . . . . . . . . . . . . 145

A.3 Zero-axis equivalent circuit of a synchronous generator. . . . . . . . . . . . . . . 145

A.4 Diagram of a simplified synchronous generator model. . . . . . . . . . . . 146

A.5 Q-Axis equivalent circuit of an induction machine. . . . . . . . . . . . 147

A.6 D-Axis equivalent circuit of an induction machine. . . . . . . . . . . . 147

A.7 Zero-axis equivalent circuit of an induction machine. . . . . . . . . . . . . 148

A.8 Diagram of a PWM current source inverter in a distribution system. . . . . . . . . 149

A.9 One line diagram of IEEE-13 node radial feeder. . . . . . . . . . . . . . 150

C.1 General structure of the simulation system. . . . . . . . . . . . . 158

C.2 General structure of the simulation program in Simulink. . . . . . . . . . 158

C.3 Simulation of a SOFC in Simulink. . . . . . . . . . . . . 159 


\section{List of Tables}

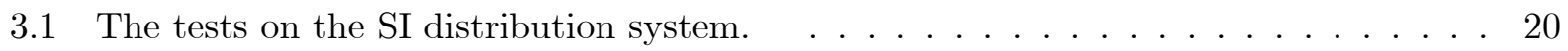

4.1 Eigenvalues of the linearized synchronous generator with gas-turbine. . . . . . . . 34

4.2 Eigenvalues of the linearized synchronous generator connected to diesel engine. . . . 35

4.3 Eigenvalues of the linearized diesel engine DG. . . . . . . . . . . . . . . . 35

4.4 Eigenvalues of the linearized distribution system with DGs. . . . . . . . . . . . 36

4.5 Eigenvalue sensitivity with respect to $X_{d} \ldots \ldots \ldots \ldots \ldots \ldots$

5.1 DC current parameters vs. record data. . . . . . . . . . . . . . . 46

5.2 Range of parameters and representative parameter values. . . . . . . . . . . . 46

5.3 Error vs. polynomial order. . . . . . . . . . . . . . . . . 47

7.1 Dominant eigenvalues of the linearized distribution system with 3 DGs. . . . . . . 69

7.2 Participation factors of eigenvalues $\lambda_{21,22}, \lambda_{25,26} \ldots \ldots \ldots \ldots \ldots$

7.3 Feedback gains through the optimal control algorithm. . . . . . . . . . . . 73

7.4 Dominant eigenvalues of the open/closed loop system. . . . . . . . . . . . . 73

8.1 Eigenvalues of the linearized induction machine. . . . . . . . . . . . 90

9.1 Eigenvalues of the open-loop linearized system. . . . . . . . . . . . . . 96

9.2 Critical eigenvalues of the open linearized system. . . . . . . . . . . . . . 97

10.1 Eigenvalues of the linearized coordinated system. . . . . . . . . . . . . . . 113

10.2 Critical Eigenvalues of the open linearized system with multi-DGs. . . . . . . . 115

10.3 Critical Eigenvalues of the multi-DGs system with different controllers. . . . . . . 116

10.4 Different real power penetration of the multi-DGs. . . . . . . . . . . . . . 118

10.5 Critical eigenvalues of the open linearized systems with different real power penetration. 118

10.6 Critical Eigenvalues of the multi-DGs system with different controllers. . . . . . . . 119

11.1 Three-phase current and voltage of distribution system with DG. . . . . . . . 126

A.1 Line segment data of IEEE 13 node test feeder. . . . . . . . . . . . . . . 151

A.2 Three-phase current and voltage of distribution system without DG. . . . . . . . 153

B.1 Parameters for the test system simulation. . . . . . . . . . . . . 155 
B.2 Parameters for the SOFC simulation. . . . . . . . . . . . . 155

B.3 Parameters of the wind-turbine DG. . . . . . . . . . . . . 156

B.4 Parameters for the TCBR simulation. . . . . . . . . . . . . . 156 


\section{Chapter 1}

\section{Introduction}

\subsection{Problem Description}

Distributed Generation (DG) has entered the vocabulary of global energy companies and has recently become a mainstream topic in energy planning, policy and new business ventures. In a restructured energy industry, DG technologies can help power providers capture new markets, serve high value customers, reduce infrastructure investment, and optimize asset utilization. Energy suppliers can gain and maintain competitive advantage with DG technologies, which include gas turbines, diesel engines, fuel cells, and wind turbines. Emerging options are being field tested and deployed by early adopters who view DG as a dynamic opportunity to strategically transform the market and gain a competitive advantage with advanced technology. Penetrating the current market will depend on successful DG applications and promoting the technology as one part of a reliable, standardized and clear solution.

Traditionally, power systems have been operated in a vertically structure. Almost all of the power has been generated at large power plants and the power is transmitted to consumers via long distance transmission system. Currently, substations are the only electric power source for loads in the distribution systems. With the advent of DGs, the newly power sources come out.

Each of the DGs has its own advantages and disadvantages. While DGs are connected to the distribution system and to supply power, their connections will have a great impact on the real time system operation and many characteristics of their integration into existing systems are still uncertain, for example, the disturbance arising from fault or load fluctuation could cause the DGs to fall out of step.

The power distribution system has several specific features when compared to the power 
transmission system: 1) Distribution systems are normally three-phase unbalanced due to the various customer loads; 2) Distribution systems are directly connected to the relatively large capacity transmission systems; 3) The lower voltage level results in higher resistor/reactance ratios (R/X) of the distribution lines. This $\mathrm{R} / \mathrm{X}$ ratio will decrease when transformer and voltage regulators are considered. In this dissertation, dynamic stability controls are designed to improve the oscillation damping of the distribution system with DGs.

To investigate the impacts of DGs on the dynamic stability of the distribution system, the four types of DGs: gas turbine synchronous generator, diesel engine synchronous generator, fuel cell power plant and wind turbine induction generator are studied. The dynamic models are expressed in state space and simulated using Matlab/Simulink. Dynamic stability controls of the distribution system with DGs are designed to improve the oscillation damping. The Flexible AC Transmission Systems (FACTS) devices such as: static var compensator (SVC), voltage source inverter (VSI), and thyristor controlled braking resistor (TCBR) are also studied. The coordinated control of DG and FACTS devices to improve the dynamic stability is an important topic in this research and has been addressed in this work.

\subsection{Outline}

The outline of this dissertation is summarized in the following.

A literature survey is presented in Chapter 2 and gives an overview of state-of-the-art and world-wide DGs research. Various DGs are introduced and compared for their modeling development in the following chapters. Since dynamic stability control of power distribution system with DGs is a new emerging topic, papers on control theories and control application in power transmission system are surveyed. The literatures will provide ideas and justification to select control schemes and device parameters for DGs' dynamic stability control.

The preliminary DG research on four specific power distribution systems is presented in Chapter 3. The power system toolbox (PST) is used to evaluate the impacts of DGs on four systems. The synchronous generator and induction machine models in PST are used to represent the DGs. This preliminary research provides the fundamental to deepen the DG modeling and dynamic stability research.

In Chapter 4, the gas turbine and diesel engine DG models are presented. To simulate the full order synchronous generator, the matrix concept is used to simplify the model building process. A substation model for dynamic study is also presented. 
Chapters 5-7 focus on fuel cells and their dynamic controls. Two types of fuel cells are studied: phosphoric acid fuel cell (PAFC) and solid oxide fuel cell (SOFC). In Chapter 5, a PAFC model is obtained through the data fitting method. Chapters $6 \& 7$ focus on the dynamic model and control of a SOFC power plant. An average power conditioning unit (PCU) is developed to connect the SOFC to the system. To design damping controller for SOFC power plants, the lead-lag units are used to compensate the dominant eigenvalues and an optimal control algorithm is applied to select the gains of the compensation units simultaneously.

The wind turbine DG modeling and control are studied in Chapters $8 \& 9$. A multivariable controller is designed to control the wind turbine generator and SVC. The robustness of the controller is verified over the parameter uncertainty of the dynamic loads. The IEEE-13 node system with the gas turbine and diesel engine DGs is the test system to study the fuel cell and the wind turbine DGs. The linearized model and eigenvalue based method are studied to design the dynamic stability controller.

A coordinated operation of the multi-DG system is evaluated in Chapter 10. The interactions between the DGs are studied. The controller is designed for a coordinated operation. The robustness of the controller is investigated at different real power penetration level.

In Chapter 11, the three-phase approach is presented to evaluate the DG models on unbalanced distribution systems. A three-phase TCBR is connected to absorb the surplus energy when the system is subjected to a disturbance.

The conclusions and suggestions for future work are presented in Chapter 12 . 


\section{Chapter 2}

\section{Literature Survey}

\section{$2.1 \quad$ Introduction}

The objective of this dissertation is to develop dynamic models of four types of DGs, to evaluate their impacts on the dynamic stability of distribution systems and to design controllers to improve the dynamic performance of system. Therefore, the three-category of literatures are surveyed: distributed generation (DG) models, power electronics application and power system control schemes.

\subsection{Models of Distributed Generations}

DG technologies offer many advantages including high efficiency, short construction lead time, modular installation, and low capital expense. In the near future, small scale power generation technologies, such as gas turbine, diesel engine, wind turbine, photovoltaics and fuel cell will likely replace some conventional power generation [59]. Simulation of various types of DGs in a suitable software environment is the first step in analyzing the dynamic characteristics of DGs and designing the control strategies.

Gas turbine, diesel engine, fuel cell and wind turbine DGs are four of the several types of new DG sources that have experienced considerable development progress in recent years. However, even simplified models covering dynamic characteristics of these types of DGs (and other newer DG sources such as photovoltaic and microturbines, etc.) are not openly available. Hence, the first task necessary to study these dynamic effects of the four types of DGs on the distribution lines is to develop models based on the literature and any available operational data on DGs and secondly to utilize that data and the references to develop dynamic models. 


\subsubsection{Gas Turbine}

As gas turbines have fast run-up capacities characteristics, it is suitable to be connected to weakly supply systems or even used in an isolated operation system. Several types of gas turbine models are presented [44][50][107].

A detailed gas turbine generator model has been presented by Hung [50]. Based on the hypothesis that transient thermodynamic and flow processes are considered as quasi-static, the dynamic response of gas turbine is described as a series of linearized equations. The fundamental equations are:

$$
\begin{gathered}
\Delta Q_{F}=Q_{F}-Q_{F 0} \\
\Delta N_{G}=\mu_{N G} \frac{1}{\left(1+s T_{G}\right)\left(1+s T_{C}\right)} \Delta Q_{F} \\
\Delta X=\mu_{X} \frac{\left(1+s a_{x} T_{G}\right)}{\left(1+s T_{G}\right)\left(1+s T_{C}\right)} \Delta Q_{F} \\
N_{G}=N_{G 0}+\Delta N_{G} \\
X=X_{0}+\Delta X
\end{gathered}
$$

where $X$ is a gas turbine variable vector, which includes the compressor discharge pressure, the exhaust gas pressure, the exhaust gas temperature and exhaust gas power. $N_{G}$ is the engine speed. $\mu_{N G}$ and $\mu_{X}$ are the sensitivity of $X$ an $N_{G}$ to $Q_{F} \cdot a_{x}$ is the lead-lag ratio of $X . T_{G}$ and $T_{C}$ are the equivalent engine and the combustion chamber time constants.

The model is developed to investigate and improve the dynamic control of the gas turbine following a disturbance. A least square cubic spline curve fitting technique is used to fit curves to get the parameters: time constants, lead-lag ratios and so on. Unfortunately, operation curves are not shown in the paper.

In [44] a twin shaft gas turbine model is presented. In the model, the generator is located in the center with a twin-shaft combustion turbine on each side. The model includes free turbine, engine speed control, and exhaust gas temperature control. The turbine dynamics are represented by a set of functions which can be determined by steady state measurements. The dynamic characteristics of the gas turbine consist of: turbine power $P_{m}$ in the low pressure turbine, torque $T_{H P}$ developed by the high pressure turbine, the turbine exhaust temperature $T_{e x}$ and the load torque on the compressor $T_{\text {load }}$. This model is suitable for studying the dynamic performance of the twin-shaft gas turbine. However, the type of gas turbine model cannot be used in this dissertation research due to the limitation of the measured data. 


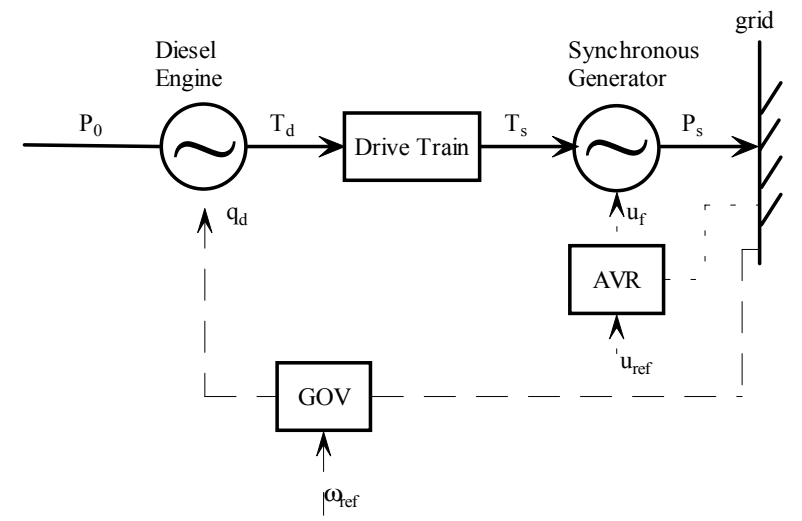

Figure 2.1: General structure of a diesel-engine DG.

In our research, the simplified gas turbine model represented in mathematical equations [107] is selected as reference model and is simulated. It is suitable to study the dynamic stability of gas turbine in power system. Another important reason to select this model is that this model is tested in Trinidad and Tobago system [114]. The validation of this model is tested. The mathematical model, simulation and control schemes are developed in the later Chapters.

\subsubsection{Diesel Engine}

Diesel engine powered synchronous generator is another type of important DG. The diesel engine DG model consists of combustion, drive train, and synchronous generator. Besides the function to supply the continuous power to the important customers, it is also used for back up, emergency and stand by. Sometimes, the diesel engine DG is working together with the solar electric or wind power system or for a standby alone DG. In [133], the diesel engine generator is to supply the emergency power in a nuclear power plant. The papers [11][18][62] [124] presented the combined multiple renewable energy source systems of the integration of diesel engine with other types of DGs.

The general structure of a diesel engine DG is illustrated in Figure 2.1 [18]:

In Figure 2.1, $T_{d}$ is the average shaft torque, $p_{0}$ is the zero torque pressure, $q_{d}$ is the input fuel flow rates, $T_{s}$ is the air gap torque of the synchronous generator, $P_{s}$ is the real power to grid.

A detailed diesel engine generator including drive train is presented in [18]. A diesel engine 
is presented by the state equations:

$$
\begin{gathered}
\dot{q}_{e f f}=\frac{1}{\tau_{c}}\left(-q_{e f f}+q_{d}\left(t-\tau_{d}\right)\right) \\
p_{e}=\varepsilon K_{c} q_{e f f} \\
T_{d a}=K_{v}\left(p_{e}-p_{0}\right)
\end{gathered}
$$

where $p_{e}$ is the average engine chamber pressure, $q_{e f f}$ is the effective fuel flow rates, $\varepsilon$ is the fuel efficiency, $K_{c}$ is constant relating pressure and fuel consumption, $K_{v}$ is the stroke volume of the engine, $\tau_{c}$ is the time constant of the actuator and combustion process, and $\tau_{d}$ is time delay of combustion. The drive-train model can be expressed as:

$$
\begin{gathered}
\dot{\theta}_{c l}=\omega_{d}-\omega_{s} \\
\dot{\omega}_{d}=\frac{1}{J_{d}}\left(\varepsilon K_{c} K_{v} q_{e f f}-C_{c l} \theta_{c l}-\left(D_{d}+D_{c l}\right) \omega_{d}-K_{v} p_{0}\right) \\
\dot{\omega}_{s}=\frac{1}{J_{s}}\left(C_{c l} \theta_{c l}+D_{c l} \omega_{c l}-\left(D_{s}+D_{c l}\right) \omega_{s}-T_{s}\right)
\end{gathered}
$$

where $\theta_{c l}$ is the torsion angle of the engine-generator shift, $\omega_{d}$ is the rotational speed of the diesel engine, $\omega_{s}$ is the rotational speed of the electrical generator, $D_{d}$ and $J_{d}$ are the damping and inertia of the diesel engine, $D_{s}$ and $J_{s}$ are the damping and inertia. The diesel engine DG is connected with a wind turbine directly to provide reliable power and save fuel. The adaptive fuzzy logic control scheme is implemented to cope with the unpredictable fluctuation of the wind resources. The impact of the diesel engine and wind turbine DG system on a weak system has been studied.

The impacts of a diesel-wind-photovoltaic generation system is presented in [11]. The ACSL language based software package has been developed to evaluate the integrated DG system. Modular subroutines in FORTRAN 77 are called during simulation. The interaction of multi-type DGs is evaluated under different operating conditions. The software provides a good tool to analyze the dynamic performance and design controllers. The DGs and load are considered to be located very close to each other.

The diesel-wind turbine system of [62] supplies power to isolated loads. The interactions between two types of DGs are assessed. However, The distribution system network and the iterations with the substation are not considered.

In [133], the model of the diesel engine generator is used to assess the power supplying to the dynamic loads during various transient procedure. This model includes the two parts of the general structure: diesel engine and synchronous generator. The governor and the AVR units 
are also considered. The transient process of the drive train is ignored. The results of the field measurement verify the model. Also, this model is implemented in Power System Blockset (PSB) [54] as a demo case.

Due to the verification of the field measurement, and application in PSB, the model in [133] is considered to be adopted in our DG research.

\subsubsection{Fuel Cell}

Fuel cells will be important components of distribution system due to their high efficiency and low environmental pollution. For example, the net fuel-to-electricity of the direct carbonate fuel cell (DCFC) power plant is about 55-60\%. Carbon dioxide emissions of DCFC are much less compared to conventional power generators with a similar power size [77]. Due to an electric-chemical process of power generation, there is no noise develop usually in mechanical members of conventional generator. The modular design satisfies the versatile demands of customers. All of these features will without any doubt lead to their wide application in the power industry in the near future.

Several types of fuel cells have been reported in the literatures: phosphor acid fuel cell (PAFC) [106][135], solid oxide fuel cell (SOFC) [42][92], molten carbonate fuel cell (MCFC)[46][77][76][116] and proton exchange membrane fuel cell (PEMFC) [70].

The PAFC has been commercially used in hospitals, nursing homes, utility power plants, etc. The electric efficiency is more than $40 \%$. MCFC uses a liquid solution as an electrolyte. Normally, the generation electric efficiency is about $60 \%$, and the operating temperature is $1200^{\circ} \mathrm{F}$. The operating temperature of PEMFC is about $175^{\circ} \mathrm{F}$. However, the PEMFC is very sensitive to fuel impurities. The SOFC uses a hard ceramic material of solid zirconium oxide as the electrolyte and operating temperatures can reach $1800^{\circ} \mathrm{F}$, with an improved efficiency of about $60 \%$. The SOFC can be used in large-power applications such as central electricity generation station. Since PAFC has been commercially used, and SOFC has the highest potential in large power application, these two types of fuel cells will be studied.

Fuel cells must be connected to the distribution system via DC/AC inverters. Therefore, low cost and high efficiency inverters are required together with acting controllers for fast tracking of real and reactive power demands.

Electrochemical and thermal simulations of a SOFC was reported in [9] to identify the key parameters of fuel cell systems from a single cell to an $m \times n$ cell stack bundle. A transient dynamic model of SOFC was proposed in [42]. The cell's terminal voltage during a load change is discussed. 
Reference [92] proposed a dynamic model for a SOFC stack and gave the general structure of a fuel cell power plant (see Figure 2.2). The fuel cell control is achieved by adjusting the input volume of gas and air and controlling real power output.

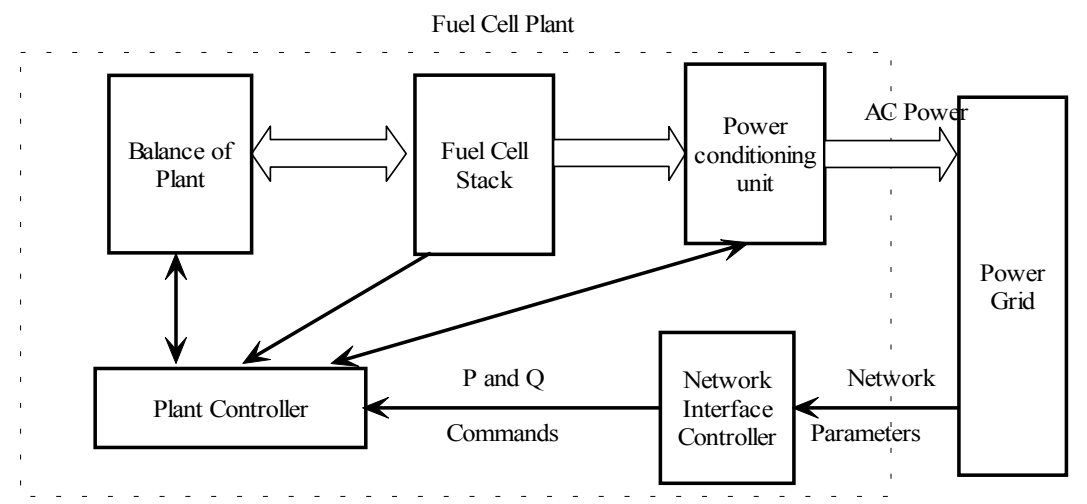

Figure 2.2: Structure of a fuel cell power plant.

The inverter serves as the interface between the fuel cell and the power distribution system. It is controlled in order to provide real and reactive power set point tracking and to adjust the power factor.

\subsubsection{Wind Turbine}

Wind turbines are widely used as they are environmental friendly energy sources. Wind turbines can either be connected to a synchronous generator [68][88] or an induction generator [1]. In these papers, a controllable horizontal wind turbine model is adopted. This model is suitable for analyzing dynamic characteristics of wind turbines and designing control. A simpler wind turbine induction generator model is developed in [59] as it was specifically used for dynamic studies of dispersed wind turbine applications. Another wind turbine model is presented in [62].

The wind turbine system of [88] can be summarized as shown in Figure 2.3. The model includes the synchronous generator, torque computing unit, torsional system and the control loop using output-feedback design.

In [1], a wind turbine is connected to an induction generator to implement the energy conversion. A static var compensator (SVC) is used to regulate its voltage. The model is:

$$
\lambda=\frac{\Omega R}{V_{\omega}}
$$




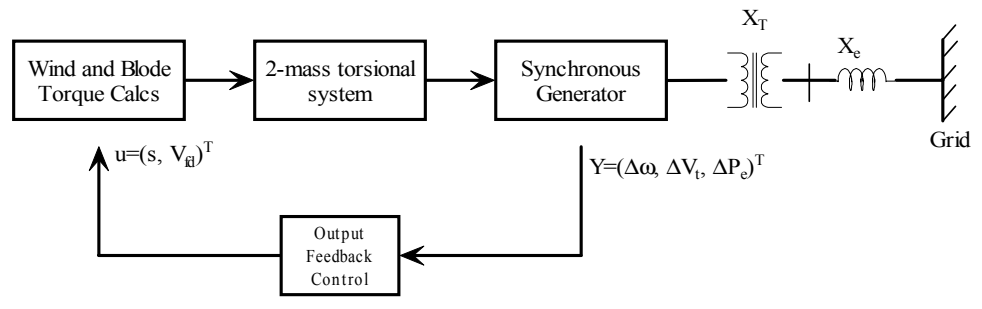

Figure 2.3: A wind-synchronous generator with a control loop.

$$
\begin{gathered}
C_{p}=(0.44-0.0167 \beta) \sin \left[\frac{\pi(\lambda-3)}{15-0.3 \beta}\right]-0.00184(\lambda-3) \beta \\
T_{m}=\frac{\frac{1}{2} \rho A R C_{p} V_{\omega}^{2}}{\lambda}
\end{gathered}
$$

where: $\lambda$ is the blade tip speed ratio, $\beta$ is the blade tip pitch angle, $R$ is the wind turbine rotor radius, $\Omega$ is the mechanical angular velocity, $V_{\omega}$ is the wind velocity, $C_{p}$ is the coefficient of nondimentional curves of the power, $\rho$ is the air density, $A$ is the set area by the blades, and $T_{m}$ is output mechanical torque of the wind turbine.

The simplified wind turbine induction generator model [59] is expressed as:

$$
\begin{gathered}
\dot{\omega}_{G}=\frac{-\left(D_{G}-D_{T}\right)}{M_{G}} \omega_{G}+\frac{\left(D_{G}-D_{T}\right)}{M_{G}} \omega_{T}+\frac{1}{M_{G}} T_{G}-\frac{1}{M_{G}} P_{G} \\
\dot{\delta}=-\omega_{G}+\omega_{T} \\
\dot{\omega}_{T}=\frac{D_{T}}{M_{T}} \omega_{G}-\frac{K}{M_{T}}-\frac{D_{T}}{M_{T}} \omega_{T}+\frac{1}{M_{T}} T_{\omega}
\end{gathered}
$$

where: $M_{G}, M_{T}, D_{G}$ and $D_{T}$ are the generator and turbine inertias and damping coefficients. $T_{\omega}$ is the wind torque. $K$ is the torsional spring constant.

To implement the multiple renewable energy source system, integration of multiple types of DGs are discussed in [11], [18], [62] and [124]. In these papers, the coordination of the wind turbine and the diesel engine is investigated.

A wind model is expressed by the instantaneous wind velocity [62]:

$$
U_{w}=\bar{U}+u(m / s)
$$

where $\bar{U}$ is the mean wind speed, $u$ is the turbulent component of the wind. In [62], an algorithm is given to provide the two wind speed components separately. In this research, the wind turbine is considered to work at the rated power regime and the disturbance of the wind model is beyond consideration. 


\subsection{Control Strategies for DGs}

To improve the dynamic stability of the distribution system with multiple types DGs, control strategies for DGs are investigated. As a relatively new topic, most of the literatures found concentrates on the control theory application on the transmission level, for example, [5], [22], [26], [30], [71], [126] and [131]. However, power distribution systems have their own unique features: large capacity substation, relatively small coverage area and unbalanced loads. These concerns have to be addressed. Both decentralized control and global control schemes are investigated.

Since the substations of distribution systems have a relatively large capacity, it is usually considered as an infinite bus. The dynamic stability is the major stability problem rather than the transient stability. At present, the residue and the damping torque analysis methods are mature and have been applied to design dynamic stability controllers as PSS and FACTS devices.

The centralized control can effectively improve the dynamic stability of the whole system. The signal communication between remote areas is a constraint on developing controllers. However the power distribution system is located in a relatively small area, hence the signal communication is practically feasible. The centralized control scheme will be considered as the major type of control to improve oscillation damping of distribution systems with DGs.

\subsubsection{Linear Analysis}

The purpose of the DG controllers is to improve the dynamic stability of the system. The linear analysis methodology has long been used to study the stability problem by eigenvalue calculation and critical oscillation modes identification. The authors of [32] and [115] proposed indices to rank eigenvalues. The eigenvalue with the largest index is the most critical one.

By using this approach, the most critical oscillation modes can be identified during control design.

\subsubsection{Model Reduction}

Model reduction is considered as the first step in modeling large-scale systems and designing feedback controllers. Applications can be viewed in [32], [23] and [53].

Feliachi proposed an algorithm based on optimizing output performance index in [32]. The outputs of the system are the state variables. The method has been implemented in [53]. By

reducing the model to a simplified reduced order system model, eigenvalue assignment method is applied to design a controller and promising results have been achieved. 
Another eigenvalue assignment based on a matrix reduction technique with application to power systems was proposed by Choudhry [23].

The power distribution system has the distinct feature of strong connections between components. Hence, a subgroup of eigenvalues that can represent the system performance with little errors cannot be found since all components may have similar contribution to eigenvalues. Based on these references, the author obtained a reduced system and designed a controller using eigenvalue assignment method. This controller can move certain eigenvalues that have been included in the reduced model perfectly to destined locations. However, when the controller is applied in the original system model, some eigenvalues not included in the reduced model shifted to the right-half plane which worsen the dynamic performance of the system. In addition, the distribution test system is of order 50, a size that can be easily handled. Therefore the full system model is used to design controllers.

\subsubsection{Control Schemes}

Residue based indices were proposed in papers of Martin [78] and Yang [131]. This method is suitable for designing single input single output (SISO) controllers at a specific operating point.

The centralized control can effectively improve the dynamic stability of the whole system. For a large-scale system, signal communication is the constraint to develop such controllers. However, the power distribution system is relatively small and signal communication can be easily achieved. The centralized control scheme will be considered as the major type of control to improve oscillation damping of the distribution system with DGs.

Output feedback control is one kind of centralized control scheme using information from different locations as input. This scheme will be adopted in this dissertation to design controller for wind turbine controller.

Both decentralized and centralized controllers as mentioned above are designed for a specific operating condition and may not function well when the operating condition changes. In reality, power transactions between areas and loads vary considerably and the operating condition changes frequently. Therefore, uncertainty in operating conditions has to be addressed in the control design process. A structured singular value approach was presented in [26] to address this issue by designing a robust controller which is able to accommodate the uncertainties.

In this dissertation, uncertainty will be modeled and the capability of the controller to handle uncertainties will be discussed to study its robustness. 


\subsubsection{Coordinated Control}

The issues of coordinated control have been addressed in transmission systems [71][34] where PSS and FACTS devices such as TCSC and SVC have been installed. The design of one controller to improve the damping of a certain oscillation mode should not deteriorate the damping of other modes. A widely used coordinated control strategy is the multivariable optimal control.

With different DGs in the system, different kinds of controllers will be installed. The coordination among controllers is very important for the system to function properly and have a good dynamic performance.

\subsubsection{Robust Analysis of the Load Parameter Uncertainty}

The robustness of designed controllers will be verified by testing loads with parameters uncertainties and/or different operating conditions. The influence of the load parameters on the dynamic stability of the system has been studied in [85]. An additional SVC stabilizer (ACS) has been tuned for robust control. However, in [85], only voltage dependant static loads are involved.

The effect of load models on stability of a modulated AC/DC system is investigated in [29]. An eigenvalue sensitivity calculation method is developed to predict effects of load characteristics on system stability. A method to design robust modulation controller over a wide range of load characteristics for $\mathrm{AC} / \mathrm{DC}$ system is proposed in [22].

In our research, the parameter uncertainties of dynamic loads are taken into consideration during the controller design.

\subsection{Power Electronics Application}

Power electronics are commonly used in power transmission system as they are the main components of Flexible AC Transmission Systems (FACTS). Power electronics are also applied in existing power distribution systems to improve power quality by applying power conditioning units [48]. Unlike the customer power, in our DG project, power electronics are applied as the important part of the DGs as DC/AC the interface of the fuel cell, or as the var compensator for the wind turbine. The rapid response feature of the power electronics enables them as the good real/reactive power control devices. 


\subsubsection{Static VAR Compensator (SVC)}

As a mature technology, the SVC is widely used in power systems to supply reactive power. A modular structure for SVCs for the dynamic study is proposed in [56]. Two basic modeling approaches with different methods to realize the slope function are recommended. In method one, the voltage regulator is of the proportional type and the gain, $K_{R}$, is the inverse of the slope - a gain of $100 \mathrm{pu} B_{s v c} / p u \Delta V$ on the SVC base means a $1 \%$ slope. In method two, the voltage regulator is of the integral, or proportional plus integral type and the slope, $K_{S L}$, is realized through current feedback. A practical model for advance power flow is presented in [93]. The controlled susceptance vs. different firing angles is illustrated.

\subsubsection{Current/Voltage Source Inverter (CSI/VSI)}

The requirements of the interface between the fuel cell system and the power distribution system include low cost, high reliability and efficiency, adjustable power factor and low line-current distortion [89]. Different approachs/realization can be found in the literatures.

A vector space controlled inverter based on GTO switches fulfills the above requirements [6][17]. The "inverter flux vectors" with additional reactance are used in [6] to control real and reactive output power. A completely current regulated PWM_VSI (pulse width modulation voltage source inverter) is described in [87]. It is simpler and easier to implement. This kind of inverter has been used to connect photovoltaic arrays to the AC grid [6]. In [132], an average inverter model is described to represent the static synchronous compensator (StatCom) which converts the DC battery energy storage to the AC transmission system.

\subsubsection{Thyristor Controlled Braking Resistor (TCBR)}

A TCBR is a simple, highly reliable, low cost and very effective Flexible AC Transmission Systems (FACTS) device. In [47], the functions of TCBR are summarized as: 1) Damp low frequency interconnection oscillation; 2) Prevent first cycle swing transient instability; 3) Damp subsynchronous resonance (SSR); 4) Facilitate synchronizing a turbine-generator, etc.

Many control strategies have been proposed. A closed-loop quasi-optimal switching schema was reported in [97]. In [97], a control cost index was used to optimize the control strategy. In [128], a variable structure controller (VSC) was implemented to damp the interconnection oscillation in a multi-machine system. With the VSC controller, the inertia modes are damped effectively. 
This TCBR and VSC control strategy will be implemented during the three-phase system study to improve oscillation damping of the whole system [81]. 


\section{Chapter 3}

\section{Preliminary Research of DGs}

\subsection{Introduction}

In the distributed generations (DGs) research, two years have been invested in a DG project evaluating various DG sources connected to computer simulation models of actual distribution systems. As an example, the actual suburban system I (SI) is represented in this chapter to briefly demonstrate the utilities related DGs research. Some of the results are illustrated in this chapter, and others will be represented in the following chapters together with the continued research.

The simulations of the substation, lines, loads, and DGs of real system are discussed. The DGs are modeled as synchronous generators with simplified turbine and excitation. The substation is modeled as a combination of a synchronous generator and a transformer. A series of case studies is conducted to evaluate the models. The impacts of DG on line voltage and system stability are evaluated including the effects of several groups of factors. In this preliminary DG research, the power system toolbox (PST) is utilized as the tool for study and analysis.

\subsection{Models of An Actual Distribution System}

\subsubsection{Suburban System I (SI)}

The one-line diagram for the SI distribution system is shown in Figure 3.1. The SI system is a typical suburban system. The total load and voltage of this system are $20.5 \mathrm{MVA}$ and $23.0 \mathrm{kV}$ respectively [65][66]. 


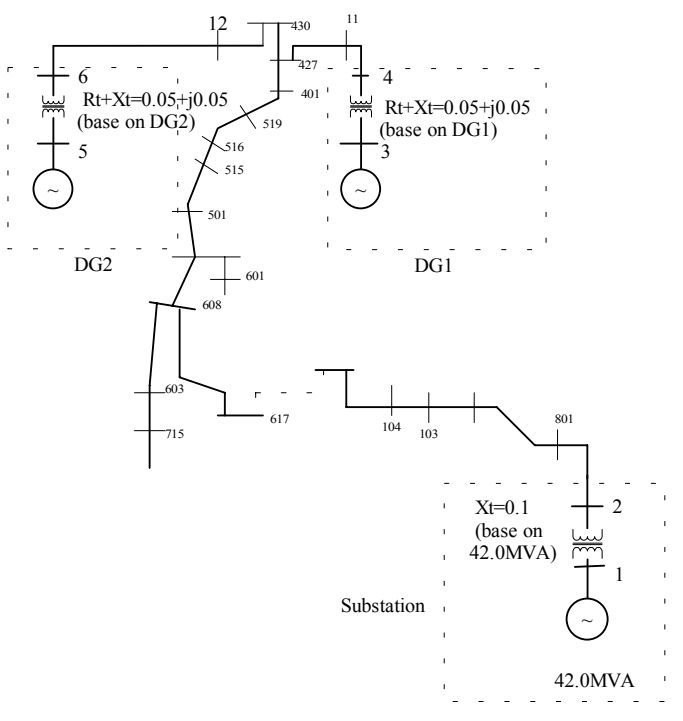

Figure 3.1: One-line diagram of the SI distribution system with DGs.

\subsubsection{Models}

The SI distribution system is simulated in PST.

1) Substation

Traditionally, a model for a substation for use with a distribution system is a voltage source in series with an impedance. To investigate dynamic characteristics of the distribution system with DG, a new distribution substation model is developed [80] and the model will be described in detail in Chapter 4. The form of the substation model used here consists of a synchronous generator and a transformer. The synchronous generator is assumed to have a very large inertia and capacity.

2) Loads

The loads along the distribution lines were represented as static loads with a fixed power factor of 0.85 lagging. The distribution line is represented by the equivalent impedance which reflect the active and reactive losses. The load of the single line equivalent system was based on the sum of loads in the unreduced (e.g. three-phase) system (see Figure 3.2). Using $V_{\text {base }}=23 k V$, $S_{\text {base }}=20.5 M V A$ as the system base, all the other lines and loads are represented in per unit on this base. The bases were used to model all the remaining details of all the lines and transformers in order to derive the new single line equivalent. Therefore, the single line equivalent represents all the losses.

3) Distribution Line 


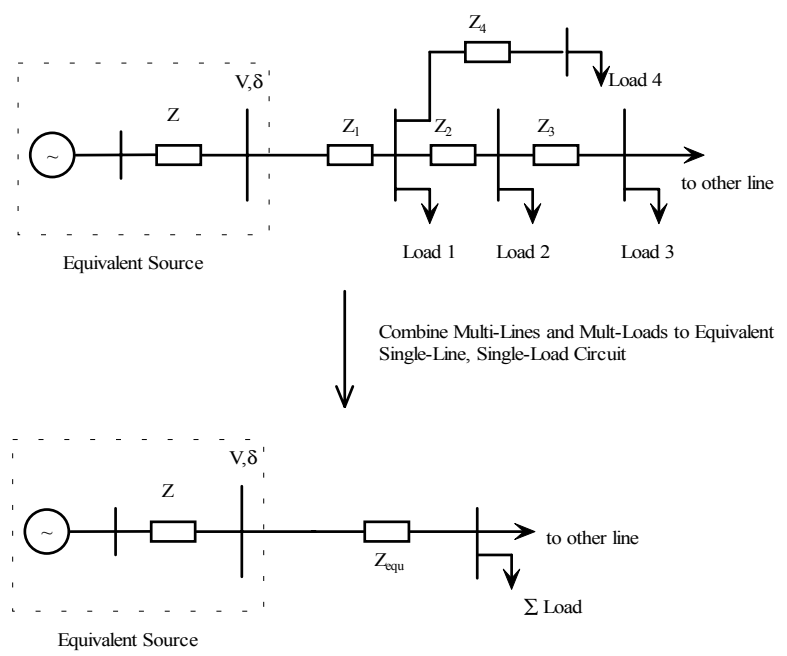

Figure 3.2: Diagram illustrating the procedure used to combine multiple lines and multiple loads into an equivalent single line and single load equivalent circuit.

The distribution line considered is a three-phase balanced line and is modeled as a singlephase line with static parameters. The original three-phase line was represented by the single-phase line as shown in Figure 3.3.

4) Distributed Generation (DG)

Each DG is modeled as a synchronous generator with simplified turbine and excitation, and a transformer. A transformer compatible to the DG capacity connects the DG to the distribution line. The simplified turbine governor model and exciter model are used for the DGs [95].

\subsection{Test Cases and Simulation Results}

A set of test cases was designed to investigate the transient stability and dynamic performance of the system based on different load characteristics. In Figure 3.1 two DGs (synchronous generators) are located at buses 11 and 12. Fault locations for the different experiments are next to the DG, such as at buses 11 and 12, and in the middle of the distribution feeder line, such as at buses 103 and 515. Referring to the protection manual [25], a fault clearing time of 0.084s, and a reclosing time of $0.64 \mathrm{~s}$ were chosen. Several simulations with other fault clearing and reclosing times are done and all the results are also compared. The different impacts of the DG on the distribution system are classified as:

\section{. $\quad$ Different fault location;}




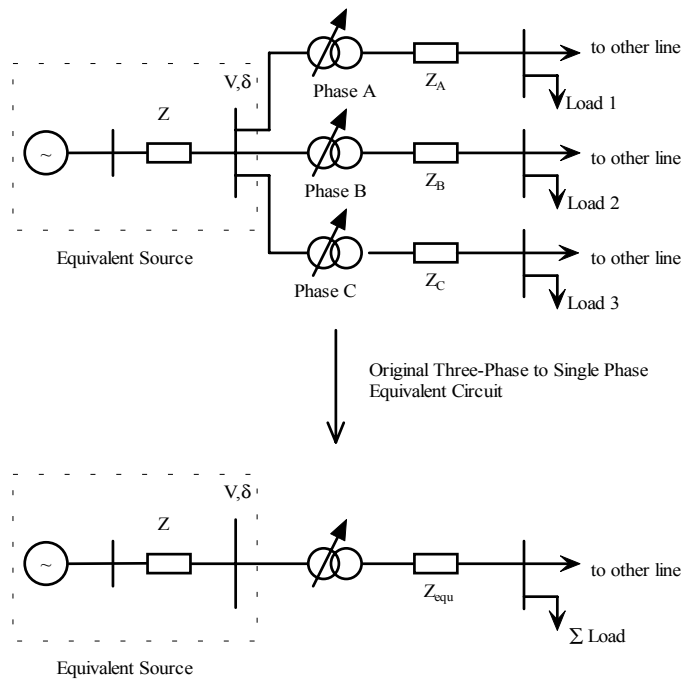

Figure 3.3: Diagram illustrating the procedure for representing three-phase as a single-phase equivalent circuit.

- Different fault clearing time;

. $\quad$ Different reclosing time;

. $\quad$ Different power size of DGs;

· $\quad$ Different DG location.

In the following five subsections, the simulation results illustrate the impacts of the part of factors. Plots of voltage profile, frequency responses, rotor angle, and real power are used to illustrate the transient process.

\subsubsection{Fault Location}

Worst cases for different fault locations appear to be those in which the fault is near the DG source as would be anticipated. Cases 9, 22 and 30 shown in Figure 3.4 and a series of other simulations tabulated in Table 3.1 displayed this result.

\subsubsection{Fault Clearing Time}

Generally, it would be anticipated that shorter fault clearing times would contribute to reduced power system disturbances. Figure 3.5 shows the voltage profile of the substation with different fault clearing times. During the fault time, the voltage of the substation falls below 0.8pu. Such 
Table 3.1: The tests on the SI distribution system.

\begin{tabular}{|c|c|c|c|c|}
\hline Case & $\begin{array}{c}G 1, G 2 \\
\text { PowerSize } \\
(M W)\end{array}$ & $\begin{array}{c}\text { Fault } \\
\text { Location }\end{array}$ & $\begin{array}{c}\text { Clear } \\
\text { Time } \\
(\mathrm{sec})\end{array}$ & $\begin{array}{c}\text { Reclose } \\
\text { time } \\
(\text { sec })\end{array}$ \\
\hline$\overline{1}$ & $0.8,0.8$ & $11-427$ & 0.084 & 0.64 \\
\hline 2 & $1.6,0.8$ & $11-427$ & 0.084 & 0.64 \\
\hline 3 & $0.2,0.2$ & $11-427$ & 0.084 & 0.64 \\
\hline 4 & $0.1,0.1$ & $11-427$ & 0.084 & 0.64 \\
\hline 5 & $0.4,0.4$ & $11-427$ & 0.084 & 0.64 \\
\hline 6 & $0.4,0.2$ & $11-427$ & 0.084 & 0.64 \\
\hline 7 & $0.1,0.1$ & $11-427$ & 0.084 & 0.64 \\
\hline 8 & $1.6,1.6$ & $103-104$ & 0.084 & 0.64 \\
\hline 9 & $2.4,2.4$ & 103-104 & 0.084 & 0.64 \\
\hline 10 & $2.4,2.4$ & $103-104$ & 0.15 & 0.64 \\
\hline 11 & $2.4,2.4$ & 103-104 & 0.30 & 0.64 \\
\hline 14 & $1.6,1.6$ & $519-401$ & 0.084 & 0.64 \\
\hline 15 & $0.8,0.8$ & $12-430$ & 0.084 & 0.64 \\
\hline 16 & $0.4,0.4$ & $12-430$ & 0.084 & 0.64 \\
\hline 17 & $4.0,4.0$ & 103-104 & 0.084 & 0.64 \\
\hline 18 & $6.0,4.0$ & 103-104 & 0.084 & 0.64 \\
\hline 19 & $6.0,6.0$ & 103-104 & 0.084 & 0.64 \\
\hline 20 & $2.4,2.4$ & $515-516$ & 0.30 & 0.64 \\
\hline 21 & $2.4,2.4$ & $515-516$ & 0.15 & 0.64 \\
\hline 22 & $2.4,2.4$ & $515-516$ & 0.084 & 0.64 \\
\hline 23 & $2.4,2.4$ & $515-516$ & 0.084 & 1.28 \\
\hline 24 & $2.4,2.4$ & $515-516$ & 0.084 & 2.56 \\
\hline $25^{*}$ & $2.4,2.4$ & $515-516$ & 0.084 & 0.64 \\
\hline $26^{*}$ & $2.4,2.4$ & $515-516$ & 0.15 & 0.64 \\
\hline $27^{*}$ & $2.4,2.4$ & $515-516$ & 0.30 & 0.64 \\
\hline $28^{*}$ & $2.4,2.4$ & $515-516$ & 0.084 & 1.28 \\
\hline $29^{*}$ & $2.4,2.4$ & $515-516$ & 0.084 & 2.56 \\
\hline 30 & $2.4,2.4$ & $11-427$ & 0.084 & 0.64 \\
\hline 31 & $2.4,2.4$ & 11-427 & 0.084 & 2.56 \\
\hline
\end{tabular}




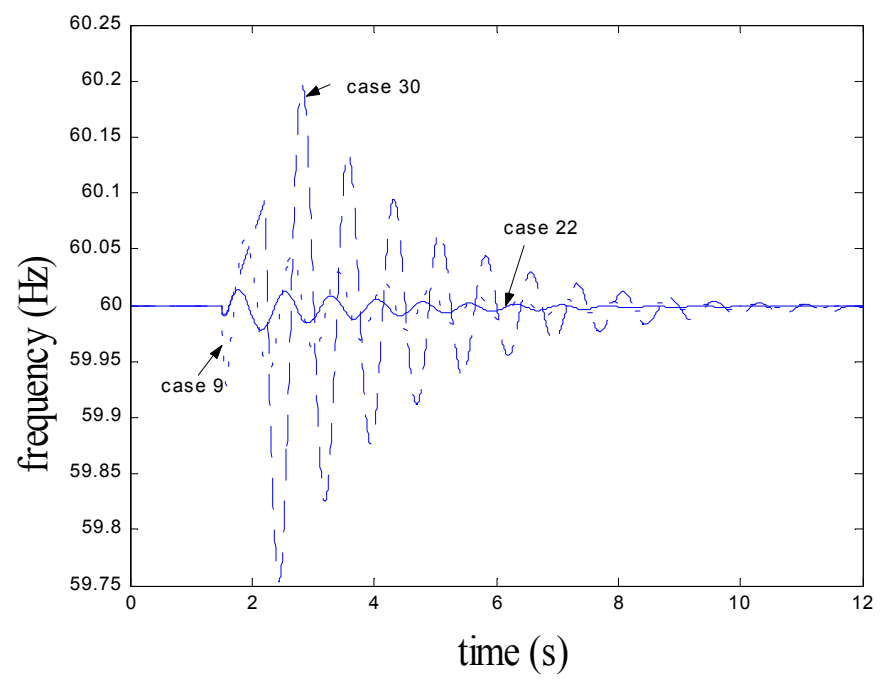

Figure 3.4: Frequency of DG1 with different fault location (case 9, case 22, case 30).

a low voltage may have undesirable impacts on other loads connected to the substation (e.g. it may cause them to be disconnected). The longer the fault lasts, the worse the voltage quality is. Therefore, faster fault clearing times will improve the power quality.

\subsubsection{Reclosing Time}

The impact of the reclosing time is investigated in cases 30 and 31. Reclosing times for cases 30, and 31 are $0.64 \mathrm{~s}$ and $2.56 \mathrm{~s}$, respectively. All other simulation conditions are the same. Figure 3.6 shows that for larger reclosing times the amplitude of the resulting damped oscillation is larger and may even result in divergence (see case 31 ).

\subsection{Summary}

Whether a distribution system remains stable or not when DG is added depends on contingencies such as faults types, fault locations, DG power sizes, fault clearing times, reclosing times, and DG locations, variations in all of which were evaluated via 31 different simulation cases (see Table 1). Five selected groups of cases are presented here to illustrate the impacts of these factors. These simulation results show: 


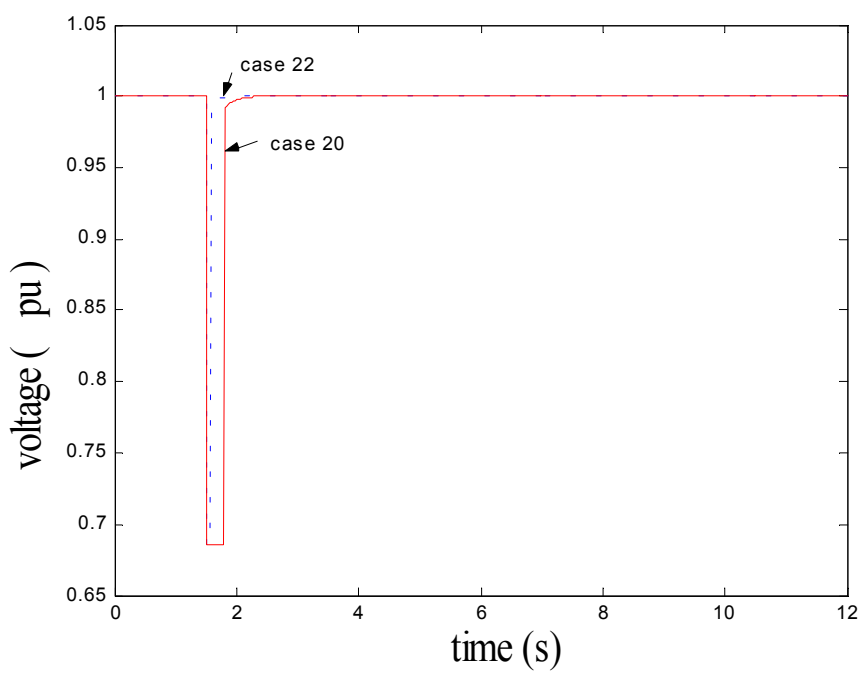

Figure 3.5: The voltage magnitude of the substation with different fault location (case 20, case 22).

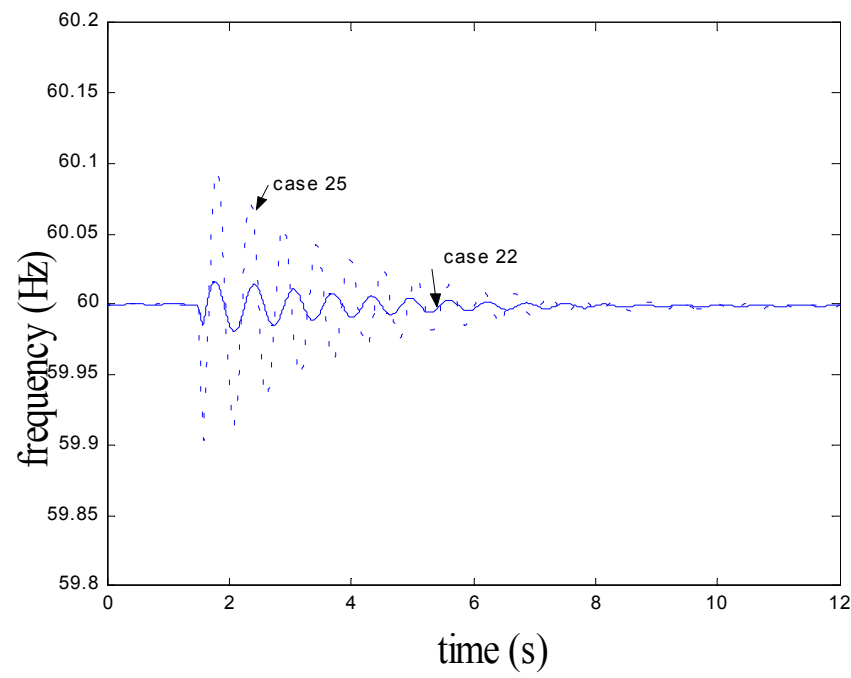

Figure 3.6: Frequency of DG1 with different DG1's location (case 22, case 25). 
- Fault location is an important factor affecting the relative stability of the distribution system. Worst case faults are those occurring near the DG sources;

. Fault clearing time impacts the most on voltage quality along the distribution system. Shorter fault clearing times improve the voltage quality;

- $\quad$ Shorter reclosing times improve system stability;

- The DG location is an important factor in determining frequency deviation and the frequency recovery time, thus the relative stability characteristics of the system.

The most important factors affecting the degree of system relative stability are the fault location, reclosing time and the DG locations. The fault clearing time and the DG size also affect the stability of the SI distribution system, but to lesser degree than the above three factors. 


\section{Chapter 4}

\section{DGs Simulation and Linear Analysis with Simulink}

\subsection{Introduction}

In the preliminary research, the SI system and the distributed generations (DGs) are represented in the power system toolbox (PST). As discussed before, the PST is difficult to insert some specific electric components, such as gas turbine, voltage source inverter. In the following chapters, a software package is developed in Matlab/Simulink step by step to study the distribution system with DGs. The program structure of this simulation package is presented in Appendix C. At the same time, Matlab/Simulink provides a tool to obtain the linearized model from the nonlinear simulation models in Simulink.

In this chapter, two of the four types DGs model: gas turbine and diesel engine DGs are developed. In the early power system studies, the synchronous generator was represented by the simplified transient/subtransient model. In the DGs research, it has become apparent that these simplified models are not adequate to describe the dynamic response of a complicated power distribution system. The full-order synchronous model is chosen to be connected with gas turbine and diesel engine. As a new solution, the synchronous machine model is simulated using the matrix/vector concepts in Simulink. This matrix/vector based method can avoid the numerical algebraic loop problems.

In this chapter, the following tasks have been done:

1. Develop the gas turbine model and diesel engine model, simulate these models in 
Simulink;

2. Investigate and simulate the full-order synchronous generator in Simulink, then connect them to the gas turbine, diesel engine and excitation system to represent the DGs. These two types of DG are considered as the basic DGs and their models will be included in the test system;

3. Represent the substation by a simplified two-axis synchronous generator model;

4. Simplify the IEEE-13 node feeder, and simulate it in Simulink;

5. Analyze the eigenvalues of the distribution system with DGs and each of its components;

6. Form a way to compute the first-order eigenvalue sensitivity via Simulink.

\subsection{System Models}

To study the dynamic characteristics of the gas turbine and the diesel engine DGs, the full order synchronous generator is developed in Simulink, while the substation is modeled as a simplified two-axis synchronous generator.

\subsubsection{Full-Order Synchronous Generator}

The full-order synchronous generator model consists of $6^{\text {th }}$-order electrical equations and $2^{\text {nd }}$-order mechanical equations. The $6^{\text {th }}$-order state equations of the electrical part can be expressed as:

$$
\begin{gathered}
v_{q s}^{r}=-r_{s} i_{q s}^{r}+\frac{\omega_{r}}{\omega_{b}} \psi_{d s}^{r}+\frac{p}{\omega_{b}} \psi_{q s}^{r} \\
v_{d s}^{r}=-r_{s} i_{d s}^{r}-\frac{\omega_{r}}{\omega_{b}} \psi_{q s}^{r}+\frac{p}{\omega_{b}} \psi_{d s}^{r} \\
v_{f d}^{\prime r}=r_{f d}^{\prime} i_{f d}^{\prime r}+\frac{p}{\omega_{b}} \psi_{f d}^{\prime r} \\
v_{k d}^{\prime r}=r_{k d}^{\prime} i_{k d}^{\prime r}+\frac{p}{\omega_{b}} \psi_{k d}^{\prime r} \\
v_{k q 1}^{\prime r}=r_{k q 1}^{\prime} i_{k q 1}^{\prime r}+\frac{p}{\omega_{b}} \psi_{k q 1}^{\prime r} \\
v_{k q 2}^{\prime r}=r_{k q 2}^{\prime} i_{k q 2}^{\prime r}+\frac{p}{\omega_{b}} \psi_{k q 2}^{\prime r}
\end{gathered}
$$

where $p=\frac{d}{d t}$.

The $2^{\text {nd }}$-order state equations of the mechanical part are:

$$
\begin{gathered}
\frac{p}{\omega_{b}} \omega_{r}=-\frac{1}{2 H}\left(T_{e}-T_{m}\right) \\
p \delta_{r}=\omega_{r}-1
\end{gathered}
$$




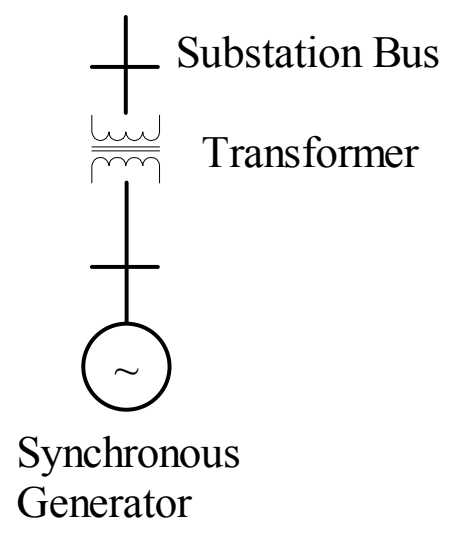

Figure 4.1: Diagram of the substation model of the distribution system.

where $\omega_{b}$ corresponds to rated or base frequency, and the torque in per unit is:

$$
T_{e}=\psi_{d s}^{r} i_{q s}^{r}-\psi_{q s}^{r} i_{d s}^{r}
$$

The detailed full-order synchronous generator model is described in Appendix A. The $\omega_{b}$ is used to calculate the inductive reactances.

\subsubsection{Substation Model}

To investigate dynamic characteristics of the distribution system with DG, a new distribution substation model is proposed in [80]. The form of the substation model used here consists of a synchronous generator and a transformer (see Figure 4.1). The synchronous generator is assumed to have a very large inertia and capacity. There are three reasons for this assumption: first, since the substation can provide adequate power for the distribution system, the capacity of the substation can be so adjusted. Second, since the substation is connected with the grid, its frequency is assumed to be constant requiring that the inertia of the synchronous generator must be sufficiently large. Third, with small transient reactance and large capacity, the terminal voltage magnitude of the synchronous generator is considered to be constant, similar to actual practice.

The state equations of the electrical part are:

$$
\begin{gathered}
p E_{d}^{\prime}=\frac{1}{t_{q 0}^{\prime}}\left(-E_{d}^{\prime}+\left(x_{q}-x_{q}^{\prime}\right) I_{q}\right. \\
p E_{q}^{\prime}=\frac{1}{t_{d 0}^{\prime}}\left(-E_{q}^{\prime}+E_{F D}+\left(x_{d}-x_{d}^{\prime}\right) I_{d}\right)
\end{gathered}
$$


The electrical torque output is:

$$
T_{e}=E_{d}^{\prime} I_{d}+E_{q}^{\prime} I_{q}-\left(L_{q}^{\prime}-L_{d}^{\prime}\right) I_{d} I_{q}
$$

The state equations of the mechanical part are:

$$
\begin{gathered}
p \omega=\frac{1}{t_{j}}\left(T_{m}-D \omega-T_{e}\right) \\
p \delta=\omega-1
\end{gathered}
$$

The transformer is modeled as a pure reactance with capacity equal to the capacity of the substation.

The capacity of the synchronous generator is determined by thermal constraint of the $138 \mathrm{kV}$ grid connected to the SI distribution system. The power carried by the $138 \mathrm{kV}$, called surge impedance loading or natural load, is $43 \mathrm{MW}$ [63]. Then, the rating of the $138 \mathrm{kV}$ is three times the surge impedance loading [31]:

$$
M V A=3 * 43.0=129.0 M V A
$$

\subsubsection{Gas Turbine}

A gas turbine driven synchronous generator is one of the important DGs studied. A simplified dynamic single-shaft gas turbine model is shown in Figure 4.2 [114] [107]. This gas turbine model is suitable to investigate the dynamic stability of gas turbine generator in power distribution system.

The gas turbine model consists of speed governor, limits, valve position, fuel pump, and turbine. The input signal is synchronous generator speed $N$, and output is control signal $P_{m e c h}$ to a synchronous generator. The turbine output is:

$$
\begin{aligned}
P_{\text {mech }} & =f\left(N, W_{f}\right) \\
& =1.3\left(W_{f}-0.23\right)+\frac{1-N}{2}
\end{aligned}
$$

where

$N$ : is the synchronous generator speed in per unit;

$W_{f}$ : is the fuel flow;

$I C 1, I C 2$ : are initial values of valve position and fuel pump. 


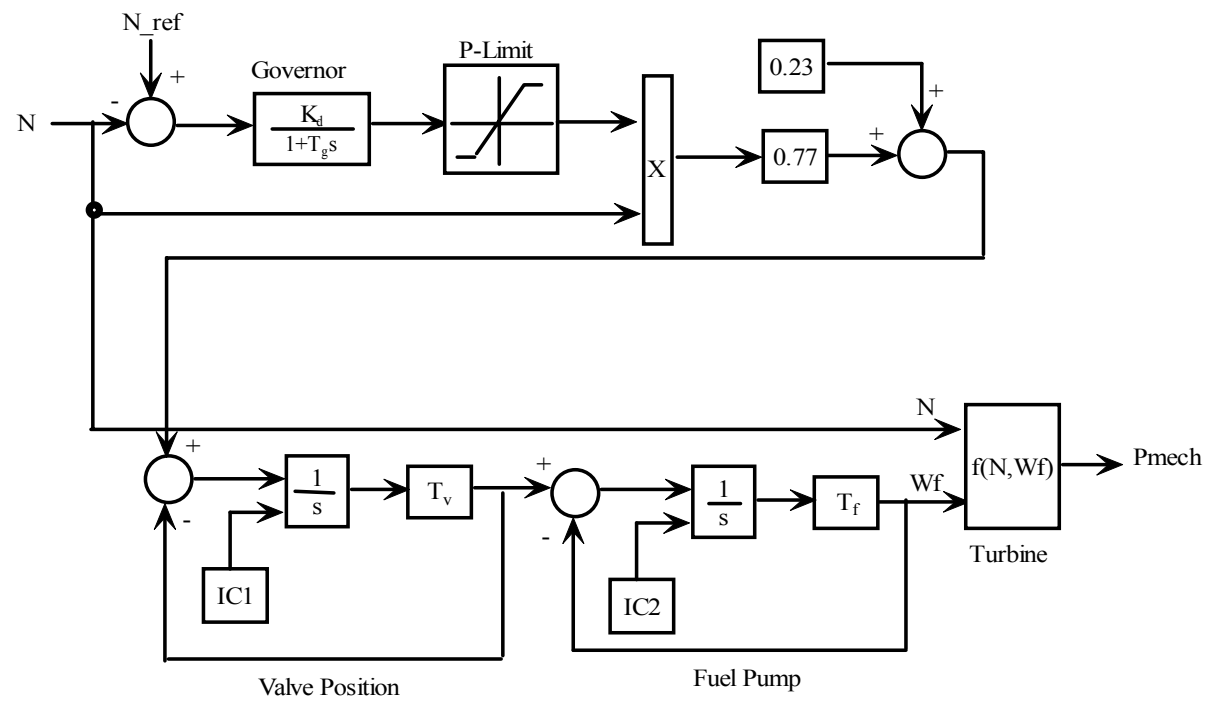

Figure 4.2: Diagram of a simplified gas turbine model.

\subsubsection{Diesel Engine}

A diesel engine driven synchronous generator is the second type of DG to be studied. The diesel engine model is shown in Figure 4.3 [133].

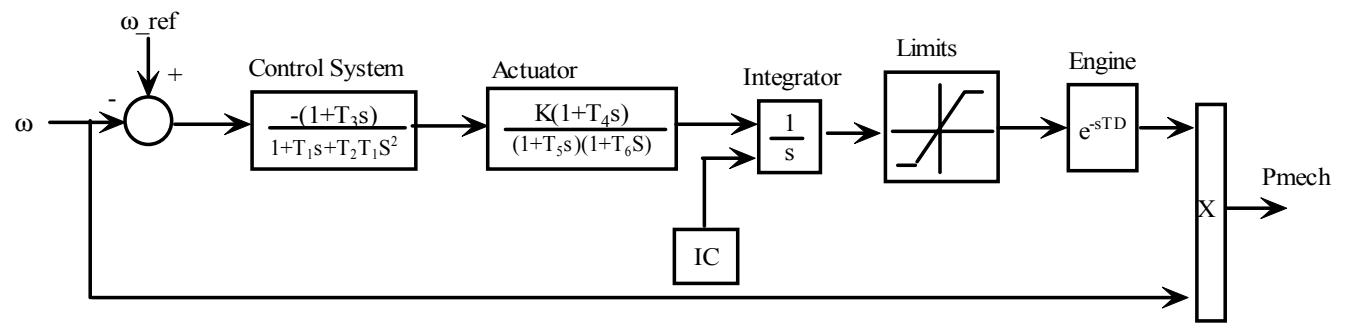

Figure 4.3: Diagram of a diesel engine and a governor model.

The input signal is the synchronous generator speed $\omega$ in per unit, and the output is the control signal $P_{\text {mech }}$ to a synchronous generator. The $I C$ is the initial value of the integrator.

\subsubsection{Average Model of IEEE-13 Node Feeder}

To simulate the IEEE-13 node feeder and use the linearization tool of Simulink, the following assumptions are taken into consideration to transfer the three-phase unbalanced distribution system 


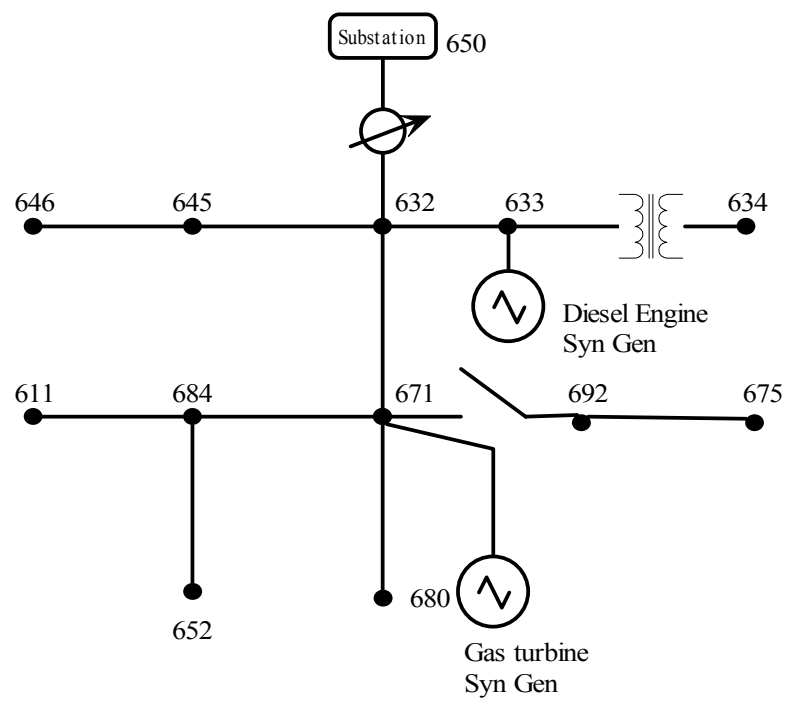

Figure 4.4: IEEE-13 node distribution system with a gas turbine DG and a diesel engine DG.

into a balanced single-phase system:

1. Three, two or single phase loads of each bus are represented as single load, the value is the average over three. For instance, the load of bus 675 is $\frac{485+j 190+68+j 60+290+j 212}{3}=281+j 154$;

2. The one-phase impedance of each feeder is used to represent the feeder;

3. Transformer and voltage regulator are represented single-phase reactance;

4. The substation and the DGs are represented in synchronous p-q reference frame.

\subsection{Building Synchronous Generator Model using Matrix Concept in Simulink}

Matrix and vector are basic concepts used in Matlab/Simulink. Vector computation is one of the features of Matlab. Using matrix/vector concepts not only simplifies problems but also contributes to time saving in debugging. This concept is to be used in simulation in full-order synchronous machine.

Dynamic machinery models are usually expressed in a set of differential equations. When building models in Matlab/Simulink, each differential equation can be represented by a transfer function composed of an integral unit. With a set of differential equations, a set of integral units will be used. While an input of one integral unit might be the function of the outputs of other 
integral units, the Simulink model can be very complex and unorganized with lines interweaving. Using matrix concepts, a set of differential equations will be expressed as:

$$
\dot{x}=A x+B u
$$

where $x$ and $u$ are vectors, $A$ and $B$ are matrices. Hence one integral unit is enough to express this model.

The dynamic model of synchronous machine (see equation 4.1-4.6) can be equivalently expressed as the current state variables equations[69]. The equations will be presented blow in terms of equation (4.17). The Simulink expressions are also shown blow which will use voltages as inputs and currents as the outputs of the model block.

The equations of a full-order synchronous machine model in the arbitrary reference frame can be written in term of the currents as shown in equation (4.18).

$$
\left[\begin{array}{c}
v_{q s} \\
v_{d s} \\
v_{k q 1}^{\prime} \\
v_{k q 2}^{\prime} \\
v_{f d}^{\prime} \\
v_{k d}^{\prime}
\end{array}\right]=M \cdot\left[\begin{array}{c}
i_{q s} \\
i_{d s} \\
i_{k q 1}^{\prime} \\
i_{k q 2}^{\prime} \\
i_{f d}^{\prime} \\
i_{k d}^{\prime}
\end{array}\right]
$$

where:

$$
M=\left[\begin{array}{cccccc}
-r_{s}-\frac{p}{\omega_{b}} X_{q} & -\frac{\omega_{r}}{\omega_{b}} X_{d} & \frac{p}{\omega_{b}} X_{m q} & \frac{p}{\omega_{b}} X_{m q} & \frac{\omega_{r}}{\omega_{b}} X_{m d} & \frac{\omega_{r}}{\omega_{b}} X_{m d} \\
\frac{\omega_{r}}{\omega_{b}} X_{q} & -r_{s}-\frac{p}{\omega_{b}} X_{d} & -\frac{\omega_{r}}{\omega_{b}} X_{m q} & -\frac{\omega_{r}}{\omega_{b}} X_{m q} & \frac{p}{\omega_{b}} X_{m d} & \frac{p}{\omega_{b}} X_{m d} \\
-\frac{p}{\omega_{b}} X_{m q} & 0 & r_{k q 1}^{\prime}+\frac{p}{\omega_{b}} X_{k q 1}^{\prime} & \frac{p}{\omega_{b}} X_{m q} & 0 & 0 \\
-\frac{p}{\omega_{b}} X_{m q} & 0 & \frac{p}{\omega_{b}} X_{m q} & r_{k q 2}^{\prime}+\frac{p}{\omega_{b}} X_{k q 2}^{\prime} & 0 & 0 \\
0 & -\frac{X_{m d}}{r_{f d}^{\prime}}\left(\frac{p}{\omega_{b}} X_{m d}\right) & 0 & 0 & \frac{X_{m d}}{r_{f d}^{\prime}}\left(r_{f d}^{\prime}+\frac{p}{\omega_{b}} X_{f d}^{\prime}\right) & \frac{X_{m d}}{r_{f d}^{\prime}}\left(\frac{p}{\omega_{b}} X_{m d}\right) \\
0 & -\frac{p}{\omega_{b}} X_{m d} & 0 & 0 & \frac{p}{\omega_{b}} X_{m d} & r_{k d}^{\prime}+\frac{p}{\omega_{b}} X_{k d}^{\prime}
\end{array}\right]
$$

Assume that the reference frame is a synchronous reference frame and that all quantities are in per unit value. This equation can be further written into: $\dot{x}=A x+B u$, where $x=$ $\left[i_{q s}, i_{d s}, i_{k q 1}^{\prime}, i_{k q 2}^{\prime}, i_{f d}^{\prime}, i_{k d}^{\prime}\right]^{T}$ 


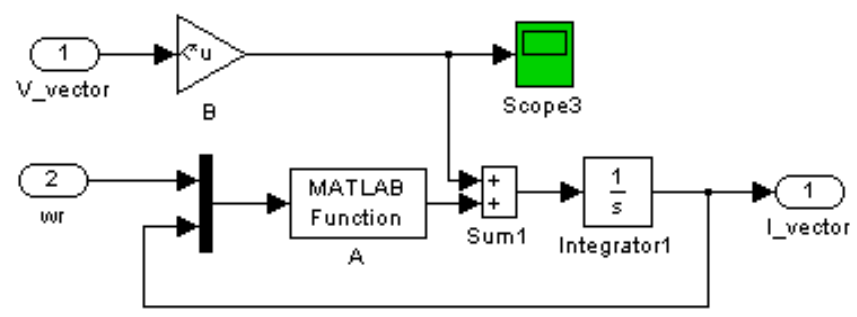

Figure 4.5: Using matrix/vector to represent the synchronous generator model in Simulink.

$$
\begin{aligned}
& B=\left[\begin{array}{cccccc}
-\frac{1}{\omega_{b}} X_{q} & 0 & \frac{1}{\omega_{b}} X_{m q} & \frac{1}{\omega_{b}} X_{m q} & 0 & 0 \\
0 & -\frac{1}{\omega_{b}} X_{d} & 0 & 0 & \frac{1}{\omega_{b}} X_{m d} & \frac{1}{\omega_{b}} X_{m d} \\
-\frac{1}{\omega_{b}} X_{m q} & 0 & \frac{1}{\omega_{b}} X_{k q 1}^{\prime} & \frac{1}{\omega_{b}} X_{m q} & 0 & 0 \\
-\frac{1}{\omega_{b}} X_{m q} & 0 & \frac{1}{\omega_{b}} X_{m q} & \frac{1}{\omega_{b}} X_{k q 2}^{\prime} & 0 & 0 \\
0 & -\frac{X_{m d}}{r_{f d}^{\prime}}\left(\frac{1}{\omega_{b}} X_{m d}\right) & 0 & 0 & \frac{X_{m d}}{r_{f d}^{\prime}}\left(\frac{1}{\omega_{b}} X_{f d}^{\prime}\right) & \frac{X_{m d}}{r_{f d}^{\prime}}\left(\frac{1}{\omega_{b}} X_{m d}\right) \\
0 & -\frac{1}{\omega_{b}} X_{m d} & 0 & 0 & \frac{1}{\omega_{b}} X_{m d} & \frac{1}{\omega_{b}} X_{k d}^{\prime}
\end{array}\right]^{-1} \\
& A=-B \cdot\left[\begin{array}{cccccc}
-r_{s} & -\frac{\omega_{r}}{\omega_{b}} X_{d} & 0 & 0 & \frac{\omega_{r}}{\omega_{b}} X_{m d} & \frac{\omega_{r}}{\omega_{b}} X_{m d} \\
\frac{\omega_{r}}{\omega_{b}} X_{q} & -r_{s} & -\frac{\omega_{r}}{\omega_{b}} X_{m q} & -\frac{\omega_{r}}{\omega_{b}} X_{m q} & 0 & 0 \\
0 & 0 & r_{k q 1}^{\prime} & 0 & 0 & 0 \\
0 & 0 & 0 & r_{k q 2}^{\prime} & 0 & 0 \\
0 & 0 & 0 & 0 & X_{m d} & 0 \\
0 & 0 & 0 & 0 & 0 & r_{k d}^{\prime}
\end{array}\right]
\end{aligned}
$$

The Simulink model for (4.18) is very simple shown in Figure 4.5.

In this model block, inputs are voltage and rotor speed, output is current vector. This model is quite simple and easy to understand. It saves not only model building time but also debug time. This model can avoid the numerical algebra loop.

The induction machine model simulated with the matrix/vector structure is presented in Chapter 8.

\subsection{Models Linearization}

Under the operating point, the DGs can be treated as linear models for controller design to improve the damping of the distribution system. To analyze the dynamic characteristics and design the 


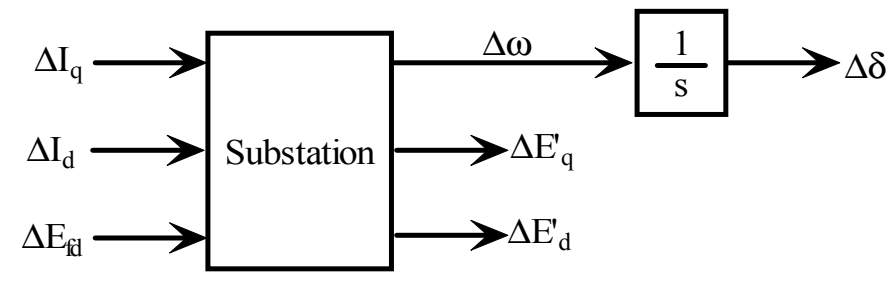

Figure 4.6: Diagram of the linearized substation model of the distribution system.

dynamic controller of the distribution system with DGs, the linearized models of each components are obtained via the Simulink.

In this chapter, the distribution system consists of the gas turbine synchronous generator (DG1), diesel engine synchronous generator (DG2) and substation. The substation is considered as a reference bus and the two DGs are considered as PV bus.

$$
\begin{aligned}
& S_{b}=4.0 M V A, V_{b}=4.16 k V . P_{D G 1}=0.1578, V_{D G 1}=1.0, P_{D G 2}=0.0875, V_{D G 2}=1.0 . \\
& \text { Synchronous generators: } r_{s}=0.003, X_{l s}=0.19, X_{q}=1.8, X_{d}=1.8, r_{k q 1}^{\prime}=0.00178, \\
X_{l k q 1}^{\prime}= & 0.8125, r_{f d}^{\prime}=0.000929, X_{l f d}^{\prime}=0.1414, r_{k d}^{\prime}=0.01334, X_{l k d}^{\prime}=0.08125 .
\end{aligned}
$$

Substation: $H=2364, T_{d 0}=8.96, T_{q 0}=0.1, r=0, x_{d}=0.8958, x_{q}=0.8645, x_{d}^{\prime}=x_{q}^{\prime}=$ $0.1198, D=0.1$.

These parameters and the parameters of gas turbine and diesel engine are summarized in the appendix. (see Table B.1).

\subsubsection{Linearized Substation Model}

The linearized substation model can be represented as the diagram in Figure 4.6.

The linearization model is obtained from nonlinear model in Simulink directly.

\subsubsection{Linearized Gas Turbine Synchronous Generator}

The linearized gas turbine powered synchronous generator model (DG1) is illustrated in Figure 4.7. The three state variables of the gas turbine are: governor power $\left(x_{\text {gov }}\right)$, valve position $\left(x_{v a l}\right)$ and fuel pump $\left(x_{f p}\right)$.

In the linearized model (4.19), the system plant $(A)$ consists of: the synchronous generator $(A 11)$, the gas turbine $(A 22)$ and the interactions between the gas turbine and the synchronous generator $(A 12, A 21)$. The reference of equation (4.19) is the rotor of the synchronous generator. 


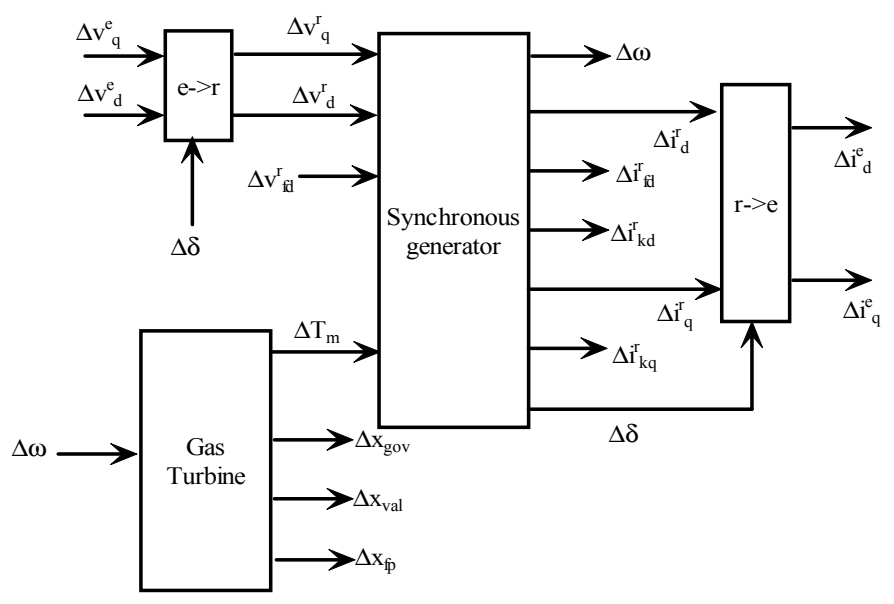

Figure 4.7: Linearized gas-turbine powered synchronous generator.

$$
\left[\begin{array}{c}
\Delta \dot{\omega} \\
\Delta \dot{i}_{d}^{r} \\
\Delta \dot{i}_{f d}^{r} \\
\Delta \dot{i}_{k d}^{r} \\
\Delta \dot{i}_{q}^{r} \\
\Delta \dot{i}_{k q}^{r} \\
\Delta \dot{\delta}^{r} \\
\cdots \\
\Delta \dot{x}_{g o v} \\
\Delta \dot{x}_{v a l} \\
\Delta \dot{x}_{f p}
\end{array}\right]=\left[\begin{array}{ll}
A 11 & A 12 \\
A 21 & A 22
\end{array}\right] \cdot\left[\begin{array}{c}
\Delta \omega \\
\Delta i_{d}^{r} \\
\Delta i_{f d}^{r} \\
\Delta i_{k d}^{r} \\
\Delta i_{q}^{r} \\
\Delta i_{k q}^{r} \\
\Delta \delta \\
\cdots \\
\Delta x_{g o v} \\
\Delta x_{v a l} \\
\Delta x_{f p}
\end{array}\right]+B \cdot\left[\begin{array}{c}
\Delta v_{q}^{r} \\
\Delta v_{d}^{r} \\
\Delta v_{f d}^{r}
\end{array}\right]
$$

where the eigenvalues of the gas turbine synchronous generator under the specific operating point is:

\subsubsection{Linearized Diesel Engine Synchronous Generator}

The linearized diesel engine powered synchronous generator model (DG2) is shown in Figure 4.8. The diesel engine unit has four independent state variables: two controller states $\left(x_{\text {con } 1}, x_{\text {con } 2}\right)$, actuator state \#1 $\left(x_{T F 1}\right)$ and actuator state \#2 $\left(x_{T F 2}\right)$. Under specific operating point, the output of the integrator $\left(x_{i n t}\right)$ depends on the four states. 
Table 4.1: Eigenvalues of the linearized synchronous generator with gas-turbine.

\begin{tabular}{|c|c|}
\hline NO. & Eigenvalues \\
\hline \hline$\lambda_{1,2}$ & $-3.2937 \pm 377.06 \mathrm{i}$ \\
\hline$\lambda_{3}$ & -30.983 \\
\hline$\lambda_{4,5}$ & $-20.028 \pm 0.73761 \mathrm{i}$ \\
\hline$\lambda_{6,7}$ & $-0.69465 \pm 2.6572 \mathrm{i}$ \\
\hline$\lambda_{8}$ & -0.37188 \\
\hline$\lambda_{9}$ & -1.1222 \\
\hline$\lambda_{10}$ & -2.4543 \\
\hline
\end{tabular}

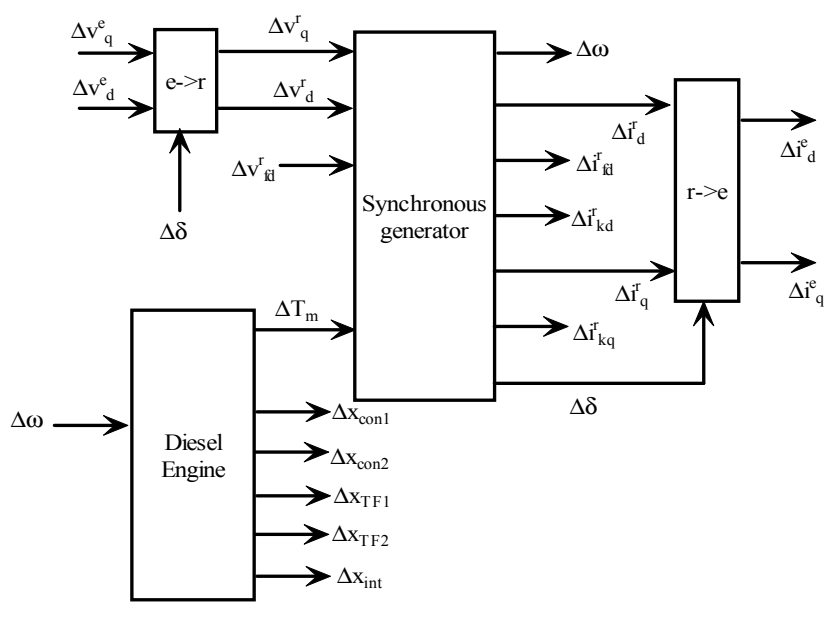

Figure 4.8: Linearized diesel engine powered synchronous generator. 
Table 4.2: Eigenvalues of the linearized synchronous generator connected to diesel engine.

\begin{tabular}{|c|c|}
\hline NO. & Eigenvalues \\
\hline \hline$\lambda_{1,2}$ & $-3.2935 \pm 377.06 \mathrm{i}$ \\
\hline$\lambda_{3}$ & -30.983 \\
\hline$\lambda_{4,5}$ & $-0.70467 \pm 2.4787 \mathrm{i}$ \\
\hline$\lambda_{6}$ & -0.4116 \\
\hline$\lambda_{7}$ & -1.065 \\
\hline
\end{tabular}

Table 4.3: Eigenvalues of the linearized diesel engine DG.

\begin{tabular}{|c|c|}
\hline NO. & Eigenvalues \\
\hline \hline$\lambda_{1}$ & 0 \\
\hline$\lambda_{2}$ & -26.042 \\
\hline$\lambda_{3}$ & -111.11 \\
\hline$\lambda_{4,5}$ & $-25 \pm 66.144 \mathrm{i}$ \\
\hline
\end{tabular}

The linearized synchronous generator model is different from the model of DG1 since they have different operating points. The eigenvalues of the synchronous generator of DG2 are given in Table 4.2.

The linearized model of the diesel engine is shown in equation (4.20).

$$
\left[\begin{array}{c}
\Delta \dot{x}_{c o n 1} \\
\Delta \dot{x}_{c o n 2} \\
\Delta \dot{x}_{T F 1} \\
\Delta \dot{x}_{T F 2} \\
\Delta \dot{x}_{i n t}
\end{array}\right]=A_{d i e s} \cdot\left[\begin{array}{c}
\Delta x_{c o n 1} \\
\Delta x_{c o n 2} \\
\Delta x_{T F 1} \\
\Delta x_{T F 2} \\
\Delta x_{i n t}
\end{array}\right]
$$

where the eigenvalues of the diesel engine are given in Table 4.3.

The zero eigenvalue is corresponding to the $\Delta x_{i n t}$. It means the integrator is only an output of the isolated linearized diesel engine model.

\subsection{Eigenvalue Analysis}

\subsubsection{Eigenvalue of the Distribution System with DGs}

The eigenvalues of each components are discussed in above section. The results show the numbers of each component as: 
4 states of substation: $\left[\begin{array}{cccc}\Delta \omega & \Delta E_{q}^{\prime} & \Delta E_{d}^{\prime} & \Delta \delta\end{array}\right]^{T}$;

10 states of gas turbine synchronous generator +1 state of excitation system:

$\left[\begin{array}{ccccccccccc}\Delta \omega & \Delta \lambda_{d} & \Delta \lambda_{f d} & \Delta \lambda_{k d} & \Delta \lambda_{q} & \Delta \lambda_{k q} & \Delta \delta & : & \Delta x_{\text {gov }} & \Delta x_{v a l} & \Delta x_{f p}\end{array}\right]^{T}+\left[\Delta x_{e x}\right]^{T}$

11 states of diesel engine synchronous generator +1 integrator +1 state of excitation system:

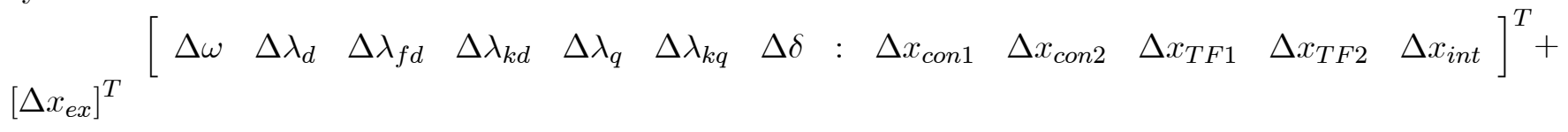

In the distribution system with substation and DGs, the angle $\delta$ of substation is considered as a reference, so the system contains $(4+11+13-1=27)$ states:

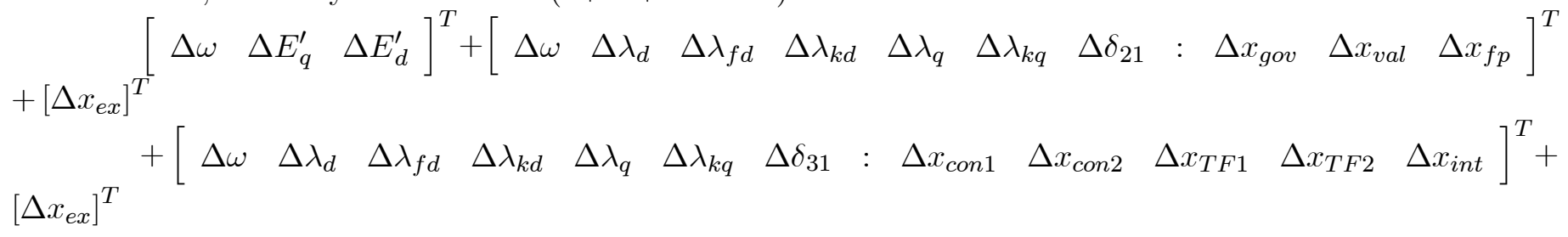

The eigenvalues of the distribution system under the specific operating point are given in

Table 4.4.

Table 4.4: Eigenvalues of the linearized distribution system with DGs.

\begin{tabular}{|c|c|}
\hline NO. & Eigenvalues \\
\hline \hline$\lambda_{1,2}$ & $-140.66 \pm 928.54 \mathrm{i}$ \\
\hline$\lambda_{3,4}$ & $-30.606 \pm 440.48 \mathrm{i}$ \\
\hline$\lambda_{5}$ & -108.59 \\
\hline$\lambda_{6,7}$ & $-22.913 \pm 64.387 \mathrm{i}$ \\
\hline$\lambda_{8}$ & -31.956 \\
\hline$\lambda_{9}$ & -30.745 \\
\hline$\lambda_{10}$ & -31.343 \\
\hline$\lambda_{11}$ & -25.968 \\
\hline$\lambda_{12,13}$ & $-20.024 \pm 0.73748 \mathrm{i}$ \\
\hline$\lambda_{14,15}$ & $-6.2691 \pm 10.487 \mathrm{i}$ \\
\hline$\lambda_{16}$ & -11.803 \\
\hline$\lambda_{17,18}$ & $-1.1171 \pm 8.4846 \mathrm{i}$ \\
\hline$\lambda_{19,20}$ & $-0.8487 \pm 3.8898 \mathrm{i}$ \\
\hline$\lambda_{21}$ & -4.225 \\
\hline$\lambda_{22}$ & -2.4564 \\
\hline$\lambda_{23,24}$ & $-0.0020607 \pm 0.081228 \mathrm{i}$ \\
\hline$\lambda_{25}$ & -0.41639 \\
\hline$\lambda_{26}$ & -0.48735 \\
\hline$\lambda_{27}$ & -0.46964 \\
\hline
\end{tabular}




\subsubsection{Eigenvalue Sensitivity}

In a linear system $[A, B, C, D]$, assume the system plant $A(n \times n)$ is a function of a general system parameter $a_{k}(k=1,2, \ldots, r)$. An important stability issue of the system is to determine the eigenvalues deviation $(\Delta \Lambda)$ corresponding to the change of the parameters $a_{k}$. A second order Taylor-series expansion is given to estimate the $\Delta \Lambda$ over the parameter $a_{k}$ as:

$$
\Delta \Lambda=\frac{\partial \Lambda}{\partial a_{k}}\left(\Delta a_{k}\right)+\frac{1}{2} \frac{\partial^{2} \Lambda}{\partial a_{k}^{2}}\left(\Delta a_{k}\right)^{2}
$$

where

$$
\begin{aligned}
& \Delta \Lambda=\operatorname{diag}\left[\Delta \lambda_{1}, \Delta \lambda_{2}, \ldots, \Delta \lambda_{n}\right] \\
& \frac{\partial \Lambda}{\partial a_{k}}=\operatorname{diag}\left[\frac{\partial \lambda_{1}}{\partial a_{k}}, \frac{\partial \lambda_{2}}{\partial a_{k}}, \ldots, \frac{\partial \lambda_{n}}{\partial a_{k}}\right] \\
& \frac{\partial^{2} \Lambda}{\partial a_{k}^{2}}=\operatorname{diag}\left[\frac{\partial \lambda_{1}^{2}}{\partial a_{k}^{2}}, \frac{\partial \lambda_{2}^{2}}{\partial a_{k}^{2}}, \ldots, \frac{\partial \lambda_{n}^{2}}{\partial a_{k}^{2}}\right] \\
& k=1,2, \ldots, r
\end{aligned}
$$

The terms $\frac{\partial \Lambda}{\partial a_{k}}$ and $\frac{\partial^{2} \Lambda}{\partial a_{k}^{2}}$ in equation 4.21 are defined as the first-order and second-order eigenvalue sensitivities with respect to the system parameter $a_{k}(k=1,2, \ldots, r)$.

The right $\left(v_{i}\right)$ and left $\left(w_{i}^{T}\right)$ eigenvectors of the system plant $A(n \times n)$ corresponding to the eigenvalue $\lambda_{i}(i=1,2, \ldots, n)$ are defined by:

$$
\begin{gathered}
A v_{i}=v_{i} \lambda_{i}, v_{i} \neq 0 \\
w_{i}^{T} A=\lambda_{i} w_{i}^{T}, w_{i}^{T} \neq 0
\end{gathered}
$$

where $\lambda_{i}$ is the $i^{\text {th }}$ eigenvalue, and the product of left and right eigenvectors has the characteristic:

$$
w_{i}^{T} v_{i}=1 \text {, if } i=j, 0 \text { otherwise }
$$

So, if the system $A$ has $n$ different eigenvalues, the following relations exist:

$$
\begin{gathered}
\Lambda=W^{T} A V \\
I=W^{T} V
\end{gathered}
$$

where

$\Lambda: \operatorname{diag}\left[\lambda_{1}, \quad \ldots ., \lambda_{n}\right]$

$W^{T}: n \times n$ matrix which has $w_{i}^{T}$ as its $i^{\text {th }}$ row

$V: n \times n$ matrix which has $v_{i}$ as its $i^{\text {th }}$ column

$I: n \times n$ identity matrix 
Table 4.5: Eigenvalue sensitivity with respect to $X_{d}$.

\begin{tabular}{|c|c|}
\hline NO. & Eigenvalues sensitivity vs. $X_{d}$ \\
\hline \hline$\lambda_{1,2}$ & $-292.06 \mp 921.28 \mathrm{i}$ \\
\hline$\lambda_{3,4}$ & $-4.7684 \mp 101.44 \mathrm{i}$ \\
\hline$\lambda_{5}$ & -0.0002 \\
\hline$\lambda_{6,7}$ & $-0.00056 \pm 0.00044 \mathrm{i}$ \\
\hline$\lambda_{8}$ & 5.2170 \\
\hline$\lambda_{9}$ & 14.999 \\
\hline$\lambda_{10}$ & -0.6977 \\
\hline$\lambda_{11}$ & 0.0065 \\
\hline$\lambda_{12,13}$ & $-0.00015 \mp 0.00026 \mathrm{i}$ \\
\hline$\lambda_{14,15}$ & $-1.1141 \mp 8.1231 \mathrm{i}$ \\
\hline$\lambda_{16}$ & -14.105 \\
\hline$\lambda_{17,18}$ & $0.1963 \mp 0.0904 \mathrm{i}$ \\
\hline$\lambda_{19,20}$ & $0.0458 \pm 0.0125 \mathrm{i}$ \\
\hline$\lambda_{21}$ & 14.022 \\
\hline$\lambda_{22}$ & 0.0064 \\
\hline$\lambda_{23,24}$ & $(-0.458 \mp 3.974 \mathrm{i}) \times 10^{-6}$ \\
\hline$\lambda_{25}$ & -0.00219 \\
\hline$\lambda_{26}$ & 0.01005 \\
\hline$\lambda_{27}$ & -0.00171 \\
\hline
\end{tabular}

$T$ : denotes transposition

Taking derivatives of both sides of equation (4.25) with respect to a specific parameter $\alpha_{k}$ yields:

$$
\begin{aligned}
\frac{\partial \Lambda}{\partial a_{k}} & =\frac{\partial W^{T}}{\partial a_{k}} A V+\left(W^{T}\right) \frac{\partial A}{\partial a_{k}} V+\left(W^{T} A\right) \frac{\partial V}{\partial a_{k}} \\
& =\frac{\partial W^{T}}{\partial a_{k}}\left(W^{T}\right)^{-1} \Lambda+\left(W^{T}\right) \frac{\partial A}{\partial a_{k}} V+\Lambda V^{-1} \frac{\partial V}{\partial a_{k}} \\
& =\frac{\partial W^{T}}{\partial a_{k}} V \Lambda+\left(W^{T}\right) \frac{\partial A}{\partial a_{k}} V+\Lambda W^{T} \frac{\partial V}{\partial a_{k}}
\end{aligned}
$$

The derivative of equation (4.26) is:

$$
\frac{\partial W^{T}}{\partial a_{k}} V+W^{T} \frac{\partial V}{\partial a_{k}}=0
$$

Using the relationship $\frac{\partial W^{T}}{\partial a_{k}} V=0$ and $W^{T} \frac{\partial V}{\partial a_{k}}=0$, the equation (4.29) can be written as:

$$
\frac{\partial \Lambda}{\partial a_{k}}=\left(W^{T}\right) \frac{\partial A}{\partial a_{k}} V
$$


In conventional solution, the $\frac{\partial A}{\partial a_{k}}$ is derived from the linearized equations [69][73]. With the help of the Simulink toolbox, the $\frac{\partial A}{\partial a_{k}}$ can be calculated as:

$$
\frac{\partial A}{\partial a_{k}}=\frac{A_{\Delta a_{k}}-A}{\Delta a_{k}}
$$

where $A_{\Delta a_{k}}$ is the system plant of the linearized system in Simulink with very small deviation of parameter $a_{k}$.

For example, the eigenvalue sensitivity with respect to the parameter $X_{d}$ is listed in Table 4.5. While calculating the $A_{\Delta a_{k}}$, the parameter is changed from $X_{d} 1.8$ to 1.82 and $\Delta a_{k}$ is 0.02 .

\subsection{Summary}

The matrix/vector concept in Simulink is used to simulate the full-order synchronous generator. This method can simplify the simulation and avoid the algebra loop. The substation model for dynamic studies is developed. It consists of a large inertia synchronous generator and a transformer. 


\section{Chapter 5}

\section{A Phosphoric Acid Fuel Cell Model from Data Fitting}

\subsection{Introduction}

This chapter presents a fuel cell model obtained through data fitting method with the operating data of a phosphoric acid fuel cell (PAFC). The impedance characteristics of the fuel cell are investigated. Dynamic simulations in MATLAB/SIMULINK are then studied toward the integrated system of the fuel cell for the IEEE 13-node power distribution system with existing gas turbine and diesel engine distributed generations (DGs). The impacts of fuel cell on the system are investigated. An efficient way to develop the complicated fuel cell model is presented in this chapter. The nonlinear simulation illustrates that the model is helpful to investigate the dynamic stability of the distribution system with a fuel cell power plant.

With the assistance of local electric utilities, operating data on a phosphoric acid fuel cell system [66][83] was obtained. Actual data was recorded by a Digital Fault Recorder (DFR) system monitoring the operation of the cell.

A phosphoric acid fuel cell contains the primary subsystems shown in Figure 5.1.

Dynamic behavior of components can be modeled using systems theory in several ways. Here, the data on the fuel cell operation is retrieved and applied to obtain generic structures describing the dynamics such as transfer functions and their time domain counterparts, differential equations.

A large volume of data is available from recorded events on the subject fuel cell. 


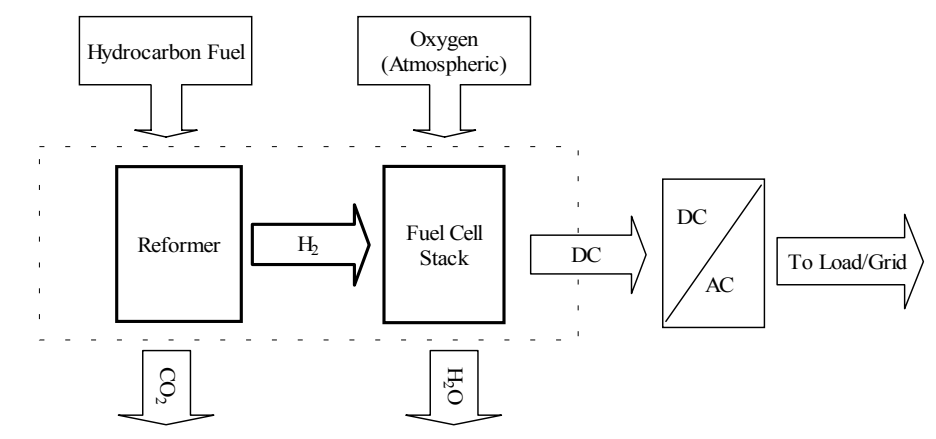

Figure 5.1: Diagram of a PAFC's generalized schematic.

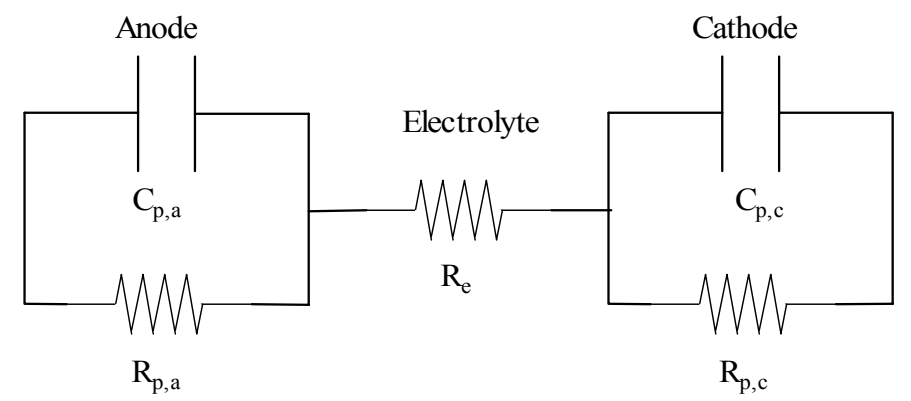

Figure 5.2: An equivalent circuit of the PAFC.

\subsection{V-I Characteristics}

A PAFC can be electrically modeled as shown in the equivalent circuit of Figure 5.2 [135]. The structure is composed of an electrolyte and two electrodes. $R_{e}$ is the resistance of electrolyte in the matrix of the PAFC. The capacitive component of the electrolyte is ignored since the electrolyte is highly conductive. $R_{p, a}$ represents the anodic polarization resistance, in parallel with the doublelayer capacitance of the interface between the electrolyte and the anode. $R_{p, c}$ corresponds to polarization resistance of the cathode. $C_{p, a}$ and $C_{p, c}$ represent the double-layer capacitances near the anode and the cathode.

The current-voltage nonlinear characteristics of a single PAFC with a variation in the amount of the dispersant can be obtained from the performance data. A certain voltage is found as an open circuit voltage (OCV). The current increases with decreasing potential below the OCV. Thus the fuel cell can be represented as a controllable current source controlled with variable 


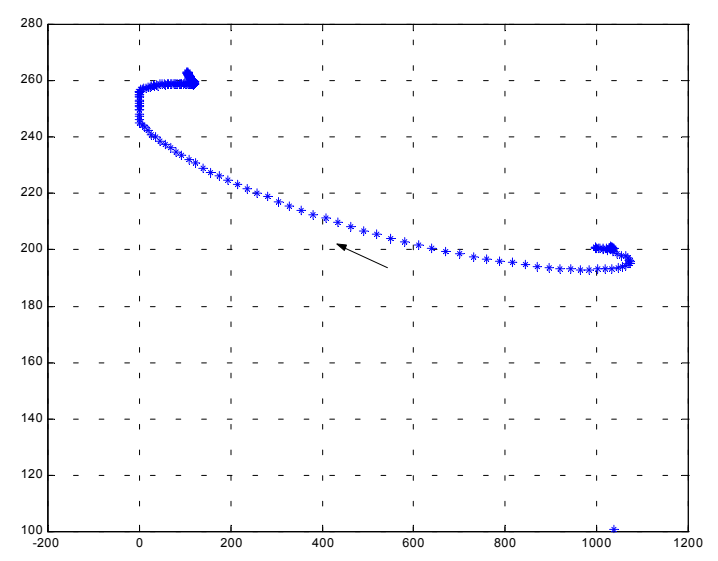

Figure 5.3: I-V characteristics of the PAFC obtained from the recorded data. (X axis: current (A); $\mathrm{Y}$ axis: voltage $(\mathrm{V}))$

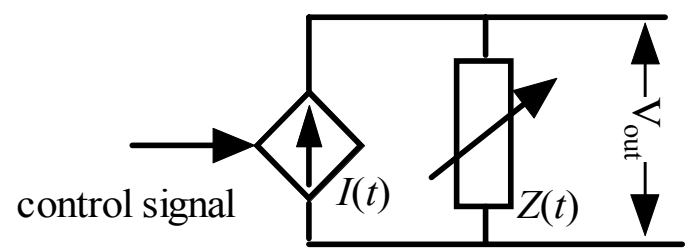

Figure 5.4: A model of the PAFC's DC part.

impedance. The RMS AC output voltage value is proportional to the DC output voltage value.

Figure 5.3 shows the I-V characteristic of the PAFC obtained from the recorded data during a shut down cycle process. Overall, the voltage increases when the current decreases. The impedance characteristic is similar to that in [135].

Therefore, if we can obtain the impedance characteristic of the fuel cell and the gas valve turn off process, a detailed fuel cell model can be constructed. In the turning off process, the DC current is used to represent the valve of the fuel cell. The controllable current source and the output voltage can be obtained through data fitting. By dividing the voltage by the current the impedance is obtained. Thus the whole fuel cell model is known. Figure 5.4 shows the DC part of the PAFC model. 


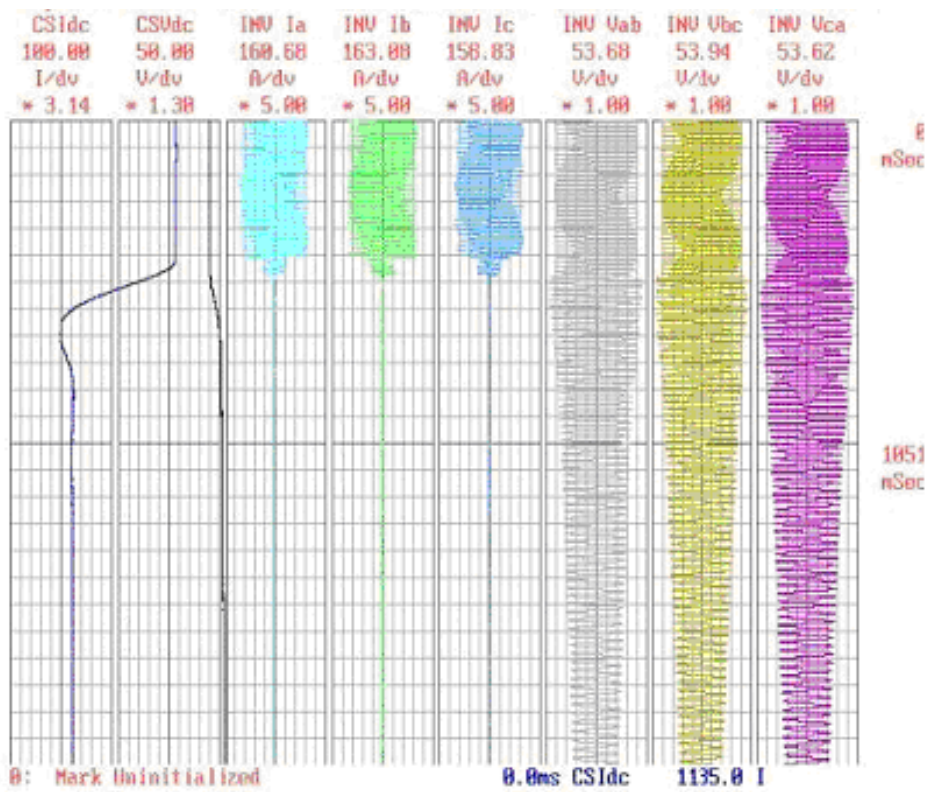

Figure 5.5: Diagram of the sampled data of the DFR device.

\subsection{Data Fitting}

To obtain the transfer function $\mathrm{H}(\mathrm{s})$, for the fuel cell from the analysis of the real, raw data, there are three steps[134]:

1. Identification of the candidate time domain function.

2. Estimation of the parameters in the time domain function.

3. Obtaining the transfer function from the actual time domain data.

Figure 5.5 shows the sampled data of the DFR device. Several such data samples were used to obtain the models in this chapter.

\subsubsection{Least Squares Optimization Algorithm}

The estimation of the parameter of the time domain function is accomplished through data fitting. Here the least square optimization method is used.

The objective function is expressed as the integral of the least square error:

$$
\min _{x \in R^{n}} \int_{t_{2}}^{t_{1}}(y(x, t)-\phi(t))^{2} d t
$$


where $y(x, t)$ is the estimated output function with $x$ and $t$ as parameters and $\phi(t)$ is the real data. $y(x, t)$ is required to follow the trajectory of $\phi(t)$. Equation (5.1) is discretized and formulated as a least squares problem:

$$
\min _{x \in R^{n}} f(x)=\sum_{i=1}^{m}(\overline{y(x, t)}-\overline{\phi(t)})^{2}
$$

where $\bar{y}$ and $\bar{\phi}$ include the weights of the quadrature scheme.

The MATLAB Optimization toolbox was applied to solve this problem and generate the numerical optimal parameters.

\subsubsection{Fuel Cell Transient Output Current Modeling}

From the general form of the fuel cell's DC current, it can be seen that it has the general form of analytical response:

$$
I(t)=k e^{-\alpha\left(t-t_{0}\right)} \cos \left(\omega\left(t-t_{0}\right)\right)+c
$$

where $k, \alpha, \omega, t_{0}$ and $c$ are the undetermined constants. They will be determined by fitting this analytical expression to the current data record. The data records from the DFR can be used to make the fit using MATLAB. Three different data records were fitted to this form.

Figure 5.6 shows the DC current response corresponding to a fuel cell shut down (Case 1). The identified values of the parameters in equation (5.3) are shown in Figure 5.6. The small circles denote the fuel cell (DFR) sampled data and the continuous line is the equation (5.3) fitted approximation of the actual data.

A second approximation example (Case 2) selected was the DC current response on a different data set (e.g. independent data set). Figure 5.7 gives the measured data (circles), the equation (5.3) approximation values (continuous line) and the equation (5.3) parameter values which resulted from the best fit of equation (5.1) to the actual measured fuel cell data.

Finally, a third example fuel cell shut down data set (Case 3) is selected for approximation of the DC current. Table 5.1 summarizes the best-fit parameters for all three of the above calculated fuel cell shut down dynamics cases.

It can be seen that the parameter values given in Table 5.1 result in very good fits of equation (5.3) to the actual fuel cell data.

From Table 5.1, the approximate ranges of equation (5.3) parameter values are as given in Table 5.2. From these intervals of parameter values, one might select the typical set of parameter 


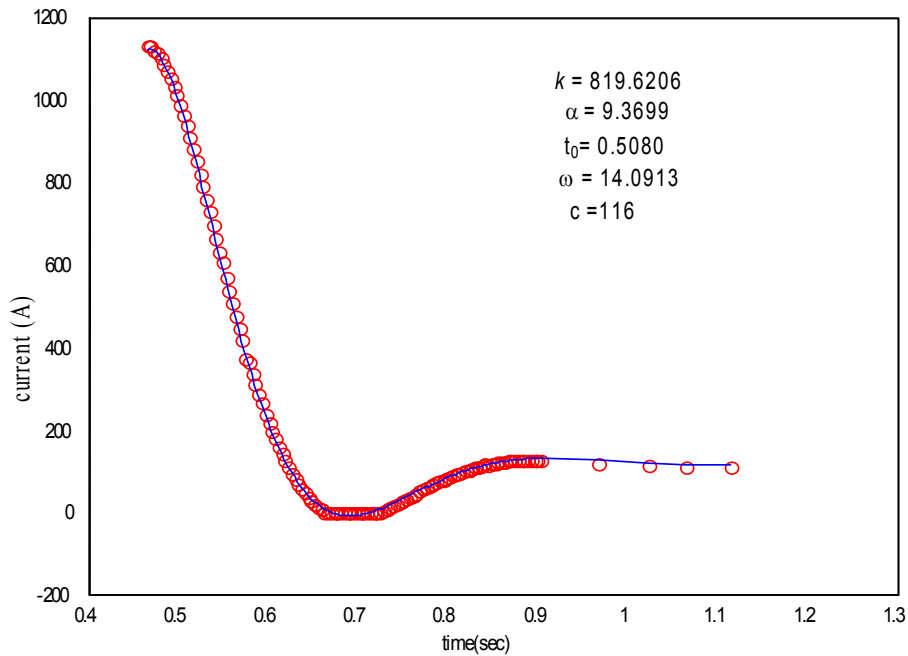

Figure 5.6: The recorded data and fitted curve of the PAFC's DC current (Case 1).

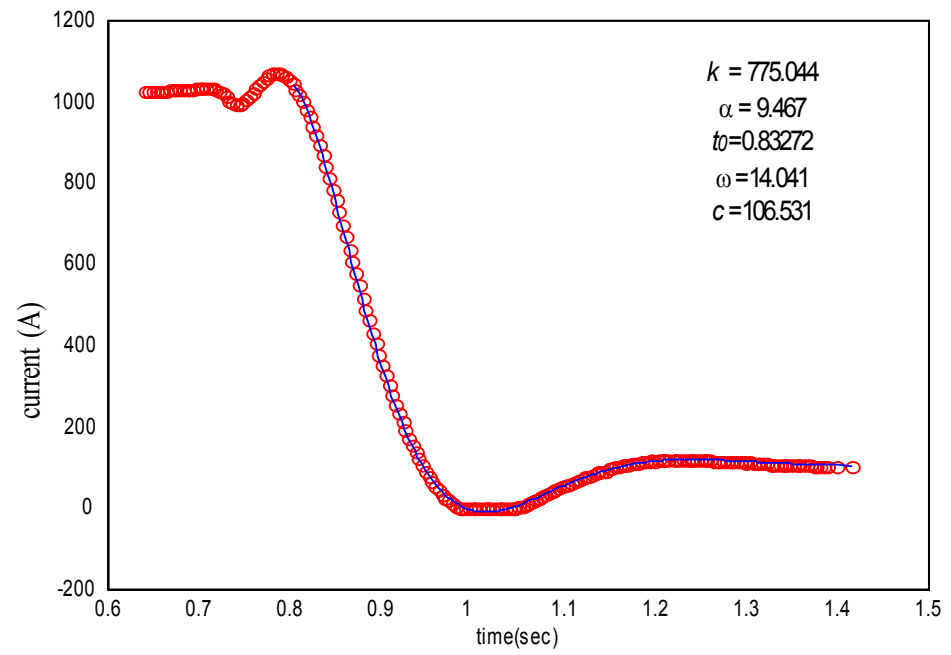

Figure 5.7: The recorded data and fitted curve of the PAFC's DC current (Case 2). 
Table 5.1: DC current parameters vs. record data.

\begin{tabular}{|l|c|c|c|c|c|}
\hline NO. & $k$ & $\alpha$ & $c$ & $\omega$ & $t_{0}$ \\
\hline \hline Case 1 & 819.6 & 9.370 & 116 & 14.09 & 0.508 \\
\hline Case 2 & 775.0 & 9.467 & 106.5 & 14.04 & 0.833 \\
\hline Case 3 & 766.9 & 9.045 & 111.4 & 13.87 & 0.533 \\
\hline
\end{tabular}

Table 5.2: Range of parameters and representative parameter values.

\begin{tabular}{|l|c|c|c|c|}
\hline NO. & $k$ & $\alpha$ & $c$ & $\omega$ \\
\hline \hline Range & $750-819.6$ & $9-9.5$ & $110-120$ & $13.15-14.15$ \\
\hline Representative & 785.0 & 9.25 & 115 & 14.0 \\
\hline
\end{tabular}

values shown in Table 5.2 as representative values for a generic model of this class of PAFC fuel cell shut down dynamics.

Considering the shut down to be a response to a unit step (or switched) input,

$$
U(s)=-\frac{U_{0}}{s}
$$

where $U_{0}$ is the amplitude of the down step, the output current response to this input shut down is equation (5.3). Taking the Laplace transform of equation (5.3), the Laplace transform of the output response $I(s)$ is:

$$
I(s)=\frac{k s}{(s+\alpha)^{2}+\omega^{2}} e^{t_{0} s}+\frac{c}{s}
$$

Therefore the transfer function is:

$$
H(s)=\frac{I(s)}{U(s)}=-\frac{k s}{(s+\alpha)^{2}+\omega^{2}} e^{t_{0} s}-\frac{c}{s}
$$

where $k=785, c=115, \alpha=9.25, \omega=14.0$.

\subsubsection{Fuel Cell Transient Output Voltage Modeling}

Next the fuel cell DC output voltage response is modeled. In this case, the most appropriate analytical function form is a polynomial. Again, MATLAB Optimization toolbox is used to fit an approximation polynomial to actual fuel cell data provided. The MATLAB function POLYFIT is used to match a polynomial in time to the fuel cell DC voltage data vs. time by minimizing the mean squared error between the analytical polynomial and the voltage data. POLYFIT adjusts 
Table 5.3: Error vs. polynomial order.

\begin{tabular}{|c|c|c|c|c|c|c|c|c|c|c|}
\hline \hline$N$ & 4 & 5 & 6 & 7 & 8 & 9 & 10 & 11 & 12 & 13 \\
\hline Error & 29.70 & 9.03 & 5.95 & 4.10 & 2.12 & 1.96 & 1.95 & 1.94 & 1.94 & 1.94 \\
\hline
\end{tabular}

the polynomial coefficients to achieve the best fit. The equations are:

$$
V(t)=\sum_{n=0}^{N} a_{n}\left(t-t_{0}\right)^{n}
$$

The vector of coefficients is:

$$
\text { Coef }=\left[a_{N}, a_{N-1}, a_{N-2}, \ldots, a_{1}, a_{0}\right]
$$

The root mean square error between any set of sample values of the fuel cell's DC voltage data and equation (5.7) values is:

$$
\text { Error }=\sqrt{\sum\left(V_{\text {sampling }}-V_{\text {estimate }}\right)^{2}}
$$

As an example, for the Case 1 fuel cell data set, the value of the error versus the number of terms in the polynomial for polynomials of order four through thirteen are shown in Table 5.3. A graph of this relationship plotting error on the vertical axis versus number of polynomial terms (the order of the polynomial) is shown in Figure 8.

From Table 5.3 and Figure 5.8, it is observable that the $8^{\text {th }}$ order polynomial is almost as good as any polynomial of higher order to approximate the DC voltage's waveform. Therefore only an eighth order polynomial is needed to represent this transient DC voltage.

The coefficients of the $8^{\text {th }}$ order polynomial are:

$$
\begin{aligned}
& \text { Coef }=1.0 e+006 *\left[\begin{array}{llll}
-0.4206 & 1.1891 & -1.3581 & .7877
\end{array}\right. \\
& \left.\begin{array}{lllll}
-0.2339 & 0.0285 & 0.0003 & -0.0000 & 0.0002
\end{array}\right]
\end{aligned}
$$

and the polynomial is:

$$
V(t)=\sum_{n=0}^{8} \operatorname{coef}(n)\left(t-t_{0}\right)^{n}
$$

Figure 5.9 shows the recorded data and fitted curve of the output voltage. 


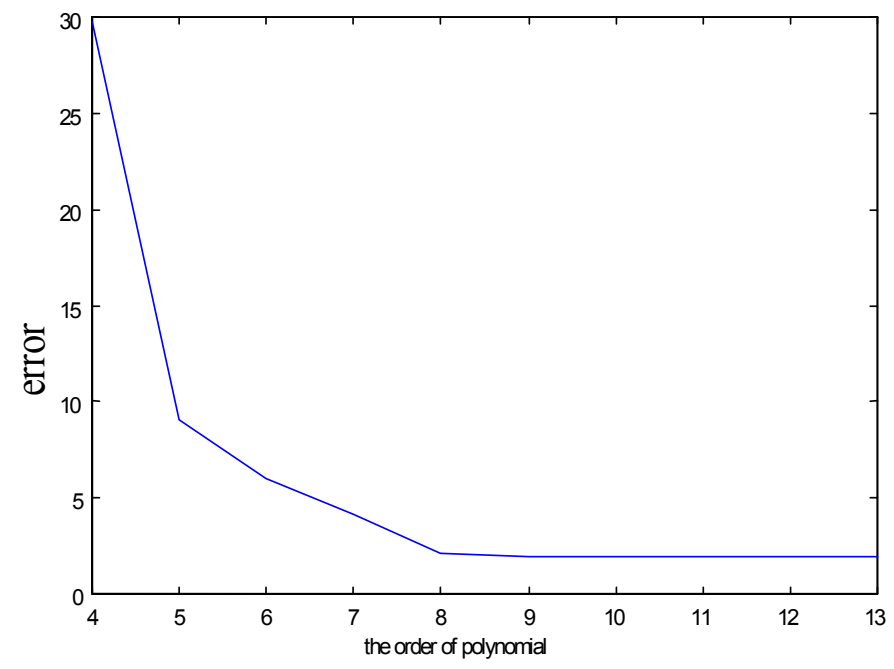

Figure 5.8: Diagram of the Error vs. polynomial order for the PAFC's DC voltage.

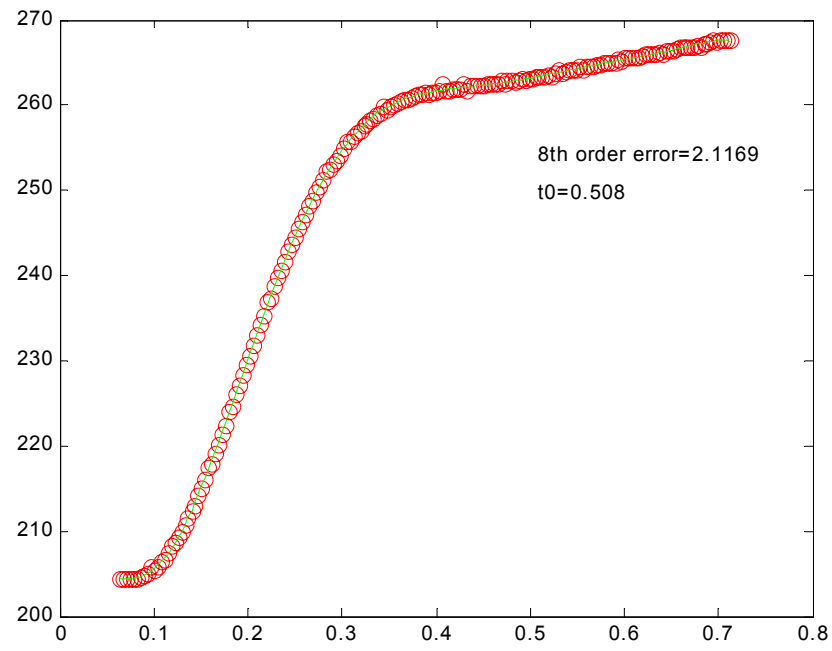

Figure 5.9: The recorded data and fitted curve of the PAFC's DC voltage (case 1). (x axis: time (s); y axis: voltage (v)). 


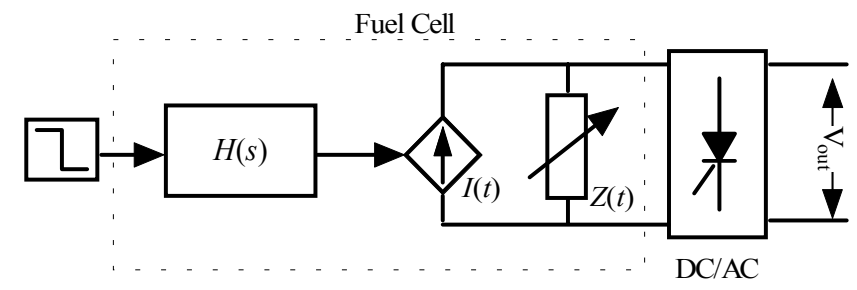

Figure 5.10: Diagram of the proposed PAFC's dynamic model.

\subsubsection{Fuel Cell Modeling}

Figure 5.10 shows the proposed fuel cell model. The model represents the turn down process of the fuel cell.

In Figure 5.10, the $I(t)$ is determined by the $H(s)$ in equation (5.6), and the open circuit impedance is expressed as:

$$
Z(t)=\frac{V(t)}{I(t)}
$$

Since the DC voltage (V), and DC current (A) outputs from the fuel cell model are available in Matlab, Z(t) in equation (5.12) can be calculated. Figure 5.11 gives the resulting V-I curve.

The impedance curve of the fuel cell model is shown in Figure 5.12.

\subsection{Configuration of Test System with DGs}

Figure 5.13 shows test system to evaluate the impacts of the PAFC on the power distribution system. The test system is the IEEE 13-node system with a gas turbine synchronous generator and a diesel engine synchronous generator. The PAFC model is connected to the gas turbine DG directly.

The IEEE-13 node power distribution system with multiple types of DGs is represented in Matlab/Simulink by an average model.

In Figure 5.13, the synchronous generator connected with the gas turbine and the diesel engine is represented by a full-order model. The gas turbine model consists of speed governor, valve position, fuel pump, and turbine. The diesel engine model consists of the control system, actuator, integrator and the engine itself. The models of the gas turbine synchronous generator and diesel 


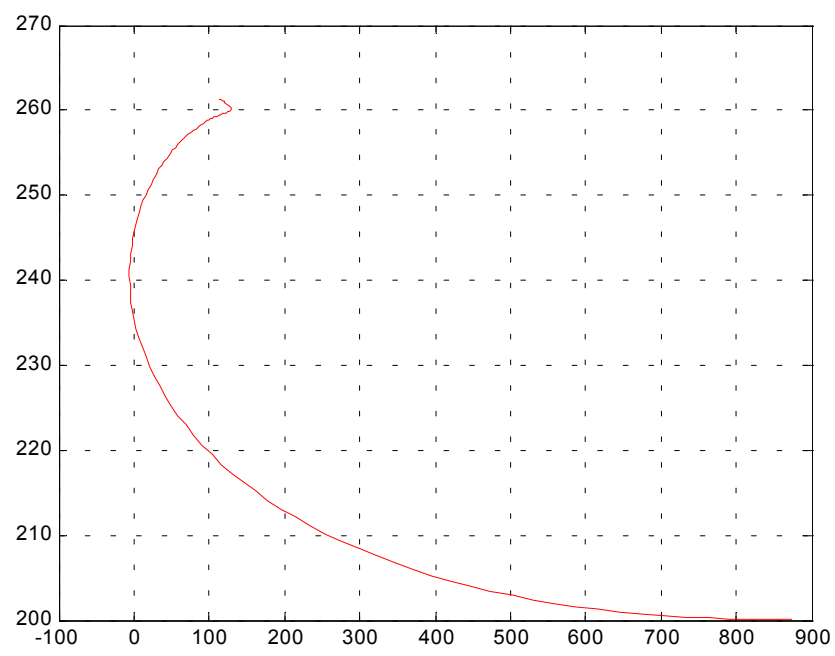

Figure 5.11: The V-I curve of the obtained PAFC's model. (X: current (A); Y: voltage (V)).

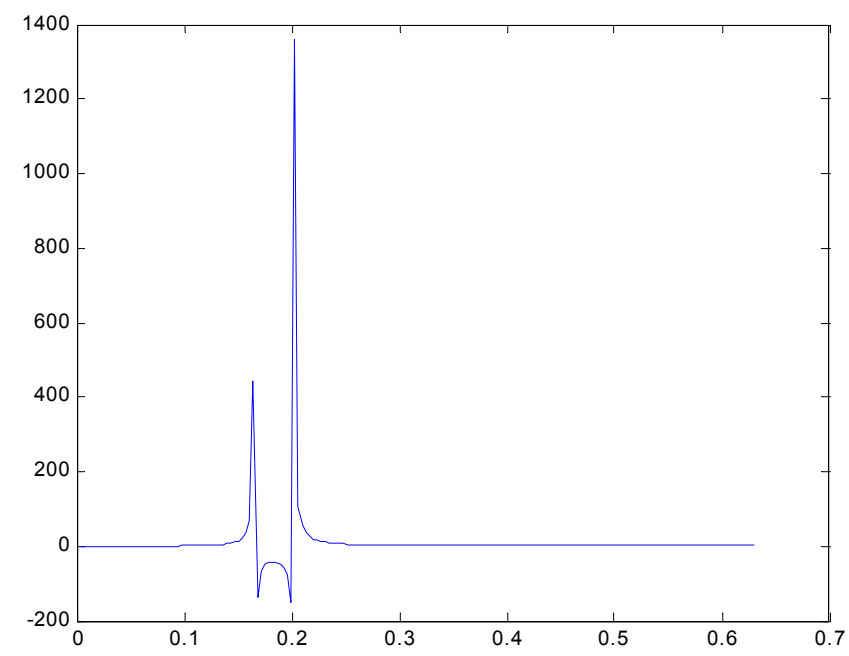

Figure 5.12: The impedance of the obtained PAFC's model vs. time. (X axis: time (s); Y axis: impedance $(\Omega))$. 


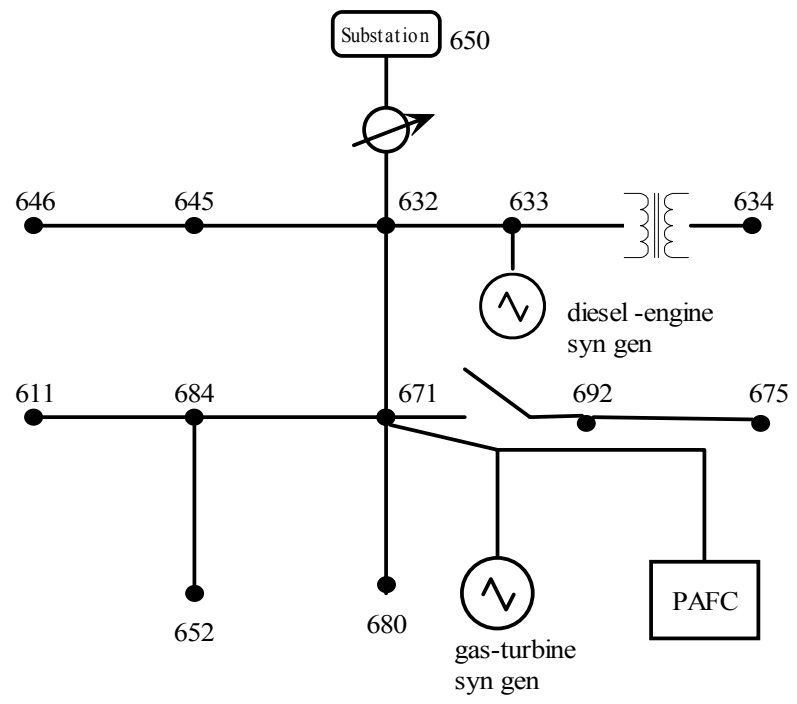

Figure 5.13: IEEE-13 node power distribution system with mult-types of DGs.

engine synchronous generator have been described in detail in Chapter 4 [81]. In this chapter, the full-order synchronous generator is simulated by Simulink, not with the Power system Blockset. A simplified excitation system is used.

\subsection{Simulation Study}

In section 5.3, the voltage curves, current curves, and the impedance characteristic curves are studied respectively. During the turn off procedure, the current input from the PAFC affects the dynamic stability of the distribution system directly. The effects of voltage are relatively indirectly. The approximately monotonic change of the V-I curve in Figure 5.11 means the impedance of the PAFC can be maintained relatively constant within the operating range. This is a very important characteristic of the fuel cell power plant to implement the real/reactive power control via the $\mathrm{DC} / \mathrm{AC}$ inverter.

Here, the current model of the PAFC is used to investigate the impacts of the PAFC on the dynamic stability of the power distribution system during PAFC turn off.

The base of the distribution system: $S_{\text {base }}=4.0 \mathrm{MVA}, V_{\text {base }}=4.16 \mathrm{kV}$. These base values are used in Chapters 5-10.

The initial power penetration of gas turbine is $S_{\text {gas }}=0.2625+j 0.1166(\mathrm{pu})$; the initial 


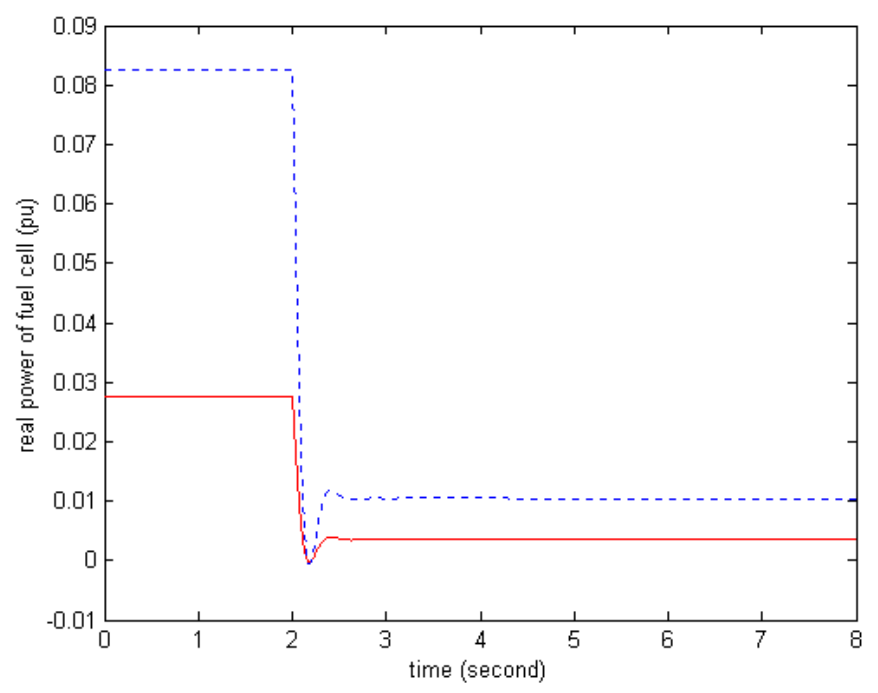

Figure 5.14: Real power penetration from the PAFC power plant to IEEE-13 node power distribution system (dotted line: Case I, solid line: Case II).

power penetration of diesel engine is $S_{\text {diesel }}=0.1375+j 0.1026$.

Two cases are conducted with different initial real power penetrations from the fuel cell power plant:

Case I: $P_{\text {fuelcell }}=0.0825$;

Case II: $P_{\text {fuelcell }}=0.02475$.

Figures 5.14-5.17 show the simulation results to investigate the impacts of the fuel cell model on the distribution system. In the figures, dotted lines represent the Case I and solid lines represent the Case II.

Figure 5.14 shows the dynamic procedure of the real power penetration from the fuel cell power plant to power distribution system. Figure 5.15 is the bus voltage magnitude. Figures 5.165.17 show the dynamic response of the gas turbine and diesel engine DGs. The simulation results show that the larger penetration of fuel cell will produce great impact on the system during the turn-off procedure.

\subsection{Summary}

This chapter presents a practical method to develop the complicated fuel cell model via the data fitting. The model is useful to evaluate the dynamic impact of the PAFC power plant on the 


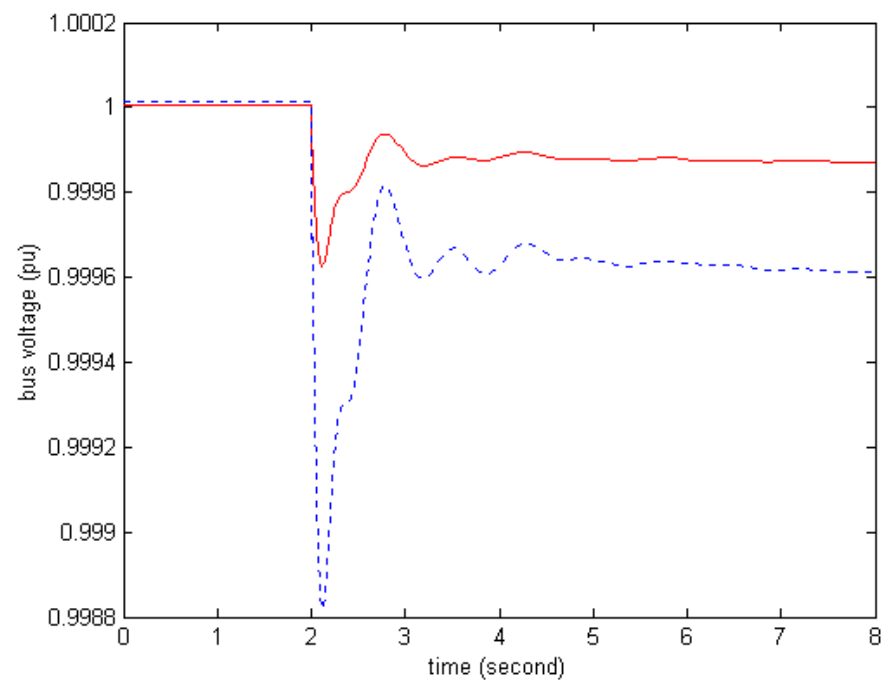

Figure 5.15: Voltage magnitude of bus 671 during the PAFC's turn-off procedure (dotted line: Case I, solid line: Case II).

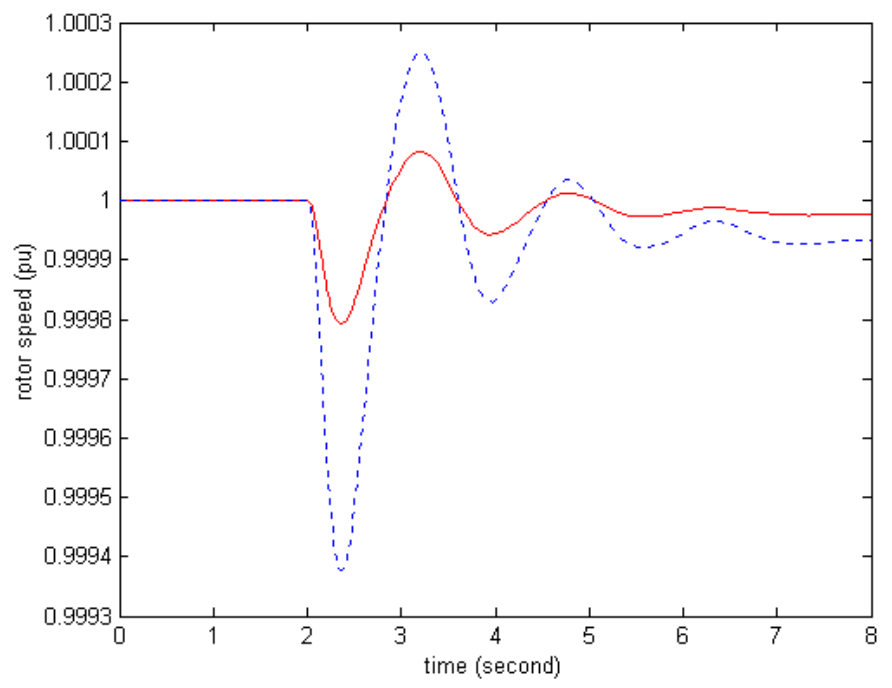

Figure 5.16: Rotor speed response of the gas-turbine synchronous generator during the PAFC's turn-off procedure (dotted line: Case I, solid line: Case II). 


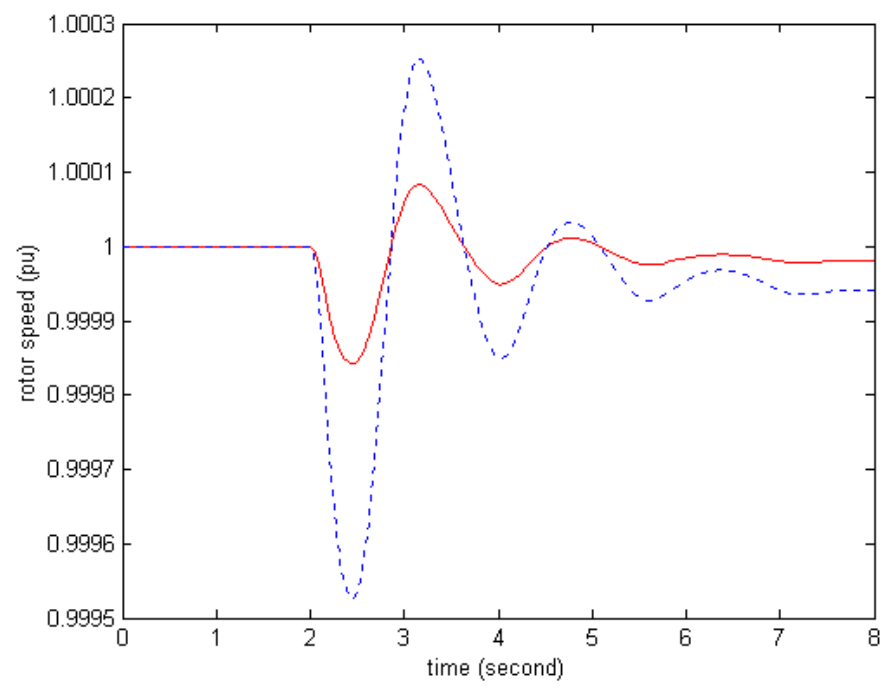

Figure 5.17: Rotor speed response of the diesel-engine synchronous generator during the PAFC's turn-off procedure (dotted line: Case I, solid line: Case II).

power distribution system. The obtained impedance characteristic of the fuel cell model is the precondition to develop the inverter-based controllable fuel cell model. The nonlinear simulation in Matlab/Simulink was done to investigate the impacts of the PAFC model on the power distribution system with different power penetration. The results show that the larger penetration of fuel cell will produce greater impact on the system during the turn-off procedure. 


\section{Chapter 6}

\section{Dynamic Modeling of A Solid Oxide Fuel Cell Power Plant}

\subsection{Introduction}

In Chapter 5, a methodology is presented to obtain a phosphoric acid fuel cell (PAFC) model at certain operating condition. In this chapter and Chapter 7, the dynamic model and stability control of solid oxide fuel cell (SOFC) power plant are investigated.

A fuel cell power plant is a type of DG to convert chemical energy into electricity via the electrochemical procedure directly. However, the conventional electric generation, such as gas turbine and diesel engine DGs convert the energy via the rotating generator. Normally, the electrochemical process of fuel cell is lower temperature, less noise and lower emissions. These characteristics of fuel cell are attracting increasing power provider's interest.

To study the impact of the fuel cell power plant on the power distribution, a controllable dynamic model of a SOFC power plant is developed in this chapter. Base on the model in [92] (see Figure 2.2), the model is simplified and developed to be suitable for simulation in Simulink. In the developed model (see Figure.6.1), the connection between the SOFC and the power conditioning unit $(\mathrm{PCU})$ is equivalently represented as the voltage $\left(v_{f c}\right)$ instead of the real power. Besides the control of the fuel supply, the adjustment of real power transmission between the SOFC and PCU will be implemented by the voltage.

The objectives of this chapter are to:

1. analyze each component of a SOFC power plant system, determine the system structure 


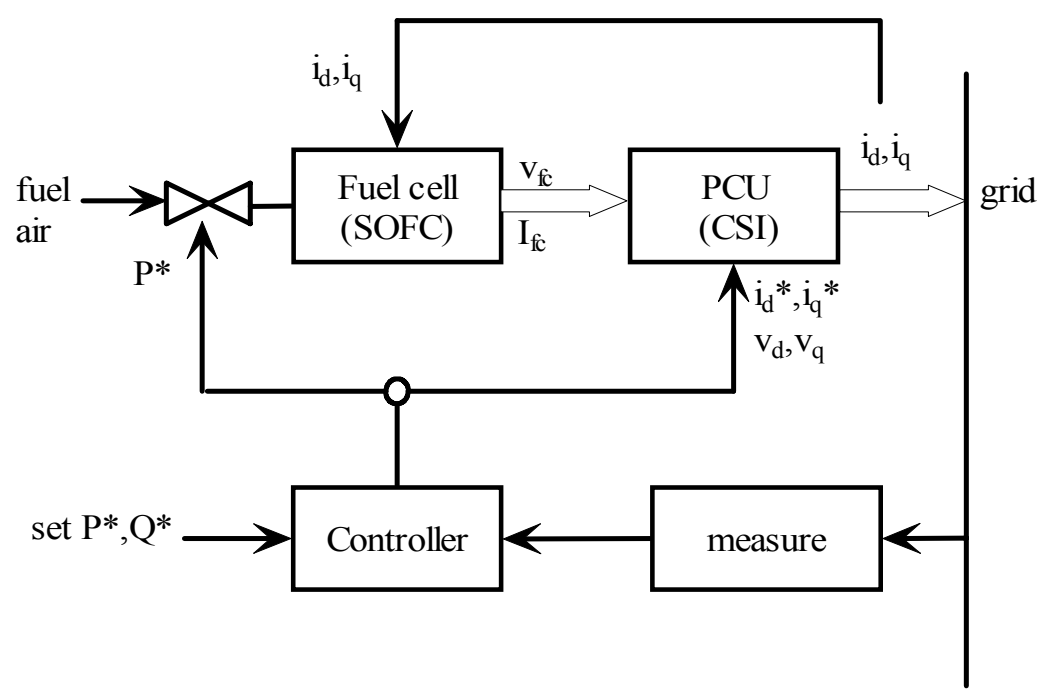

Figure 6.1: Diagram of the general structure of a SOFC power plant.

of a typical fuel cell power plant;

2. develop the dynamic model of the SOFC power plant and represent it as ordinary differential equations;

3. simulate the SOFC power plant in Simulink, and test the dynamic response of the model.

\subsection{Structure of A SOFC Power Plant}

Basically, fuel cells are devices that transform chemical energy into electrical energy. The output of a fuel cell is DC current which will be transformed to $\mathrm{AC}$ currents through dc/ac inverter to be connected with ac network. A plant structure of a SOFC based DG is presented in [92], in which the plant is grouped into five parts: fuel cell stack, power conditioning unit, balance of plant, network interface controller and plant controller (see Figure 2.2).

The structure of a controllable dynamic SOFC power plant is developed (see Figure 6.1) from [92]. In the Figure 6.1, the real and reactive power set point $\left(P^{*}, Q^{*}\right)$, measured voltage $\left(v_{d}\right.$, $\left.v_{q}\right)$ and current $\left(i_{d}, i_{q}\right)$, are used to obtain voltage $\left(V_{f c}\right)$ as the output of the SOFC. 


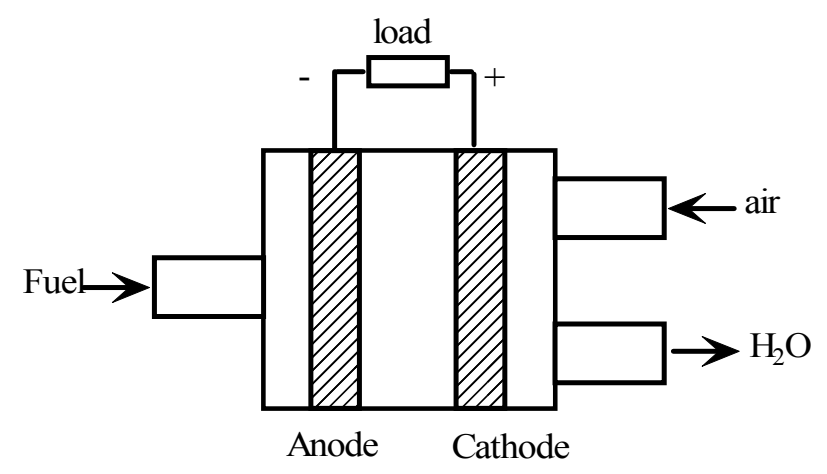

Figure 6.2: Structure of a fuel cell.

\subsection{Dynamic Model of Solid Oxide Fuel Cell (SOFC)}

A fuel cell consists of an anode, a cathode, and an electrolyte (see Figure 6.2). The amount of the fuel and air is set by the set real power $\left(P^{*}\right)$. The output of the cell is the direct current voltage $\left(V_{f c}\right)$. From the Nernst's law, the voltage of a fuel cell is determined by the three state variables: partial pressure of hydrogen, partial pressure of oxygen and partial pressure of steam. Also, the size of the load affects the terminal voltage of the cell.

A practical fuel cell power plant consists of one or more fuel cell stacks. Each fuel cell stack has many seriesly connected cells. The terminal voltage of the fuel cell plant depends on the number of in series connected cells and the capacity is determined by the total number of the cells. Here, one fuel cell stack is simulated and studied.

In this chapter, the dynamic model of SOFC [92] is presented. The partial pressure of the three type of substances in a cell can be expressed as:

$$
\begin{gathered}
p P_{H_{2}}=-\frac{1}{t_{H_{2}}}\left(P_{H_{2}}+\frac{1}{K_{H_{2}}}\left(q_{H_{2}}^{i n}-2 K_{r} I_{f c}\right)\right) \\
p P_{H_{2} O}=-\frac{1}{t_{H_{2} O}}\left(P_{H_{2} O}+\frac{2 K_{r} I_{f c}}{K_{H_{2} O}}\right) \\
p P_{O_{2}}=-\frac{1}{t_{O_{2}}}\left(P_{O_{2}}+\frac{1}{K_{O_{2}}}\left(q_{O_{2}}^{i n}-K_{r} I_{f c}\right)\right)
\end{gathered}
$$

where $q_{\mathrm{H}_{2}}^{i n}$ and $q_{\mathrm{O}_{2}}^{i n}$ are the molar flows of hydrogen and oxygen, $K_{r}=\frac{N_{0}}{2 F}, N_{0}$ is the number of cells of one stack, $F$ is the Faraday's constant. The time constant $t_{H 2}, t_{H 2 O}, t_{O 2}$ are determined by the volume of the anode, the universal gas constant, the absolute temperature, and so on. 


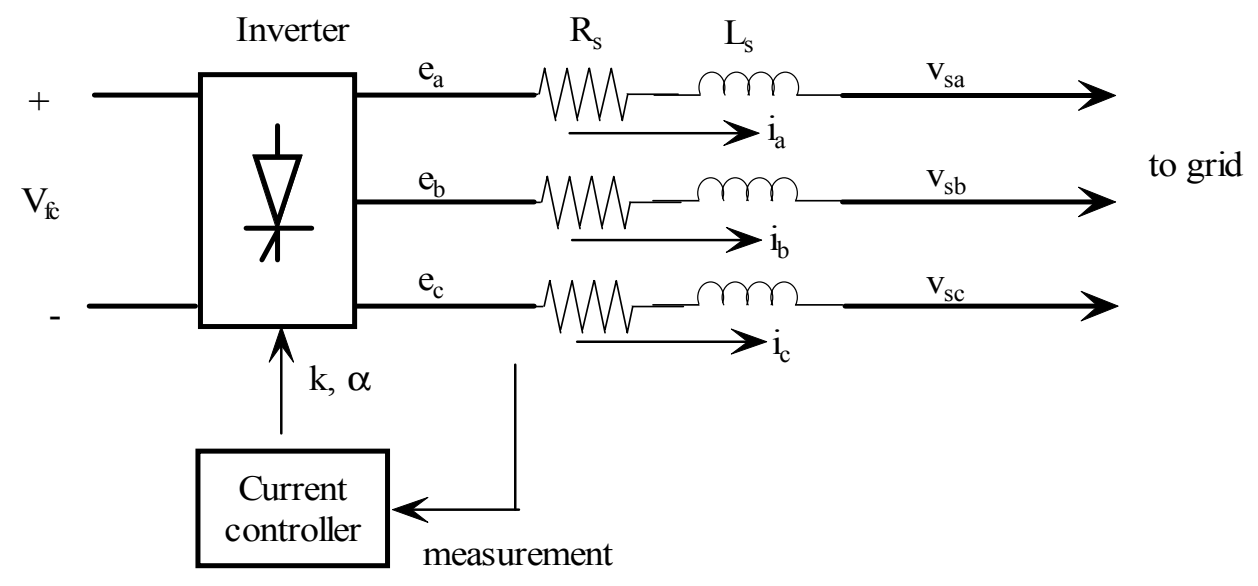

Figure 6.3: Three-phase CSI-based PCU.

The voltage of the fuel cell stack can be determined by the Nernst's equation and Ohm's law. The following equations show the voltage of the fuel cell stack:

$$
\begin{aligned}
V_{f c} & =N_{0}\left(E_{0}+\frac{R T}{2 F}\left(\ln \left(\frac{P_{H_{2}} P_{O_{2}}^{0.5}}{P_{H_{2} O}}\right)\right)-r I_{f c}\right. \\
& =V_{\text {Nernst }}-r I_{f c}
\end{aligned}
$$

where $I_{f c}$ is the current of the fuel cell stack.

\subsection{Power Conditioning Unit (PCU)}

A PCU is an interface to connect the fuel cell with the utility grid. The basic functions can be summarize as: DC/AC transformation, output voltage/current modulation.

To study the dynamic characteristic of PCU, a dynamic model of PCU for fuel cell is developed. Three-phase equivalent circuit of PCU is shown in Figure 6.3. In Figure 6.3, $R_{s}$ represents the sum of the losses of a $Y / \Delta$ transformer resistance and the inverter conduction, $L_{s}$ represents the leakage inductance of the transformer, $e_{a}, e_{b}, e_{c}$ are the three-phase $\mathrm{AC}$ voltage output of inverter, and $i_{a}, i_{b}, i_{c}$ are the three-phase $\mathrm{AC}$ current output of inverter. The input of inverter are the pulse width modulation (PWM) gain $k$ and angle $\alpha$. The DC voltage $V_{f c}$ is the output of a SOFC.

The state equations of the three-phase current source inverter (CSI) based PCU are the differential equations of voltage and current [101][132]. 


$$
p i_{p}=-\frac{R_{s}}{L_{s}} i_{p}+\frac{1}{L_{s}}\left(e_{p}-v_{s p}\right)
$$

where $p=\{a, b, c\}$.

The phase a grid voltage at the interconnecting point PCU is given by:

$$
v_{s a}=\sqrt{2} V_{s} \cos \left(\omega_{s} t+\theta_{s}\right)
$$

where $V_{s} \angle \theta_{s}$ is voltage phasor of connecting bus, and $\omega_{s}$ is the system frequency.

The ac side phase a voltage of inverter is:

$$
e_{a}=k V_{f c} \cos \left(\omega_{s} t+\alpha\right)
$$

where $k$ and $\alpha$ are the PWM modulation gain and angle.

For the sake of stability analysis and controller design, the state equation (6.6) is transformed to the system synchronous reference frame as:

$$
\left[\begin{array}{c}
p i_{q} \\
p i_{d}
\end{array}\right]=A_{I}\left[\begin{array}{c}
i_{q} \\
i_{d}
\end{array}\right]+B_{I 1} V_{f c}+B_{I 2} V_{s}
$$

where

cell;

$$
\begin{aligned}
A_{I}= & {\left[\begin{array}{cc}
-\frac{R_{s}^{\prime} \omega_{s}}{L_{s}^{\prime}} & -\omega_{s} \\
\omega_{s} & -\frac{R_{s}^{\prime} \omega_{s}}{L_{s}^{\prime}}
\end{array}\right] } \\
B_{I 1} & =\left[\begin{array}{c}
\frac{\omega_{s}}{L_{s}^{\prime}} k \sin \left(\alpha+\theta_{s}\right) \\
\frac{\omega_{s}}{L_{s}^{\prime}} k \cos \left(\alpha+\theta_{s}\right)
\end{array}\right], \text { which represents the interaction between inverter and fuel }
\end{aligned}
$$

$B_{I 2}=\left[\begin{array}{c}-\frac{\omega_{s}}{L_{s}^{\prime}} \sin \theta_{s} \\ -\frac{\omega_{s}}{L_{s}^{\prime}} \cos \theta_{s}\end{array}\right]$, which represents the interaction between inverter and grid.

In the DC circuit, the relationship between voltage and current may be expressed as:

$$
I_{f c}=\frac{1}{R_{d c}^{\prime}} V_{f c}+i_{d} k \cos \left(\alpha+\theta_{s}\right)+i_{q} k \sin \left(\alpha+\theta_{s}\right)
$$

where $R_{d c}^{\prime}$ represents the switching losses.

\subsection{Inverter Control Unit}

Besides the fuel cell (SOFC) and inverter, the control unit is another important component in the fuel cell power plant (see Figure 6.1). The current tracking inverter control strategy can be used 


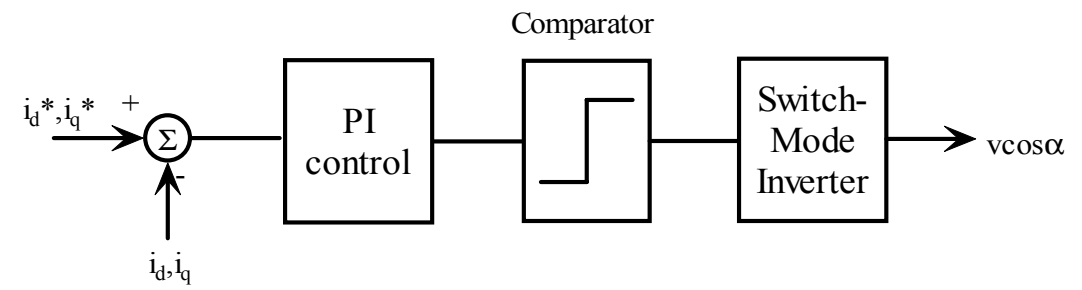

Figure 6.4: Diagram of the current control scheme for the CSI-based PCU.

to track the real power $\left(P^{*}\right)$ and reactive power $\left(Q^{*}\right)$ requirement, or to track the real power $\left(P^{*}\right)$ and voltage $\left(V^{*}\right)$ requirement. Thus the fuel cell power plant can be considered as a PQ bus or a PV bus depending on the different control strategies. Here, the current tracking PQ type control strategy is presented.

The basic idea of current tracking inverter control is illustrated in Figure 6.4. The input values are errors between measured $i_{d}, i_{q}$ and reference $i_{d}^{*}, i_{q}^{*}$. They are passed through to the PI controller and comparator, which has output $k, \alpha$. The output of the switch-mode inverter is the AC voltage $v \cos \alpha\left(k V_{f c} \cos \left(\omega_{s} t+\alpha\right)\right)$.

The relationship between the inverter controller parameters and the current has been expressed in (6.9). To develop the dynamic model of PCU, the equation (6.9) is linearized under the specific operating point as [82]:

$$
\left[\begin{array}{c}
p \Delta i_{q} \\
p \Delta i_{d}
\end{array}\right]=A_{\Delta}\left[\begin{array}{c}
\Delta i_{q} \\
\Delta i_{d}
\end{array}\right]+B_{\Delta 1}\left[\begin{array}{c}
\Delta v_{q} \\
\Delta v_{d}
\end{array}\right]+B_{\Delta 2}\left[\begin{array}{c}
\Delta \alpha \\
\Delta k \\
\Delta V_{f c} \\
\Delta \theta
\end{array}\right]
$$

Considering that the DC voltage deviation of the SOFC is very small $\Delta V_{f c}=0$; the voltage deviation of the grid is very small $\Delta \theta=0$, the linearized model can be simplified as:

$$
\left[\begin{array}{c}
p \Delta i_{q} \\
p \Delta i_{d}
\end{array}\right]=A_{\Delta}\left[\begin{array}{c}
\Delta i_{q} \\
\Delta i_{d}
\end{array}\right]+B_{\Delta 1}\left[\begin{array}{c}
\Delta v_{q} \\
\Delta v_{d}
\end{array}\right]+B_{\Delta 2}\left[\begin{array}{c}
\Delta k \\
\Delta \alpha
\end{array}\right]
$$

where

$$
\begin{aligned}
& A_{\Delta}=\left[\begin{array}{cc}
-\frac{R_{s}^{\prime} \omega_{0}}{L_{s}^{\prime}} & -\omega_{0} \\
\omega_{0} & -\frac{R_{s}^{\prime} \omega_{0}}{L_{s}^{\prime}}
\end{array}\right] ; \\
& B_{\Delta 1}=\left[\begin{array}{c}
-\frac{\omega_{0}}{L_{s}^{\prime}} \\
-\frac{\omega_{0}}{L_{s}^{\prime}}
\end{array}\right]
\end{aligned}
$$




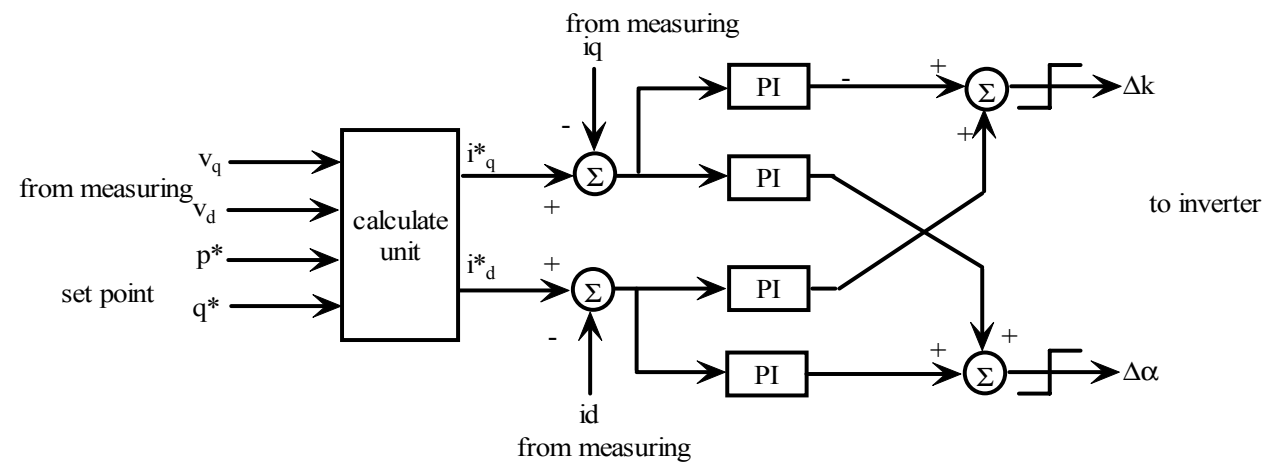

Figure 6.5: Diagram of an average model of a CSI-based PCU.

$$
B_{\Delta 2}=\left[\begin{array}{cc}
\frac{\omega_{0} V_{f c}}{L_{s}^{\prime}} \sin \left(\alpha_{0}+\theta_{s}\right) & \frac{\omega_{0} V_{f c}}{L_{s}^{\prime}} k_{0} \cos \left(\alpha_{0}+\theta_{s}\right) \\
\frac{\omega_{0} V_{f c}}{L_{s}^{\prime}} \cos \left(\alpha_{0}+\theta_{s}\right) & -\frac{\omega_{0} V_{f c}}{L_{s}^{\prime}} k_{0} \sin \left(\alpha_{0}+\theta_{s}\right)
\end{array}\right] \triangleq\left[\begin{array}{cc}
k_{11} & k_{12} \\
k_{21} & k_{22}
\end{array}\right]
$$

According to the linearized equation (6.12), the current $i_{d}$ and $i_{q}$ can be controlled by the adjustment of the gain $k$ and/or firing angle $\alpha$. Then the control unit of CSI is demonstrated in Figure 6.5.

In Figure 6.5, the calculate unit represents the following equations.

$$
\left[\begin{array}{c}
i_{q}^{*} \\
i_{d}^{*}
\end{array}\right]=\frac{1}{v_{q}^{2}+v_{d}^{2}}\left[\begin{array}{cc}
v_{q} & v_{d} \\
-v_{d} & v_{q}
\end{array}\right]\left[\begin{array}{c}
P^{*} \\
Q^{*}
\end{array}\right]
$$

\subsection{Model Simulation and Test}

To test the mathematical model presented in previous sections, the fuel cell power plant is simulated in Simulink. The single fuel cell power plant and infinite bus system (see Figure 6.6) are used to test the effectiveness of the developed model. One case study is conducted to test dynamic response as the real power set point is changed.

The parameters of fuel cell [92] are: $N_{0}=384, K_{H 2}=8.43 e^{-4}, K_{H 2 O}=2.81 e^{-4}, K_{O 2}=$ $2.52 e^{-3}, t_{H 2}=26.1, t_{H 2 O}=78.3, t_{O 2}=2.91, r=0.126, R_{s}=0.9, L_{s}=0.01$.

The real power set point $\mathrm{P}^{*}$ makes a step change from 0.875 to 0.7 at $\mathrm{t}=5.0 \mathrm{~s}$ and the reactive power set point $\mathrm{Q}^{*}$ remains constant. Figure (6.7-6.8) show the measured $\mathrm{P}$ and $\mathrm{Q}$ responses and Figure 6.9 shows the terminal voltage response of SOFC. The simulation results illustrate the capacity to track the real power set point. The delay time of the inverter is 0.1 s. Figure 6.7 illus- 


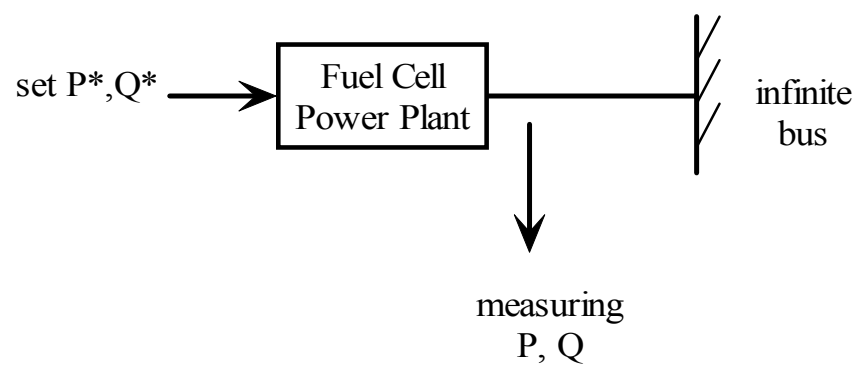

Figure 6.6: Diagram of single fuel cell power plant and infinite bus.

trate the real power changes from 0.875 to 0.75 in $0.1 \mathrm{~s}$. The response speed slows down due to the change of the SOFC terminal voltage.

Figure 6.10 shows the SOFC internal Nernst's voltage response of the step change in real power set point. The SOFC internal Nernst's voltage is determined by the three state variables inside the SOFC. The voltage speed is very slow due to the large time constants of the pressures.

\subsection{Summary}

In this chapter, a dynamic SOFC power plant model is developed. As a contribution of this DG research, an average PCU model is proposed with four PI controllers to connect the SOFC into the distribution system. The nonlinear simulation results illustrate that the SOFC power plant can track the real/reactive power set points rapidly. 


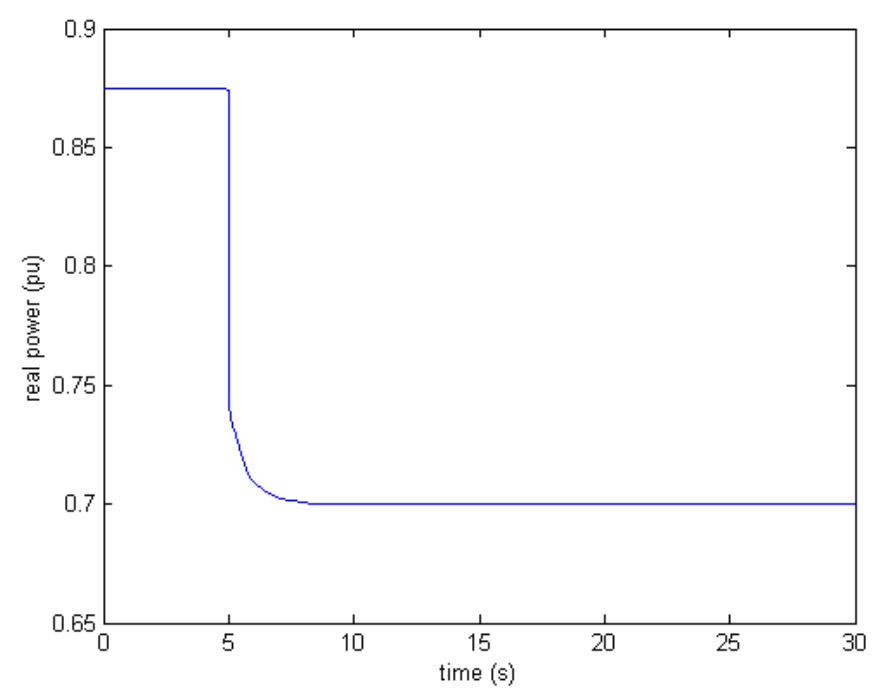

Figure 6.7: Real power response of the step change in real power set point.

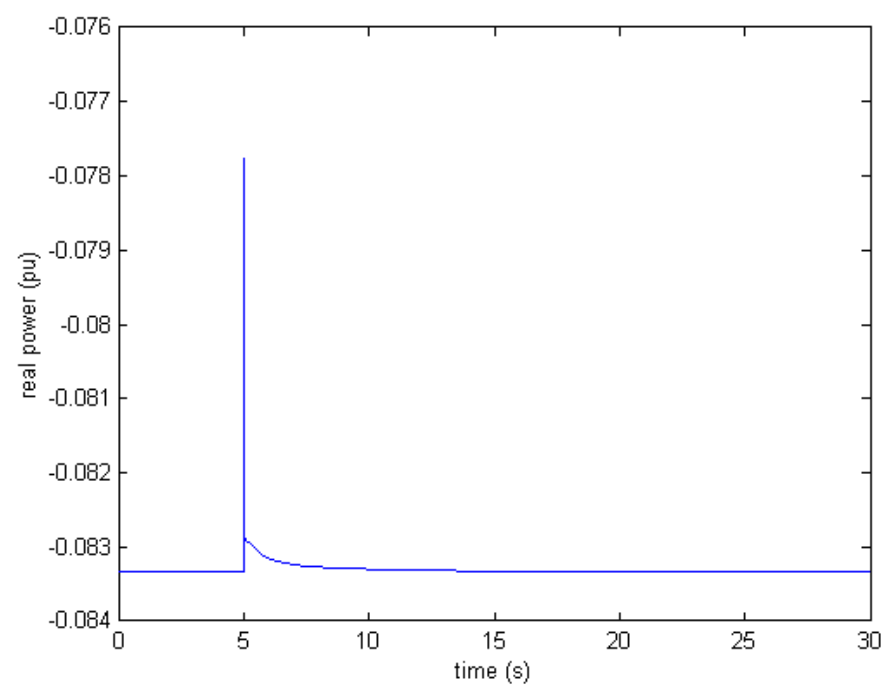

Figure 6.8: Reactive power response of the step change in real power set point. 


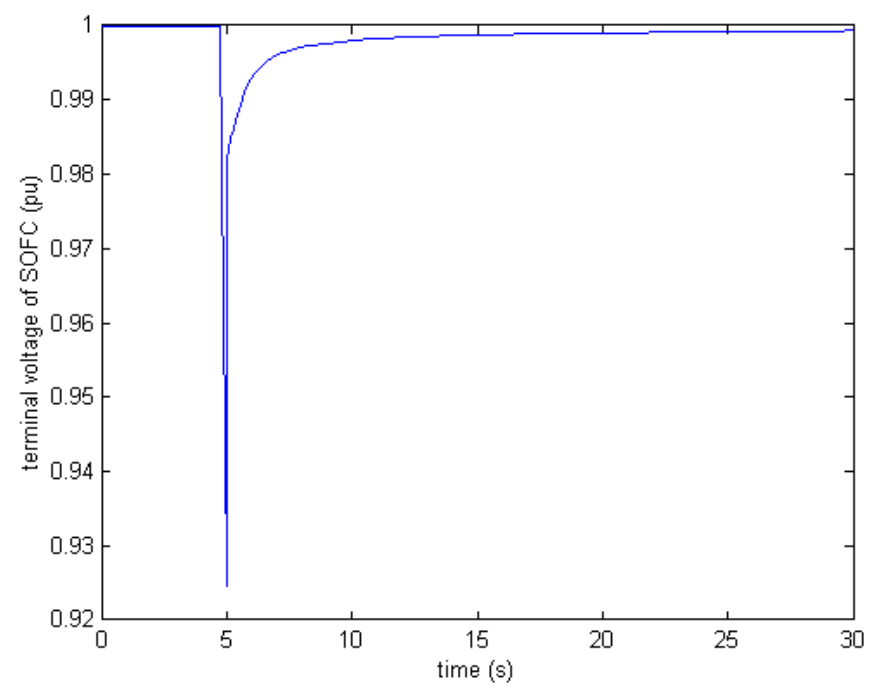

Figure 6.9: SOFC terminal voltage response of the step change in the real power set point.

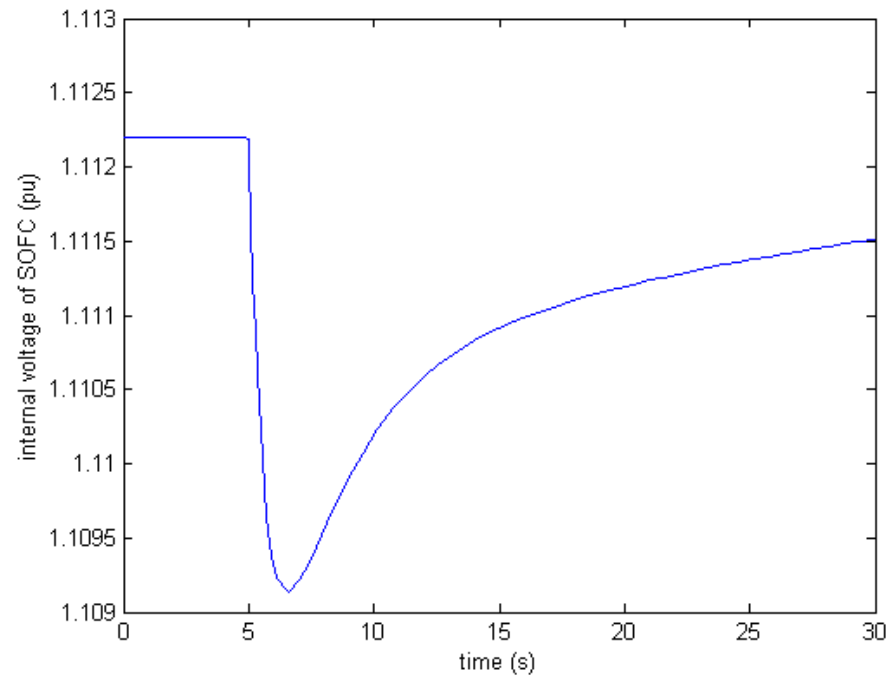

Figure 6.10: SOFC internal Nernst's voltage response of the step change in real power set point. 


\section{Chapter 7}

\section{Dynamic Stability Control for A SOFC Power Plant}

\subsection{Introduction}

The fuel cell power plant is gradually used as a new type of distributed generation (DG). The dynamic model of a SOFC power plant studied in Chapter 6 illustrates that the fuel cell power plant can track the real and reactive power instantaneously. The response time of the inverter is 0.1s. These rapid real/reactive power track characteristics provide the potential of a fuel cell power plant to improve oscillation damping in the power distribution system.

In this chapter, the integration of a SOFC power plant dynamic model to the power distribution system is investigated and the impact of the fuel cell on the system is studied; the linearized model of the system with a fuel cell power plant, a gas turbine DG and a diesel engine DG is developed. Based on the linearized model, the optimal control is designed and the controller is tested under different fault locations.

\subsection{System Configuration}

To study the impact of the fuel cell on the power distribution system with multiple types of DGs, the fuel cell power plant is connected to the IEEE-13 node distribution system with a gas turbine synchronous generator and a diesel engine synchronous generator (see Figure 7.1).

The average model of the IEEE-13 system with a gas turbine DG and a diesel engine DG has been presented in Chapter 4 [81]. The fuel cell power plant and the gas turbine DG are connected 


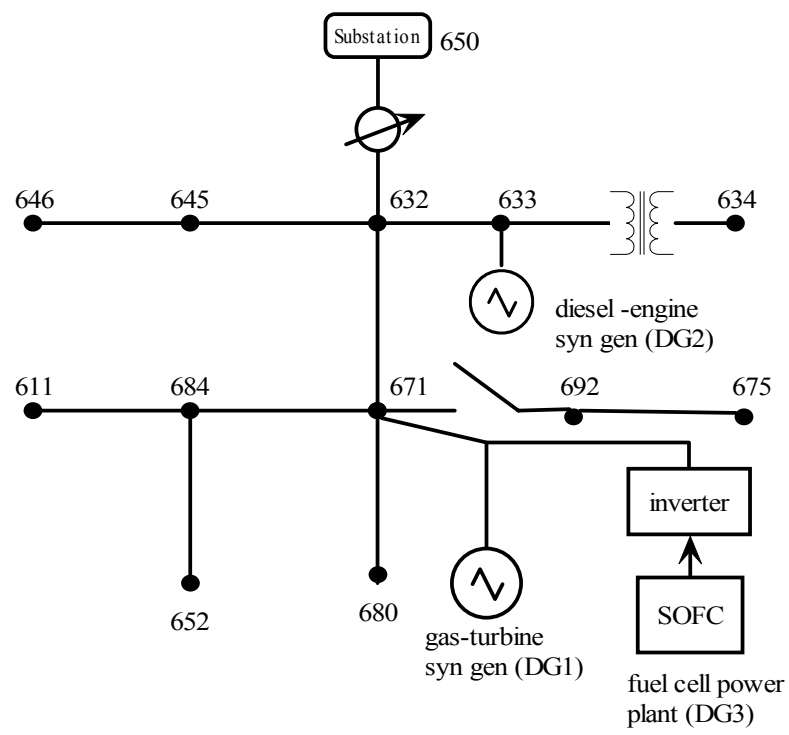

Figure 7.1: IEEE-13 node power distribution system with multi-types of DGs to evaluate the impact of a SOFC power plant.

at the same bus. At the initial condition, the fuel cell supplies the power $s=0.2625+j 0.05$.

To evaluate the impact of the fuel cell power plant on the distribution system, a case study is conducted that a ground fault occurs at bus 632 and this fault is cleared after 0.25s. Figures (7.2-7.4) show the simulation results. Figure 7.2 shows the ground fault disturbance results in the rotor speed deviation of DG1 and DG2. In the following sections, the controller is designed to improve the oscillation damping.

\subsection{System Linearization}

As discussed in Chapter 4, the linearized model plays a very important role to analyze the nonlinear system. The Matlab/Simulink provides a powerful tool to linearize the nonlinear system in Simulink under a specific operating condition.

The operating condition of the power distribution system with DGs is listed as: $P_{\text {gas }}=$ $0.1578, V_{\text {gas }}=1.0, P_{\text {diesel }}=0.0875, V_{\text {diesel }}=1.0$, and $P_{\text {sofc }}=0.0875$. The parameters of the substation, the gas turbine DG and the diesel engine DG are listed in Appedix B (Table B.1).

Around that operating point, the integrated system can be represented by linear models, based on which controllers are designed to improve the oscillation damping of the distribution 


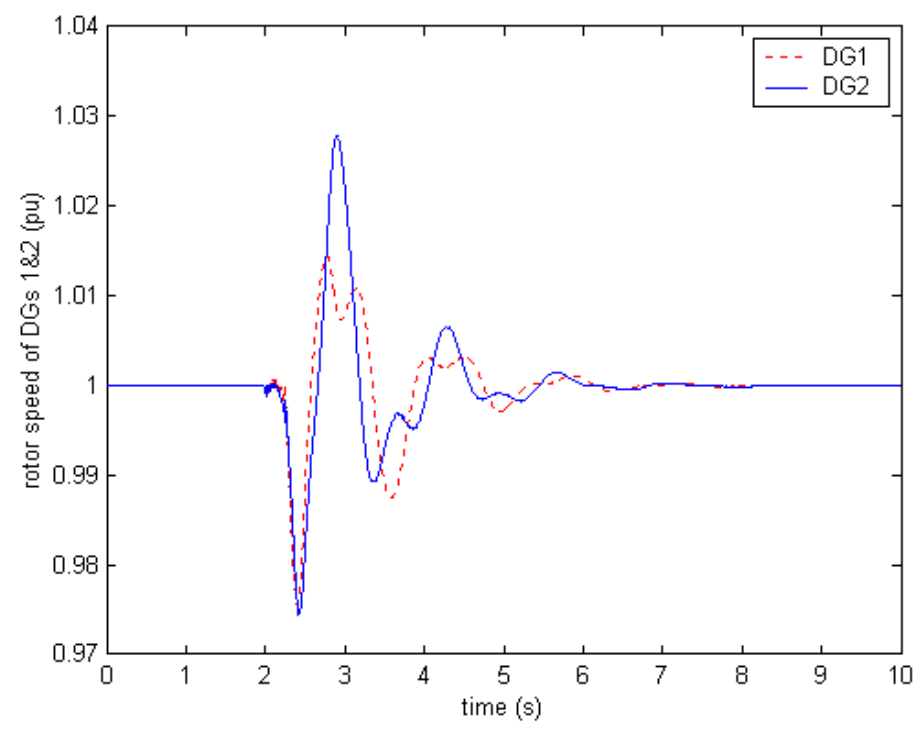

Figure 7.2: Rotor speeds of DGs $1 \& 2$ as a fault occures at bus 632 without controller.

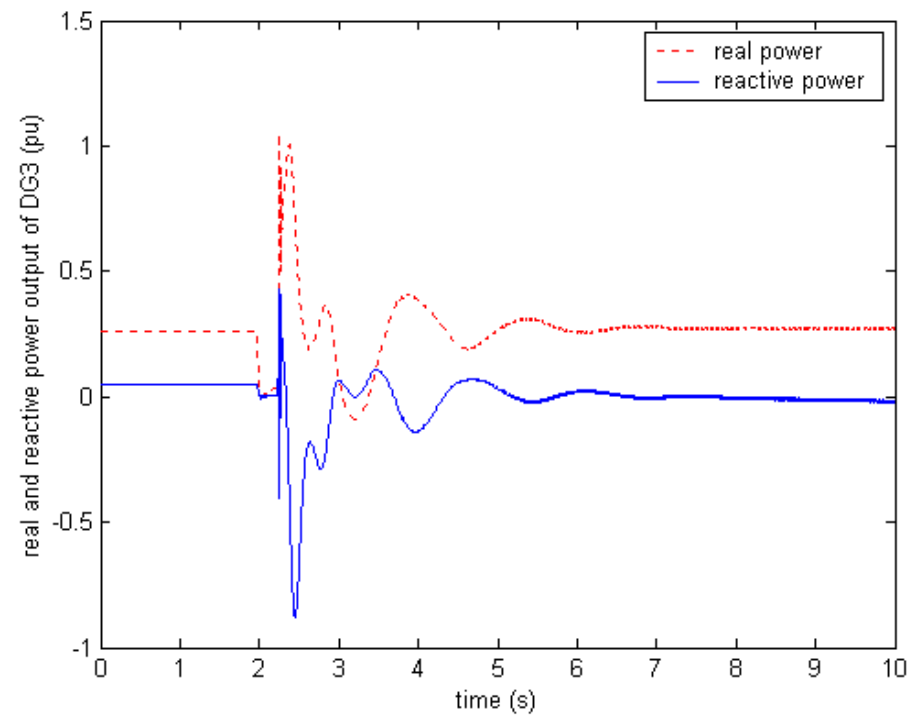

Figure 7.3: Real and reactive power of the SOFC power plant as a fault occures at bus 632 without controller. 


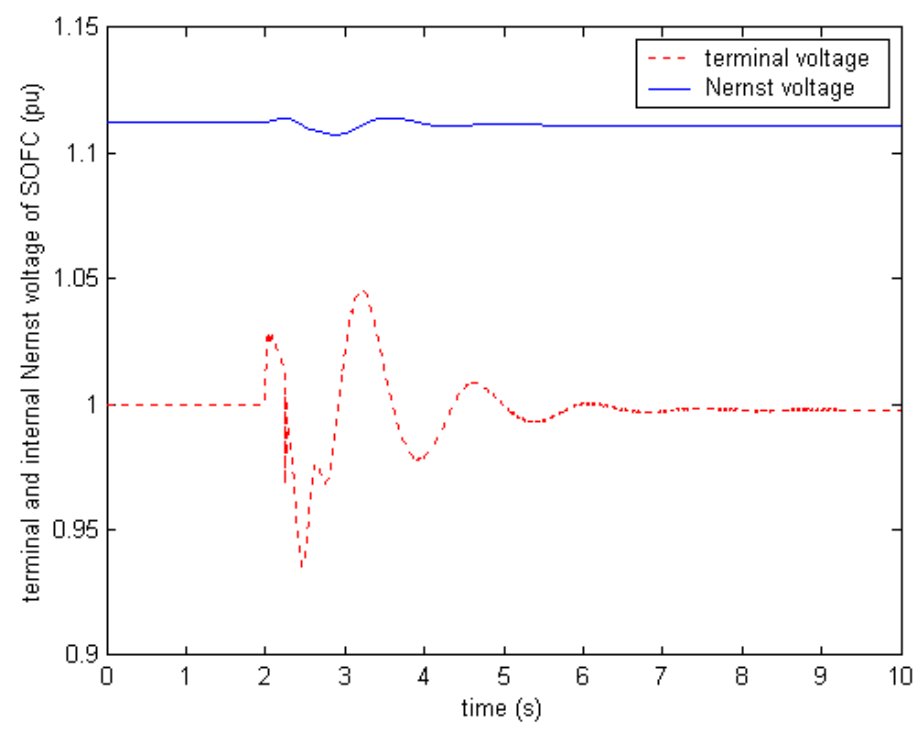

Figure 7.4: Terminal and internal Nernst voltage of SOFC as a fault occures at bus 632 without controller.

system. To analyze the dynamic characteristics and design the dynamic controller of the distribution system with DGs, the linearized models of the distribution system with multiple types of DGs are obtained by the Simulink.

The linearized models of a gas turbine DG, a diesel engine DG and the substation have been presented in Chapter 4.

Gas turbine DG consists of the $7^{\text {th }}$ order synchronous generator, the $3^{\text {rd }}$ order gas turbine and the $1^{\text {st }}$ order excitation system: $\left[\begin{array}{lllllllllllll}\omega & i_{d}^{r} & i_{f d}^{r} & i_{k d}^{r} & i_{q}^{r} & i_{k q}^{r} & \delta & : & x_{\text {gov }} & x_{v a l} & x_{f p} & : & x_{\text {ext }}\end{array}\right]^{T}$ Diesel engine DG consists of the $7^{\text {th }}$ order synchronous generator, the $5^{\text {th }}$ order diesel engine and the $1^{\text {st }}$ order excitation system.

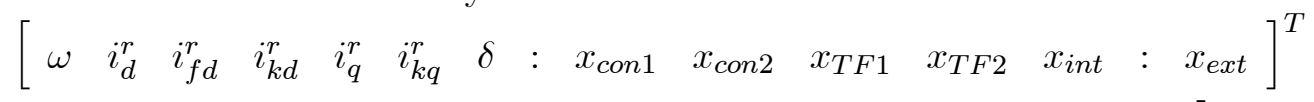

Substation is represented as the transient synchronous generator model. $\left[\begin{array}{cccc}\omega & E_{q}^{\prime} & E_{d}^{\prime} & \delta\end{array}\right]^{T}$ The fuel cell consists of $3^{\text {rd }}$ order SOFC model, $2^{\text {nd }}$ order dynamic PCU model and four PI controllers:

The state variables $x=\left[\begin{array}{lllllllllll}P_{\mathrm{H}_{2}} & P_{\mathrm{H}_{2} \mathrm{O}} & P_{\mathrm{O}_{2}} & : & i_{q} & i_{d} & : & x_{P I 1} & x_{P I 2} & x_{P I 3} & x_{P I 4}\end{array}\right]^{T}$

The four integral states of the PI controller are weakly connected to the oscillation modes of linearized system. 


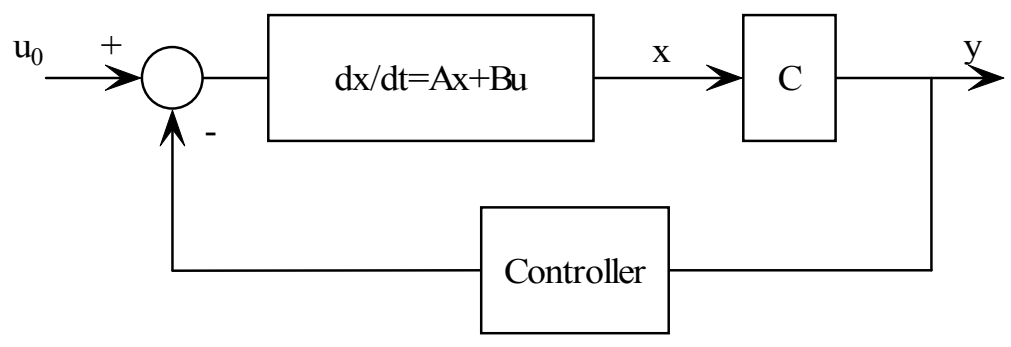

Figure 7.5: Structure of the linearized output feedback control.

Table 7.1: Dominant eigenvalues of the linearized distribution system with 3 DGs.

\begin{tabular}{|l|c|}
\hline NO. & Open Loop Eigenvalues \\
\hline \hline$\lambda_{21,22}$ & $-0.9580 \pm 4.6650 \mathrm{i}$ \\
\hline$\lambda_{25,26}$ & $-1.1168 \pm 9.0009 \mathrm{i}$ \\
\hline
\end{tabular}

Once the three synchronous generators (2 DGs + Substation) are connected in the distribution system, only two rotor angles are independent. So, in the linearized distribution system, there are in total 36 state variables. The linearization results in Simulink verify above analysis.

Based on the linearized model (A, B, C, D), the controller is designed via eigenvalue analysis. The controller design is studied in the following section.

\subsection{Controller Design to Assign Eigenvalues}

Consider the above linearized power distribution system with multiple types of DGs represented in the form:

$$
\begin{gathered}
\dot{x}=A x+B u \\
y=C x
\end{gathered}
$$

where $x$ are the linearized state variables vector and $u$ is the input of fuel cell.

The structure of the linearized output feedback controller is shown in Figure 7.5.

From the analysis in section 7.3, the linearized power distribution system has 36 total state variables. The dominant eigenvalues are listed in Table 7.1.

The controller objective is to improve the oscillation damping of the system, especially modes $\left(\lambda_{21,22}, \lambda_{25,26}\right)$. To select the control signal, the participation factor is used to select the 
Table 7.2: Participation factors of eigenvalues $\lambda_{21,22}, \lambda_{25,26}$.

\begin{tabular}{|c|c|c|}
\hline State Variables & PF of $\lambda_{21,22}$ & PF of $\lambda_{25,26}$ \\
\hline \hline$\Delta \omega_{\text {gas }}$ & 0.2420 & 0.2273 \\
\hline$\Delta \delta_{\text {gas_substation }}$ & 0.2267 & 0.2363 \\
\hline$\Delta \omega_{\text {diesel }}$ & 0.2483 & 0.2684 \\
\hline$\Delta \delta_{\text {diesel_substation }}$ & 0.2398 & 0.2668 \\
\hline
\end{tabular}

most relative state variables to the critical modes. The participation factor, $P F_{k i}$, of system $(\mathrm{A}, \mathrm{B}$, C, D) is defined as:

$$
P F_{k i}=V_{i k} W_{k i}
$$

where $V$ and $W$ are the right and left eigenvectors of the system (A, B, C, D). The participation factor $P F_{k i}$ reflects the participation of the $k^{\text {th }}$ eigenvalue in the zero input response of the $i^{\text {th }}$ state variable. To associate a state variable with an eigenvalue, the participation matrix, PM, is defined. The dimension of $\mathrm{PM}$ is same as system matrix $\mathrm{A}$, and the element $\mathrm{PM}(\mathrm{k}, \mathrm{i})$ of $\mathrm{PM}$ is $\left|P F_{k i}\right|$. $\mathrm{A}$ large factor $\left|P F_{k i}\right|$ in PM means the eigenvalue $\lambda_{k}$ is mostly associated with $x_{i}$.

In the linearized distribution system, each of the 36 states has a factor related to the modes $\left(\lambda_{21,22}, \lambda_{25,26}\right)$. The participation factors demonstrate that the most relative state variables are: rotor speed of the gas turbine DG, rotor speed of the diesel engine DG, the rotor angle difference between the gas turbine DG, and the rotor angle difference between the diesel engine and the substation. In the controller design, the four outputs of the system may be considered as the input of the controller. The four most related states are listed in Table 7.2.

The four participation factors of each oscillation modes are very close. For the sake of the convenient measuring and signal communicating, the rotor speed of gas turbine DG and diesel engine DG are selected as the control signal.

To improve the oscillation damping of the dominant modes, the linearized output feedback control is designed. The centralized control scheme is proposed in Figure 7.6. The phase compensate unit is the lead-lag compensation network. The lead-lag network is designed based on the residue of each input control signal respectively. The output optimal feedback control algorithm is implemented to select the centralized gains $(\mathrm{k} 1, \mathrm{k} 2)$ including the phase compensation unit. 


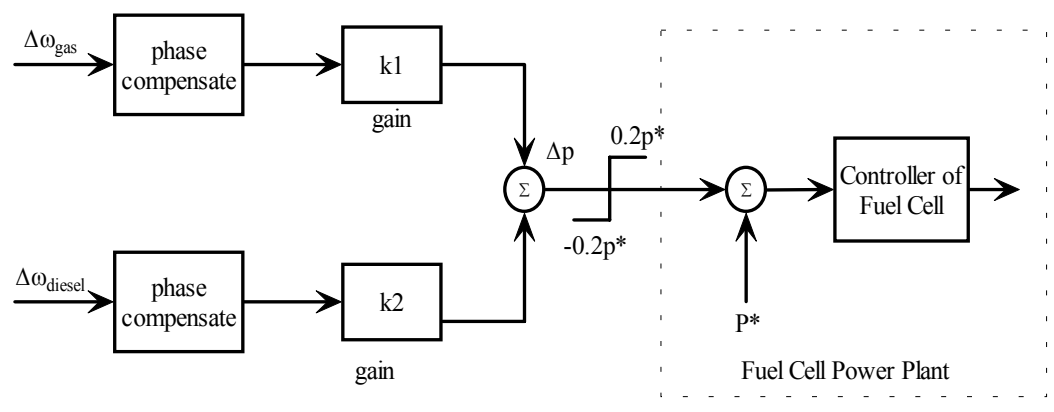

Figure 7.6: Coordinated control scheme of the SOFC power plant.

\subsubsection{Phase Angle Compensation}

In Figure 7.6, the coordinated control scheme has two inputs and one output. The control inputs $\left(\Delta \omega_{\text {gas }}, \Delta \omega_{\text {diesel }}\right)$ are considered to compensate the two pairs of the critical modes $\left(\lambda_{21,22}, \lambda_{25,26}\right)$ respectively. Thus, two single input single output (SISO) systems are considered. If the linearized system has $\mathrm{n}$ distinct eigenvalues, each of the SISO system can be described as is:

$$
G_{l}(s)=\frac{R_{l, 1}}{s-\lambda_{1}}+\frac{R_{l, 2}}{s-\lambda_{2}}+\ldots+\frac{R_{l, n}}{s-\lambda_{n}}
$$

where $l=1,2$ for each input, and $R_{l, i}$ is the residue of the eigenvalue $\lambda_{i}$.

The lead-lag network is used to compensate the critical modes, thus to improve the oscillation damping of the power distribution system. The least damped critical modes should be considered first. The lead-lag network shifts the phase of input signal from the plant G(s)[117].

$$
K(s)=\left(\frac{1+\alpha_{j} \tau_{j} s}{1+\tau_{j} s}\right)^{m}
$$

which consists of $\mathrm{m}$ phase lead-lag stages.

In each phase lead-lag stage, $\alpha_{j}$ is determined by the maximal compensation angle of this stage at frequency $\omega_{j}$ :

$$
\phi_{j}\left(\omega_{j}\right)=\sin ^{-1}\left(\frac{\alpha_{j}-1}{\alpha_{j}-1}\right)
$$

where $\omega_{j}$ can be the imaginary part of a critical mode or a frequency where phase margin is needed. Time constant $t_{j}$ is evaluated from:

$$
\tau_{j}=\frac{1}{\omega_{j} \sqrt{\alpha_{j}}}
$$

At this time constant, the maximum phase lead-lag occurs at frequency $\omega_{j}$. 
1) Compensate $\lambda_{21,22}$ with $\Delta \omega_{\text {gas }}$

To compensate the phase angle of $\Delta \omega_{\text {gas }}$, this signal is considered to improve the oscillation damping of the modes $\lambda_{21,22}$.

The corresponding residues are:

$$
\begin{aligned}
R_{1,(21,22)} & =0.0118 \pm 0.00119 i \\
& =0.0118 \angle \pm 5.74^{\circ}
\end{aligned}
$$

The residues show that there is no need to compensate the modes $\left(\lambda_{21,22}\right)$.

2) Compensate $\lambda_{25,26}$ with $\Delta \omega_{\text {diesel }}$

The signal $\Delta \omega_{\text {diesel }}$ is considered to improve the oscillation damping of the modes $\lambda_{25,26}$. The corresponding residues are:

$$
\begin{aligned}
R_{2,(25,26)} & =0.0006483 \pm 0.001877 i \\
& =0.01986 \angle \pm 70.95^{\circ}
\end{aligned}
$$

The residues show the phase angle can be compensated up to $70.95^{\circ}$. To compensate the $70.95^{\circ}$ total phase angle, two stages of lead-lag networks are designed, each stage contributing $35.0^{\circ}$. From the equations (7.6-7.7), the parameters of one compensation unit are: $\alpha=3.69, \tau=0.05784$.

\subsubsection{Optimal Control Algorithm to Select Gains}

The optimal control algorithm is used to determine the gain $\left(k_{1}, k_{2}\right)$ of the feedback controller. Consider the linear system represented by equations (7.1-7.2). The output feedback controller is:

$$
u=-K y
$$

Define the performance index:

$$
J=\int_{0}^{\infty}\left(x^{T} Q x+u^{T} R u\right) d t
$$

with $Q=Q^{T} \geqslant 0$ and $R=R^{T}>0$. The optimal gain design equations:

$$
\begin{gathered}
0=A_{c}^{T} M+M A_{c}+C^{T} K^{T} R K C+Q \\
0=S A_{C}^{T}+A_{C} S+X \\
K=R^{T} B^{T} M S C^{T}\left(C S C^{T}\right)^{-1}
\end{gathered}
$$


Table 7.3: Feedback gains through the optimal control algorithm.

\begin{tabular}{|c|c|c|}
\hline & With phase Compensation & Without phase compensation \\
\hline \hline$k_{1}$ & -53.22 & -37.56 \\
\hline$k_{2}$ & -57.35 & -76.46 \\
\hline Iterations & 523 & 498 \\
\hline
\end{tabular}

Table 7.4: Dominant eigenvalues of the open/closed loop system.

\begin{tabular}{|l|c|c|c|}
\hline NO. & open loop eigenvalues & $\begin{array}{c}\text { Closed loop Eigenvalues } \\
\text { with compensator }\end{array}$ & $\begin{array}{c}\text { Closed loop Eigenvalues } \\
\text { without compensator }\end{array}$ \\
\hline \hline$\lambda_{21,22}$ & $-0.9580 \pm 4.6650 \mathrm{i}$ & $-1.699 \pm 3.868 \mathrm{i}$ & $-2.328 \pm 4.562 \mathrm{i}$ \\
\hline$\lambda_{25,26}$ & $-1.1168 \pm 9.0009 \mathrm{i}$ & $-1.298 \pm 8.869 \mathrm{i}$ & $-1.159 \pm 9.075 \mathrm{i}$ \\
\hline
\end{tabular}

where $A_{c}=A-B K C$, and $X=E\left\{x(0) x^{T}(0)\right\}$. The performance index is:

$$
J=0.5 \operatorname{Trace}(M u)
$$

In the linearized distribution system (A, B, C, D), the dimension of $\mathrm{A}$ is $38 \times 38$, the dimension of $\mathrm{B}$ is $38 \times 1$, the dimension of $\mathrm{C}$ is $2 \times 38$, and the dimension of $\mathrm{D}$ is $2 \times 1$. In the performance index, the $\mathrm{Q}$ is $38 \times 38$ identity matrix and $R=10$. To compute the optimal gain $\left(k_{1}, k_{2}\right)$, the deviation of rotor speed $\left(\Delta \omega_{\text {gas }}, \Delta \omega_{\text {diesel }}\right)$ of gas turbine DG and diesel engine DG are considered for the initial condition, and initial condition of other linearized state variables are set as zeros. Table 7.3 illustrates the gains with/without phase angle compensation through the optimal feedback control algorithm.

The closed-loop system dominant eigenvalues are listed in Table 7.4. The nonlinear simulation results with/without controllers are shown in the following section.

\subsection{Simulation Results}

In this section the dynamic simulation results are presented with/without controller. The cases were done under the condition that a ground fault occurs. The operating condition was described in the previous section. Simulation results show that the control via the fuel cell can effectively improve the oscillation damping of the two synchronous generator DGs. Two types of controller are tested: controller \#1 is output feedback controller without phase angle compensation, controller \#2 is output feedback controller with compensation unit. Figures 7.7-7.15 show the simulation results. In the figures, the dashed lines represent the dynamic response without controller, the 


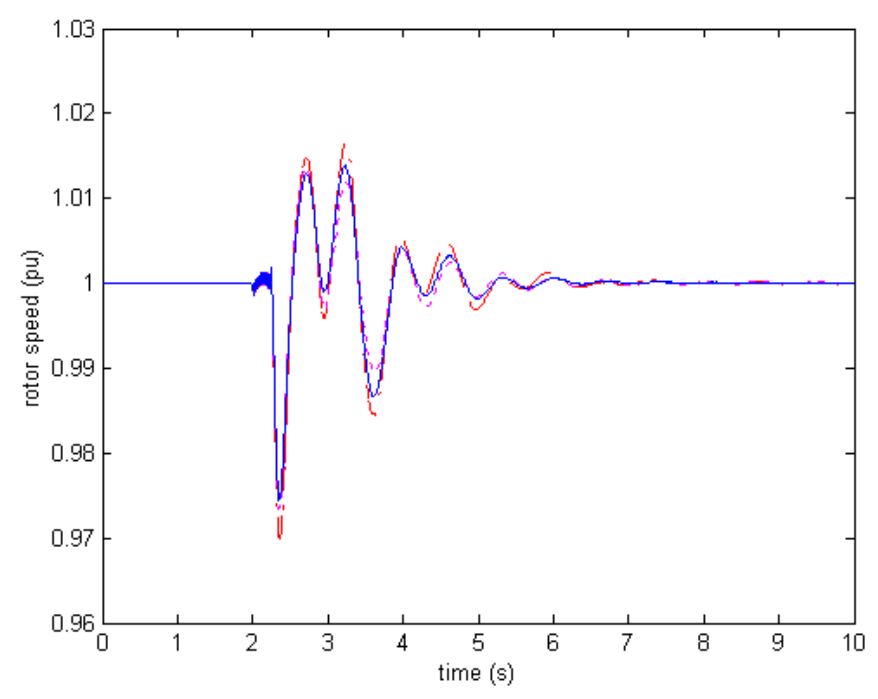

Figure 7.7: Rotor speed of the gas turbine DG when a fault occurs at bus 634 (Case 1).

dotted lines represent dynamic response with controller $\# 1$, and the solid lines represent dynamic response with controller \#2. Three cases with different fault locations are simulated to test the robustness of the optimal output feedback controller. The simulation results verify that the optimal controller can effectively improve oscillation damping of the power distribution system with DGs.

Case 1: Fault occurs at bus 634. The fault occurs closer to the diesel engine DG. Figures 7.7-7.9 show the simulation results.

Case 2: Fault occurs at bus 684. The fault occurs closer to the gas turbine DG. Figures 7.10-7.12 show the simulation results.

Case 3: Fault occurs at bus 632. The fault occurs between the diesel engine DG and the gas turbine DG. Figures 7.13-7.15 show the simulation results.

\subsection{Summary}

In this chapter, the impacts of the dynamic SOFC power plant on a distribution system with multiple DGs are investigated. Multi-variable output feedback optimal controller based on a linearized model is designed using lead-lag compensator and optimal control algorithm. The simulation results show that the fuel cell with appropriate controllers can effectively improve the oscillation damping of the whole system. 


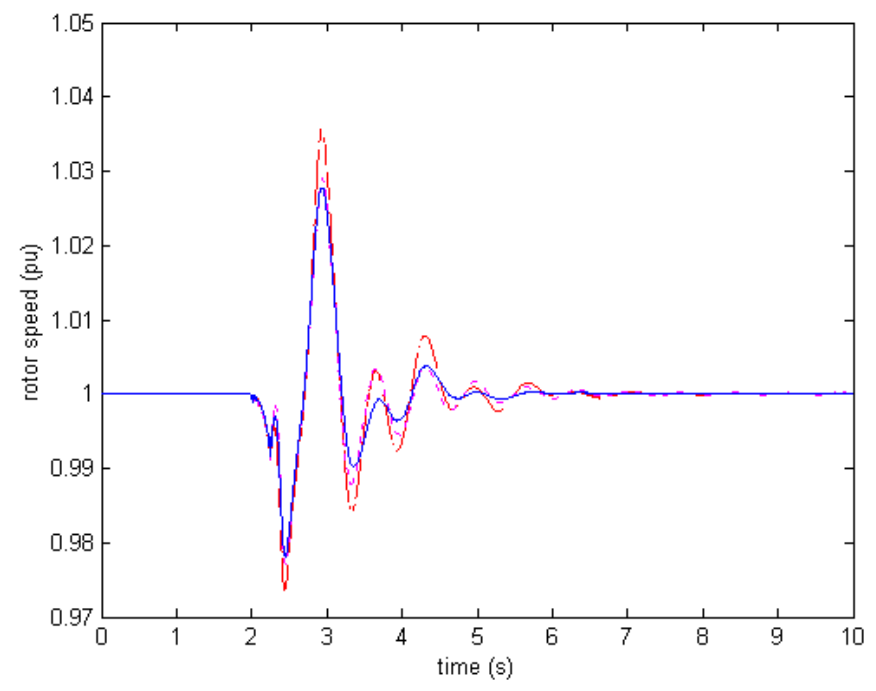

Figure 7.8: Rotor speed of the diesel engine DG when a fault occurs at bus 634 (Case 1).

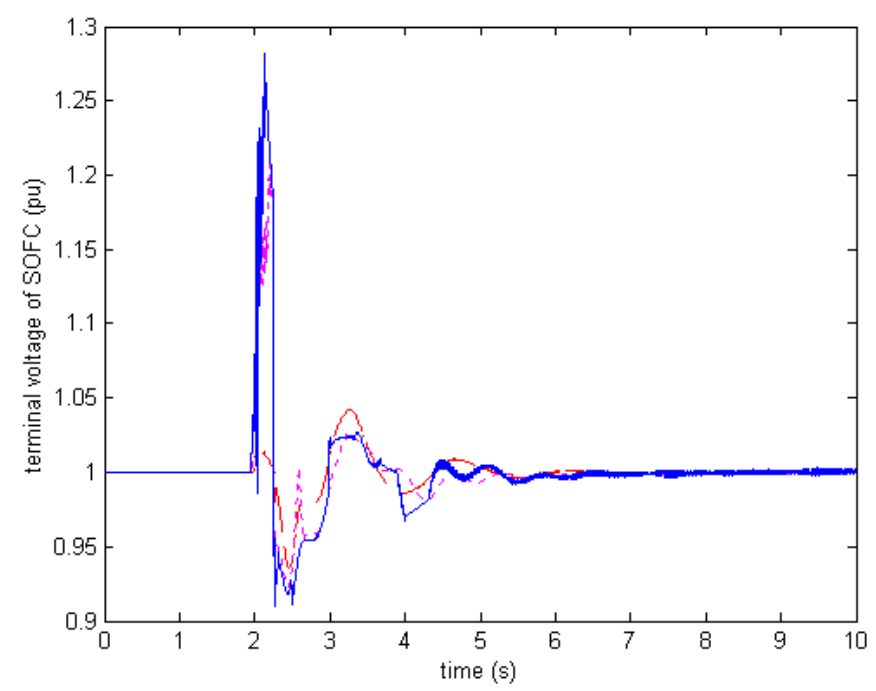

Figure 7.9: Terminal voltage of the SOFC when a fault occurs at bus 634 (Case 1). 


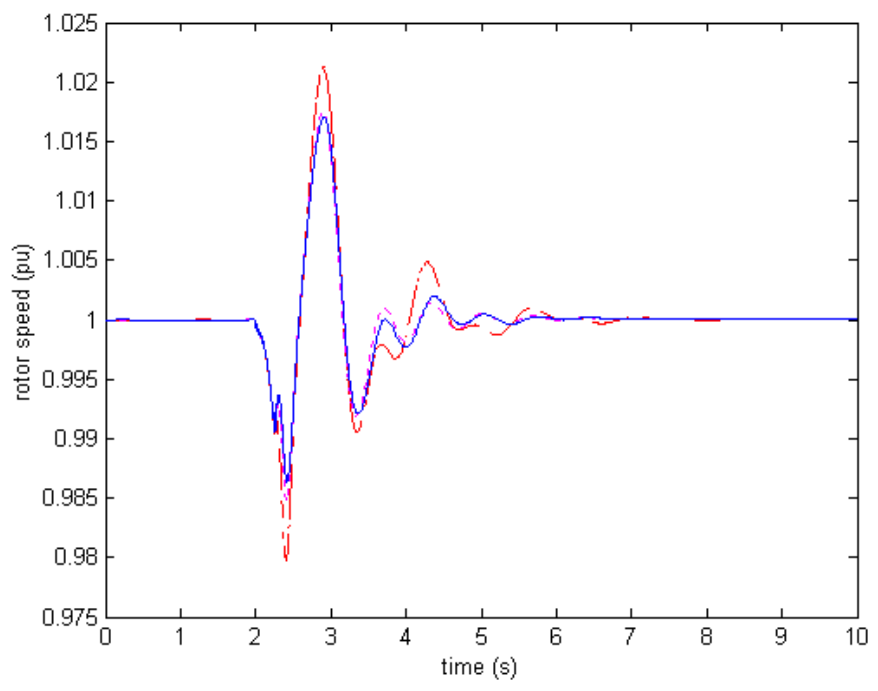

Figure 7.10: Rotor speed of the gas turbine DG when a fault occurs at bus 684 (Case 2).

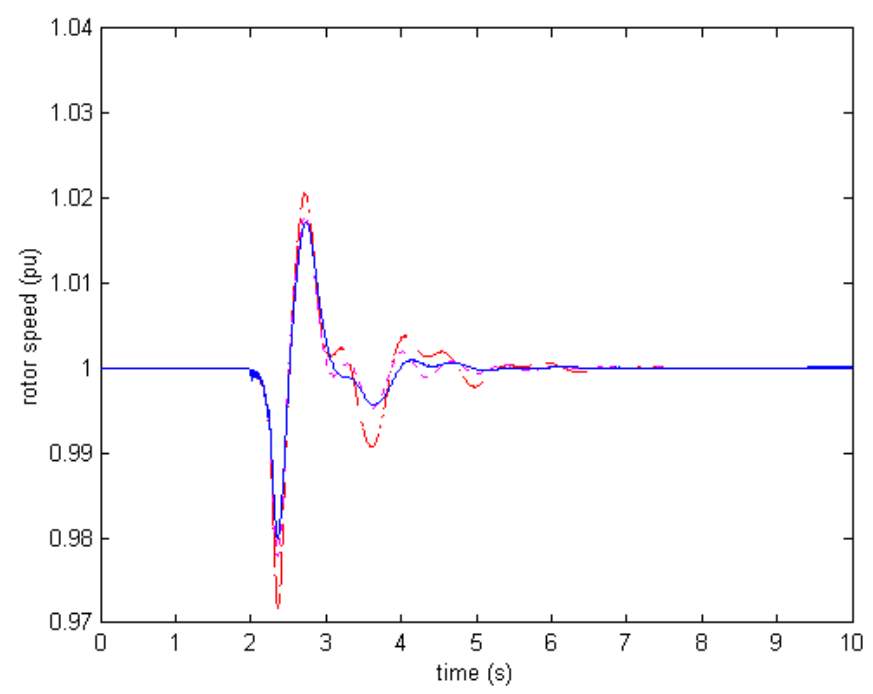

Figure 7.11: Rotor speed of the diesel engine DG when a fault occurs at bus 684 (Case 2). 


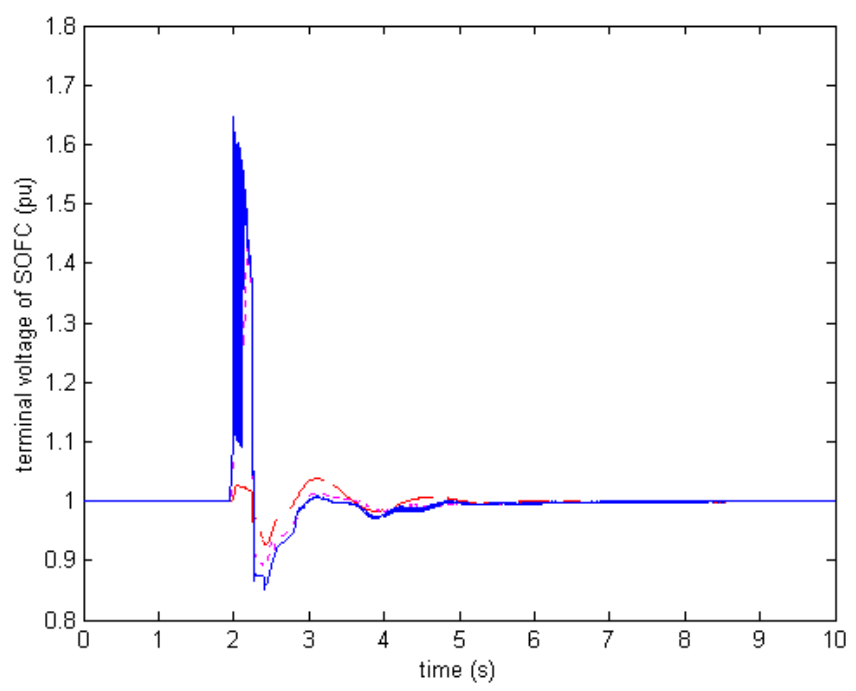

Figure 7.12: Terminal voltage of the SOFC when a fault occurs at bus 684 (Case 2).

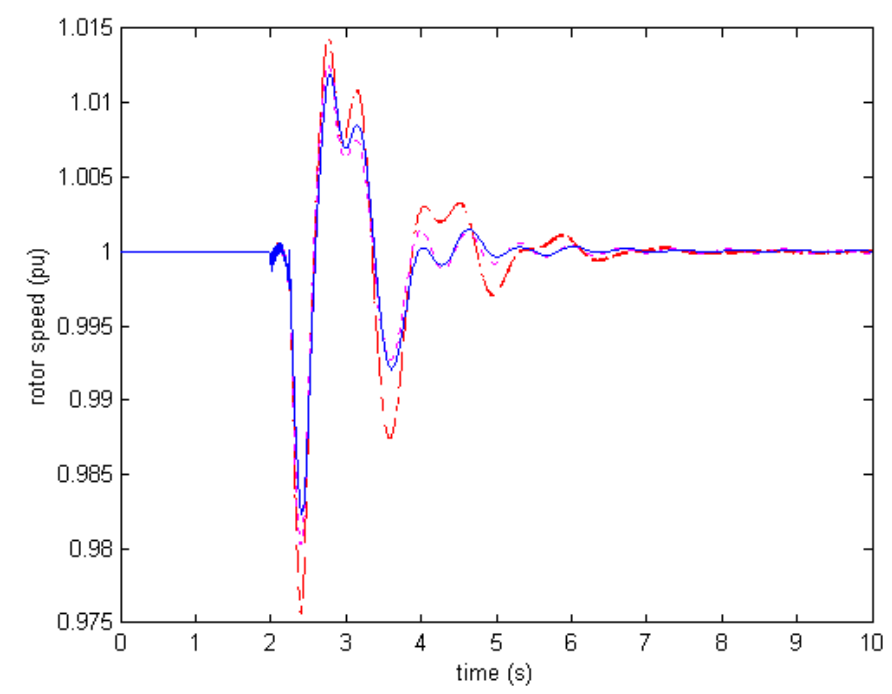

Figure 7.13: Rotor speed of the gas turbine DG when a fault occurs at bus 632 (Case 2). 


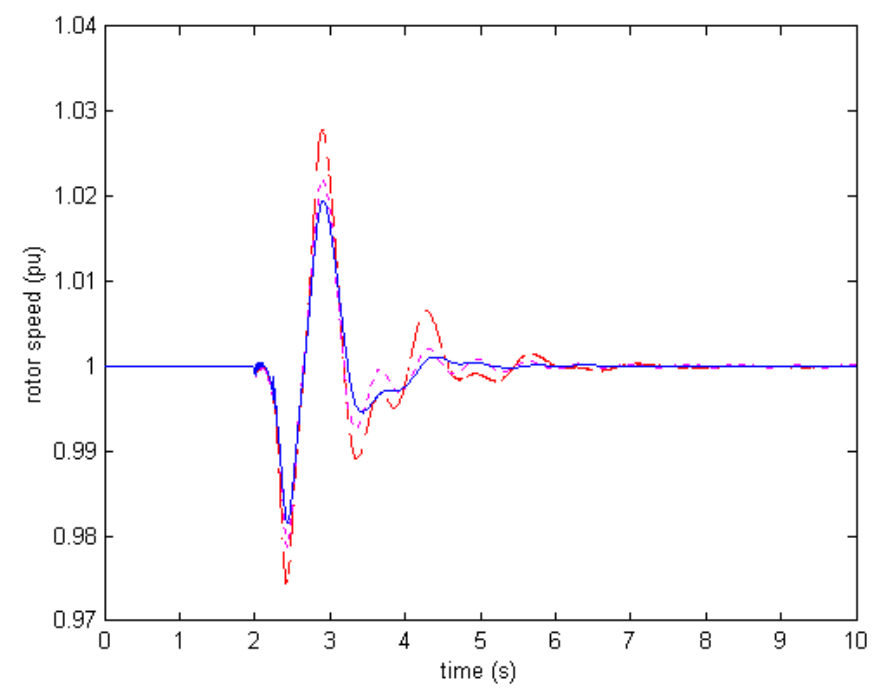

Figure 7.14: Rotor speed of the diesel engine DG when a fault occurs at bus 632 (Case 3).

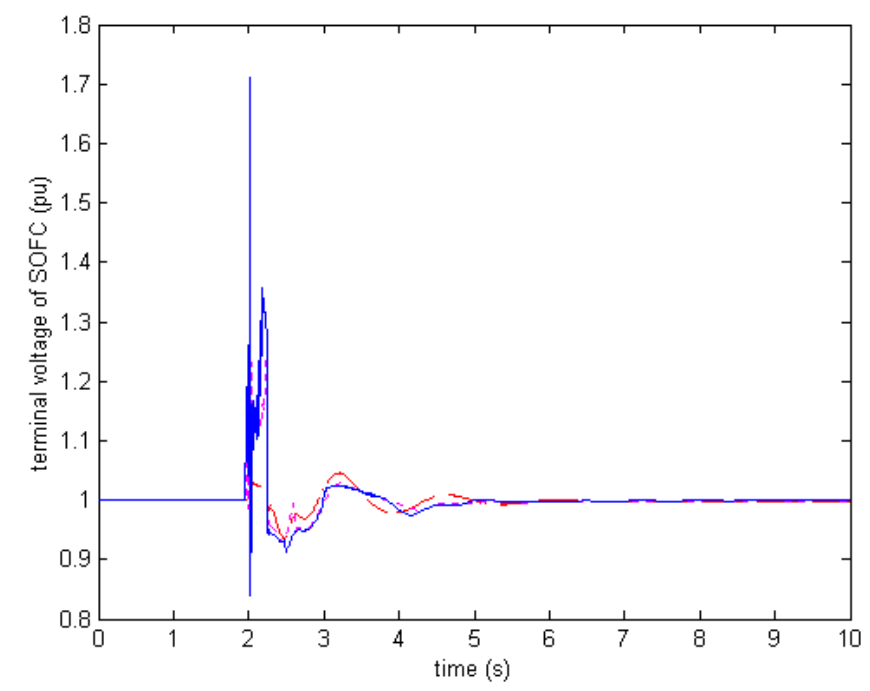

Figure 7.15: Terminal voltage of the SOFC when a fault occurs at bus 632 (Case 3). 


\section{Chapter 8}

\section{Model of the Wind Turbine DG}

\subsection{Introduction}

This chapter and Chapter 9 focus on the model and dynamic stability control of the wind turbine DG.

The wind turbine induction generator is an attractive distributed generation (DG) in a deregulated electric energy environment since wind energy is a non-polluting source. However, wind energy also has some limiting characteristics such as: unschedulable, uncontrollable, etc. To obtain relatively constant power, variable blade pitch angle control are installed[1][68][88].

In [88], the operating condition of the wind turbine is classified into several regimes: startup regime, sub-rated power regime and rated power regime. In rated power regime, a wind speed of $29 \mathrm{MPH}$ is needed for the power output to be rated. Dynamic simulation and the controller design are investigated in this regime.

A wind turbine synchronous generator unit model is given in [68][88]. A detailed dynamic turbine model was presented in [88]. The blade pitch control is used to achieve synchronous rotor speed[88]. Currently, the induction generator is attracting interest because of its lower cost, higher reliability and simpler control system. In [79], a dynamic induction generator model with control requirement is studied and the possibility of contributing negative and evaluation of its effectiveness in application in a power system is described.

A wind turbine induction generator unit model was developed in [1]. In [1], the voltage of isolated unit is regulated by the SVC and oscillation damping is improved in two ways: through multi-state feedback and through multi-output feedback.

In this chapter, a wind turbine powered induction generator is simulated. The ma- 


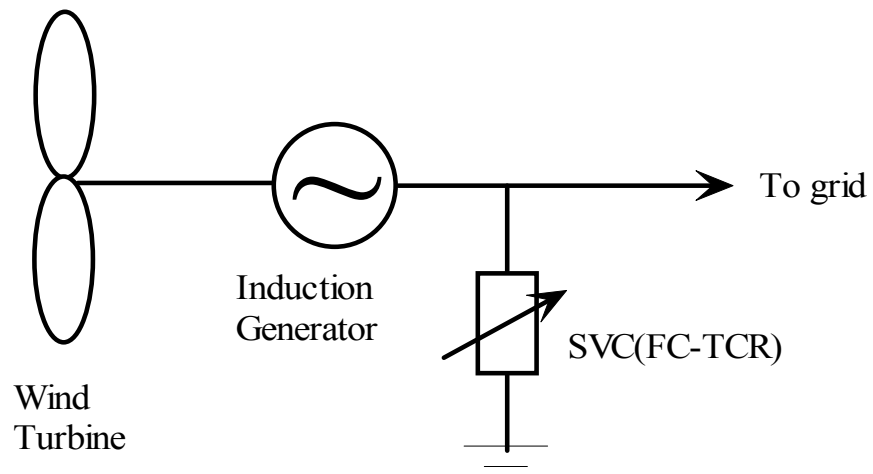

Figure 8.1: Diagram of a wind turbine DG consisting of a wind turbine, an induction generator and a SVC.

trix/vector concept based induction machine model is developed and simulated with Simulink. The fixed capacitor and thyristor controlled reactance (FC-TCR), a type of static var compensator (SVC), is used to compensate the var of the induction generator. A real power and reactive power tracking control scheme is presented.

The wind turbine induction generator with SVC (called wind turbine DG system) is illustrated in Figure 8.1.

\subsection{System Models}

The wind turbine induction generator, SVC and general load models are described in the following subsections.

\subsubsection{Wind Turbine Model}

Based on the speed of the wind, the wind turbine operating condition can be categorized into three regimes: start-up regime, sub-rated power regime and rated power regime [88]. When the speed of the wind is greater than $6.2 \mathrm{~m} / \mathrm{s}$, the start up procedure occurs. Once the speed of the wind reaches $12.8 \mathrm{~m} / \mathrm{s}$, the wind turbine works in the rated power regime. The region between start-up and rated power regime is called the sub-rated power regime. Our research focuses on the dynamic performance of the wind turbine in the rated power regime.

The dynamic output mechanical torque of the wind turbine is expressed [1][88]as:

$$
T_{m}=\frac{1}{2} \rho A R C_{p} V_{\omega}^{2} / \lambda
$$


where, $\rho$ is the air density, $A$ is the blades' swept area, $R$ is the wind turbine rotor radius, $V_{\omega}$ is wind speed, $C_{p}$ is a power coefficient of the blade which is a function of the blade pitch angle $\beta$, and the tip speed ratio is:

$$
C_{p}=(0.44-0.0167 \beta) \sin \left(\frac{\pi(\lambda-3)}{15-0.3 \beta}\right)-0.00184(\lambda-3) \beta
$$

and tip speed ratio $\lambda$ is:

$$
\lambda=\frac{\Omega R}{V_{\omega}}
$$

where $\Omega$ is the mechanical angular velocity.

\subsubsection{Induction Generator}

The electrical equations of induction generator model in the arbitrary reference frame can be expressed as:

$$
\begin{gathered}
v_{q s}=r_{s} i_{q s}+\frac{\omega}{\omega_{b}} \psi_{d s}+\frac{p}{\omega_{b}} \psi_{q s} \\
v_{d s}=r_{s} i_{d s}-\frac{\omega}{\omega_{b}} \psi_{q s}+\frac{p}{\omega_{b}} \psi_{d s} \\
v_{q r}^{\prime}=r_{r}^{\prime} i_{q r}^{\prime}+\left(\frac{\omega-\omega_{r}}{\omega_{b}}\right) \psi_{d r}^{\prime}+\frac{p}{\omega_{b}} \psi_{q r}^{\prime} \\
v_{d r}^{\prime}=r_{r}^{\prime} i_{d r}^{\prime}-\left(\frac{\omega-\omega_{r}}{\omega_{b}}\right) \psi_{q r}^{\prime}+\frac{p}{\omega_{b}} \psi_{d r}^{\prime}
\end{gathered}
$$

The $\omega_{b}$ is the base electrical angular velocity used to calculate the inductive reactances. The mechanical part is expressed in per unit as:

$$
\frac{p}{\omega_{b}} \omega_{r}=\frac{1}{2 H}\left(T_{e}-T_{m}\right)
$$

and the torque equation is expressed as:

$$
T_{e}=\psi_{q r}^{\prime} i_{d r}^{\prime}-\psi_{d r}^{\prime} i_{q r}^{\prime}
$$

The detailed induction machine model is given in Appendix A.

\subsubsection{Static VAR Compensator (SVC)}

SVC (see Figure 8.2) is used to compensate the reactive power of the induction generator. SVC consists of a fixed capacitor and a thyristor controlled reactance (FC-TCR).

The reactance of the TCR is a function of the firing angle $\alpha[1]$. 


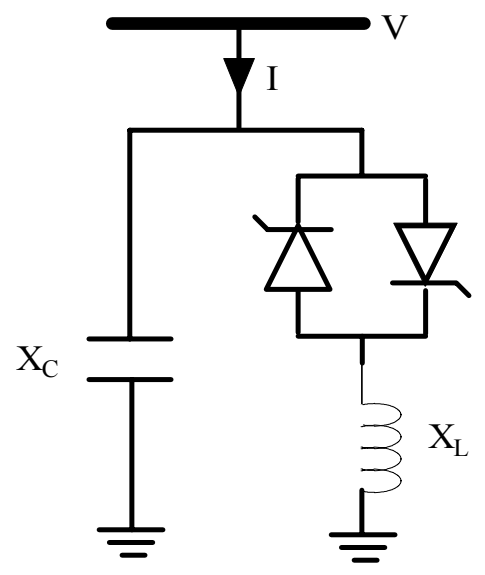

Figure 8.2: Diagram of the SVC (FC-TCR) structure.

$$
\begin{aligned}
\frac{1}{x_{L e q}} & =\frac{2(\pi-\alpha)+\sin (2 \alpha)}{\pi} \cdot \frac{1}{x_{L}} \\
& =\frac{\sigma-\sin \sigma}{\pi} \cdot \frac{1}{x_{L}}=B_{e q} \frac{1}{x_{L}}
\end{aligned}
$$

where, $x_{L}$ is reactance, $\sigma=2(\pi-\alpha)$, and $B_{e q}$ is the coefficient of the TCR reactance. The adjustable coefficient of the reactance is:

$$
0<B_{e q}<1
$$

The SVC equivalent reactance $\left(x_{e q}\right)$ is determined by the combination of FC and TCR in parallel, and it can be expressed as:

$$
x_{e q}=\frac{x_{C} x_{L}}{\frac{x_{C}}{\pi}(\sigma-\sin \sigma)-x_{L}}
$$

\subsubsection{Static and Dynamic Load Models}

The static load can be represented as a nonlinear function of load bus voltage $V_{\text {bus }}$. The load active power $P_{L}$ and reactive power $Q_{L}$ can be expressed as:

$$
\begin{gathered}
P_{L}=C_{1}\left(V_{b u s}\right)^{n_{p}} \\
Q_{L}=C_{2}\left(V_{b u s}\right)^{n_{q}}
\end{gathered}
$$




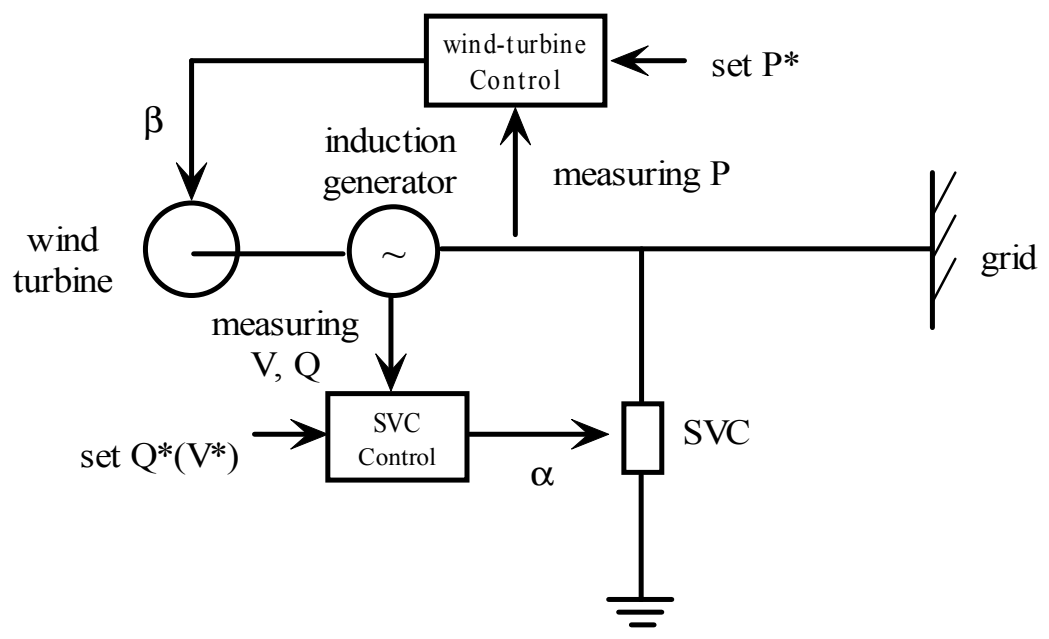

Figure 8.3: General structure of a wind turbine DG and its control unit.

where $C_{1}$ and $C_{2}$ are constant. The characteristics of different loads are given by the exponents $n_{p}$ and $n_{q}$. In this dissertation, the exponent values $n_{p}=n_{q}=2$, means that the static loads are constant impedances.

The induction motor is used to represent the dynamic load. The $5^{\text {th }}$ order state equations and the torque equation are the same as the induction generator. As a dynamic load, the rotor voltage is set to zero, $V_{q r}=V_{d r}=0$.

\subsection{Control Unit Model}

The general structure of a wind turbine induction generator with SVC and the control unit is shown in Figure 8.3 [84]. The control unit consists of the blade pitch angle control (see Figure 8.5) and the voltage regulator loop (see Figure 8.4) respectively. The wind speed is assumed to be in the rated power regime.

The voltage regulator control loop is implemented by SVC. The SVC is used to compensate the reactive power, thus stabilizing the commutating bus voltage. The ancillary signal is also considered as an input to the SVC to improve oscillation damping of the system. The frequency deviation is added as an input to the SVC to improve damping of the system [5]. The control loop of the SVC is shown in Figure 8.4. The constraints of the output $X_{L e q}$ are adjusted for different operating conditions. 


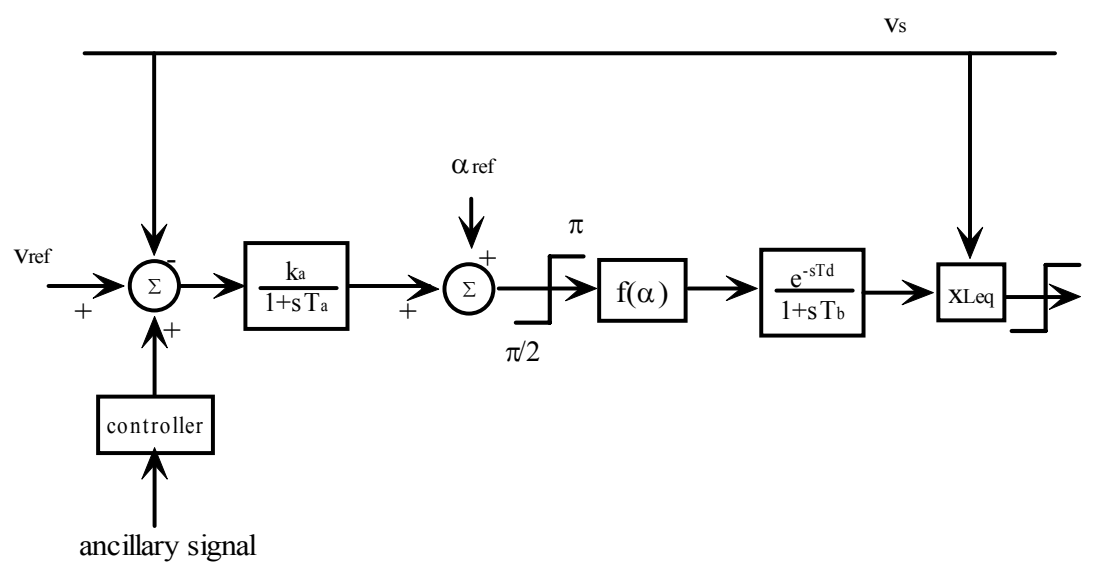

Figure 8.4: Diagram of the SVC's voltage regulator control loop.

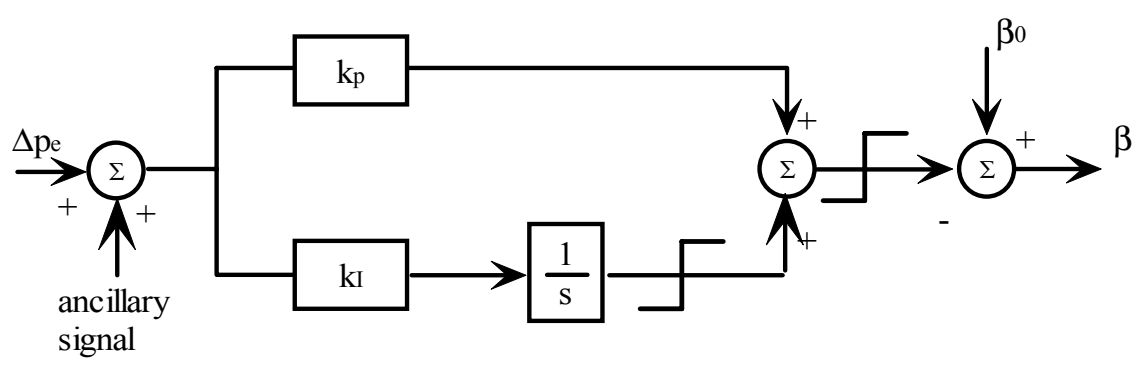

Figure 8.5: Diagram of the blade pitch angle controller of the wind turbine.

A PI controller is considered to keep the mechanical torque of the wind turbine to be constant (see Figure 8.5). A rate limit of \pm 10 degree/sec is set to limit the pitch angle actuator. The ancillary signal can be a control signal of the rotor speed deviation of the generators to improve the dynamic stability of the system.

The control for the wind turbine DG will be designed in Chapter 9.

\subsection{Induction Machine Simulation}

In this research, the nonlinear induction machine model is used to represent the generator and the dynamic load. The nonlinear model is simulated in Simulink. The eigenvalues of the linearized induction machine are obtained at a certain operating point. 
The matrix concepts in Matlab are used to simulate the induction machine. The dynamic models of induction machine is presented below in terms of (8.15). The Simulink expressions are also shown below which will use voltages as inputs and currents as the outputs of the model block.

$$
\dot{x}=A x+B u
$$

\subsubsection{Matrix Concepts Based Induction Machine Model}

The voltage equations of an induction machine model in the arbitrary reference frame can be written in term of the currents [69]. Assume that the reference frame is arbitrary reference frame and that all quantities are in per unit value. This equation can be further written into the equation (8.15). Where: $x=\left[i_{q s}, i_{d s}, i_{0 s}, i_{q r}^{\prime}, i_{d r}^{\prime}, i_{0 r}^{\prime}\right]^{T}$

$$
\begin{aligned}
& B=\left[\begin{array}{cccccc}
\frac{1}{\omega_{b}} X_{s s} & 0 & 0 & \frac{1}{\omega_{b}} X_{M} & 0 & 0 \\
0 & \frac{1}{\omega_{b}} X_{s s} & 0 & 0 & \frac{1}{\omega_{b}} X_{s s} & 0 \\
0 & 0 & \frac{1}{\omega_{b}} X_{l s} & 0 & 0 & 0 \\
\frac{1}{\omega_{b}} X_{s s} & 0 & 0 & \frac{1}{\omega_{b}} X_{r r}^{\prime} & 0 & 0 \\
0 & \frac{1}{\omega_{b}} X_{s s} & 0 & 0 & \frac{1}{\omega_{b}} X_{r r}^{\prime} & 0 \\
0 & 0 & 0 & 0 & 0 & \frac{1}{\omega_{b}} X_{l r}^{\prime}
\end{array}\right]^{-1} \\
& A=-B \cdot\left[\begin{array}{cccccc}
-r_{s} & \frac{\omega}{\omega_{b}} X_{s s} & 0 & 0 & \frac{\omega}{\omega_{b}} X_{M} & 0 \\
-\frac{\omega}{\omega_{b}} X_{s s} & r_{s} & 0 & -\frac{\omega}{\omega_{b}} X_{M} & 0 & 0 \\
0 & 0 & r_{s} & 0 & 0 & 0 \\
0 & \frac{\omega-\omega_{r}}{\omega_{b}} X_{M} & 0 & r_{r}^{\prime} & \frac{\omega-\omega_{r}}{\omega_{b}} X_{M} & 0 \\
-\frac{\omega-\omega_{r}}{\omega_{b}} X_{M} & 0 & 0 & -\frac{\omega-\omega_{r}}{\omega_{b}} X_{r r}^{\prime} & r_{r}^{\prime} & 0 \\
0 & 0 & 0 & 0 & 0 & r_{r}^{\prime}
\end{array}\right]
\end{aligned}
$$

The swing equation is:

$$
T_{e}=2 \frac{H}{\omega_{b}} \dot{\omega}_{r}+T_{L}
$$

The torque equation is:

$$
T_{e}=X_{M}\left(i_{q s} i_{d r}^{\prime}-i_{d s} i_{q r}^{\prime}\right)
$$

\subsubsection{Induction Machine Simulink Model}

The Simulink model for equation (8.15) is simply expressed as in Figure 8.6. 


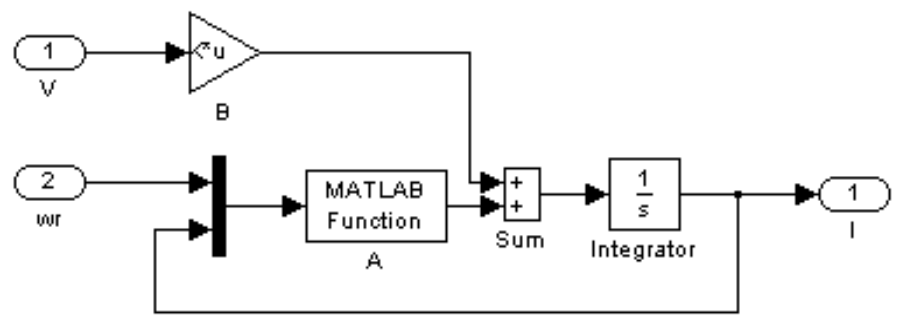

Figure 8.6: State equations of an induction machine represented in Simulink.

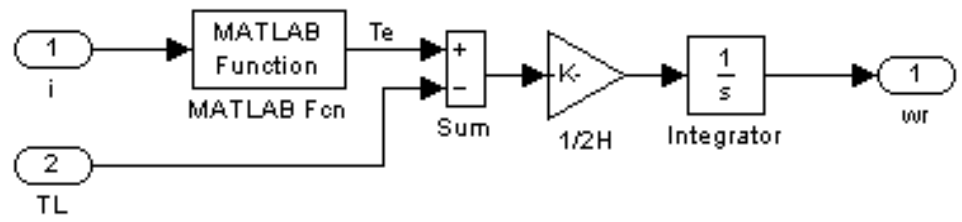

Figure 8.7: Swing equation of an induction machine represented in Simulink.

In this model block, inputs are voltage and rotor speed, output is a current vector. This model is quite simple and easy to understand. It saves not only model building time but also debugging time. The rotor speed is calculated through equation (8.16) which is modeled as in Figure 8.7.

The rotor speed will be fed back to the input of the block in Figure 8.6. The induction machine serves as a current source to the network. And the output from the network is the voltage vector. Thus, the induction machine and the power system network are interconnected and as long as the initial condition is set, dynamic simulation can be performed.

\subsubsection{Initialization of the Induction Machine}

The procedure to set the initial condition of induction machine:

Given $P_{0}, \bar{V}_{a s}$, use Newton-Raphsom method to calculate the rotor speed $\omega_{r}$, then set the steady state variables vector $(\bar{I})$. The induction machine can be represented as in Figure 8.8. 


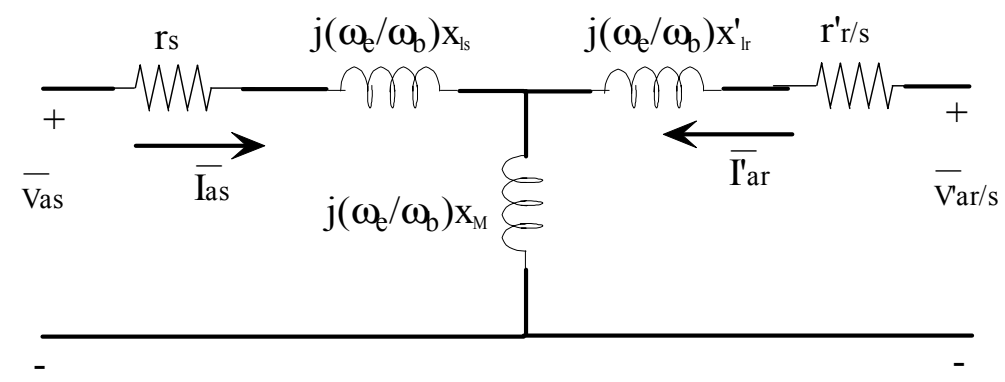

Figure 8.8: Equivalent circuit of an induction machine.

Usually, $\overline{V_{a r}^{\prime}}=0$. Therefore,

$$
\begin{gathered}
\overline{I_{a r}^{\prime}}=-\frac{j \frac{\omega_{e}}{\omega_{b}} X_{M}}{\frac{r_{r}^{\prime}}{s}+j \frac{\omega_{e}}{\omega_{b}} X_{r r}^{\prime}} \overline{I_{a s}} \\
\overline{V_{a s}}=\left(r_{s}+j \frac{\omega_{e}}{\omega_{b}} X_{l s}\right) \overline{I_{a s}}+j \frac{\omega_{e}}{\omega_{b}} X_{M}\left(\overline{I_{a s}}+\overline{I_{a r}^{\prime}}\right)
\end{gathered}
$$

Substitute equation (8.18) into (8.19):

$$
\begin{aligned}
\overline{I_{a s}} & =\frac{\overline{V_{a s}}}{\left(r_{s}+j \frac{\omega_{e}}{\omega_{b}} X_{l s}\right)+j \frac{\omega_{e}}{\omega_{b}} X_{M}\left(1-\frac{j \frac{\omega_{e}}{\omega_{b}} X_{M}}{\frac{r_{r}^{\prime}}{s}+j \frac{\omega_{e}}{\omega_{b}} X_{l r}^{\prime}+j \frac{\omega_{e}}{\omega_{b}} X_{M}}\right)} \\
& =\frac{\overline{V_{a s}}}{r_{s}-\frac{X_{M}^{2}}{\frac{r_{r}^{\prime}}{s}+j X_{l r}^{\prime}}+j X_{s s}}=\frac{\overline{X_{a s}^{2}\left(\frac{r_{r}^{\prime}}{s}-j X_{l r}^{\prime}\right)}}{r_{s}-j X_{s s}} \\
& =\frac{\overline{V_{a s}}}{r_{s}-\frac{\left.X_{M}^{\prime}\right)^{2}+\left(X_{l r}^{\prime}\right)^{2}}{\left(\frac{r_{r}^{\prime}}{s}\right)^{2}+\left(X_{l r}^{\prime}\right)^{2}}+j\left(X_{s s}+\frac{X_{l r}^{\prime}}{\left(\frac{r_{r}^{\prime}}{s}\right)^{2}+\left(X_{l r}^{\prime}\right)^{2}}\right)}=\frac{\overline{V_{a s}}}{R+j X}
\end{aligned}
$$

where $R=r_{s}-\frac{X_{M}^{2} \frac{r_{r}^{\prime}}{s}}{\left(\frac{r_{r}^{\prime}}{s}\right)^{2}+\left(X_{l r}^{\prime}\right)^{2}}, X=X_{s s}+\frac{X_{l r}^{\prime}}{\left(\frac{r_{r}^{\prime}}{s}\right)^{2}+\left(X_{l r}^{\prime}\right)^{2}}$.

So, $\frac{\overline{V_{a s}}}{\overline{I_{a s}}}=R+j X$ and $\overline{I_{a s}^{*}}=\frac{\overline{V_{a s}^{*}}}{R-j X}$.

$$
\begin{aligned}
P & =\operatorname{real}\left(\bar{V}_{a s} \bar{I}_{a s}^{*}\right)=\operatorname{real}\left(\bar{V}_{a s} \frac{\overline{V_{a s}^{*}}}{R-j X}\right)=\operatorname{real}\left(\frac{V_{a s}^{2}}{R-j X}\right) \\
& =\frac{V_{a s}^{2}}{R^{2}+X^{2}} R=f(\text { slip })
\end{aligned}
$$

Using Newton-Raphson method, given $P_{0}, \bar{V}_{a s}$, only slip is unknown and

$$
\text { slip_new }=s l i p \_o l d-\frac{P_{0}-f\left(s l i p \_o l d\right)}{f^{\prime}\left(s l i p \_o l d\right)}
$$




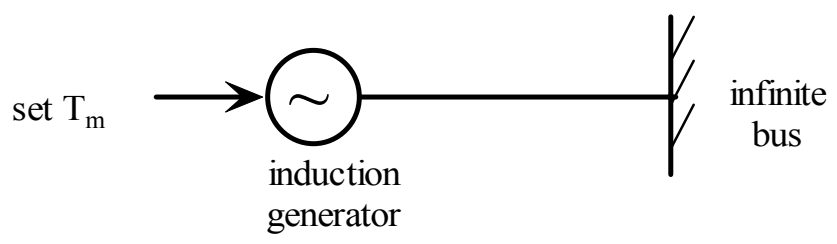

Figure 8.9: Diagram of a one-machine infinite bus system to test the induction generator.

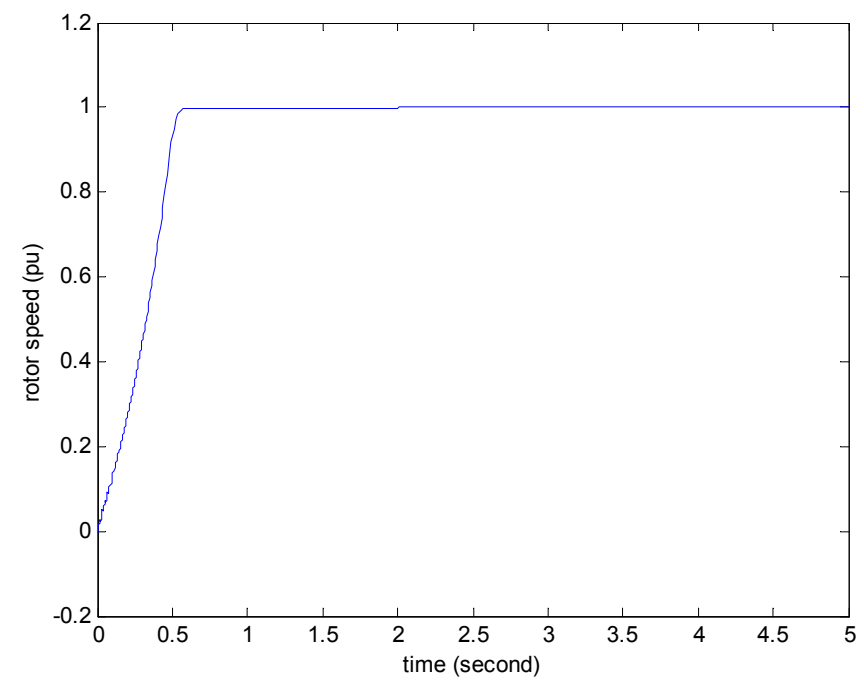

Figure 8.10: Rotor speed of an induction machine during the start-up and step response procedure.

\subsubsection{Start-up Procedure and Step Response of Induction Machine}

To test the induction machine model in Simulink, the induction generator connected to the infinite bus is simulated (see Figure 8.9). The parameters of the induction machine: $X_{l s}=0.135, X_{l r}^{\prime}=$ $0.075, X_{M}=4.161, r_{s}=0.0059, r_{r}^{\prime}=0.0339, H=0.5$.

The start-up procedure and step responses of induction machine are shown in Figures 8.10-8.12. The initial $T_{m}$ set point is $T_{m}=0.1$, the motor start at $0 s$ and the $T_{m}$ is switched from 0.1 to -0.1 at $2.0 \mathrm{~s}$.

\subsubsection{Linearized Induction Machine}

In this section, the linearized induction machine model is obtained via the Simulink toolbox. The induction machine operates as a generator and the operating point is: $P_{\text {ind }}=0.1053(\mathrm{pu}), V_{\text {ind }}=$ 


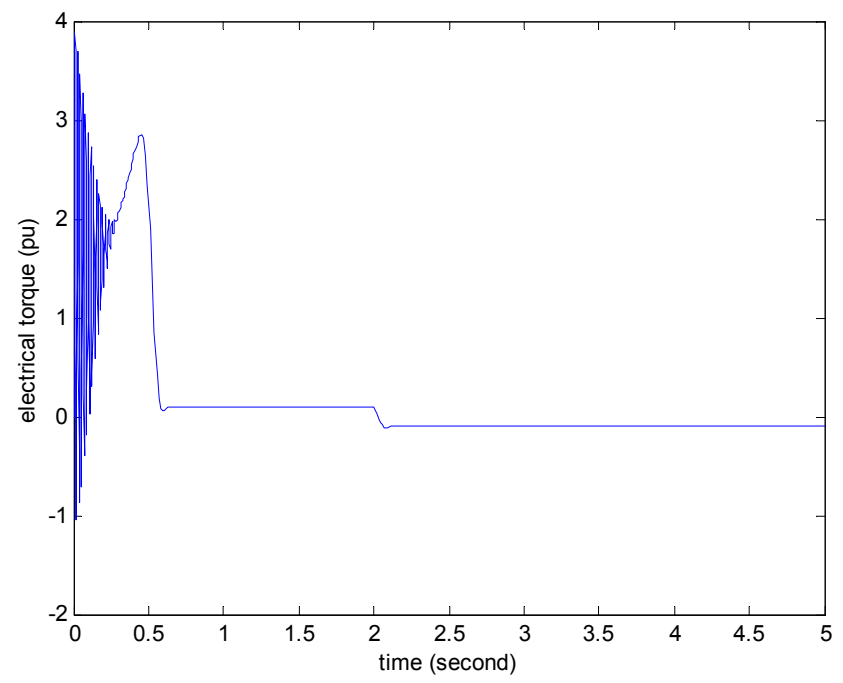

Figure 8.11: Electrical torque response of an induction machine during the start-up and step response procedure.

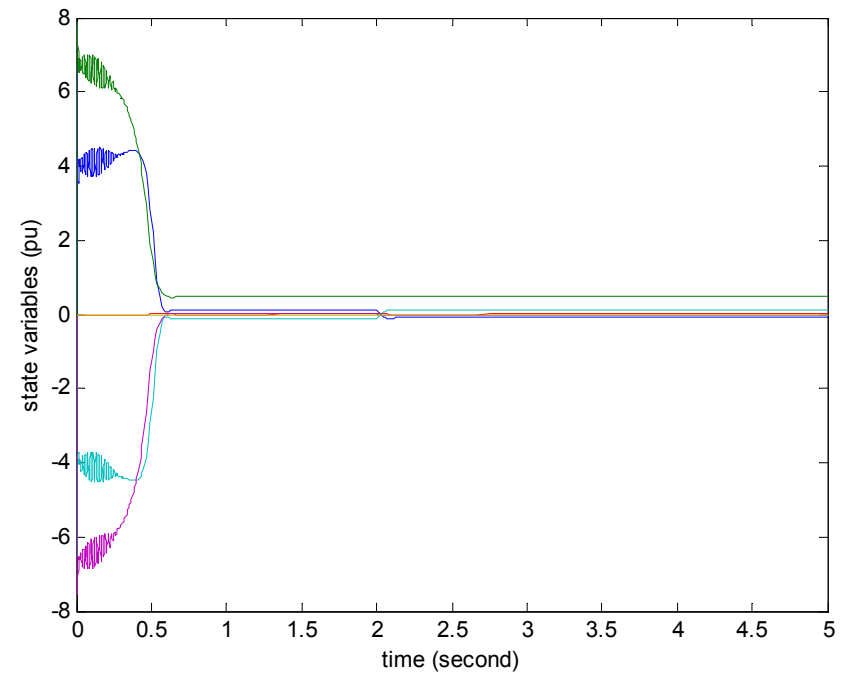

Figure 8.12: State variables of induction machine during the start-up and step response procedure. 
Table 8.1: Eigenvalues of the linearized induction machine.

\begin{tabular}{|c|c|}
\hline NO. & Eigenvalues \\
\hline \hline$\lambda_{1,2}$ & $-10.548 \pm 375.36 \mathrm{i}$ \\
\hline$\lambda_{3,4}$ & $-32.606 \pm 44.938 \mathrm{i}$ \\
\hline$\lambda_{5}$ & -59.234 \\
\hline$\lambda_{6}$ & -16.476 \\
\hline$\lambda_{7}$ & -170.40 \\
\hline
\end{tabular}

1.0. The eigenvalues are shown in Table 8.1. The two complex conjugate pairs are the "stator" eigenvalues and the "rotor" eigenvalues. For different operation condition, the frequency of "stator" pairs can remain around $\omega_{b}$, and "rotor" pairs change much[69]. This characteristic can help to identify the eigenvalues.

\subsection{Integration of Wind Turbine DG}

The wind turbine DG consists of wind turbine, induction generator and SVC (see Figure 8.1). The wind turbine transfers the wind energy to the electric power through the mechanical torque. As a characteristic of the induction machine, the induction generator can only generate the real power, meanwhile, it absorbs the reactive power from the system. The SVC is a very important part of the wind turbine DG. It supplies the controllable reactive power, part of it to the induction generator, thus balance the terminal voltage of the induction generator. The real power is tracked by the PI controller, however the first order feedback controller is used to track the voltage through the SVC.

The integration of wind turbine DG is studied in this section. A wind turbine DG and infinite bus system is simulated to test the real power $\left(\mathrm{P}^{*}\right)$ and reactive power $\left(\mathrm{Q}^{*}\right)$ track performance. The test system is shown in Figure 8.3. The parameters of wind turbine are: $\mathrm{R}=69.96 \mathrm{~m}, \mathrm{~V}_{\text {rated }}=9.3 \mathrm{~m} / \mathrm{s}, \rho_{\text {air }}=1.225, \mathrm{~K}_{i}=6.2, \mathrm{~K}_{p}=6.2$ and the parameters of the SVC are: $\mathrm{X}_{C}=0.5, \mathrm{X}_{L}=0.476, \mathrm{~T}_{b}=0.00417, \mathrm{~T}_{d}=0.0014, \mathrm{~K}_{R}=33.3, \mathrm{~T}_{R}=0.1$.

The initial operating condition: $S_{\text {base }}=4.0 M V A, V_{\text {base }}=4.16 \mathrm{kV}, P_{\text {wind }}^{*}=0.1053$, $Q_{\text {wind }}^{*}=0.0852$. Then initial condition for induction generator and SVC each: $P_{\text {ind }}=P_{\text {wind }}$, $Q_{\text {ind }}=-0.0516, S_{\text {slip }}=-0.02638$ and $Q_{S V C}=0.137$.

Case I: $\mathrm{t}=0.5 \mathrm{~s}, P_{\text {wind }}^{*}$ increases from 0.1053 to 0.1370 and $Q_{\text {wind }}^{*}$ remains constant. Figures (8.13-8.14) show the dynamic responses of the wind turbine DG. The simulation results show the reactive power output decreased since the voltage drop along the distribution line increased. 


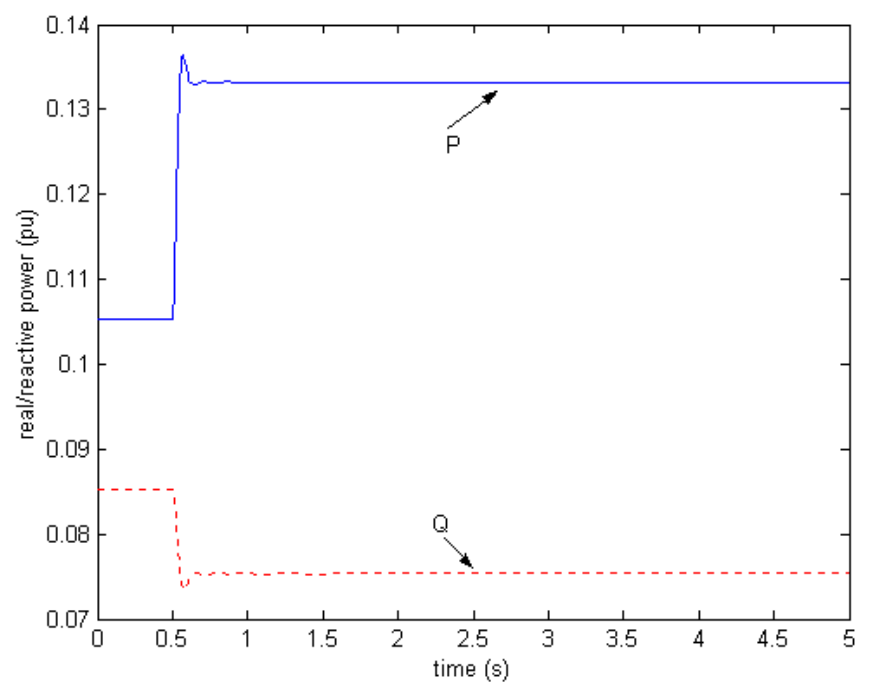

Figure 8.13: Real and reactive power responses of the wind turbine DG to track $P_{\text {wind }}^{*}$ (Case I).

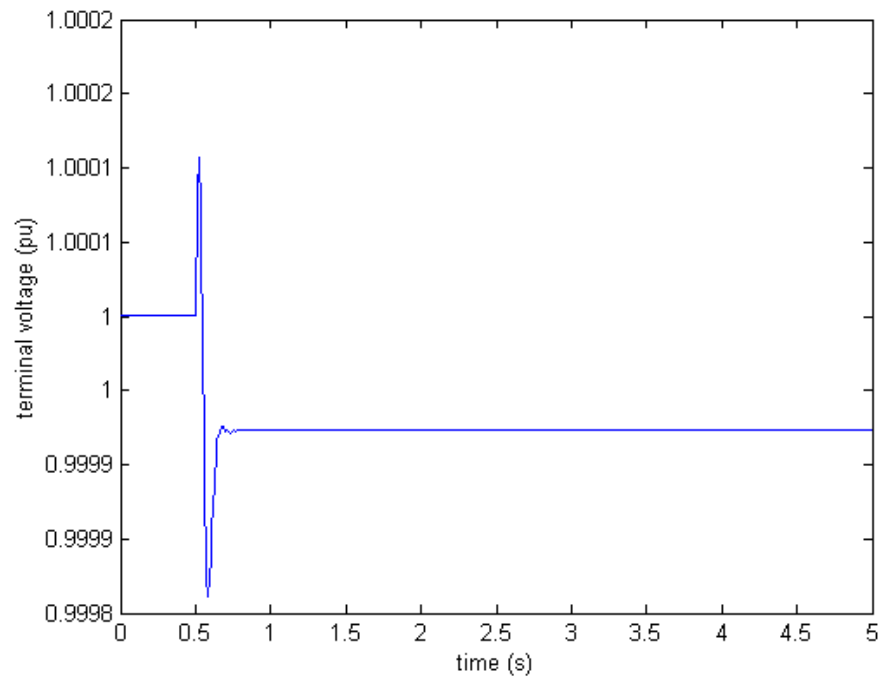

Figure 8.14: Terminal voltage response of the wind turbine DG to track $P_{\text {wind }}^{*}$ (Case I). 


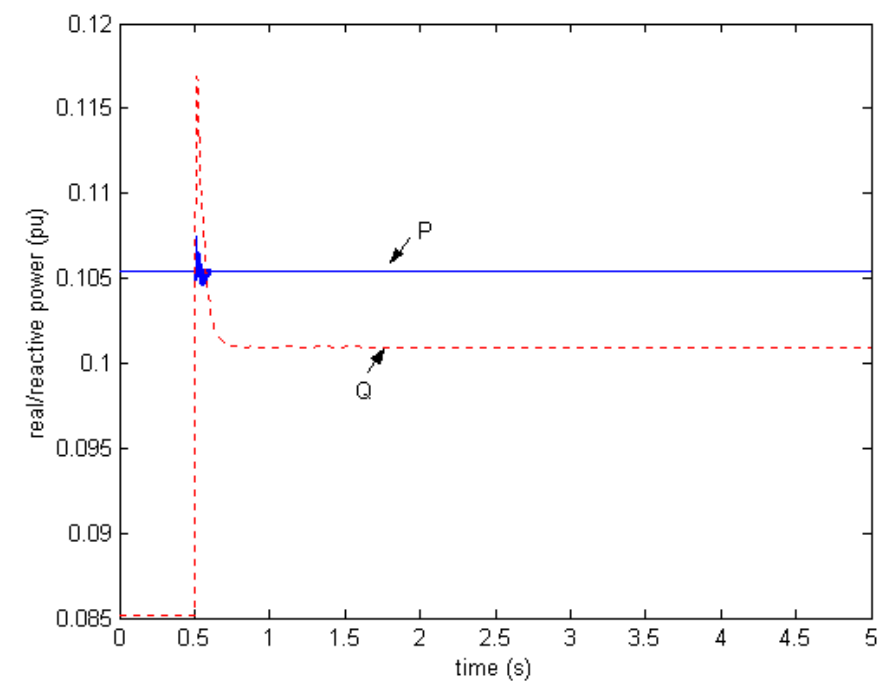

Figure 8.15: Real/reactive power responses of the wind turbine DG to track the $Q_{\text {wind }}^{*}$ (Case II).

Case II: $\mathrm{t}=0.5 \mathrm{~s}, P_{\text {wind }}^{*}$ remains constant and $Q_{\text {wind }}^{*}$ increases from 0.0852 to 0.117 . Figures (8.15-8.17) show the dynamic responses of the wind turbine DG. The reactive power response shows the output $\mathrm{Q}$ can track the set point, but cannot reach the actually changed values. The responses of the real power and the rotor speed of the induction generator illustrate the interaction between the real power and reactive power tracking procedures.

In the Chapter 9, the wind turbine DG model will be connected to the IEEE-13 system with existing DGs. The good real/reactive power tracking performance of wind turbine DG will be used to improve the dynamic stability of the system. During the controller design, an additional control signals will be input to the control units.

\subsection{Summary}

A wind turbine DG model is presented in this chapter. The model consists of an induction machine, a wind turbine and a SVC. A matrix/vector concept based simulation of the induction machine is described in detail. A practical Newton-Raphson method is used to determine the initial condition of the induction machine. The SVC is used to compensate the reactive power of the wind turbine DG, thus control the DG's terminal voltage. 


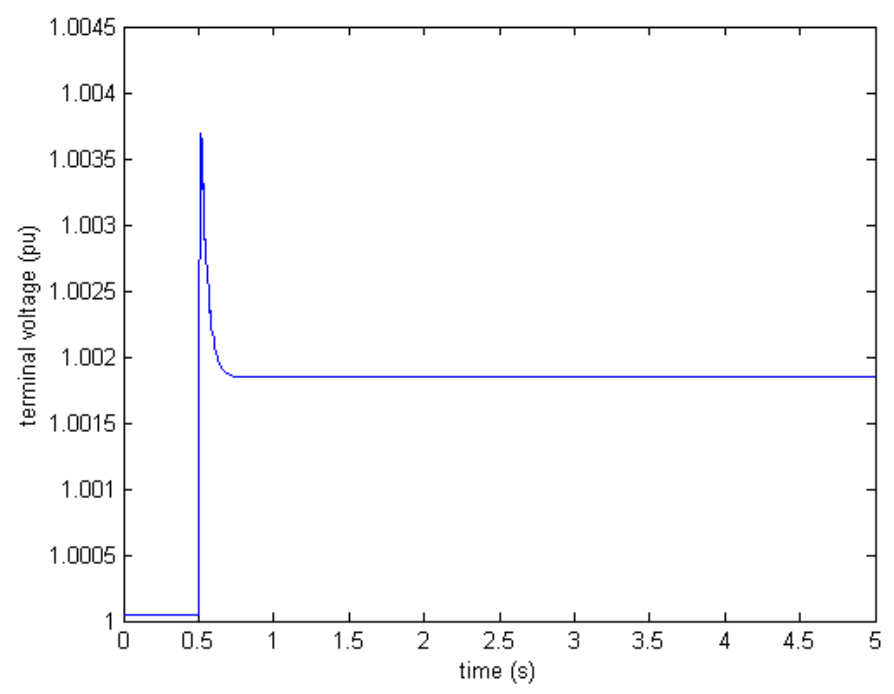

Figure 8.16: Terminal voltage of the wind turbine DG to track the $Q_{\text {wind }}^{*}$ (Case II).

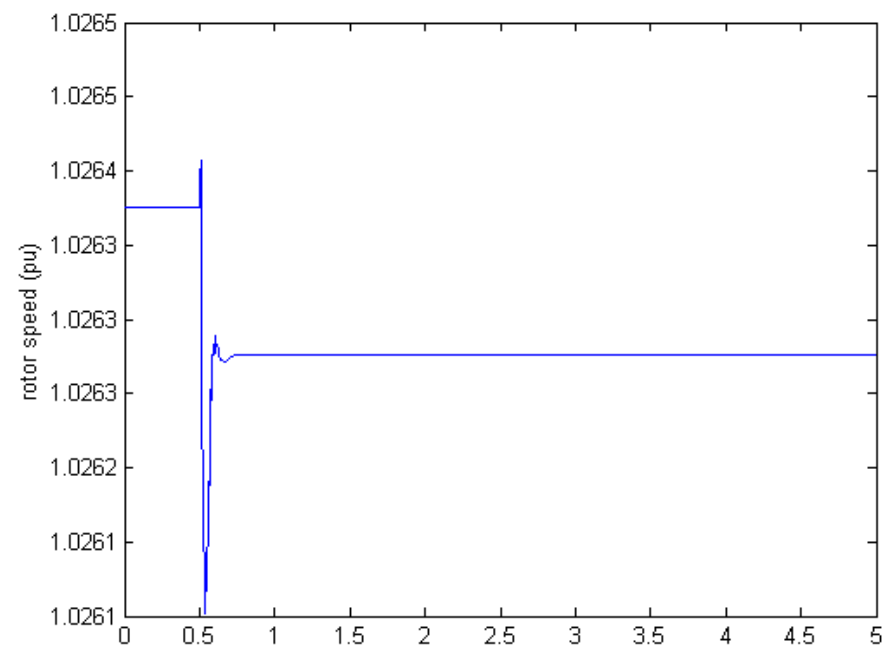

Figure 8.17: Rotor speed of the wind turbine DG to track the $Q_{\text {wind }}^{*}$ (Case II). 


\section{Chapter 9}

\section{Robust Control of Wind Turbine DG}

\subsection{Introduction}

In this chapter, the controllers of a wind turbine distributed generation (DG) are designed to improve the dynamic stability of the system. A wind turbine DG is connected to a power distribution system which has other DGs connected as well. The existing DGs are gas turbine and diesel engine DGs. The linearized model of the entire system at a certain operating condition is obtained. Dominant eigenvalues are identified using optimal ranking indices. Output feedback coordinated controllers are designed through SVC, wind turbine pitch control and the combination of the two. The dynamic loads are brought into consideration by modeling the load uncertainty as structured uncertainty. $\mu$ analysis is used to find the margin value of the load parameter. The robust stability of the controllers is evaluated.

\subsection{System Configuration}

The system studied, in Figure 9.1, consists of IEEE-13 node system to which a gas turbine synchronous generator, a diesel engine synchronous generator, a wind turbine induction generator, and a SVC are connected. A dynamic load represented by induction motor is connected at bus 634 . The distribution system model, gas turbine model and diesel engine model have been discussed in the previous chapters. 


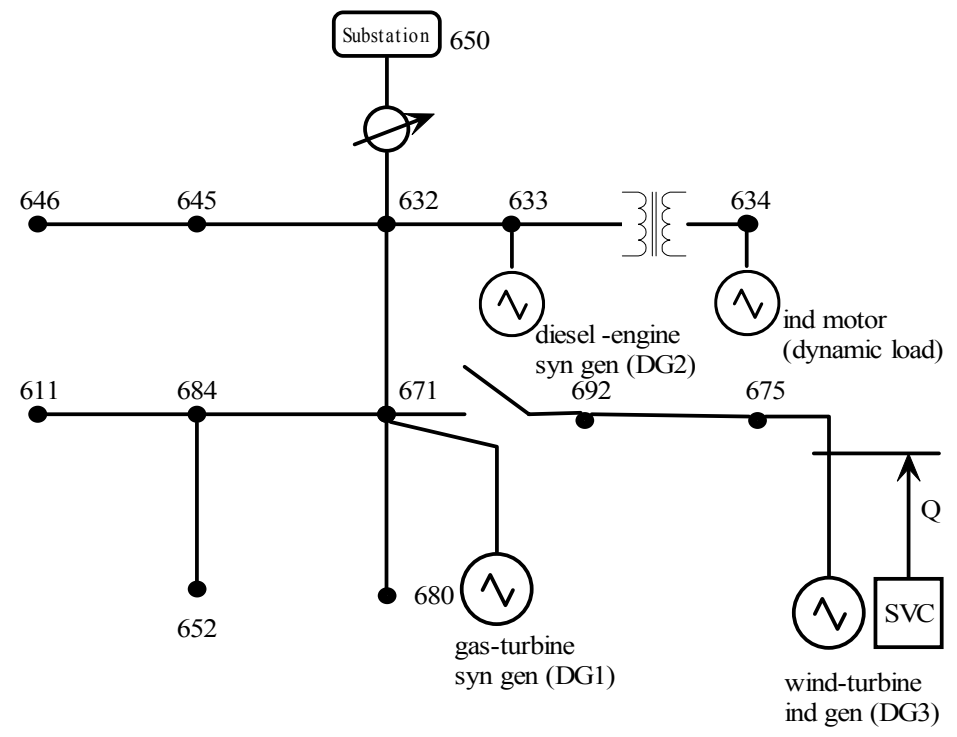

Figure 9.1: Diagram of IEEE-13 node distribution system with multi-DGs to evaluate the wind turbine DG.

\subsection{Critical Eigenvalues Identification}

The system includes 46 differential equations. In the linearized model, once the three synchronous generators (2 DGs + Substation) are connected in the distribution system, only two rotors angles are independent. Hence, in the linearized distribution system, there are a total of 45 state variables. The linearization tools in Simulink are used to get linear model (A, B, C, D) directly.

Based on the linearized model (A, B, C, D), the controller is then designed via eigenvalue analysis. The controller design process is covered in the following sections. The eigenvalues of the linearized open loop system are listed in Table 9.1.

\subsubsection{Ranking Indices of the Eigenvalues}

Consider a linear system (A, B, C) expressed as:

$$
\begin{gathered}
\dot{x}=A x+B u \\
y=C x
\end{gathered}
$$

where $x$ is the $n \times 1$ linearized state variable vector, $u$ is the $r \times 1$ control input, $A(n \times n)$ is the system plant matrix, $B(n \times r)$ is the control matrix and $C(m \times n)$ is the output matrix. The output performance index can be described as: 
Table 9.1: Eigenvalues of the open-loop linearized system.

\begin{tabular}{|c|c|c|c|}
\hline NO. & Eigenvalues & NO. & Eigenvalues \\
\hline \hline$\lambda_{1,2}$ & $-1181.08 \pm 3428.07 \mathrm{i}$ & $\lambda_{3,4}$ & $-169.370 \pm 730.473 \mathrm{i}$ \\
\hline$\lambda_{5,6}$ & $-142.016 \pm 372.950 \mathrm{i}$ & $\lambda_{7,8}$ & $-32.0687 \pm 407.515 \mathrm{i}$ \\
\hline$\lambda_{9}$ & -108.595 & $\lambda_{10,11}$ & $-33.0238 \pm 69.1077 \mathrm{i}$ \\
\hline$\lambda_{12,13}$ & $-22.9048 \pm 64.3909 \mathrm{i}$ & $\lambda_{14,15}$ & $-27.6496 \pm 48.8694 \mathrm{i}$ \\
\hline$\lambda_{16}$ & -59.7052 & $\lambda_{17}$ & -52.3933 \\
\hline$\lambda_{18}$ & -32.3338 & $\lambda_{19}$ & -31.7551 \\
\hline$\lambda_{20}$ & -30.6798 & $\lambda_{21}$ & -25.1660 \\
\hline$\lambda_{22,23}$ & $-20.0614 \pm 1.09989 \mathrm{i}$ & $\lambda_{24,25}$ & $-5.19824 \pm 13.8666 \mathrm{i}$ \\
\hline$\lambda_{26,27}$ & $-3.22992 \pm 7.22492 \mathrm{i}$ & $\lambda_{28,29}$ & $-1.124190 \pm 5.65105 \mathrm{i}$ \\
\hline$\lambda_{30}$ & -5.5730 & $\lambda_{31,32}$ & $-0.139074 \pm 3.03003 \mathrm{i}$ \\
\hline$\lambda_{33}$ & -2.29866 & $\lambda_{34}$ & -0.661145 \\
\hline$\lambda_{35}$ & -0.455469 & $\lambda_{36}$ & -0.286084 \\
\hline$\lambda_{37,38}$ & $-0.005198 \pm 0.08311 \mathrm{i}$ & $\lambda_{39}$ & -0.193158 \\
\hline$\lambda_{40}$ & -16.4759 & $\lambda_{41}$ & -170.340 \\
\hline$\lambda_{42}$ & -220.357 & $\lambda_{43}$ & -259.913 \\
\hline$\lambda_{44}$ & -20.000 & $\lambda_{45}$ & -239.808 \\
\hline
\end{tabular}

$$
J=\sum_{i=1}^{r} \int_{t=0}^{\infty} y_{i}(t)^{T} Q y_{i}(t) d t
$$

where $y_{i}(t)$ is the output of the system and $Q$ is the weight matrix of the performance index.

A way to rank the eigenvalues of the linearized system was proposed in [32][115]. The ranking indices are used to evaluate the contribution of the eigenvalues to the performance index. Referring to [32][115], the critical modes are the eigenvalues with the largest ranking indices. To calculate the ranking indices, assuming the system $(\mathrm{A}, \mathrm{B}, \mathrm{C})$ has $\mathrm{n}$ distinct eigenvalues. The right and left eigenvector matrices are $V$ and $W$. The diagonal matrix of the eigenvalues is $\Lambda=W A V$, control matrix is $\Gamma_{i}=W B_{i}$. Then the performance index can be expressed as:

$$
J=\sum_{i=1}^{n} \sum_{k=1}^{n} T_{i k} \Theta_{i k}
$$

where $T_{i k}=-\frac{R_{i k}}{\lambda_{i}^{*}+\lambda_{k}}$ is the explicit solution of : $\Lambda^{H} T+T \Lambda=-R, R=V^{H} C^{T} Q C V$ and $\Theta=$ $\sum_{i=1}^{r} \Gamma_{i} \Gamma_{i}^{H}$.

For the sake of the convenience, define $\eta_{i k}=T_{i k} \Theta_{i k}+T_{k i} \Theta_{k i}$. The contribution of each 
Table 9.2: Critical eigenvalues of the open linearized system.

\begin{tabular}{|c|c|c|}
\hline NO. & Eigenvalues & Ranking Indices $\left(\times 10^{-3}\right)$ \\
\hline \hline$\lambda_{7,8}$ & $-32.0687 \pm 407.515 \mathrm{i}$ & 0.1028 \\
\hline$\lambda_{14,15}$ & $-27.6496 \pm 48.8694 \mathrm{i}$ & 0.2258 \\
\hline$\lambda_{26,27}$ & $-3.22992 \pm 7.22492 \mathrm{i}$ & 0.05226 \\
\hline$\lambda_{28,29}$ & $-1.124190 \pm 5.65105 \mathrm{i}$ & 0.02227 \\
\hline$\lambda_{31,32}$ & $-0.139074 \pm 3.03003 \mathrm{i}$ & 0.1252 \\
\hline
\end{tabular}

eigenvalue to the performance index can be summarized as:

$$
\tau\left(\lambda_{i}\right)=\frac{1}{2} \eta_{i i}+\sum_{k=1, k \neq i}^{n} \eta_{i k}
$$

The absolute value $\rho_{i}=\left|\tau\left(\lambda_{i}\right)\right|$ is defined as the ranking index of $\lambda_{i}$ to the performance index.

\subsubsection{Dominant Eigenvalues Identification}

The rank indices are used to identify the critical eigenvalues of the system. The objective of the dynamic stability control is to improve the oscillation damping when the system is subjected to a ground fault disturbance. The performance index is composed of the speed deviations of the DGs. A large inertia synchronous generator represents the distribution substation, connecting the distribution line to the transmission system. Its speed deviation is very small and is ignored in the performance index.

The performance index is expressed as:

$$
J=\int_{0}^{\infty}\left(10 \omega_{\text {gas }}(t)^{2}+10 \omega_{\text {diesel }}(t)^{2}+\omega_{\text {wind }}(t)^{2}\right) d t
$$

The output weight matrix is $Q=\operatorname{diag}[10,10,1]$. The weights between the weights is to balance the inertia and size between the DGs. In the linearized system of the distribution system with DGs, A is $45 \times 45$, B is $45 \times 2$, and $\mathrm{C}$ is $3 \times 45$. The two inputs are control signals of wind turbine and SVC (see Figures $8.4 \& 8.5) u=\left(u_{w i d}, u_{s v c}\right)$, and three outputs are selected to calculate the ranking indices $y=\left(\omega_{\text {gas }}(t), \omega_{\text {diesel }}(t), \omega_{\text {wind }}(t)\right)$.

The dominant eigenvalues related to the oscillation can be selected out:

$\lambda_{26,27}=-3.22992 \pm 7.22492 \mathrm{i} ; \lambda_{28,29}=-1.124190 \pm 5.65105 \mathrm{i} ;$ and $\lambda_{31,32}=-0.139074 \pm$ 3.03003 i. 


\subsection{Controller Design}

\subsubsection{Multivariable Coordinated Controller}

A multi/single-input multi-output coordinated controller is to be designed using multiple inputs. The objectives of the controller are to adjust the reactive power output of the SVC, see Figure 9.1, and to adjust the real power of the wind turbine. In this case, the three outputs are the rotor speed deviations of the gas turbine DG, the diesel engine DG and the wind turbine DG.

Consider the linear system represented by equations (9.1-9.2). The output feedback which will be used to design a controller has the following form:

$$
u=-K y
$$

where three types of controllers are designed as:

1) three outputs and only SVC input (SIMO): $K_{s v c}=\left[\begin{array}{lll}k_{1} & k_{2} & k_{3}\end{array}\right]$;

2) three outputs and only wind turbine blade pitch input (SIMO): $K_{\text {wind }}=\left[\begin{array}{lll}k_{1} & k_{2} & k_{3}\end{array}\right]$;

3) three outputs and both SVC and wind turbine blade pitch input (MIMO):

$$
K=\left[\begin{array}{lll}
k_{11} & k_{12} & k_{13} \\
k_{21} & k_{22} & k_{23}
\end{array}\right] \text {. }
$$

The same output feedback optimal control algorithm as in Chapter 7 is implemented to compute the gain K. Define the performance index [30][72]:

$$
J=\int_{0}^{\infty}\left(x^{T} Q x+u^{T} R u\right) d t
$$

with $Q=Q^{T} \geq 0$ and $R=R^{T} \geq 0$. The optimal gain design equations are: $0=A_{c}^{T} M+M A_{c}+$ $C^{T} K^{T} R K C+Q, 0=S A_{c}^{T}+A_{c} S+X, K=R^{T} B^{T} M S C^{T}\left(C S C^{T}\right)^{-1}$, where $A c=A-B K C$, and $X=E\left\{x(0) x^{T}(0)\right\}$. The above equations are solved iteratively to obtain the gain matrix.

\subsubsection{Design Results}

The optimal gains are obtained through the optimal feedback control algorithm.

For the SVC only input:

$K=\left[\begin{array}{lll}-125.821 & -27.7039 & -13.5123\end{array}\right]$

and the closed-loop dominant eigenvalues are:

$\lambda_{26,27}=-3.78856 \pm 8.08721 \mathrm{i} ; \quad \lambda_{28,29}=-0.83015 \pm 5.65765 \mathrm{i} ; \quad \lambda_{31,32}=-1.1423 \pm 2.8423 \mathrm{i}$.

For the wind turbine pitch controller only input: 
$K=\left[\begin{array}{lll}-125.485 & -30.881 & -40.603\end{array}\right]$

and the closed-loop dominant eigenvalues are:

$\lambda_{26,27}=-3.2303 \pm 7.2248 \mathrm{i} ; \lambda_{28,29}=-1.1242 \pm 5.6510 \mathrm{i} ; \lambda_{31,32}=-0.1396 \pm 3.0302 \mathrm{i}$

For both SVC and wind turbine blade pitch input (MIMO):

$K=\left[\begin{array}{ccc}-392.058 & -53.824 & 66.084 \\ -50.170 & -6.413 & 2.758\end{array}\right]$

The closed loop dominant eigenvalues are:

$\lambda_{26,27}=-5.4015 \pm 8.2532 \mathrm{i} ; \lambda_{28,29}=-0.8428 \pm 5.8237 \mathrm{i} ; \lambda_{31,32}=-1.1476 \pm 2.7962 \mathrm{i}$

Comparing the three types of controllers and their closed-loop dominant eigenvalues, the controller with the single SVC is much more effective than the controller with the single wind turbine control in moving the dominant eigenvalues. Also, the closed-loop eigenvalues with two control inputs has the similar effects on $\lambda_{28,29}, \lambda_{31,32}$ as with the single SVC. For the sake of simpleness and effectiveness, the feedback controller $K_{s v c}$ is the best choice to improve the dynamic stability of the system.

\subsection{Nonlinear Simulation to Test Controller}

Nonlinear simulations are conducted to verify the controller $K_{s v c}$. The wind turbine induction generator is connected to the IEEE 13-node distribution system with existing DGs: the gas turbine synchronous generator and the diesel engine synchronous generator (see Figure 9.1). The induction motor is connected at bus 634 to represent the dynamic load. Two cases are simulated: one is with controller, the other is without controller. The following figures show the simulation results. The solid lines represent the simulation results with the controller and the dotted lines represent the case without controller.

$\mathrm{T}=2.0 \mathrm{~s}$, a ground fault occurs at bus 632 and is cleared after $0.25 \mathrm{~s}$.

Figure 9.2 shows the rotor speed of the gas turbine DG.

Figure 9.3 shows the rotor speed of the diesel engine DG.

Figure 9.4 shows the rotor speed of the wind turbine DG.

Figure 9.5 shows controlled susceptance of the SVC.

The nonlinear simulation illustrates that the controller through SVC can effectively improve the dynamic stability of the whole system. 


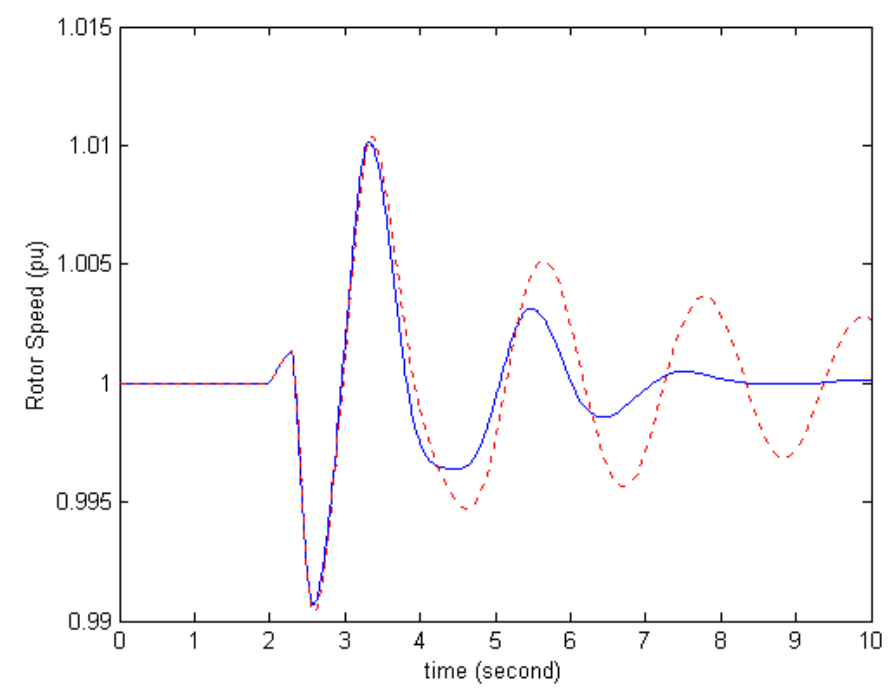

Figure 9.2: Rotor speed of the gas turbine DG with/without a controller of the SVC.

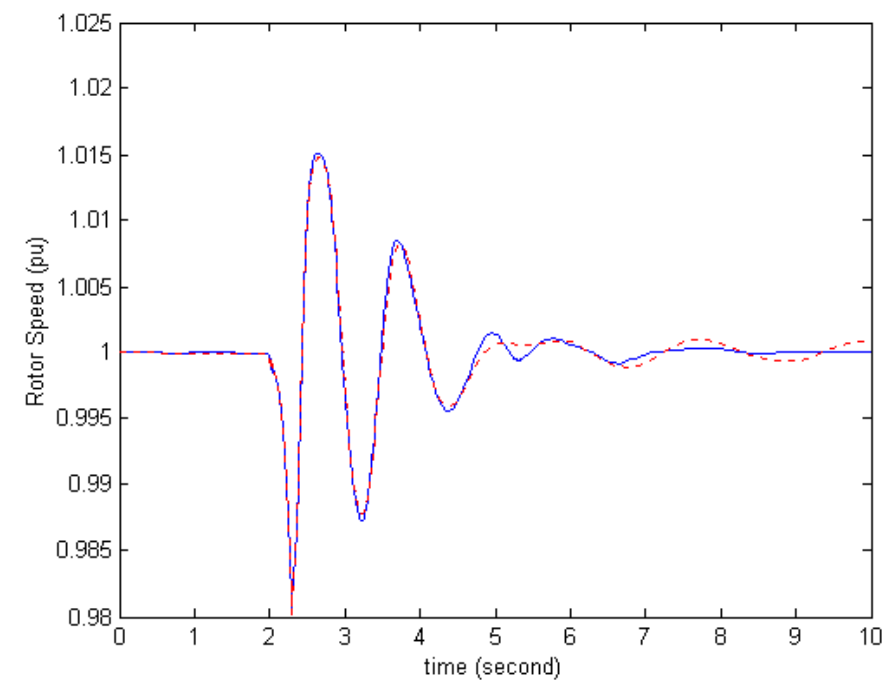

Figure 9.3: Rotor speed of the diesel engine DG with/without a controller of the SVC. 


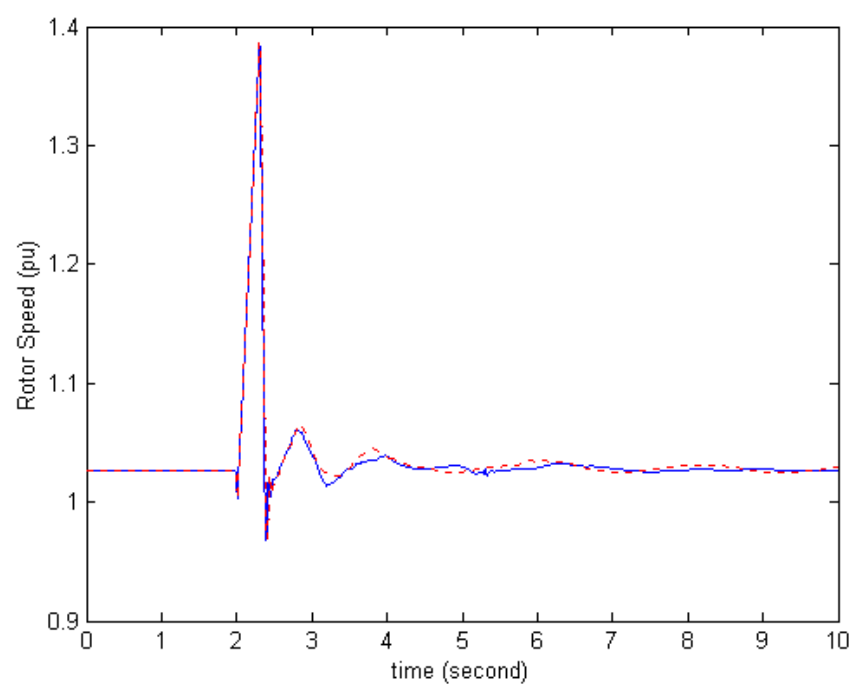

Figure 9.4: Rotor speed of the wind turbine DG with/without a controller of the SVC.

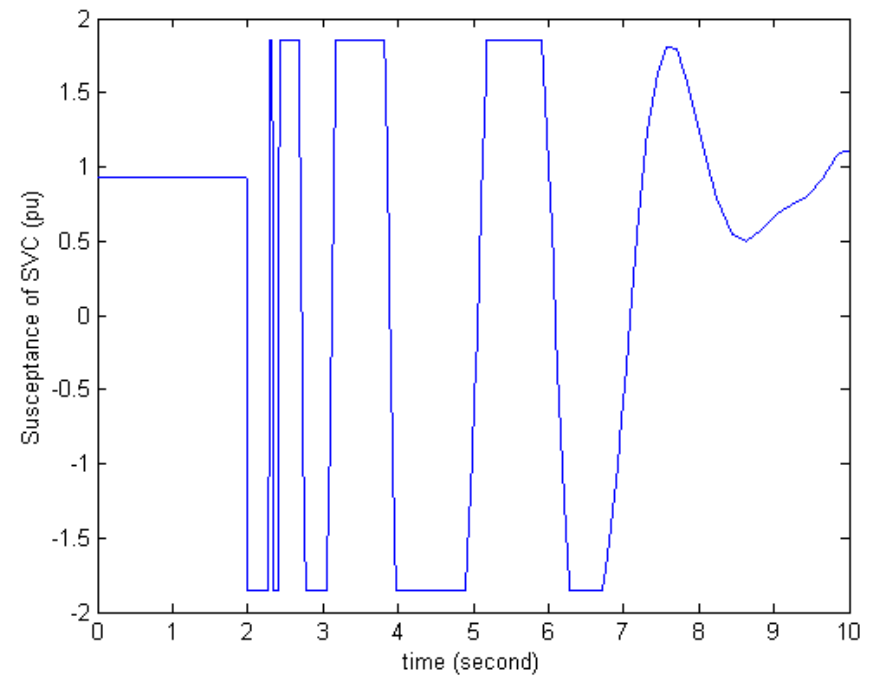

Figure 9.5: Diagram of the susceptance of SVC with controller. 


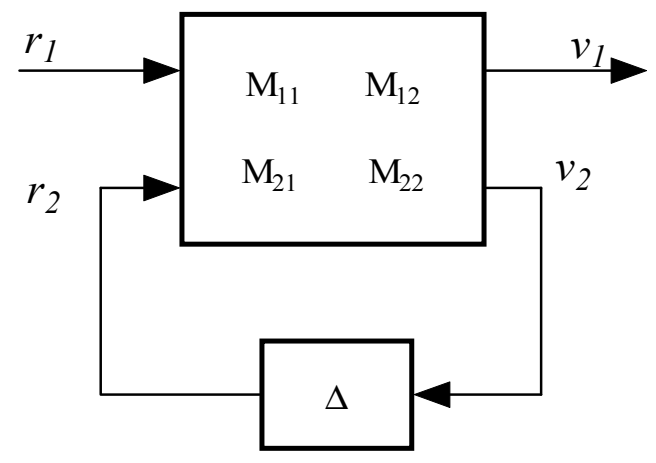

Figure 9.6: Diagram of the interconnected system.

\subsection{Controller Robustness Analysis}

The parameters, such as rotor resistance $\left(r_{r}\right)$, stator resistance $\left(r_{s}\right)$ and mutual reactance $\left(X_{M}\right)$, of a dynamic load vary when operating conditions change. To accommodate the variation of the parameters, the robustness of the controller is evaluated versus parameter uncertainty. This uncertainty is a structural uncertainty and can be represented by the linear fractional transformation (LFT).

\subsubsection{Representing Uncertainty}

Linear Fractional Transformations (LFTs) are used as a tool to represent uncertainty in matrices and systems.

An interconnected system is shown in Figure 9.6. The linear system plant $M$ can be fractionalized into $M_{11}, M_{12}, M_{21}$, and $M_{22}$. Suppose:

$$
\begin{aligned}
& v_{1}=M_{11} r_{1}+M_{12} r_{2} \\
& v_{2}=M_{21} r_{1}+M_{22} r_{2}
\end{aligned}
$$

and a matrix $\Delta$ relates $v_{2}$ to $r_{2}$, as $r_{2}=\Delta v_{2}$.

The relationship between $r_{1}$ and $v_{1}$ is:

$$
\begin{aligned}
v_{1} & =\left(M_{11}+M_{12} \Delta\left(I-M_{22} \Delta\right)^{-1} M_{21}\right) r_{1} \\
& =F_{L}(M, \Delta) r_{1}
\end{aligned}
$$

The notation $F_{L}$ indicates that the lower loop of $M$ is closed with $\Delta$. 


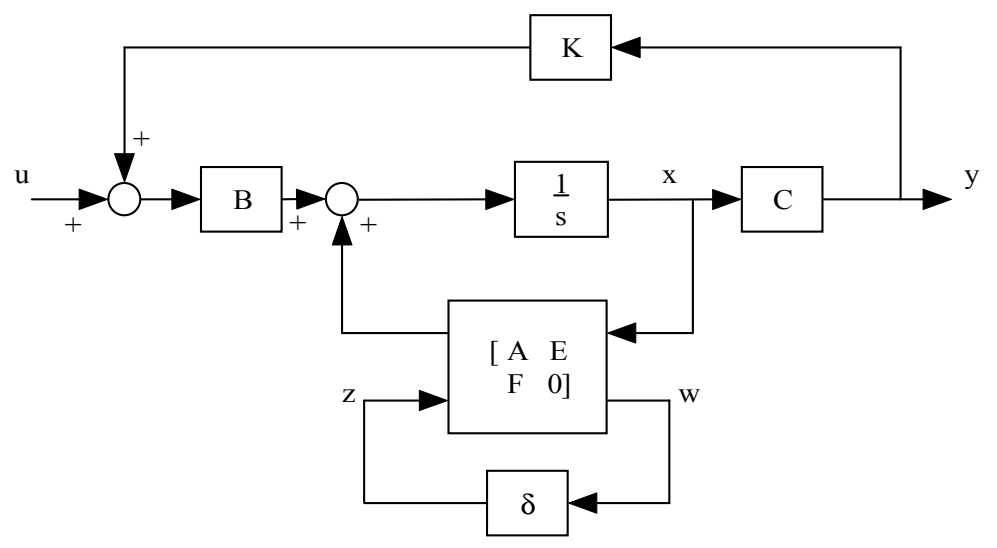

Figure 9.7: Diagram of the linear fraction transformation.

\subsubsection{Parametric Uncertainty}

For a linear system:

$$
\begin{gathered}
\dot{x}=A x+B u \\
y=C x
\end{gathered}
$$

$A$ is the coefficient matrix. Suppose there is an uncertainty of $A$ matrix and it can be written as:

$A=A 0+A^{\prime} \delta$

where $\delta$ varies within a range. $A^{\prime}$ is a coefficient matrix.

Let $A^{\prime}$ be factored as $A^{\prime}=E F$, where $E \in R^{n \times r}, F \in R^{r \times n}$

This is a linear fractional transformation (see Figure 9.7).

$A=F_{L}(G, \delta)$

where $G=\left[\begin{array}{ccc}A & B & E \\ C & D & 0 \\ F & 0 & 0\end{array}\right]$

The system of Figure 9.7 can be recast into a feedback loop system as Figure 9.8, where $M$ is a known linear system and $\delta$ is a structured perturbation.

The structure singular value $\mu$ of linear system $M$ with respect to the uncertainty set $\delta$ is used to analyze robust stability of the closed-loop system. At each frequency, the $\mu$ of $M(j \omega)$ is calculated with respect to the uncertainty set $\delta$.

The state space model of the interconnected system is 


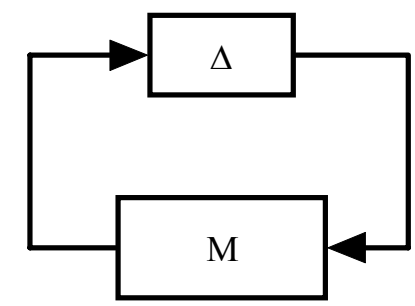

Figure 9.8: Digram of the feedback loop.

$$
\left[\begin{array}{c}
\dot{x} \\
y \\
z
\end{array}\right]=G\left[\begin{array}{l}
x \\
u \\
w
\end{array}\right]
$$

\subsubsection{Analyzing Robust Stability}

The structured singular value $\mu$ of $M$ with respect to the uncertainty set $\delta$ is used to analyze robust stability of the closed-loop system. At each frequency, $\mu$ of the matrix $M(j \omega)$ is calculated and the bounds for $\mu(M(j \omega))$ are computed, giving upper and lower bound functions of frequency. The bounds for $\mu_{\Delta}(M(j \omega))$ can be computed by MATLAB $\mu$ toolbox. If the peak of $\mu_{\Delta}(M(j \omega))$ is $\beta$, this means that for all perturbation matrices $\delta$ with the appropriate structure and satisfying $\max \left(\bar{\sigma}(\delta(j \omega))<\frac{1}{\beta}\right.$, then the perturbed system is stable where $\bar{\sigma}$ is the upper bound of $\delta(j \omega)$. If the varying region of $\delta$ is within 1 , then the system is robust stable when $\mu<1$. [137].

$\mu$ analysis has the following steps:

1. Cast the problem into the feedback loop diagram.

Let $r_{s_{-} \text {mot }}$ has a 0.005 change, $\mathrm{A}$ has a change of

$A-A_{0}=\left[\begin{array}{ccc}0_{26 \times 26} & 0_{26 \times 6} & 0_{26 \times 13} \\ 0_{6 \times 26} & A_{1} & 0_{6 \times 13} \\ 0_{13 \times 26} & 0_{13 \times 6} & 0_{13 \times 13}\end{array}\right]$

$$
A_{1}=\left[\begin{array}{cccccc}
0 & 40.142 & 0 & 16.994 & 40.775 & 0 \\
-40.142 & 0 & 0 & -40.775 & 16.994 & 0 \\
0 & 0 & 0 & 0 & 0 & 0 \\
0 & -41.666 & 0 & -17.638 & -42.323 & 0 \\
41.666 & 0 & 0 & 42.323 & -17.638 & 0 \\
0 & 0 & 0 & 0 & 0 & -58.539
\end{array}\right]
$$




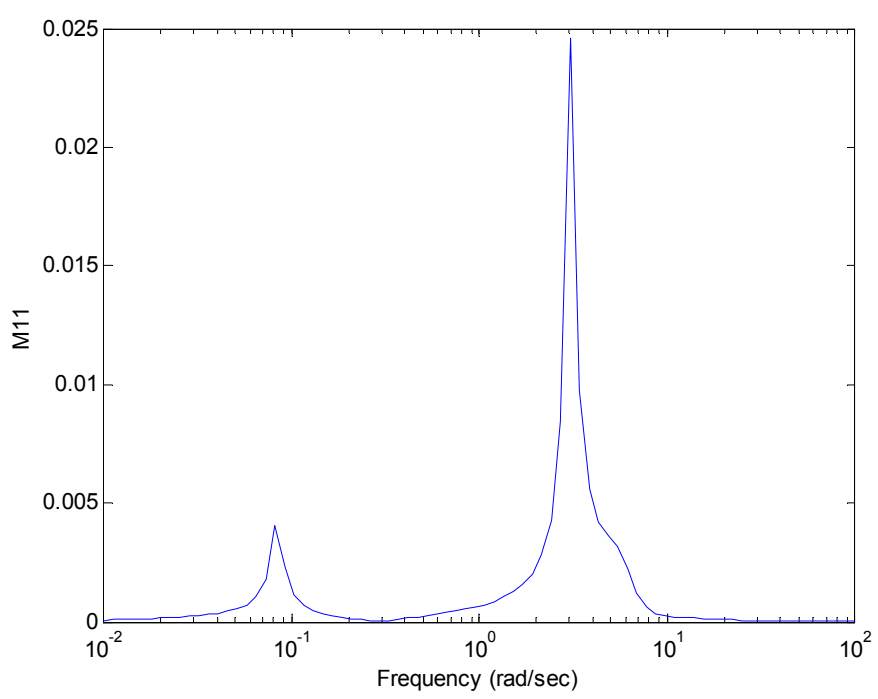

Figure 9.9: Frequency response of $M_{11}$.

$A_{1}$ can be factorized as $A_{1}=E_{1} \times F_{1}$, where

$$
E_{1}=\left[\begin{array}{ccc}
1 & 0 & 0 \\
0 & 1 & 0 \\
0 & 0 & 0 \\
-1.0378 & 0 & 0 \\
0 & -1.0378 & 0 \\
0 & 0 & 1
\end{array}\right] ; F_{1}=\left[\begin{array}{cccccc}
0 & 40.142 & 0 & 16.994 & 40.775 & 0 \\
-40.142 & 0 & 0 & -40.775 & 16.994 & 0 \\
0 & 0 & 0 & 0 & 0 & -58.539
\end{array}\right]
$$

Then $A=A_{0}+E \delta F$, where

$E=[z \operatorname{eros}(26,3) ; \quad E 1 ; z \operatorname{zeros}(13,3)]$;

$F=[z \operatorname{eros}(3,26) ; \quad F 1 ; z \operatorname{eros}(3,13)]$;

That means $r_{s_{-} m o t}$ 's uncertainty $\delta$ can be represented as: $\left[\begin{array}{ccc}\delta_{1} & 0 & 0 \\ 0 & \delta_{2} & 0 \\ 0 & 0 & \delta_{3}\end{array}\right]$

2. Calculate a frequency response of $M_{11}$.

3. Describe the structure of the perturbation of $\delta$

4. Run the Matlab command mu on frequency response to obtain the upper and lower bound of $\mu$.

The Matlab commands are shown in Appendix D. 


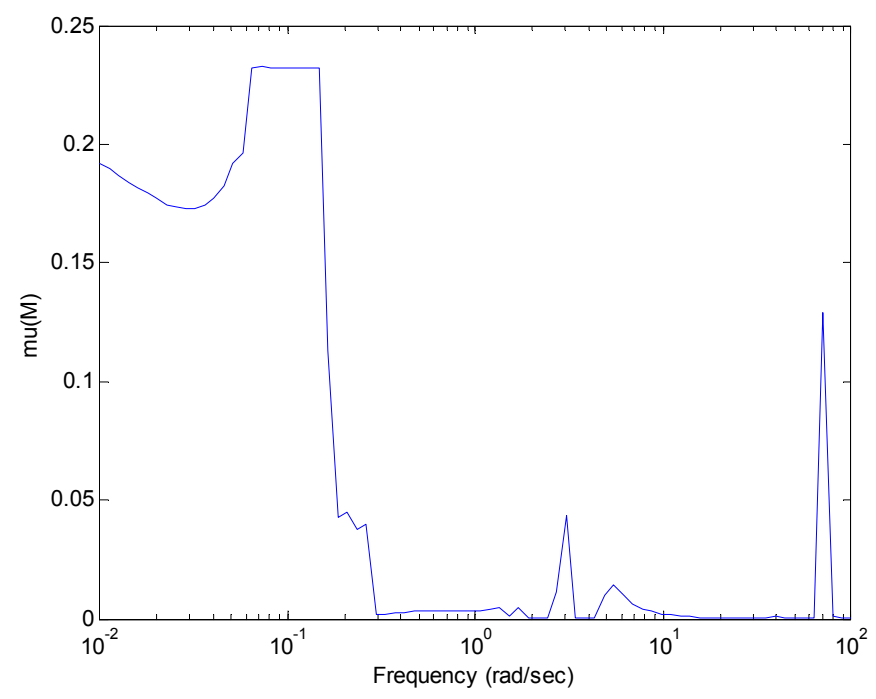

Figure 9.10: Diagram of $\mathrm{Mu}(\mu)$ as $r_{s_{-}}$mot has a 0.005 increase.

The frequency response of $M_{11}$ is shown as in Figure 9.9. Figure 9.10 shows the plot of the upper bound of singular value $\mu$. The upper bound never exceeds 1 which means when the $r_{s_{-} \text {mot }}$ has a 0.005 increase, the system is still stable.

With the value of $r_{s_{-} \text {mot }}$ having a 0.02 increase, the system is still stable since the upper bound of singular value $\mu$ doesn't exceed 1, as shown in Figure 9.11.

The third case is that the three parameters $\left(r_{s}, r_{r}, X_{M}\right)$ of the dynamic loads all increase $0.02 \mathrm{pu}$ without feedback controller $K_{s v c}$. Figure 9.12 shows the $\mu$ upper bound has exceeded the 1.0. So the system is unstable.

\subsection{Simulation Results of Robustness Analysis}

To verify the analysis results of the controller $\left(K_{s v c}\right)$ robustness, the nonlinear simulation is conducted with the changed parameters of the dynamic loads. $T=2.0 \mathrm{~s}$, a ground fault occurs at bus 632 and is cleared after $0.25 \mathrm{~s}$. When the parameters $\left(r_{s}, r_{r}, X_{M}\right)$ of dynamic loads increase 0.02(pu), Figures 9.13-9.16 illustrate the simulation results with/without controller. In Figures 9.13-9.16, the solid lines represent the simulation results with the controller and the dotted lines represent the results without controller. Figure 9.16 shows the susceptance of the SVC with the controller. 


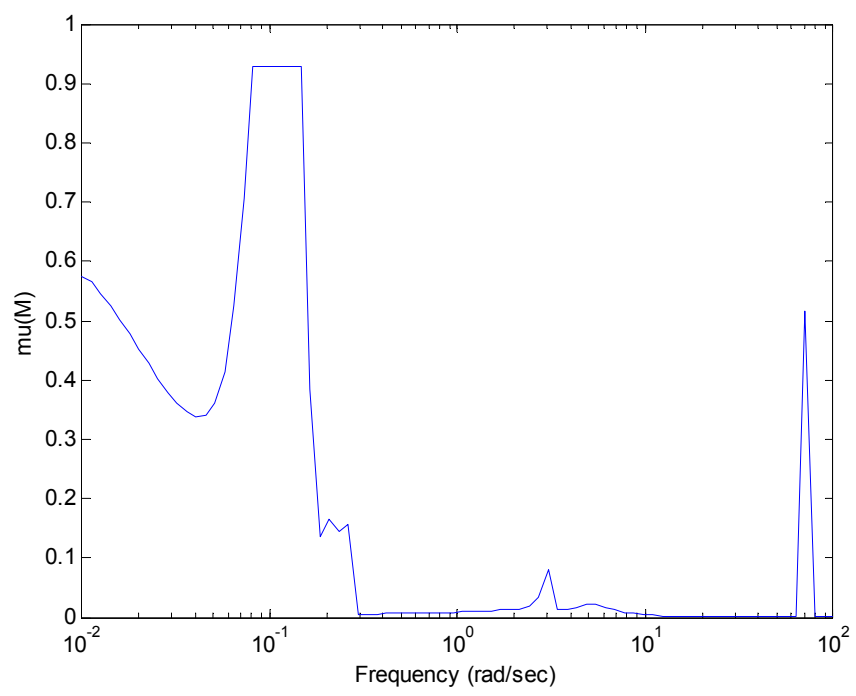

Figure 9.11: Diagram of $\mathrm{Mu}(\mu)$ as $r_{s_{-} \text {mot }}$ has a 0.02 increase.

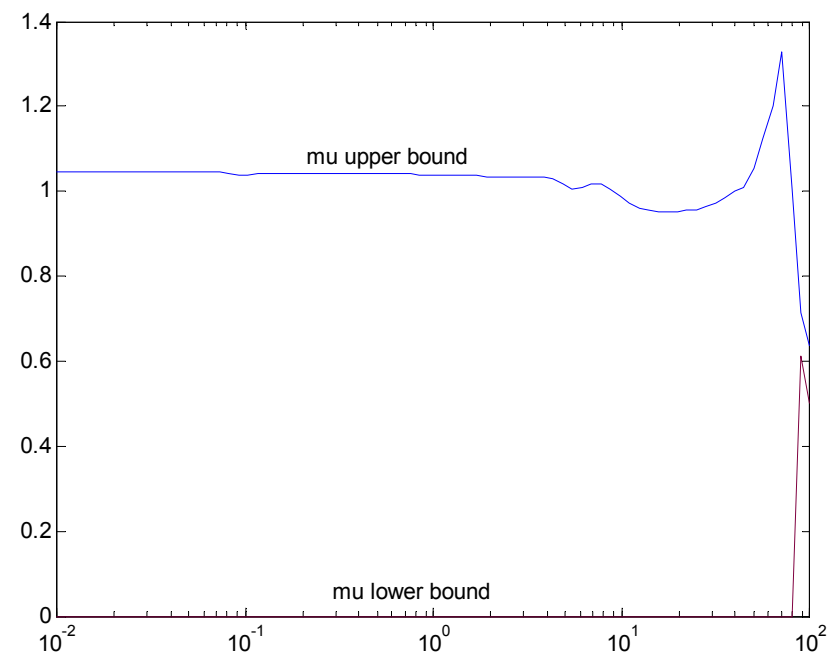

Figure 9.12: $\mu$ upper bound and lower bound of system with the three parameters $\left(r_{s}, r_{r}, X_{M}\right)$ of dynamic loads increasing 0.02pu. (X axis: frequency ( $\mathrm{rad} / \mathrm{sec})$ ) 


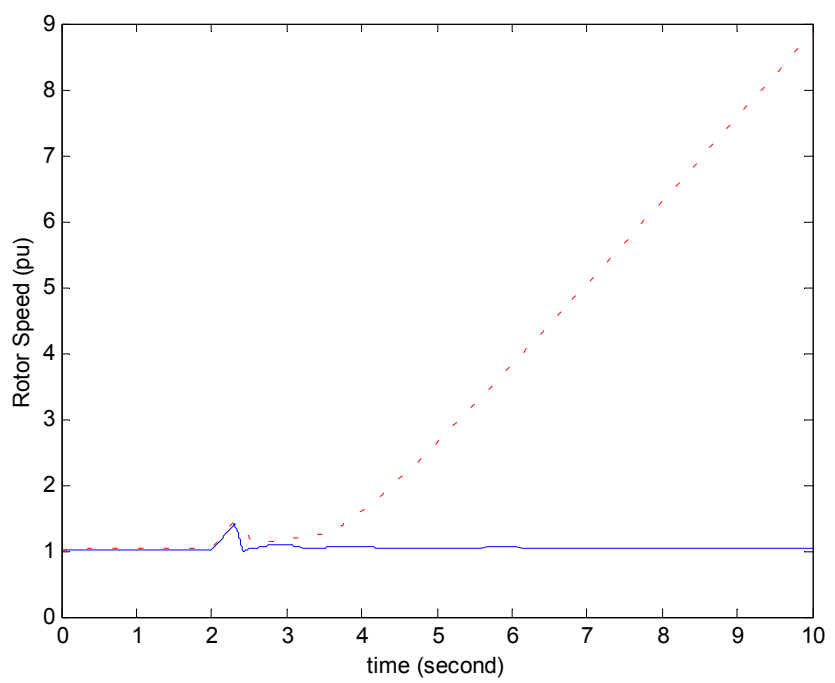

Figure 9.13: Rotor speed of the wind turbine DG with modified parameters of dynamic loads when a fault occurs at bus 632 (dotted line: without controller, solid line: with controller).

In Figure 9.13, the rotor speed of the wind turbine DG shows that the system loses the stability without the controller when the dynamic loads' parameters are changed. When the controller is added to the system, the system remains stable.

In Figures. 9.14 and 9.15, the rotor speeds of the gas turbine and diesel engine DGs show that the controller can improve the oscillation damping of the entire system as well.

The $\mu$ analysis and the nonlinear simulations show that the coordinated controller is robust in improving the dynamic stability of the system over a relatively large parameter range in the dynamic loads.

\subsection{Summary}

A robust controller is designed for the wind turbine DG to improve the oscillation damping of the system. The SVC and the blade pitch are considered as the control inputs. The wind turbine DG model is connected to the IEEE-13 node distribution system together with existing gas turbine and diesel engine DGs. A linearized model is obtained for the specific operation condition. The critical eigenvalues are identified via the ranking indices technique. Output feedback optimal control is implemented to assign the critical eigenvalues. The design results show that the SVC controller is better than the blade pitch due to SVC's rapid response characteristic. The resulting controller's 


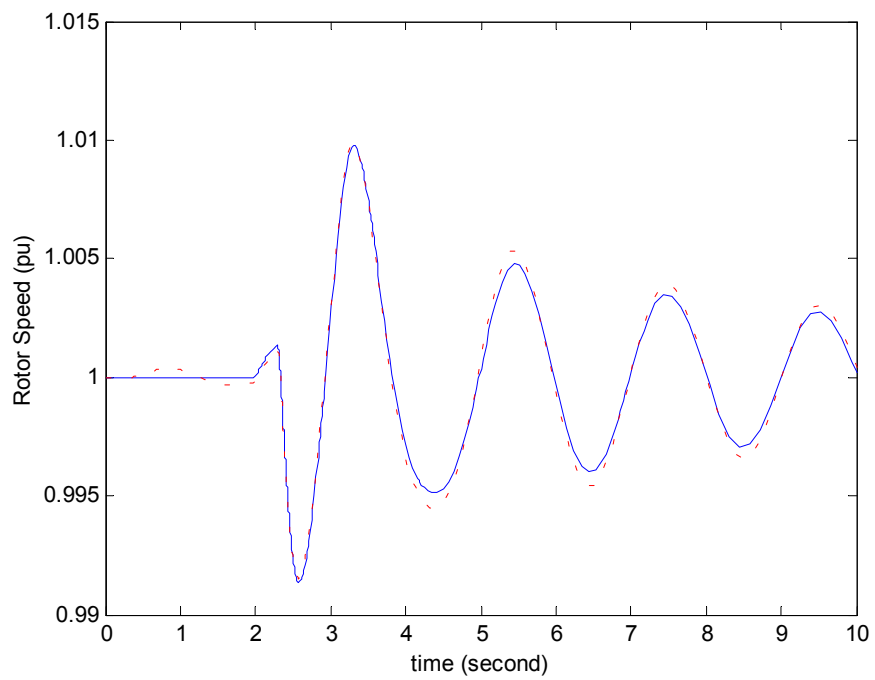

Figure 9.14: Rotor speed of the gas turbine DG with modified parameters of dynamic loads when a fault occurs at bus 632 (dotted line: without controller, solid line: with controller).

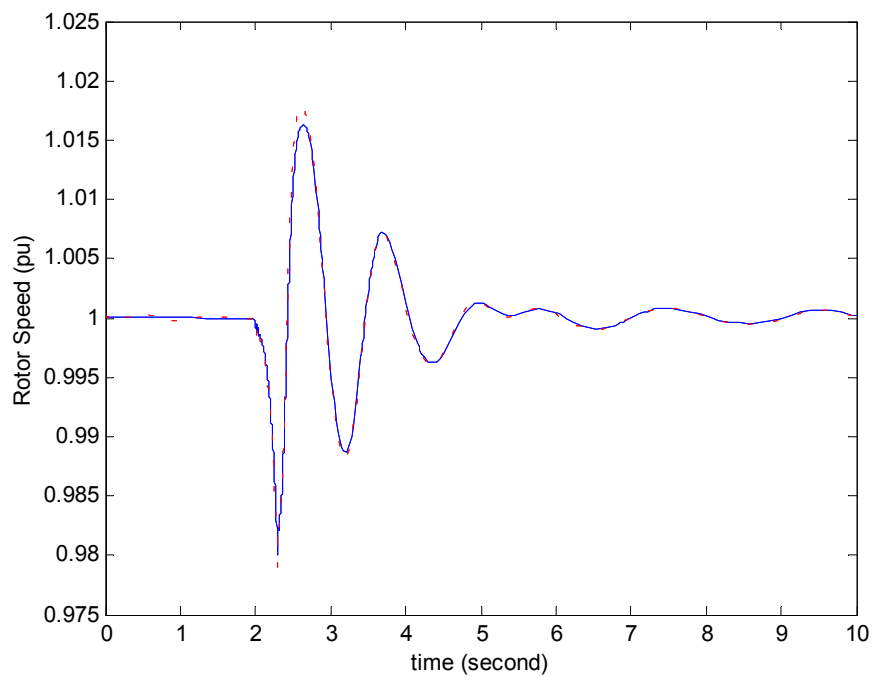

Figure 9.15: Rotor speed of the diesel engine DG with modified parameters of dynamic loads when a fault occurs at bus 632 (dotted line: without controller, solid line: with controller). 


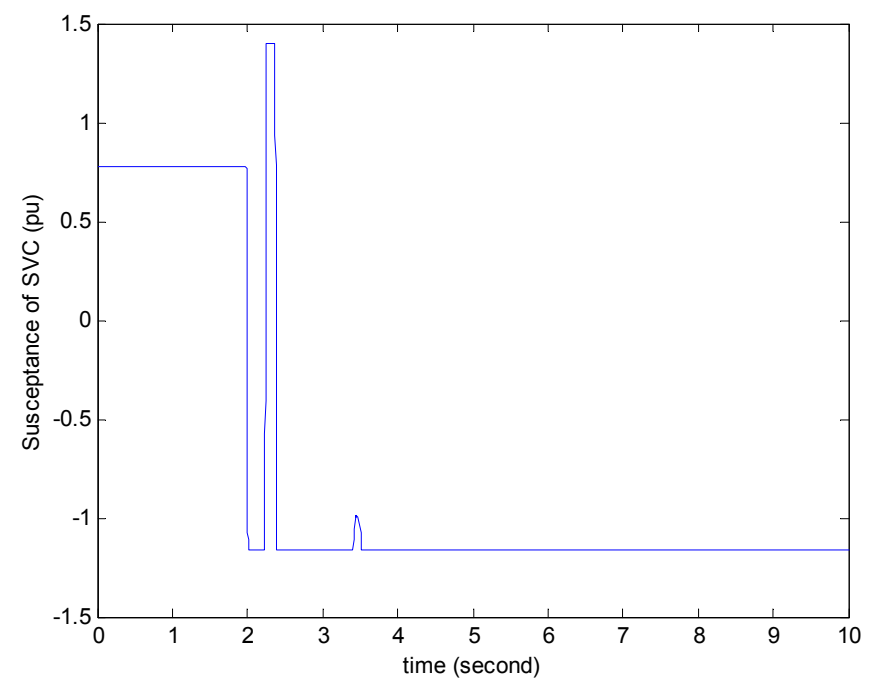

Figure 9.16: Susceptance of SVC with a controller when a fault occurs at bus 632 .

robustness is evaluated over a relatively large range of parameter uncertainty in the dynamic loads. The nonlinear simulation results illustrate the controller via the SVC can improve the dynamic stability of the system. 


\section{Chapter 10}

\section{Coordinated Operation of Multiple Types of DGs}

\subsection{Introduction}

In the future, more and more small distributed power generation units will be connected to the grid. Figure 10.1 shows a power distribution system with multiple types of distributed generations (DGs): gas turbine, diesel engine, wind turbine and fuel cell DGs.

In this system, all the four DG models which were developed in the previous chapters are connected to the system together. The interaction between DGs and the impacts of DGs on the dynamic stability of the grid will be evaluated.

Usually, in power distribution systems the distances between the ends of feeders and the substation is relatively short and it is practical to implement a centralized control for the entire system. A centralized dynamic stability controller will be used to improve the dynamic stability

The coordinated control through the rapid fuel cell inverter and the SVC of wind turbine DG are studied. The controller uses the multi-variable input to assign the eigenvalues.

The dynamic responses of the distribution system with different real power penetration of DGs are investigated to evaluate the coordinated controller.

\subsection{Interaction of DGs}

A distribution system with multi-type DGs is shown in Figure 10.1. Compared to the studied system in Chapter 9, a new DG, fuel cell power plant, is added to the system. As an example to 


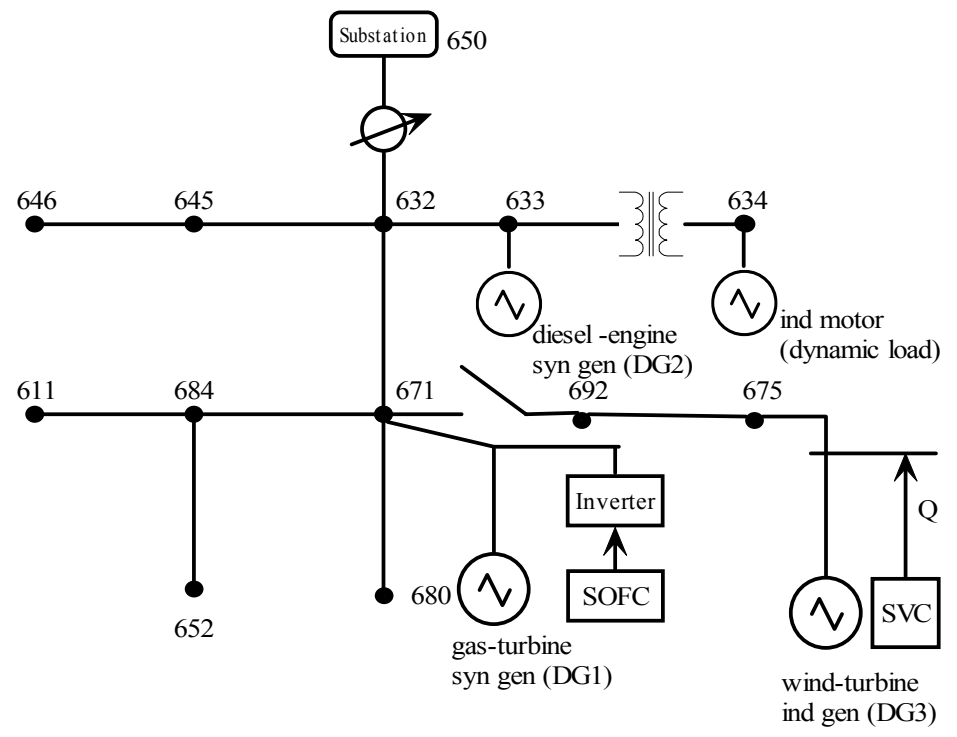

Figure 10.1: Diagram of IEEE-13 node power distribution system with multi-type of DGs to investigate the coordinated operation.

evaluate the interaction between DGs, the impact of the solid oxide fuel cell (SOFC) power plant on the linearized model and nonlinear dynamics is investigated in this section.

To evaluate the interaction of the DGs, the initial conditions and the parameters of the gas turbine, diesel engine and wind turbine DGs remain same as before (see Figure 9.1). The initial conditions are: $S_{\text {base }}=4.0 M V A, V_{\text {base }}=4.16 \mathrm{kV} ; S_{\text {gas }}=0.1969+j 0.0098 ; S_{\text {diesel }}=$ $0.1031+j 0.0666 ; S_{\text {wind }}=0.1054+j 0.0852 ; S_{\text {sofc }}=0.0656+j 0.0125$.

The eigenvalues of the linearized model are listed in Table 10.1. This linearized system is an open-loop system.

Comparing the eigenvalues in the Tables 9.1 and 10.1, the fuel cell can improve the damping of the critical eigenvalues: $\lambda_{26,27}, \lambda_{28,29}, \lambda_{31,32}$.

Dynamic simulation is also done to evaluate the interaction between DGs. The cases were done under the condition that a three-phase ground fault occurs at bus 675 and is cleared after 0.3 second. Figures 10.2-10.4 demonstrate the impact of the newly connected SOFC power plant on the dynamic stability of the system with existing DGs. In Figures 10.2-10.4, the dotted lines represent the case without SOFC and the solid lines represent the case with SOFC.

The interaction between the SOFC power plant and other DGs illustrate the newly connected DGs, such as fuel cell, with appropriate location can effectively improve the dynamic stability 
Table 10.1: Eigenvalues of the linearized coordinated system.

\begin{tabular}{|c|c|c|c|}
\hline NO. & Eigenvalues & NO. & Eigenvalues \\
\hline \hline$\lambda_{1,2}$ & $-1183.28 \pm 3428.95 \mathrm{i}$ & $\lambda_{3,4}$ & $-173.90 \pm 726.476 \mathrm{i}$ \\
\hline$\lambda_{5,6}$ & $-141.752 \pm 373.315 \mathrm{i}$ & $\lambda_{7,8}$ & $-32.2028 \pm 407.022 \mathrm{i}$ \\
\hline$\lambda_{9}$ & -108.595 & $\lambda_{10,11}$ & $-32.9941 \pm 69.2469 \mathrm{i}$ \\
\hline$\lambda_{12,13}$ & $-22.9056 \pm 64.3907 \mathrm{i}$ & $\lambda_{14,15}$ & $-27.8289 \pm 49.5015 \mathrm{i}$ \\
\hline$\lambda_{16}$ & -59.6960 & $\lambda_{17}$ & -52.5702 \\
\hline$\lambda_{18}$ & -32.3336 & $\lambda_{19}$ & -31.79003 \\
\hline$\lambda_{20}$ & -30.6929 & $\lambda_{21}$ & -25.4924 \\
\hline$\lambda_{22,23}$ & $-20.0614 \pm 1.0993 \mathrm{i}$ & $\lambda_{24,25}$ & $-5.2006 \pm 13.8649 \mathrm{i}$ \\
\hline$\lambda_{26,27}$ & $-3.3811 \pm 6.9442 \mathrm{i}$ & $\lambda_{28,29}$ & $-1.2872 \pm 5.8021 \mathrm{i}$ \\
\hline$\lambda_{30}$ & -5.2437 & $\lambda_{31,32}$ & $-0.1741 \pm 3.1382 \mathrm{i}$ \\
\hline$\lambda_{33}$ & -2.3094 & $\lambda_{34}$ & -1.1225 \\
\hline$\lambda_{35}$ & -0.64663 & $\lambda_{36}$ & -0.3014 \\
\hline$\lambda_{37,38}$ & $-0.004056 \pm 0.08155 \mathrm{i}$ & $\lambda_{39}$ & -0.19316 \\
\hline$\lambda_{40}$ & -16.4759 & $\lambda_{41}$ & -170.340 \\
\hline$\lambda_{42}$ & -220.357 & $\lambda_{43}$ & -259.913 \\
\hline$\lambda_{44}$ & -20.000 & $\lambda_{45}$ & -249.506 \\
\hline$\lambda_{46}$ & -292.339 & $\lambda_{47}$ & -0.3436 \\
\hline$\lambda_{48}$ & -0.03831 & $\lambda_{49}$ & -0.01277 \\
\hline$\lambda_{50}$ & -0.4958 & $\lambda_{51}$ & -0.4546 \\
\hline$\lambda_{52}$ & -4061.736 & & \\
\hline & & & \\
\hline
\end{tabular}

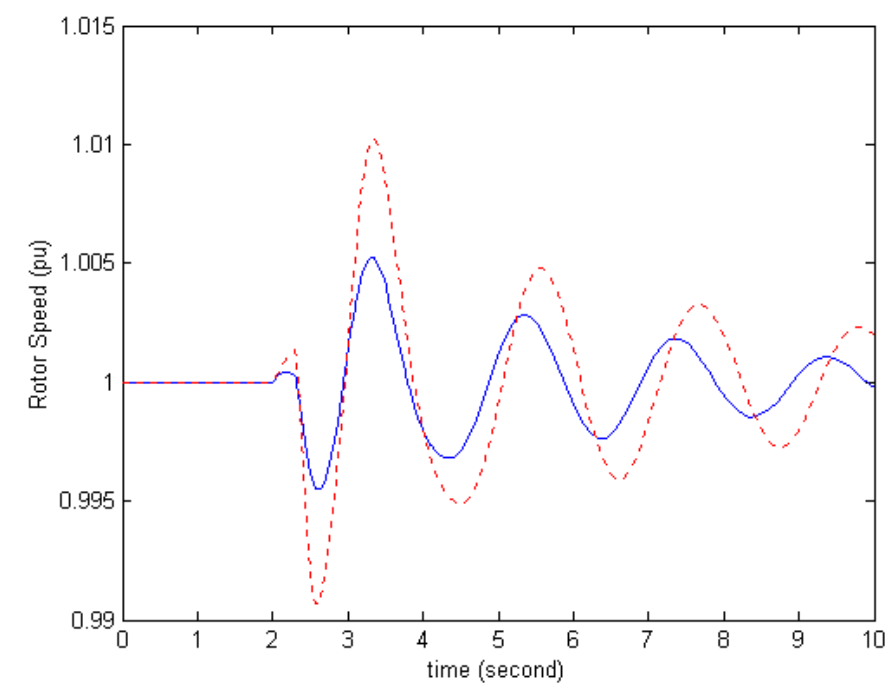

Figure 10.2: Rotor speed of the gas turbine DG with/without SOFC connected. 


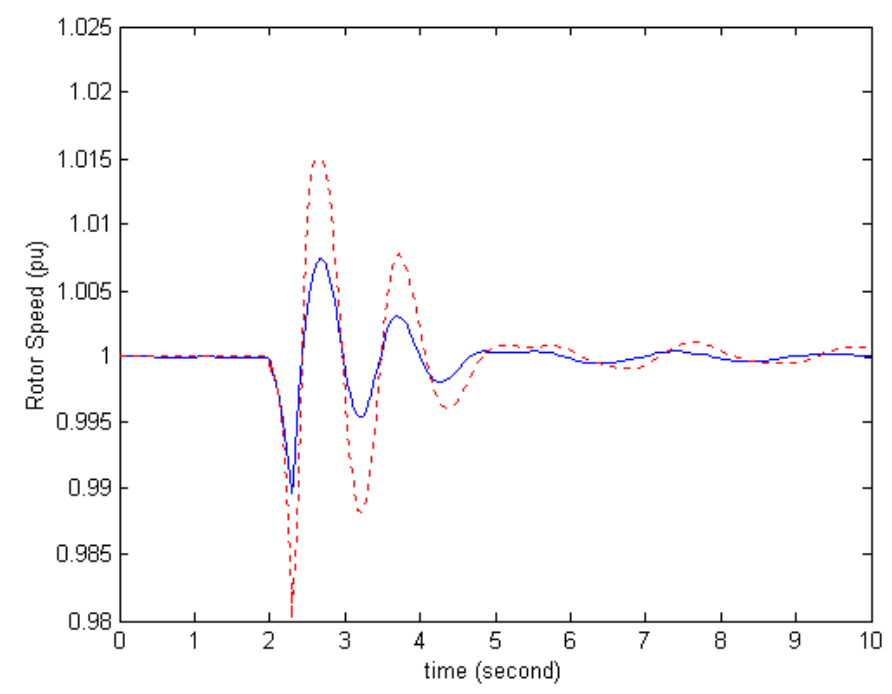

Figure 10.3: Rotor speed of the diesel engine DG with/without SOFC connected.

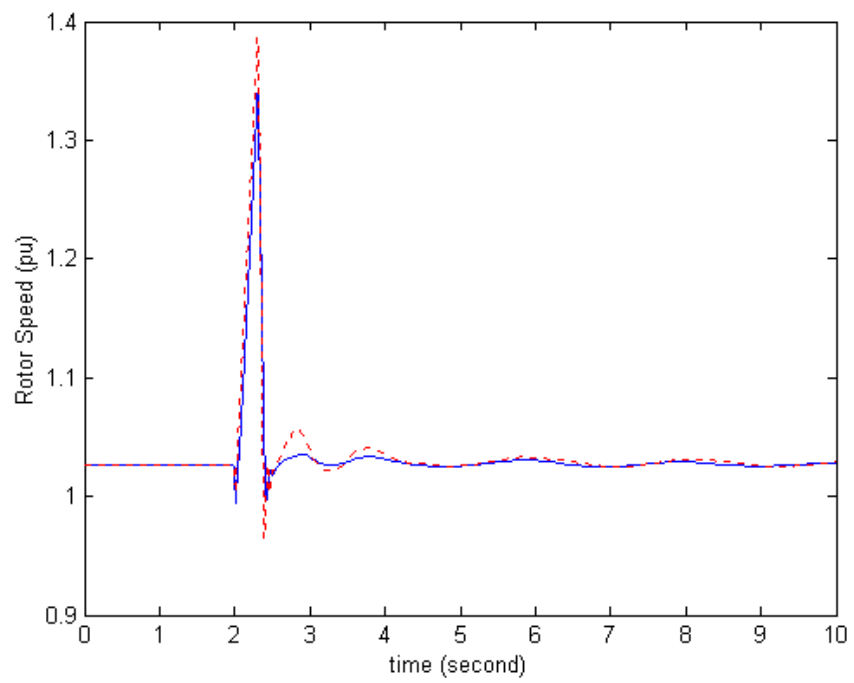

Figure 10.4: Rotor speed of the wind turbine DG with/without SOFC connected. 
Table 10.2: Critical Eigenvalues of the open linearized system with multi-DGs.

\begin{tabular}{|c|c|c|}
\hline NO. & Eigenvalues & Ranking Indices $\left(\times 10^{-3}\right)$ \\
\hline \hline$\lambda_{7,8}$ & $-32.2028 \pm 407.022 \mathrm{i}$ & 0.02165 \\
\hline$\lambda_{10,11}$ & $-32.9941 \pm 69.2469 \mathrm{i}$ & 0.02022 \\
\hline$\lambda_{14,15}$ & $-27.8289 \pm 49.5015 \mathrm{i}$ & 0.16772 \\
\hline$\lambda_{26,27}$ & $-3.3811 \pm 6.9442 \mathrm{i}$ & 0.03633 \\
\hline$\lambda_{31,32}$ & $-0.1741 \pm 3.1382 \mathrm{i}$ & 0.07266 \\
\hline
\end{tabular}

of the whole system.

\subsection{Critical Eigenvalues and Controller Design}

The critical eigenvalues are identified with the optimal algorithm. The definition and optimal algorithm of critical eigenvalues has been presented in the previous chapter. The performance index of the critical eigenvalues is expressed as:

$$
J=\int_{0}^{\infty}\left(10 \omega_{\text {gas }}(t)^{2}+10 \omega_{\text {diesel }}(t)^{2}+\omega_{\text {wind }}(t)^{2}\right) d t
$$

The critical eigenvalues and their ranking indices are listed in Table 10.2.

A coordinated control is then designed with the output feedback optimal algorithm. Here, the outputs are the rotor speed deviations of the gas turbine, diesel engine and wind turbine DGs: $y=\left[\Delta \omega_{\text {gas }}, \Delta \omega_{\text {diesel }}, \Delta \omega_{\text {wind }}\right]$. The control inputs are reactive power set point of wind turbine (SVC), and the real power set point of the fuel cell. Then the gain matrix is:

$$
\begin{aligned}
& {\left[\begin{array}{l}
u_{s v c} \\
u_{f c}
\end{array}\right]=-K_{\text {coor }} \times y} \\
& K_{\text {coor }}=\left[\begin{array}{lll}
k_{11} & k_{12} & k_{13} \\
k_{21} & k_{22} & k_{23}
\end{array}\right] .
\end{aligned}
$$

Before designing the optimal gain $K_{\text {coor }}$, the optimal gains for the SVC and fuel cell are designed separately. Then the controller with only SVC is: $u_{s v c}=-K_{s v c} \times y, K_{s v c}=\left[\begin{array}{lll}k_{1} & k_{2} & k_{3}\end{array}\right]$; and the controller with only fuel cell is: $u_{f c}=-K_{f c} \times y, K_{f c}=\left[\begin{array}{lll}k_{1} & k_{2} & k_{3}\end{array}\right]$.

The the gains are calculated by the optimal algorithm:

$$
\begin{aligned}
& K_{s v c}=\left[\begin{array}{lll}
-212.702 & -30.844 & -31.4423
\end{array}\right] ; \\
& K_{f c}=\left[\begin{array}{lll}
-302.584 & -89.061 & 34.324
\end{array}\right] ;
\end{aligned}
$$


Table 10.3: Critical Eigenvalues of the multi-DGs system with different controllers.

\begin{tabular}{|c|c|c|c|c|}
\hline NO. & Open loop & with $K_{\text {coor }}$ & with $K_{s v c}$ & with $K_{f c}$ \\
\hline \hline$\lambda_{7,8}$ & $-32.203 \pm 407.022 \mathrm{i}$ & $-54.056 \pm 417.315 \mathrm{i}$ & $-37.332 \pm 398.893 \mathrm{i}$ & $-36.820 \pm 409.775 \mathrm{i}$ \\
\hline$\lambda_{10,11}$ & $-32.994 \pm 69.247 \mathrm{i}$ & $-33.538 \pm 71.210 \mathrm{i}$ & $-30.942 \pm 68.420 \mathrm{i}$ & $-33.874 \pm 70.286 \mathrm{i}$ \\
\hline$\lambda_{14,15}$ & $-27.829 \pm 49.502 \mathrm{i}$ & $-22.943 \pm 64.371 \mathrm{i}$ & $-22.903 \pm 64.390 \mathrm{i}$ & $-4.634 \pm 52.893 \mathrm{i}$ \\
\hline$\lambda_{26,27}$ & $-3.381 \pm 6.944 \mathrm{i}$ & $-4.887 \pm 7.940 \mathrm{i}$ & $-4.588 \pm 7.927 \mathrm{i}$ & $-3.973 \pm 7.096 \mathrm{i}$ \\
\hline$\lambda_{31,32}$ & $-0.174 \pm 3.138 \mathrm{i}$ & $-3.175 \pm 1.973 \mathrm{i}$ & $-1.209 \pm 3.092 \mathrm{i}$ & $-1.630 \pm 3.062 \mathrm{i}$ \\
\hline
\end{tabular}

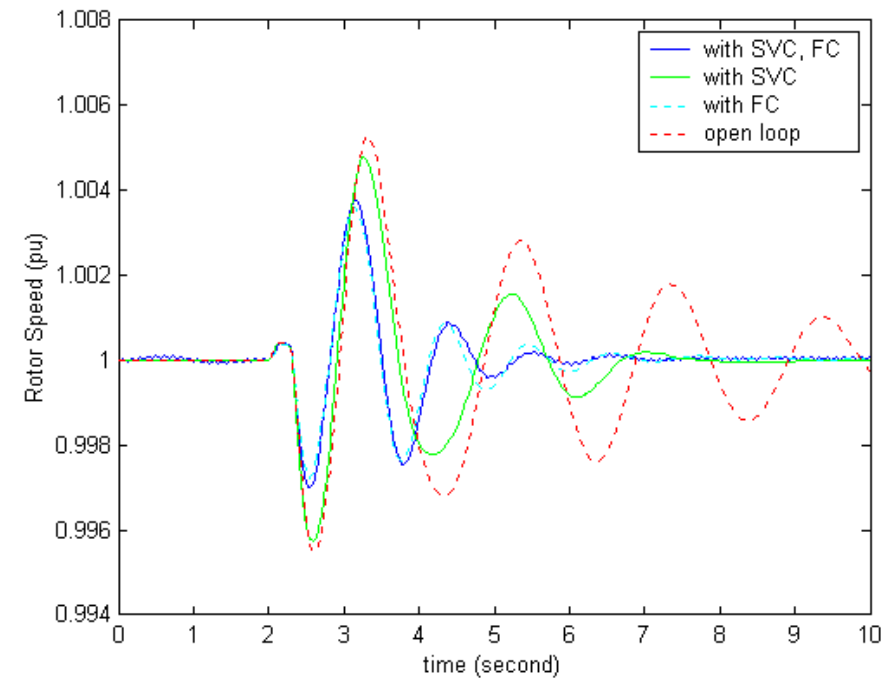

Figure 10.5: Rotor speeds of the gas turbine DG with different controllers.

$$
K_{\text {coor }}=\left[\begin{array}{ccc}
-49.810 & 4.496 & -31.307 \\
-98.915 & -41.147 & 28.461
\end{array}\right] \text {. }
$$

The critical eigenvalues with three types of controllers are listed in Table 10.3.

The dynamic simulation results with/without coordinated controller are shown in Figures (10.5-10.7). The rotor speeds of gas turbine with only SVC or fuel cell are compared in Figure 10.5. The results show that the coordinated controller is more effective to improve the dynamic stability of the system with multi-DGs. 


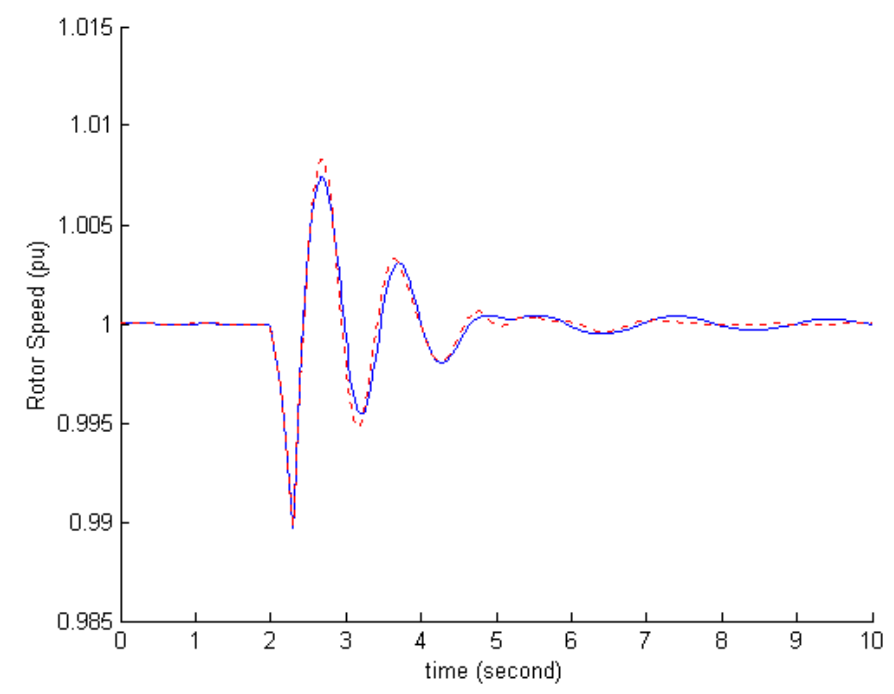

Figure 10.6: Rotor speed of diesel engine DG with/without coordinated controller.

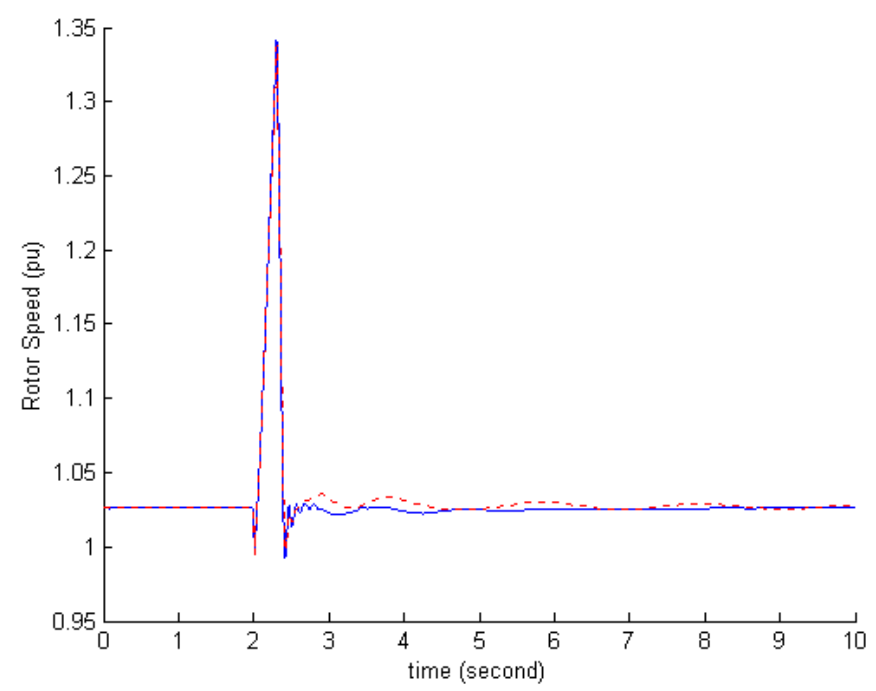

Figure 10.7: Rotor speed of the wind turbine DG with/without coordinated controller. 
Table 10.4: Different real power penetration of the multi-DGs.

\begin{tabular}{|c|c|c|c|}
\hline NO. & case 1 & case 2 & case 3 \\
\hline \hline$S_{\text {sub }}$ & $0.4388+0.3365 \mathrm{i}$ & $0.0467+0.2912 \mathrm{i}$ & $0.4865+0.3061 \mathrm{i}$ \\
\hline$S_{\text {gas }}$ & $0.1969+0.0098 \mathrm{i}$ & $0.3937+0.2844 \mathrm{i}$ & $0.1000-0.0304 \mathrm{i}$ \\
\hline$S_{\text {diesel }}$ & $0.1031 .+0.0666 \mathrm{i}$ & $0.2063+0.1152 \mathrm{i}$ & $0.1000+0.0265 \mathrm{i}$ \\
\hline$S_{\text {wind }}$ & $0.1054+0.0852 \mathrm{i}$ & $0.1054+0.0852 \mathrm{i}$ & $0.1054+0.0852 \mathrm{i}$ \\
\hline$S_{f c}$ & $0.0656+0.0125 \mathrm{i}$ & $0.2625+0.05 \mathrm{i}$ & $0.1000+0.0750 \mathrm{i}$ \\
\hline
\end{tabular}

Table 10.5: Critical eigenvalues of the open linearized systems with different real power penetration.

\begin{tabular}{|c|c|c|c|}
\hline NO. & case 1 & case 2 & case 3 \\
\hline \hline$\lambda_{7,8}$ & $-32.2028 \pm 407.022 \mathrm{i}$ & $-32.1309 \pm 406.909 \mathrm{i}$ & $-32.206 \pm 407.062 \mathrm{i}$ \\
\hline$\lambda_{10,11}$ & $-32.9941 \pm 69.2469 \mathrm{i}$ & $-33.1477 \pm 69.074 \mathrm{i}$ & $-32.948 \pm 69.3406 \mathrm{i}$ \\
\hline$\lambda_{14,15}$ & $-27.8289 \pm 49.5015 \mathrm{i}$ & $-27.974 \pm 48.079 \mathrm{i}$ & $-27.745 \pm 50.130 \mathrm{i}$ \\
\hline$\lambda_{26,27}$ & $-3.3811 \pm 6.9442 \mathrm{i}$ & $-3.322 \pm 6.486 \mathrm{i}$ & $-3.289 \pm 7.002 \mathrm{i}$ \\
\hline$\lambda_{31,32}$ & $-0.1741 \pm 3.1382 \mathrm{i}$ & $-0.118 \pm 2.749 \mathrm{i}$ & $-0.1603 \pm 3.032 \mathrm{i}$ \\
\hline
\end{tabular}

\subsection{Impacts of Different Real Power Penetrations}

To deepen the investigation of the coordinated operation of the multi-DGs, the impacts of the different real power penetrations of each DG on the dynamic stability are studied in this section.

Three cases are evaluated (see Table 10.4). Case 1 has the normal real power penetration and the controller $K_{s v c}$ is designed under this condition. In Case 2, the real power penetration of each DG is heavy and almost all the loads are supplied by the four DGs. The DGs' real power penetrations of Case 3 is near Case 1.

The open-loop system eigenvalues of the three cases are listed in Table 10.5.

To investigate the robustness of the feedback controller, the closed-loop system eigenvalues of different real-power penetration are calculated (see Table 10.6). In case 2, the The closed loop eigenvalues show that the designed controller is suitable for the lighter real power penetration of DGs. But the controller is not suitable for the heavier penetrations.

The feedback controller of the case 2 with heavy real power penetration is redesigned. The gain of the case 2 is: $K_{f c_{-} c a s e 2}=\left[\begin{array}{lll}-92.264 & -24.030 & 10.013\end{array}\right]$. The new critical closedloop system eigenvalues of the case 2 are:

$$
\begin{array}{ll}
\lambda_{7,8}=-37.214 \pm 410.224 \mathrm{i} ; & \lambda_{10,11}=-3.400 \pm 70.102 \mathrm{i} \\
\lambda_{14,15}=-4.914 \pm 50.987 \mathrm{i} ; & \lambda_{26,27}=-3.756 \pm 6.260 \mathrm{i}
\end{array}
$$


Table 10.6: Critical Eigenvalues of the multi-DGs system with different controllers.

\begin{tabular}{|c|c|c|c|c|}
\hline NO. & Open loop & case 1 & case 2 & case 3 \\
\hline \hline$\lambda_{7,8}$ & $-32.203 \pm 407.022 \mathrm{i}$ & $-36.820 \pm 409.775 \mathrm{i}$ & $-37.639 \pm 410.538 \mathrm{i}$ & $-36.426 \pm 409.558 \mathrm{i}$ \\
\hline$\lambda_{10,11}$ & $-32.994 \pm 69.247 \mathrm{i}$ & $-33.874 \pm 70.286 \mathrm{i}$ & $-33.992 \pm 70.166 \mathrm{i}$ & $-33.818 \pm 70.361 \mathrm{i}$ \\
\hline$\lambda_{14,15}$ & $-27.829 \pm 49.502 \mathrm{i}$ & $-4.634 \pm 52.893 \mathrm{i}$ & $-3.116 \pm 51.115 \mathrm{i}$ & $-5.249 \pm 53.314 \mathrm{i}$ \\
\hline$\lambda_{26,27}$ & $-3.381 \pm 6.944 \mathrm{i}$ & $-3.973 \pm 7.096 \mathrm{i}$ & $-3.799 \pm 6.146 \mathrm{i}$ & $-3.859 \pm 7.183 \mathrm{i}$ \\
\hline$\lambda_{31,32}$ & $-0.174 \pm 3.138 \mathrm{i}$ & $-1.630 \pm 3.062 \mathrm{i}$ & $-0.663 \pm 2.896 \mathrm{i}$ & $-1.421 \pm 3.060 \mathrm{i}$ \\
\hline
\end{tabular}

$\lambda_{31,32}=-0.658 \pm 2.892 \mathrm{i}$

The closed-loop eigenvalues of the redesigned controller are close to eigenvalues of cases in Table 10.6. The controller design procedure illustrates that the optimal feedback control is robust with respect to different real power penetration of the DGs. The closed-loop eigenvalues show controller $K_{s v c}$ can improve the dynamic stability for the operating point with heavy real power penetration of DGs.

\subsection{Summary}

The coordinated operation of the distribution system with multi-DGs is studied in this chapter. The study shows that the appropriate new DG location can improve the dynamic stability of the whole system. The coordinated controller is designed with the optimal output feedback algorithm. The output feedback controller is robust with respect to the different real power penetration of each DG. 


\section{Chapter 11}

\section{Three-Phase Distribution System Study}

\subsection{Introduction}

One challenge of the distributed generations (DGs) research is the three-phase unbalanced characteristics. In this chapter, the three-phase distribution system with DGs was studied using the Power System Blockset (PSB). In power distribution system, dynamic stability control is raised as a new topic while the DGs are widely used. Thyristor controlled braking resistor (TCBR) is used to improve the damping of the distribution system with DGS.

In this chapter, the gas turbine, diesel engine and excitation system are connected to the full-order synchronous generator in PSB. The IEEE-13 node system is simulated in detail. The three-phase load flows with/without DGs are solved. The three-phase dynamic simulation in PSB is done to obtain the results.

The objectives of this chapter are:

1. to simulate the three-phase TCBR and IEEE-13 node feeder in PSB;

2. to combine the models with the PSB's synchronous generator;

3. to solve the three-phase power flow to set the initial condition of each electric component;

4. to implement the variable structure control(VSC) to control the TCBR to improve the dynamic stability. 


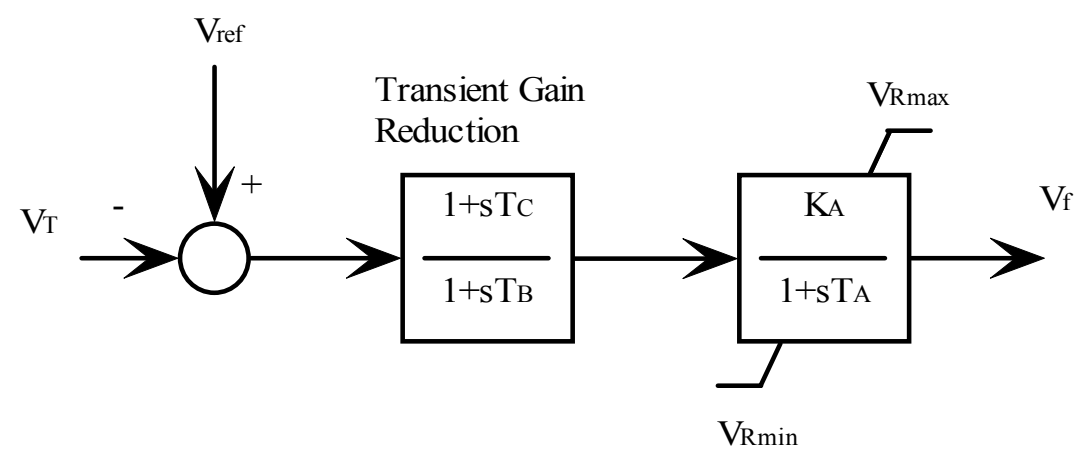

Figure 11.1: Diagram of the excitation system.

\subsection{System Models}

The excitation system of the gas turbine and diesel engine DGs is presented in this chapter. The TCBR model and its impedance characteristics are also studied.

\subsubsection{Excitation System Model}

The same excitation system model is used for both the gas turbine DG and the diesel engine DG. Figure 11.1 shows the excitation system model.

In Figure 11.1, the input signal is the terminal voltage of the synchronous generator and the output is the exciter voltage $V_{f}$. In the system computation, the field voltage of the synchronous machine is controlled by the exciter output " $V_{f}$ ".

\subsubsection{Thyristor Controlled Braking Resistor (TCBR)}

TCBR is a shunt controllable resistor. The local control input signals are frequency deviation and voltage.

The dynamic process during turning on the thyristor for each phase can be expressed as in Figure 11.2. In Figure 11.2, equivalent voltage $e$ keeps constant during each turn on process, and $Z_{\Sigma}$ is the equivalent impedance of the distribution system.

During the logic turn on process, the voltage sag is very large without the reactance $x_{0}$. 


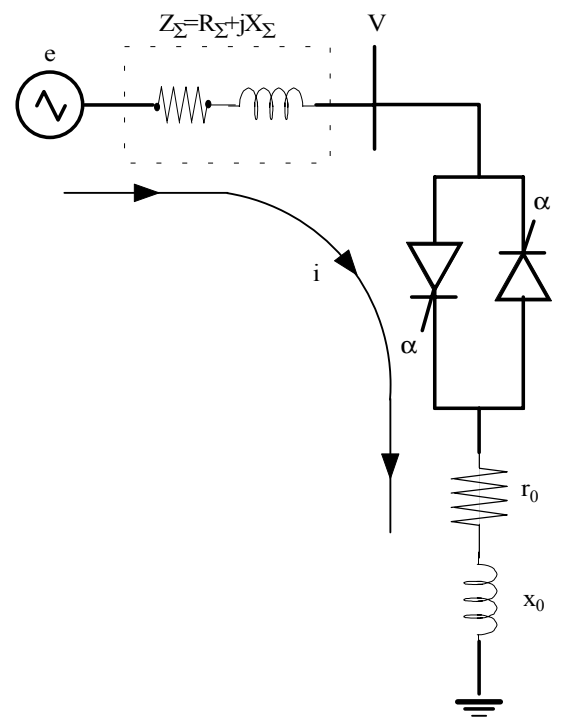

Figure 11.2: Equivalent circuit of one phase TCBR.

The average impedance of each phase is [128]:

$$
\begin{aligned}
\gamma-\sin \gamma & =\frac{\pi z_{0}}{z} \\
& =\frac{\pi\left(r_{0}+j x_{0}\right)}{r+j x}
\end{aligned}
$$

where

$\gamma=2(\pi-\alpha+\theta)$ is the conducting angle;

$\alpha$ is the firing angle;

$\theta$ is delay angle due to the reactance;

$z_{0}=r_{0}+j x_{0}$ is the fixed impedance of the TCBR;

$z=r+j x$ is the actual braking impedance, and is controlled by the firing angle $\alpha$;

To avoid switching failure of the thyristor, the constraint on the firing angle is:

$$
0<\alpha<150^{\circ}
$$

Thus the actual braking impedance $z$ of the TCBR is limited as:

$$
z_{0}<z<\infty
$$




\subsection{Controller Design}

A variable structure controller is designed based on the analysis of the distribution system with multi-machine. In this multi-machine, the reference machine, substation, is very large.

\subsubsection{Basic Concepts of Variable Structure Controller}

In general, a nonlinear power system model can be expressed as[128]:

$$
\dot{X}=A(X)+B(X) \mathbf{U}
$$

where $X=\left(X_{1}, X_{2}, \ldots, X_{n-1}, X_{n}\right)^{\mathbf{T}}$ is the the state variable vector. $A(X)$ and $B(X)$ are the nonlinear vector function. To design a VSC based controller, the state space is divided into two parts by the linear switching hyperplane. The hyperplane is defined as:

$$
S=C^{T} X=0
$$

where $C$ is a constant vector. Then,

$$
\begin{aligned}
\dot{S} & =C^{T} \dot{X} \\
& =C^{T} A(X)+C^{T} B(X) U
\end{aligned}
$$

The reaching model or reaching phase is that the state will move toward and reach the sliding surface. To get asymptote system, a reaching condition [40] should be satisfied:

$$
S \dot{S}<0
$$

\subsubsection{Dynamic Braking Control Strategy}

In the multi-machine system, the swing equation can be expressed as:

$$
M_{i} p^{2} \delta_{i}+D_{i} p \delta_{i}=P_{m i}-P_{e i}(t)-P_{b i}(t)
$$

where $M_{i}, D_{i}, P_{m i}, P_{e i}, P_{b i}$, are the inertia and damping constants, input power, electrical output power and the power absorbed by braking resistor. Neglect the damping term and select one machine (substation) as the reference machine, the swing equation becomes: 


$$
\begin{aligned}
p^{2} \delta_{i r}= & \frac{1}{M_{i}}\left(P_{m i}-P_{e i}(t)\right)-\frac{1}{M_{r}}\left(P_{m r}-P_{e r}(t)\right) \\
& -\frac{1}{M_{i}} P_{b i}(t)+\frac{1}{M_{r}} P_{b r}(t)
\end{aligned}
$$

where $\delta_{i r}=\delta_{i}-\delta_{r}$. Since the inertia of the substation is very big, $\frac{1}{M_{r}}=0$, the reference terms in 11.10 can be neglected.

To improve the damping of the oscillation of the system, the performance index is chosen:

$$
J=\min \left(\int_{t_{0}}^{t_{f}} d t\right)
$$

From the conclusion in [97] [98], the optimal control strategy of TCBR in multi-machine system is expressed as:

$$
u(t)=\left\{\begin{array}{cc}
1(\text { on }) & \text { if } \quad \Sigma_{b}>0 \\
0(\text { off }) & \text { if } \quad \Sigma_{b}<0
\end{array}\right.
$$

where $\Sigma_{b}$ is the control area. Since the substation can be considered as an infinite bus, the frequency deviation of substation can be ignored. The control can be simplified as:

$$
u(t)=\left\{\begin{array}{cc}
1(\text { on }) & \text { if } \Delta \omega_{i}>0 \\
0(\text { off }) & \text { if } \Delta \omega_{i}<0
\end{array}\right.
$$

\subsubsection{Three-Phase Control Strategy}

The three-phase one-line diagram of TCBR and its control structure is shown in Figure 11.3 [81]. The wye-connected TCBR is controlled on or off by the control unit. The net available energy for acceleration of the DG during a disturbance is absorbed by the TCBR.

In Figure 11.3, the "limits unit" sets the varying range of firing angle $\alpha$ to avoid switching failure of the thyristor. The output of "block unit" will be "1", either when $\Delta \omega$ is negative or when $|\Delta \omega|$ is very small.

A three-phase TCBR has different capacities to absorb the real power depending on the firing angle of each thyristor. The series connected $x_{0}$ is a small size reactance to prevent the large current while the thyristor is turned on. 


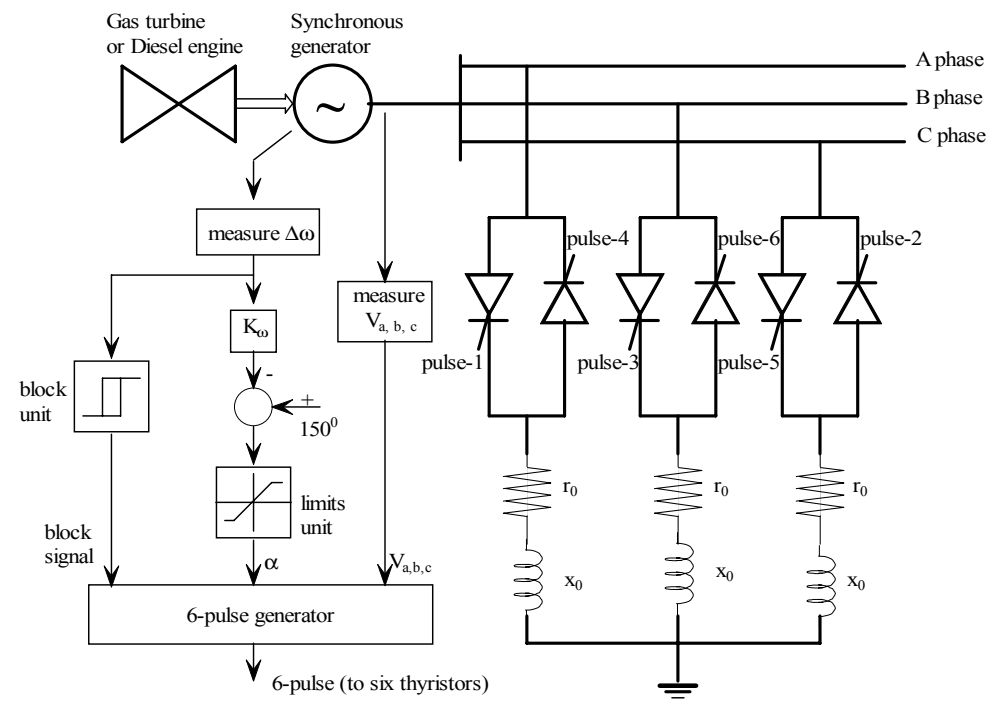

Figure 11.3: Diagram of the three-phase TCBR and its control unit.

\subsection{Test System of TCBR}

The IEEE 13 node test feeder [24] is used as the test system to investigate the dynamic characteristics of the distribution system with two DGs and the effectiveness of the TCBR on the stability of distribution system. Figure 11.4 shows the test system with the two DGs. In the test, the connected transmission system is simulated as $138 \mathrm{kV}$ system, thus the substation transformer is $138 \mathrm{kv} / 4.16 \mathrm{kv}$.

In Figure 11.4, the two DGs are shown connected to the distribution system. DG1 is a gas turbine generator and connected at bus 671. DG2 is a diesel engine generator and connected to bus 633. One TCBR is installed at the terminal of DG1. Three-phase power flow is studied first.

Three-phase power flow is computed before the dynamic simulation and the three-phase voltages and currents of each line are shown in Table I, when no DGs are connected to the distribution system. Table II shows the three-phase voltages and currents of each line with the DGs connected. In Table I and II, the voltage (V) and current (I) are measured at the second end of each line. For example, the voltage and current of "Line 650-632" are measured at bus 632 . 


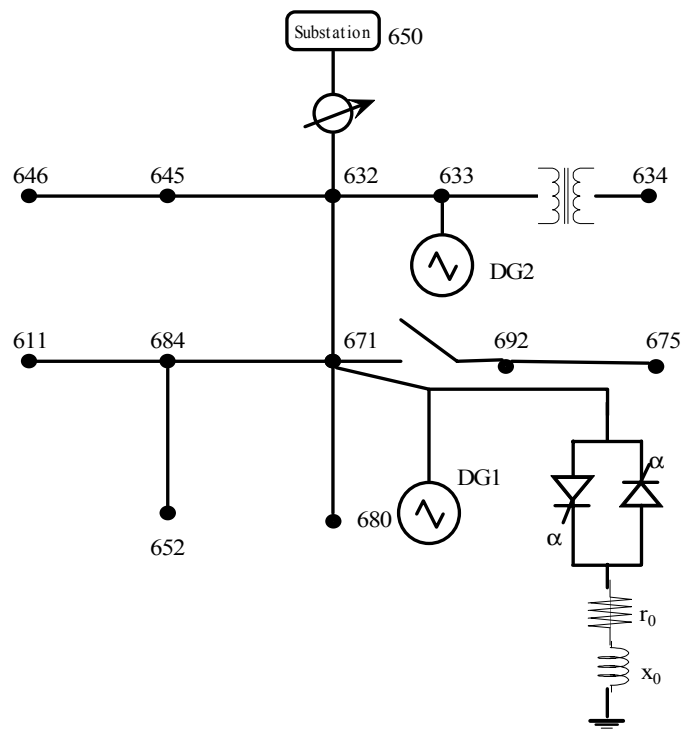

Figure 11.4: Diagram of IEEE-13 node distribution system with multi-DG and TCBR.

Table 11.1: Three-phase current and voltage of distribution system with DG.

\begin{tabular}{|c|c|c|c|c|c|c|}
\hline Line & V-Phase A & V-Phase B & V-Phase C & I-Phase A & I-Phase B & I-Phase C \\
\hline $650-632$ & $2458 \angle 0.65^{\circ}$ & $2515 \angle-118.21^{\circ}$ & $2405 \angle 120.83^{\circ}$ & $403.2 \angle-49.54^{\circ}$ & $306.3 \angle-174.50^{\circ}$ & $444.6 \angle 70.00^{\circ}$ \\
\hline $632-633$ & $2445 \angle 0.86^{\circ}$ & $2504 \angle-118.00^{\circ}$ & $2395 \angle 121.14^{\circ}$ & $162.3 \angle-84.98^{\circ}$ & $154.6 \angle 150.68^{\circ}$ & $154.6 \angle 29.06^{\circ}$ \\
\hline $633-634$ & $270.1 \angle 0.98^{\circ}$ & $279.4 \angle-117.82^{\circ}$ & $267.1 \angle 121.32^{\circ}$ & $682.8 \angle-33.52^{\circ}$ & $545.6 \angle-154.69^{\circ}$ & $521.8 \angle 84.45^{\circ}$ \\
\hline $632-645$ & 0 & $2512 \angle-118.52^{\circ}$ & $2407 \angle 120.35^{\circ}$ & 0 & $149.4 \angle-139.68^{\circ}$ & $64.27 \angle 61.33^{\circ}$ \\
\hline $645-646$ & 0 & $2516 \angle-118.60^{\circ}$ & $2406 \angle 120.24^{\circ}$ & 0 & $65.56 \angle-119.13^{\circ}$ & $65.16 \angle 60.65^{\circ}$ \\
\hline $632-671$ & $2409 \angle-1.20^{\circ}$ & $2547 \angle-117.77^{\circ}$ & $2327 \angle 120.27^{\circ}$ & $0283 \angle-31.63^{\circ}$ & $36.19 \angle 158.31^{\circ}$ & $233.7 \angle 91.99^{\circ}$ \\
\hline $671-692$ & $2409 \angle-1.20^{\circ}$ & $2547 \angle-117.77^{\circ}$ & $2327 \angle 120.27^{\circ}$ & $224.7 \angle-13.22^{\circ}$ & $70.69 \angle-53.30^{\circ}$ & $170 \angle 115.38^{\circ}$ \\
\hline $692-675$ & $2400 \angle-1.67^{\circ}$ & $2558 \angle-117.79^{\circ}$ & $2316 \angle 120.23^{\circ}$ & $201.5 \angle 0.02^{\circ}$ & $70.69 \angle-53.30^{\circ}$ & $116.3 \angle 118.59^{\circ}$ \\
\hline $671-684$ & $2407 \angle-1.29^{\circ}$ & 0 & $2321 \angle 120.16^{\circ}$ & $53.23 \angle-0.70^{\circ}$ & 0 & $68.76 \angle 127.79^{\circ}$ \\
\hline $684-611$ & 0 & 0 & $2316 \angle 120.01^{\circ}$ & 0 & 0 & $68.8 \angle 127.21^{\circ}$ \\
\hline $684-652$ & $2393 \angle-1.31^{\circ}$ & 0 & 0 & $63.97 \angle-35.21^{\circ}$ & 0 & 0 \\
\hline DG1 & $2423 \angle-0.20^{\circ}$ & $2550 \angle-116.77^{\circ}$ & $2338 \angle 121.44^{\circ}$ & $192.6 \angle 7.87^{\circ}$ & $192.6 \angle-112.13^{\circ}$ & $192.6 \angle 127.87^{\circ}$ \\
\hline DG2 & $2425 \angle 1.40^{\circ}$ & $2478 \angle-117.62^{\circ}$ & $2370 \angle 121.70^{\circ}$ & $136.7 \angle 68.15^{\circ}$ & $136.7 \angle-51.85^{\circ}$ & $136.7 \angle-171.85^{\circ}$ \\
\hline
\end{tabular}




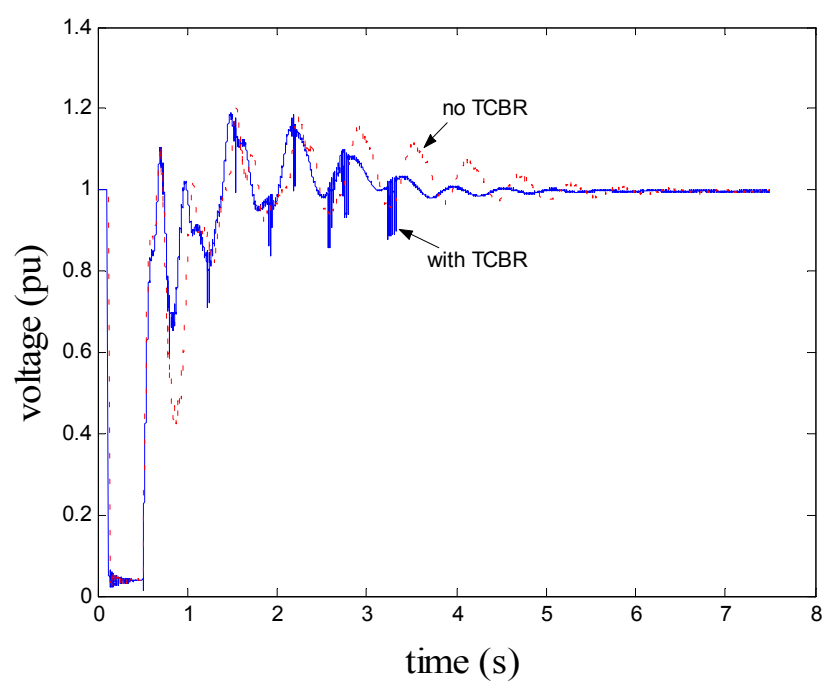

Figure 11.5: Terminal voltage of DG1 as a fault occurs at bus 684 with/without TCBR.

\subsection{Dynamic Simulation Results}

The two DGs are connected at buses 671 and 633, and the initial real power size of DG 1 is $0.671 \mathrm{pu}$, and initial real power size of DG2 is $0.3 \mathrm{pu}$. At $\mathrm{t}=0.1 \mathrm{~s}$, the fault occurs at bus 684 and the fault is cleared at $\mathrm{t}=0.5 \mathrm{~s}$.

Figures 11.5-11.6 show the dynamic simulation results of the terminal voltage and stator speed deviation for DG 1 and Figures 11.7-11.8 show the similar results for DG2. Figures 11.5 and 11.7 show the voltage of DG1 and DG2. The magnitude of the voltage minimum for DG1 is lower than for DG2. This is because the fault location is close to the DG1.

The simulation results show that one TCBR close DG1 can effectively damp the oscillation of both DG1 and DG2, thus the TCBR can improve the dynamic characteristic of the whole distribution system.

\subsection{Summary}

In this chapter, unbalanced three-phase dynamic simulation of a distribution system with two DGs connected is performed using MATLAB/Simulink. Nonlinear models for gas turbine and diesel engine driven synchronous generators are implemented to study the DGs' impact on the power 


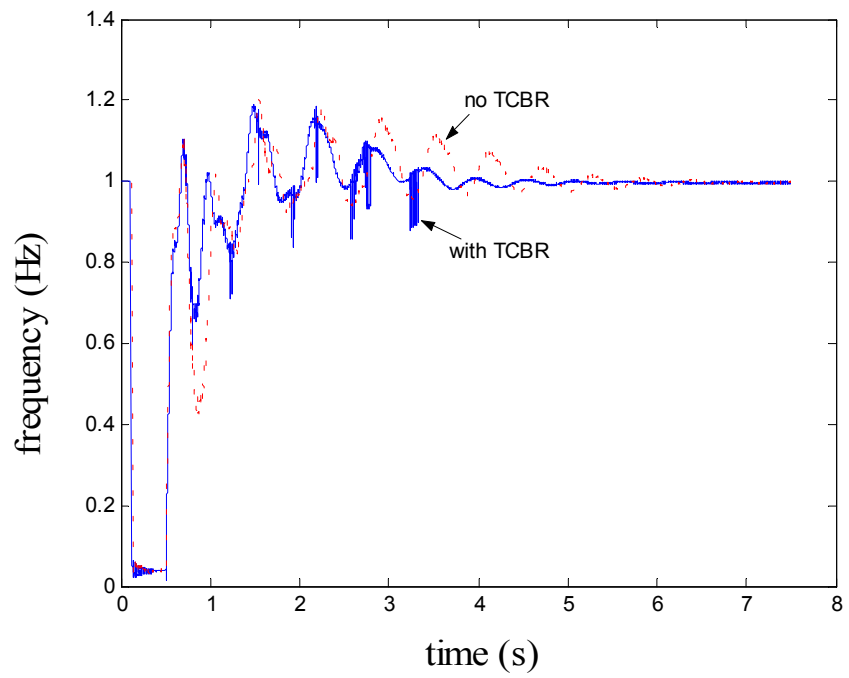

Figure 11.6: Rotor speed deviation of DG1 as a fault occurs at bus 684 with/without TCBR.

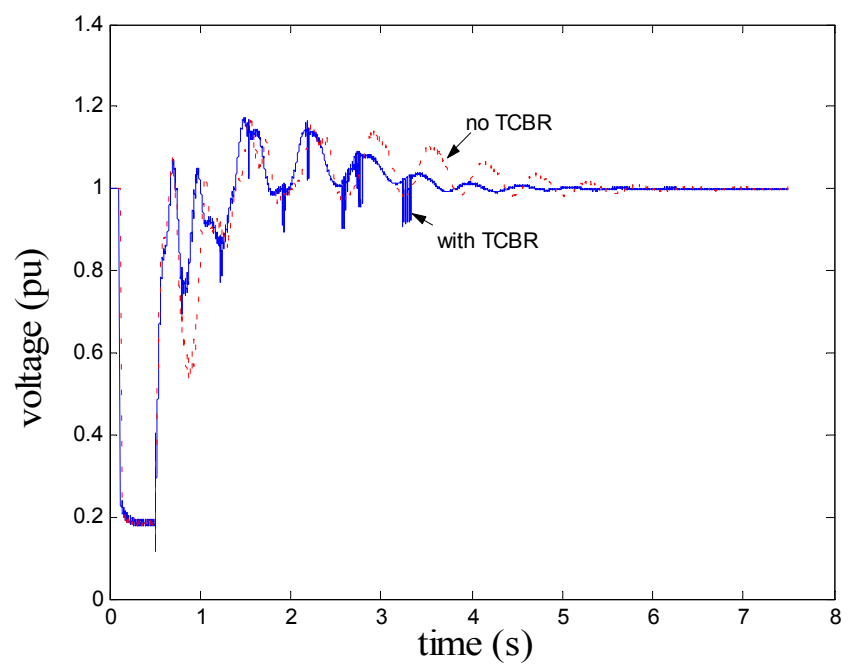

Figure 11.7: Terminal voltage of DG2 as a fault occurs at bus 684 with/without TCBR. 


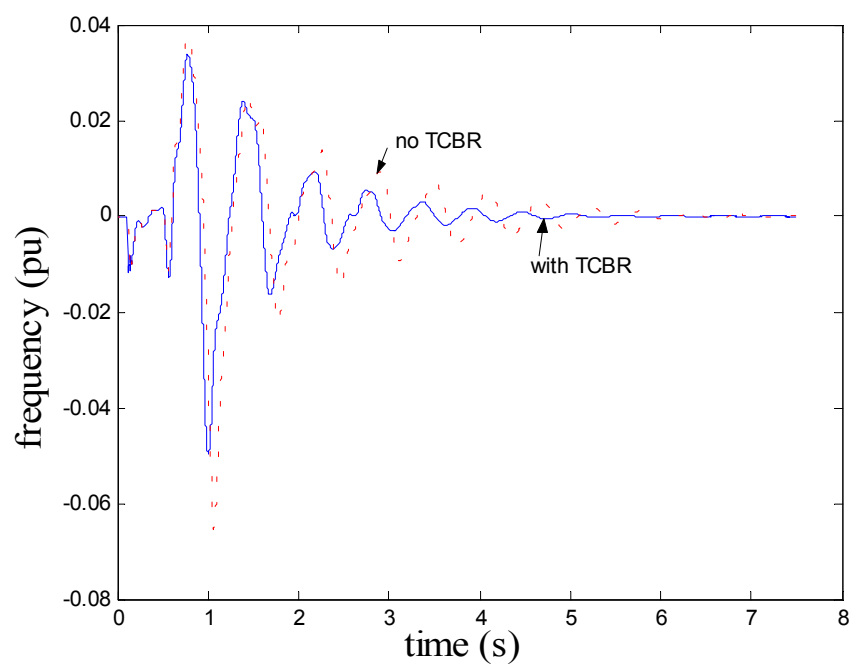

Figure 11.8: Stator speed deviation of DG2 as a fault occurs at bus 684 with/without TCBR.

distribution system. A low cost, three-phase controlled TCBR is proposed to prevent the transient instability and damp the low frequency oscillations. The three-phase dynamic simulation results show that the TCBR can effectively damp the oscillation of the whole distribution system subject to a disturbance. 


\section{Chapter 12}

\section{Conclusion}

The objective of this dissertation is to develop improved dynamic models for distributed generations (DG), to investigate their impacts on dynamic stability of power distribution systems, and to design controllers to improve the dynamic stability of the integrated power distribution system.

A two-year DG project at West Virginia University (WVU) evaluated the impacts of various DG sources on the stability of actual distribution systems by computer simulation using data supplied by two regional electric utilities. Several important issues have been including the availability of simulation tools, selection of simulation tools, modeling of various DGs and impact of DGs on the distribution system under a variety of operating conditions.

By focusing on these objectives the interaction among DGs has been evaluated and the dynamic stability of the integrated power distribution system has been examined. Three sections of the literature are surveyed: 1) mathematical models and practical parameters for gas turbine, diesel engine, fuel cell and wind turbine DGs, 2) application of power electronics devices, such as Static Var Compensation (SVC) and Thyristor Controlled Braking Resistor (TCBR) in stabilizing power distribution systems, and 3) control strategies for DGs and using FACTS when DG's are connected to a distribution line to improve the dynamic stability.

Four types of specific DGs: fuel cell power plant, wind turbine induction generator, gas turbine synchronous generator and diesel engine synchronous generator have been discussed and implemented in this dissertation.

The generator model of gas turbine generator and diesel engine generator is represented by a full order synchronous generator model. A simplified gas turbine model is chosen to be implemented. A practical diesel engine for emergency use is modeled. The generator model of wind turbine induction generator is represented by a full order induction generator. The rating power 
operating region is considered for impacts evaluations and controller design. Two types of fuel cell models are developed. One is an actual fuel cell model of the phosphoric acid fuel cell (PAFC) obtained through the data fitting, the other is a dynamic model of a solid oxide fuel cell (SOFC). Since fuel cell plant is interfaced with the network via inverter, the inverter model is developed together with the interface.

Multi-DG control is investigated in this dissertation. One DG control is fuel cell control, the other is wind turbine control. Control of fuel cell (SOFC) plant is accomplished through inverters by adjusting its active power injection into the network during the transient period using fast acting voltage-source inverters. The control of wind turbine generator is accomplished through a parallel connected SVC by adjusting the reactive power injection into the system. Both controls are centralized schemes.

Linear analysis methodologies were utilized in designing controls. In fuel cell control design, two pairs of critical modes have been identified using eigenvalue analysis and the participation factors. Two specific lead-lag compensation units were designed to damp each modes respectively. The gains of the two compensation units were then obtained via optimal control methodology. In wind turbine DG control design procedure, three rotor speed deviations are used as input signals while the controller outputs are the firing angle for SVC and the pitch angle for the wind turbine DG. An output feedback controller is designed. Dynamic load characteristic have been considered by modeling them as structured uncertainty. $\mu$-analysis is used to evaluate the robust stability of the controllers with respect to parameter uncertainties. The IEEE-13 node radial feeder with an existing gas turbine DG and an existing diesel engine DG is used as a system to test the multi-DG control. The simulation results demonstrate the effectiveness of the control strategies.

Coordinated operation of all the DGs is investigated. Simulation results show that good configurations of DGs within the system can improve system stability. Furthermore, the fast acting SVC is very effective in improving system damping. Among the DGs investigated in this research, the fuel cell plant control is the best choice for overall coordinated operation.

Finally, a full three-phase approach to model a power distribution system is investigated. The impact of the DGs is evaluated on the three-phase unbalanced distribution system. The threephase 13-node system with gas turbine and diesel engine DGs are simulated in the Power System Blockset (PSB). In the simulation, the three-phase thyristor controlled braking resistor (TCBR) is connected to absorb surplus energy when the system is subjected to a disturbance. Simulation results demonstrate the effectiveness of the proposed strategy.

This dissertation has not included other types of DG, such as solar power plants. Solar 
energy has been commercially used in the electric utility industry. Dynamic modeling of solar could be considered in the further research. Impacts on the distribution system with existing DGs, interactions with other types of DGs, and the dynamic control of solar DG could be investigated.

Also, the advanced three-phase representation of distribution systems needs further development. In this dissertation, a three-phase representation is implemented in PSB. If the number of state variables becomes very larger, the running speed will become very slow. At present, no tools are available to linearize the nonlinear model in PSB, so this three-phase approach is not suitable to design a controller system directly yet. In a more advanced approach, the gas turbine, the diesel engine, the fuel cell and the wind turbine DGs models could be used with the zero-axis circuits added. Then, with the transformation of dq0 to abc, these DGs models could be connected to the three-phase network. The major problem is to solve the three-phase unbalanced power flow and to set the initial condition of each state variable. The advantage of this methodology is that the speed could be tremendously improved, so the approach can be used in large-scale systems. 


\section{References}

[1] E.S. Abdin, and W. Xu: "Control Design and Dynamic Performance Analysis of a Wind Turbine Induction Generator Unit," IEEE Trans. Energy Conversion, Vol. 15, No. 1, March 2000 .

[2] P.M. Anderson, and A.A. Fouad: Power System Control and Stability, Revised Printin, The Institute of Electrical and Electronics Engineering, Inc. New York, 1994.

[3] O. Akhrif, F.A. Okou, L.A. Dessaint, and R. Champagne: "Application of a Multivariable Feedback Linearization Scheme for Rotor Angle Stability and Voltage Regulation of Power Systems," IEEE Transaction on Power Systems, Vol. 14, No. 2, May 1999, pp. 620-628.

[4] S.M. Alghuwainem: "Speed Control of a PV Powered DC Motor Driving a Self-Excited 3-Phase Induction Generator for Maximum Utilization Efficiency," IEEE Trans. Energy Conversion, Vol. 11, No. 4, December 1996, pp. 768-773.

[5] S.M. Badran, and M.A. Choudhry: "Design of Modulation Controller for AC/DC Power System," IEEE Trans. Power Systems, Vol. 8, No. 4, November 1993, pp. 1490-1496.

[6] P.G. Barbosa, L.G.B. Rolim, E.H. Watanabe, and R. Hanitsch: "Control Strategy for gridconnected DC-AC Converter with Load Power Factor Correction," IEE Proc. Gener. Transm. Distrib., Vol 145, No. 5, September 1998, pp. 487-491.

[7] H.D. Battista, P.F. Puleston, R.J. Mantz, and C.F. Christiansen: "Sliding Model Control of Wind Energy Systems with DOIG - Power Efficiency and Torsional Dynamics Optimization," IEEE Trans. Power Systems, Vol. 15, No. 2, May 2000, pp. 728-734.

[8] R. Belhomme et al: "Case Study on the Integration of Non-Utility Induction Generator to the Hydro Quebec Distribution," IEEE Trans. Power Delivery, Vol. 10, No. 3, July 1995.

[9] N. F. Bessette II, and W. J. Wepfer: "Electricochemical and Thermal Simulation of a Solid Oxide Fuel Cell," Chem. Eng. Comm., Vol. 147, 1996, pp. 1-15.

[10] B.S. Borowy, and Z.M. Salameh: "Dynamic Response of a Stand-Alone Wind Energy Conversion System with Battery Energy Storage to a Wind Gust," IEEE Trans. Energy Conversion, Vol. 12, No. 1, March 1997, pp. 73-78. 
[11] F. Bonanno, A. Consoli, A. Raciti, B. Morgana, and U. Nocera: "Transient Analysis of Integrated Diesel-Wind-Photovoltaic Generation Systems," IEEE Trans. Energy Conversion, Vol. 14, No. 2, June 1999, pp. 232-238.

[12] W.L. Brogan: Modern Control Theory, Third Edition, New Jersey: Prentice Hall, 1991.

[13] H.P.L.H. Bussel, F.G.H. Koene, and R.K.A.M. Mallant: "Dynamic Model of Solid Polymer Fuel Cell Water Management," Journal of Power Sources, Vol 71, 1998, pp. 218-222.

[14] A. Campos, .G. Joos, P.D. Zioga, and J.F. Lindsay: "Analysis and Design of a Series Voltage Unbalance Compensator Based on a Three-Phase VSI Operating With Unbalanced Switching Functions," IEEE Trans. Power Electronics, Vol. 9, No. 3, May 1994, pp. 269-274.

[15] R. Cardenas, R. Pena, G. Asher, and J. Clare: "Control Strategies for Enhanced Power Smoothing in Wind Energy Systems Using a Flywheel Driven by a Vector-Controlled Induction Machine," IEEE Trans. Industrial Electronics, Vol. 48, No. 3, June 2001, pp. 625-635.

[16] T. F. Chan: "Performance Analysis of a Three-phase Induction Generator Self-excited with a Single Capacitance," IEEE Trans. Energy Conversion, Vol. 14, No. 4, December 1995, pp. 894-900.

[17] M.C. Chandorkar, D.M. Divan, and R. Adapa: "Control of Parallel Connected Inverters in Standalone ac Supply Systems," IEEE Trans. Industry Application, Vol. 29, No. 1, January/February 1993, pp. 136-143.

[18] R.B. Chedid, S.H. Karaki, and C.E. Chamali: "Adaptive Fuzzy Control for Wind-Diesel Weak Power Systems," IEEE Trans. Energy Conversion, Vol. 15, No. 1, March 2000, pp. 71-78.

[19] Z. Chen, and E. Spooner: "Grid Power Quality with Variable Speed Wind Turbines," IEEE Trans. Energy Conversion, Vol. 16, No. 2, June 2001, pp. 148-154.

[20] G.C. Cho, G.H. Jung, N.S. Choi, G.H. Cho: "Analysis and Controller Design of Static Var Compensator Using Three-Level GTO Inverter," IEEE Trans. Power Electronics, Vol. 11, No. 1, January 1996, pp. 57-65.

[21] J.H. Choi, and J.C. Kim: "Advanced Voltage Regulation Method at the Power Distribution Systems Interconnected with Dispersed Storage and Generation Systems," IEEE Trans. Power Delivery, Vol. 15, No. 2, April 2000, pp. 691-696.

[22] M.A. Choudry, M.A. Reza, and K.A. Ellithy: "Design of A Robust Modulation Controller Over A Wide Range of Load Characteristics for AC/DC Systems," IEEE Transaction on Power Systems, Vol. 5, No. 1, February 1990.

[23] M.A. Choudry, and K. Lateef: "Robust Design of Dynamic Compensator for HV AC Power System", Power Symposium, 1990, Proceedings of the 22th Annual North American, 1990, pp. 2-7.

[24] Distribution System Analysis Subcommittee Report: "Radial Distribution Test Feeders," Columbus, OH, IEEE PES Winter meeting, 2001. 
REFERENCES

[25] Distribution System Protection Manual, McGraw-Hill Book Company, New York, 1973.

[26] M.B. Djukanovic, M.H. Khammash, and V. Vittal: "Sensitivity Based Structured Singular Value Approach to Stability Robustness of Power Systems," IEEE Trans. Power Systems, Vol. 15, No. 2, May 2000, pp. 825-830.

[27] M.K. Donnelly, J.R. Smith, R.M. Johnson, J.F. Hauer, R.W. Brush, and R. Adapa: "Control of A Dynamic Brake to Reduce Turbine-Generator Shaft Transient Torques," IEEE Trans. Power Systems, Vol. 8, No. 1, February 1993, pp. 67-73.

[28] M. K. Donnelly, J. E. Dagle, D. J. Trudnowski, and G. J. Rogers: "Impacts of the Distributed Utility on Transmission System Stability," IEEE Trans. Power Systems, Vol. 11, No. 2, May 1996, pp. 741-746.

[29] K.A. Ellithy, and M.A. Choudry: "Effect of Load Models on AC/DC System Stability and Modulation Control Design," IEEE Transaction on Power Systems, Vol. 8, No. 1, February 1993.

[30] A.S. Emarah, and M.A. Choudry: "Eigenvalue Assignment Using Optimal Control," IEEE Transaction on Circuits and Systems, Vol. CAS-32, No. 11, November 1985.

[31] Electric Power Research Institute: Transmission Line Reference Book, Second Edition, 1982, pp. 23.

[32] A. Feliachi: "Identification of Critical Modes in Power Systems," IEEE Transaction on Power Systems, Vol. 5, No. 3, Aug. 1990.

[33] G.D. Galanos, C.I. Hatzladoniu, X.J. Cheng, and D. Maratukulam: "Advanced Static Compensator for Flexible AC Transmission," IEEE Trans. Power Systems, Vol. PWRD-1, No. 2, April 1986.

[34] J.J.S. Gasca: "Coordinated Control of Two FACTS Devices for Damping Interarea Oscillations," IEEE Transaction on Power Systems, Vol. 13, No. 2, May 1998.

[35] A. Ghosh, and A. Joshi: "A New Approach to Load Balancing and Power Factor Correction in Power Distribution System," IEEE Trans. Power Delivery, Vol. 15, No. 1, January 2000, pp. 417-422.

[36] W.B. Gish: "Small Induction Generator and Synchronous Generator Constants for DSG Isolation Studies," IEEE Trans. Power Systems, Vol. PWRD-1, No. 2, April 1986.

[37] A.M. Gole, A. Keri, E.W. Gunther, and etc: "Guidelines for Modeling Power electronics in Electric Power Engineering Application," IEEE Trans. Power Delivery, Vol. 12, No. 1, January 1994, pp. 505-514.

[38] Electric Power Distribution System Engineering, New York: McGraw-Hill Book Company, 1986.

[39] P.G. Gonzalez, and A.G. Cerrada: "Control System for PWM-Based STATCOM," IEEE Trans. Power Delivery, Vol. 15, No. 4, October 1994, pp. 1252-1257. 
[40] Q.P. Ha, Q.H. Nguyen, D.C. Rye, and H.F. Durrant-Whyte: "Fuzzy Sliding-Mode Controller with Applications," IEEE Trans. Industrial Electronics, Vol. 48, No. 1, February 2001, pp. $38-46$.

[41] N. Hadjsaid, J.F. Canard, and F. Dumas: "Dispersed generation increase the complexity of controlling protection, and maintaining the distribution systems," IEEE Trans. Computer Applications in Power, Vol. 12, No. 2, April 1999, pp. 22-28.

[42] D.J. Hall, and R.G. Colclaser: "Transient Modeling and Simulation of a Tubular Solid Oxide Fuel Cell," IEEE Trans. Energy Conversion, Vol. 14, No. 3, September 1999, pp. 749-753.

[43] T.J. Hammons, and S.C. Lai: "Voltage Dips due to Direct Connection of Induction Generators in Low Head Hydro Electric Schemes," IEEE Trans. Energy Conversion, Vol. 9, No. 3, September 1994, pp. 460-465.

[44] L.N. Hannett, G. Jee, and B.Fardanesh: "A Governor/Turbine Model for a Twin-Shaft Combustion Turbine," IEEE Transaction on Power Systems, Vol. 10, No. 1, February 1995, pp. 133-140.

[45] C.J. Hatziadoniu, F.E. Chalkiadakis, and V.K. Feiste: "A Power Conditioner for a GridConnected Photovoltaic Generator Based on the 3-Level Inverter, " IEEE Trans. Energy Conversion, Vol. 14, No. 4, December 1999, pp. 1605-1610.

[46] W. He: "Dynamic Model for Molten Carbonate Fuel Cell Power-Generation Systems," Energy Conver. Mgmt, Vol. 39, No. 8, 1998, pp. 775-783.

[47] N. G. Hingorani, and L. Gyugyi, Understanding FACTS, New York: IEEE Press, 1999, pp. 362.

[48] N.G. Hingorani: "Introducing Custom Power," IEEE Spectrum, June 1995, pp. 41-48.

[49] I.A. Hiskens, and J.V. Milanovic: "Locating Dynamic Loads Which Significantly Influence Damping," IEEE Transaction on Power Systems, Vol. 12, No. 1, February 1997, pp. 255-261.

[50] W. W. Hung: "Dynamic simulation of gas-turbine generating unit," IEE Proceedings-C., Vol. 138, No. 4, July 1991, pp. 342-350.

[51] J.Y. Hung, W. Gao, and J. Hung: "Variable Structure Control: A Survey," IEEE Transaction on Industrial Electronics, Vol. 40, No. 1, February 1993, pp. 2-22.

[52] S.J. Huang, and F.S. Pai: "Design and Operation of Grid-Connected Photovoltaic System with Power-Factor Control and Active Islanding Detection," IEE Proc. - Gener. Transm. Distrib, Vol 148, No. 2, March 2001, pp. 243-250.

[53] T.L. Huang, S.C. Chen, T.Y. Hwang, and W.T. Yang: "Power System Output Feedback Stablizer Design via Optimal Subeigenstructure Assignment," IEEE Trans. Power System, Vol. 6, No. 3, August 1991, pp. 1035-1041.

[54] Hydro Quebec TEQSIM International, Power System Blockset for Use with Simulink[Online]. Available: http://www.mathworks.com. 
REFERENCES

[55] IEEE Distribution Planning Working Group Report: "Radial Distribution Test Feeders," IEEE Trans. Power System, Vol. 6, No. 3, August 1991, pp. 975-985.

[56] IEEE Special Stability Controls Working Group: "Static Var Compenstor Models for Power Flow and Dynamic Performance Simulation," IEEE Transaction on Power Systems, Vol. 9, No. 1, Feb. 1994.

[57] IEEE Working Group on Prime Mover and Energy Supply Models for System Dynamic Performance Studies: "Hydraulic Turbine and Turbine Control Models for System Dynamic Studies," IEEE Trans. Power Systems, Vol. 7, No. 1, February 1992.

[58] IEEE Working Group on Computer Modelling of Excitation Systems: "Excitation System Models for Power System Stability Studies," IEEE Trans. Power Apparatus and Systems, Vol. PAS-100, No. 2, February 1981, pp. 494-509.

[59] M. Ilic, F. Galiana, and L. Fink, Power Systems Restrcuturing, Engineering and Economics, Kluwer Academic Publishers, Boston, 1998.

[60] H. Jiang, J. Dorsey, T. Habetler, and K. V. Eckroth, "A Cost Effective Generator Brake For Improved Generator Transient Response," IEEE Trans. Power Systems, vol. 9, pp.. 1840-1846, Nov. 1994.

[61] C.L. Kana, M. Thamodharan, and A. Wolf: "System Management of a Wind-Energy Converter," IEEE Trans. Power Electronics, vol. 16, No. 3, May 2001, pp. 375-381.

[62] G.N. Kariniotakis, and G.S. Stavrakakis: "A General Simulation Algorithm for the Accurate Assessment of Isolated Diesel-Wind Turbines Systems Interaction. PART II: Implementation of the Algorithm and Case-Studies With Induction Generators," IEEE Trans. Energy Conversion, Vol. 10, No. 3, September 1995, pp. 584-590.

[63] E.W. Kimbark: Direct Current Transmission, vol. 1, New York: John Wiley \& Sons, 1971, pp. 20.

[64] Y.H. Kim, and S.S. Kim: "An Electrical Modeling and Fuzzy Logic Control of a Fuel Cell Generation System," IEEE Trans. Energy Conversion, Vol. 14, No. 2, June 1999, pp. 239-244.

[65] R.L. Klein, M.A. Choudhry, Z. Miao, and L. Fan: Impacts of Distribution Generation on Voltage and System Stability, Technical Report, West Virginia University, Morgantown, May, 2000 .

[66] R.L. Klein, M.A. Choudhry, and Z. Miao: Impacts of Distribution Generation on Voltage and System Stability, Final Report, West Virginia University, Morgantown, April, 2001.

[67] M.L Kothari, J. Nanda, and K. Bhattacharya: "Design of variable structure power system stabilizers with desired eigenvalues in the sliding mode," IEE Proceedings-C, Vol. 140, No. 4, July 1993, pp. 263-268.

[68] P.C. Krause, and D.T. Man, "Transient Behavior of a Class of Wind Turbine Generators During Electrical Disturbance," IEEE Trans. PAS, vol. PAS-100, No. 5, pp.. 2204-2210, May 1981. 
[69] P.C. Krause, O. Wasynczuk, and S.D. Sudhoff, Analysis of Electric Machinery, IEEE Press, New York, 1995.

[70] J.H. Lee, T.R. Lalk, and A.J. Appleby: "Modeling Electrochemical Performance in Large Scale Proton Exchange Membrane Fuel Cell Stacke," Journal of Power Sources 70, 1998, pp. 258-268.

[71] X. Lei, E.N. Lerch, and D. Povh: "Optimization and Coordination of Damping Controls for Improving System Dynamic Performance," IEEE Trans. Power Systems, Vol. 16, No. 3, August 2001, pp. 473-480.

[72] F.L. Lewis, and V.L. Syrmos, Optimal Control, Second edition, John Wiley \& Sons, Inc., New York, 1995.

[73] E.E.S. Lima, L.F.J. Fernandes: "Assessing Eigenvalue Sensitivities," IEEE Trans. Power Systems, Vol. 15, No. 1, February 2000, pp. 299-306.

[74] R. Lind, and D. Karlsson: "Distribution System Modelling for Voltage Stability Studies," IEEE Trans. Power Systems, Vol. 11, No. 4, November 1996.

[75] W.M. Lin, Y.S. Su, H.C. Chin, and J.H. Teng: "Three-Phase Unbalanced Distribution Power Flow Solutions with Minimum Data Preparation," IEEE Trans. Power Systems, Vol. 14, No. 3, August 1999, pp. 1178-1183.

[76] M.D. Lukas, K.Y. Lee, and H.G. Ayagh: "Development of a Stack Simulation Model for Control Study on Direct Reforming Molten Carbonate Fuel Cell Power Plant," IEEE Trans. Energy Conversion, Vol. 14, No. 4, December 1999, pp. 1651-1657.

[77] M.D. Lukas, K.Y. Lee, and H.G. Ayagh: "An Explicit Dynamic Model for Direct Reforming Carbonate Fuel Cell Stack," IEEE Trans. Energy Conversion, Vol. 16, No. 3, September 2001, pp. 289-295.

[78] N. Martins, and L.T. Lima: "Determination of Suitable Locations for Power System Stabilizers and Static VAR Compensator for Damping Electromechanical Oscillations in Large Scale Power Systems," IEEE Trans. Power Systems, Vol. 5, No. 4, November 1990, pp. 1455-1469.

[79] F.D. Mello, J.W. Feltes, L.N. Hannett, and J.C. White, "Application of Induction Generators in Power System," IEEE Trans. PAS, vol. PAS-101, No. 9, September 1982, pp. 3385-3393.

[80] Z. Miao, R.L. Klein, and M.A. Choudhry: "Case Study on the Impacts of Distributed Generation on the Power Distribution System," Proceeding of North American Power Symposium 2001, October, 2001, College Station, TX.

[81] Z. Miao, M.A. Choudhry, and R.L. Klein, "Dynamic Simulation and Stability Control of Three-Phase Power Distribution System With Distribution Generators," IEEE PES Winter Meeting 2002, Jan. 26-Jan. 31, New York City.

[82] Z. Miao, M.A. Choudhry, and R.L. Klein, "Dynamic Model and Control of A Fuel Cell Power Plant in Power Distribution System," submitted to IEEE Trans. Power Systems. 
[83] Z. Miao, R.L. Klein, M.A. Choudhry, and L. Fan, "A Fuel Cell Model from Data Fitting Method and Its Impacts on a Power Distribution System with DGs," accepted by North American Power Symposium 2002, Tempe, AZ.

[84] Z. Miao, M.A. Choudhry, and R.L. Klein, "Control of Wind Turbine-Generator in a Power Distribution System with Multiple Types of Distributed Generators (DG)," accepted by North American Power Symposium 2002, Tempe, AZ.

[85] J.V. Milanovic, and I.A. Hiskens: "Damping Enhancement by Robust Tuning of SVC Controllers in the Presence of Load Parameters Uncertainty," IEEE Trans. Power Systems, Vol. 13, No. 4, November 1998, pp. 1298-1303.

[86] T. Hiyama, M.Mishiro, H. Kihara, and T.H. Ortmeyer: "Fuzzy Logic Switching of Thyristor Controller Braking Resistor Considering Coordination with SVC," IEEE Trans. Power Delivery, Vol. 10, No. 4, October 1995, pp. 2020-2026.

[87] N. Mohan, T.M. Undeland, and W.P. Robbins, Power Electronics: Converters, Applications, and Design, New York: John Wiley \& Sons, Inc., 1995.

[88] A. Murdoch, R.S. Barton J.R. Winkelman, and S.H. Javid: "Control Design and Performance Analysis of a 6 MW Wind Turbine-Generator," IEEE Trans. Power Apparatus and Systems, Vol. PAS-102, No. 5, May 1983, pp. 1340-1347.

[89] R. Naik, N. Mohan, M. Rogers, and A. Bulawka: "A Novel Grid Interface, Optimized for Utility-Scale Applications of Photovoltaic, Wind-electric, and Fuel-cell Systems," IEEE Trans. Power Delivery, Vol. 10, No. 4, October 1995, pp. 1920-1926.

[90] H.K. Nam, Y.K. Kim, K.S. Shim, an K.Y. Lee: "A New Eigen-Sensitivity Theory of Augmented Matrix and its Applications to Power System Stablity Analysis," IEEE Trans. Power Systems, Vol. 15, No. 1, February 2000, pp. 363-369.

[91] T.J. Overbye: "Reengineering the Electric Grid," American Scientist, Vol. 88, May-June 2000, pp. 220-229.

[92] J. Padulles, G.W. Ault, and J.R. McDond: "An integrated SOFC plant dynamic model for power systems simulation," Journal of Power Sources, 2000, pp. 495-500.

[93] H.A. Perez, E. Acha, and C.R.F. Esquivel: "Advanced SVC Models for Newton-Raphson Load Flow and Newton Optimal Power Flow Studies," IEEE Trans. Power Systems, Vol. 15, No. 1, February 2000, pp. 129-136.

[94] B.K. Perkins, M.R. Iravani: "Dynamic Modeling of High Power Static Switching Circuits in the dq-frame," IEEE Transaction on Power Systems, Vol. 14, No. 2, May 1999.

[95] Power System Toolbox-Dynamic Tutorial and Functions, Version 2.0, Cherry Tree Scientific Software, Ontario Canada, 1998.

[96] R. Pena, J.C. Clare, and G.M. Asher: "Doubly Fed Induction Generator Using Back-toBack PWM Converters and Its Application to Variable-Speed Wind-Energy Generation," IEE Proc. Electr. Power Appl. vol. 143, No. 3, May 1996, pp. 231-241. 
REFERENCES

[97] A.H.M.A. Rahim, and D.A.H. Alamgir: "A Closed-loop Quasi-Optimal Dynamic Braking Resistor and Shunt Reactor Control Strategy for Transient Stability," IEEE Trans. Power Systems, Vol. 3, No. 3, August 1988, , pp. 879-886.

[98] A.H.M.A. Rahim, A.M. Al-Shehri, and A.I.J. Al-Shehri: "Optimum Control Stategies for Transient as Well as Oscillator Instability of Power Systems," IEEE Trans. Power Systems, Vol. 8, No. 2, May 1993, pp. 491-496.

[99] N. M.A. Rahim, J. E. Quaicoe: "Analysis and Design of a Multiple Feedback Loop Control Strategy for Single-Phase Voltage-Source UPS Inverters," IEEE Trans. Power Electronics, Vol. 11, No. 4, July 1996, pp. 532-541.

[100] C.S. Rao, T.K.N. Sarkar: "Half Wave Thyristor Controlled Dynamic Brake to Improve Transient Stability," IEEE Trans. Power Apparatus and Systems, Vol. PAS-103, No. 5, May 1984, pp. 1077-1082.

[101] P. Rao, M.L. Crow, and Z. Yang: "STATCOM Control for Power System Voltage Control Application," IEEE Trans. Power Delivery, Vol. 15, No. 4, October 2000, pp. 1311-1317.

[102] Power Electronics: Circuits, Devices, and Application, Second Edition, New Jersey: Prentice Hall, 1998.

[103] N.S. Rau, and Y.H. Wan: "Optimum Location of Resources in Distributed Planning," IEEE Trans. Power Systems, Vol. 9, No. 4, November 1994, pp. 2014-2020.

[104] D. Reichelt, E. Echnauer, and H. Glavitsch: "Estimation of Steady-state Unbalanced System Conditions Combining Conventional Power Flow and Fault Analysis Software," IEEE Trans. Power Systems, Vol. 11, No. 1, February 1996, pp. 422-427.

[105] N. Rostomakolai, A.G. Phadke, W.F. Long, and J.S. Thorp: "An Adaptive Optimal Control Strategy for Dynamic Stability Enhancement of AC/DC Power Systems," IEEE Transaction on Power Systems, Vol. 3, No. 3, August 1988.

[106] K. Ro, and S. Rahman: "Two-Loop Controller for Maximizing Performance of a GridConnected Photovoltaic-Fuel Cell Hybrid Power Plant," IEEE Trans. Energy Conversion, Vol. 13, No. 3, September 1998, pp. 276-281.

[107] W.I. Rowen: "Simplified Mathematical Representations of Heavy-Duty Gas Turbines," Journal of Engineering for Power, Vol. 105, October 1983, pp. 865-869.

[108] I. Roytelman, and V. Ganesan: "Coordinated Local and Centralized Control in Distribution Management Systems," IEEE Trans. Power Delivery, Vol. 15, No. 2, April 2000, pp. 718-724.

[109] S.D. Rubira, and M.D. McCulloch: "Control Method Comparison of Doubly Fed Wind Generators Connected to the Grid by Asymmetric Transmission Lines," IEEE Trans. Industry Application, Vol. 36, No. 4, July/August 2000, pp. 986-991.

[110] Z. Saad-Saoud, M.L. Lisboa, J.B. Ekanayake, and etc.: "Application of STATCOMs to Wind Farms," Vol. 145, No. 5, September 1998, pp. 511-516. 
REFERENCES

[111] O. Samuelsson, and M. Akke: "On-off Control of an Active Load for Power System DampingTheory and Field Test," IEEE Trans. Power Systems, Vol. 14, No. 2, May 1999, pp. 608-613.

[112] E. Santos, T. I. Asiain, D. Ruiz, and D. Olguin: "The effect of induction generators in the transient stability of an electric power system," 34th Universities Power Engineering Conference. Univ. Leicester, UK; Vol. 1, 1999, pp. 26-29.

[113] P.S. Sensarma, K.R. Padiyar, and V. Ramanarayana: "Analysis and Performance Evaluation of a Distribution STATCOM for Compensating Voltage Fluctuations," IEEE Trans. Power Delivery, Vol. 16, No. 2, April 2001, pp. 259-264.

[114] C. Sharma: "Modeling of an Island Grid," IEEE Trans. Power Delivery, Vol. 13, No. 3, August 1998, pp. 971-978.

[115] J. She, and A. Feliachi: "On Eigenvalue Ranking Indices for Continues Linear Time Invariant Systems," System Engineering, 1991, IEEE International Conference on, 1991, pp. 291-294.

[116] T. Shinoki, M. Matsumura, and A. Sasaki: "Development of an Internal Reforming Molten Carbonate Fuel Cell Stack," IEEE Trans. Energy Converison, Vol. 10, No. 4, December 1995, pp. 722-729.

[117] S.M. Shinners, Modern Control System Theory and Application, Second Edition, AddisonWesley Publishing Company, 1978.

[118] J.J. Slotine, W. Li, Applied Nonlinear Control, New Jersy: Prentice Hall, 1991.

[119] T.J. Sobczyk, and B.L. Sapinski: "Analysis of Phase-Controlled Converters for Induction Motors," IEEE Trans. Power Electronics, Vol. 5, No. 2, April 1990, pp. 172-181.

[120] W.D. Stevenson, Jr., Elements of Power System Analysis, Fourth Edition, New York: McGraw-Hill Publishing Company, 1982.

[121] W. Sweet: “Networking Assets," IEEE Spectrum, January 2001, pp. 84-86.

[122] I. Takahashi, and T. Noguchi: "A New Quick-Response and High-Efficiency Control Strategy of an Induction Motor," IEEE Trans. Industry Application, Vol. IA-22, No. 5, September/October 1986, pp. 820-827.

[123] M. Tsuda, Y. Mitani, K. Tsuji, and K. Kakihana: "Application of Resistor Based Superconducting Fault Current Limiter to Enhancement of Power System Transient Stability," IEEE Trans. Applied Superconductivity, Vol. 11, No. 1, March 2001, pp. 2122-2125.

[124] K. Uhlen, B.A. Foss, and O.B. Gjosater: "Robust Control and Analysis of a Wind-Diesel Hybrid Power Plant," IEEE Trans. Energy Conversion, Vol. 9, No. 4, December 1994, pp. 701-708.

[125] K.W. Wang, C.Y. Chung, and K.M. Tsang: "Improved probabilistic method for power system dynamic stability studies," IEE Proc.-Gener. Transm. Distib. vol. 147, No. 1, January 2000, pp. 37-43. 
REFERENCES

[126] K.W. Wang, C.Y. Chung, and K.M. Tsang: "Multimachine Eigenvalue Sensitivities of Power System Parameters," IEEE Trans. Power Systems, Vol. 15, No. 2, May 2000, pp. 741-747.

[127] L. Wang, and R.Y. Deng: "Transient Performance of an Isolated Induction Generator under Unbalanced Excitation Capacitors," IEEE Trans. Energy Conversion, Vol. 14, No. 4, December 1999, pp. 887-893.

[128] Yu Wang, R.R. Mohler, W.A. Mittelstadt, and D.J. Maratukulam: "Variable-Structure Braking-Resistor Control in A Multimachine Power System," IEEE Trans. Power Systems, Vol. 9, No. 3, August 1994, pp. 1557-1562.

[129] R.S. Weissbach, G.G. Karady, and R.G. Farmer: "Dynamic Voltage Compensation on Distribution Feeders using Flywheel Energy Storage," IEEE Trans. Power Delivery, Vol. 14, No. 2, April 1999, pp. 465-471.

[130] R.H. Wolk: "Fuel Cell for Homes and Hospitals," IEEE Spectrum, May 1999, pp. 45-52.

[131] X. Yang, and A. Feliachi.: "Stabilization of Inter-Area Oscillation Modes Through Excitation Systems," IEEE Trans. Power Systems, Vol. 9, No. 1, February 1994, pp. 494-502.

[132] Z. Yang, C. Shen, L. Zhang, and etc.: "Integration of a StatCom and Battery Energy Storage," IEEE Trans. Power Systems, Vol. 16, No. 2, May 2001, pp. 254-260.

[133] K.E. Yeager, and J.R. Willis: "Modeling of Emergency Diesel Generators in an 800 MegaWatt Nuclear Power Plant," IEEE Trans. Energy Conversion, Vol. 8, No. 3, September 1993, pp. 433-441.

[134] A. Yilmaz, and I. Sabuncuoglu: "Input Data Analysis Using Neural Networks," Simulation, March 2000, pp. 128-137.

[135] K. H. Yoon, J. H. Jang, and Y. S. Cho, "Impedance Characteristics of a Phosphoric Acid Fuel Cell." Journal of Materials Science Letters, Vol. 17, No. 20, Oct. 1998, pp. 1755-8.

[136] M. Yoshihara, Y. Uriu, and F. Koyanagi: "Optimal Allocation and Evaluation of the Dispersed Fuel Cell Generator on the Power System," UPEC '97.

[137] K. Zhou, and J.C Doyle, Essentials of Robust Control, New Jersy: Prentice Hall, 1998.

[138] R.D. Zimmerman, and H.D. Chiang: "Fast Decoupled Power Flow for Unbalanced Radial Distribution Systems," IEEE Trans. Power Systems, Vol. 10, No. 4, November 1995, pp. 2045-2052. 


\section{Appendix A}

\section{Configuration of Models}

\section{A.1 Full-Order Synchronous Generator Model}

To investigate the dynamic stability characteristics of a synchronous generator, a full-order model [69] is simulated. This model is used in the gas turbine DG and the diesel engine DG. The substation is represented as a simplified synchronous generator and will be discussed in the following section. The following equations are represented in the rotor reference frame. Figures A.1 - A.3 show the equivalent circuits. The equations (A.1-A.7) represent the $7^{\text {th }}$ order state space electrical part of the synchronous generator. The mechanical system are illustrated as equations (A.9- A.10). In this DG research, the full-order synchronous generator ingored the zero-axis part (A.7).

In the equations,

$d, q: \quad \mathrm{d}$ and $\mathrm{q}$ axis quantity;

$r, s: \quad$ rotor and stator quantity;

$l, m$ : leakage and magnetizing inductance;

$f, k$ : field and damper winding quantity.

The voltage equations are:

$$
\begin{gathered}
v_{q s}^{r}=-r_{s} i_{q s}^{r}+\omega_{r} \lambda_{d s}^{r}+p \lambda_{q s}^{r} \\
v_{d s}^{r}=-r_{s} i_{d s}^{r}-\omega_{r} \lambda_{q s}^{r}+p \lambda_{d s}^{r} \\
v_{f d}^{\prime r}=r_{f d}^{\prime} i_{f d}^{\prime r}+p \lambda_{f d}^{\prime r} \\
v_{k d}^{\prime r}=r_{k d^{\prime}}^{\prime} i_{k d}^{r}+p \lambda_{k d}^{\prime r} \\
v_{k q 1}^{\prime r}=r_{k q 1}^{\prime} i_{k q 1}^{\prime r}+p \lambda_{k q 1}^{\prime r}
\end{gathered}
$$




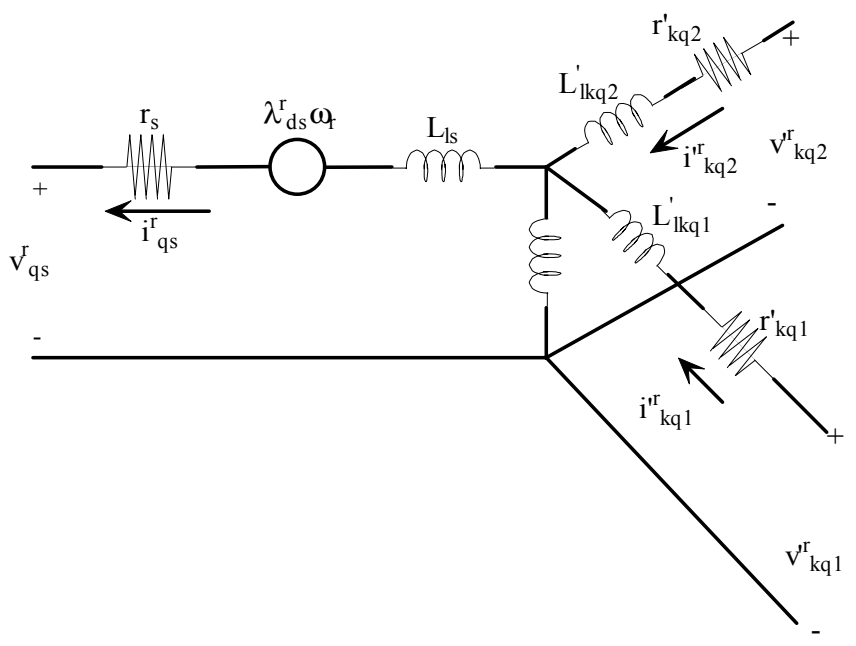

Figure A.1: Q-axis equivalent circuit of a synchronous generator.

$$
\begin{gathered}
v_{k q 2}^{\prime r}=r_{k q 2}^{\prime} i_{k q 2}^{\prime r}+p \lambda_{k q 2}^{\prime r} \\
v_{0 s}=-r_{s} i_{0 s}+p \lambda_{0 s}
\end{gathered}
$$

where $p=\frac{d}{d t}$.

The flux linkage equations are illustrated as:

$$
\left[\begin{array}{c}
\lambda_{q s}^{r} \\
\lambda_{d s}^{r} \\
\lambda_{f d}^{\prime r} \\
\lambda_{k d}^{\prime r} \\
\lambda_{k q 1}^{\prime r} \\
\lambda_{k q 2}^{\prime r} \\
\lambda_{0 s}^{\prime r}
\end{array}\right]=L_{-} s y n *\left[\begin{array}{c}
i_{q s}^{r} \\
i_{d s}^{r} \\
i_{f d}^{\prime r} \\
i_{k d}^{\prime r} \\
i_{k q 1}^{\prime r} \\
i_{k q 2}^{\prime r} \\
i_{0 s}
\end{array}\right]
$$

where 


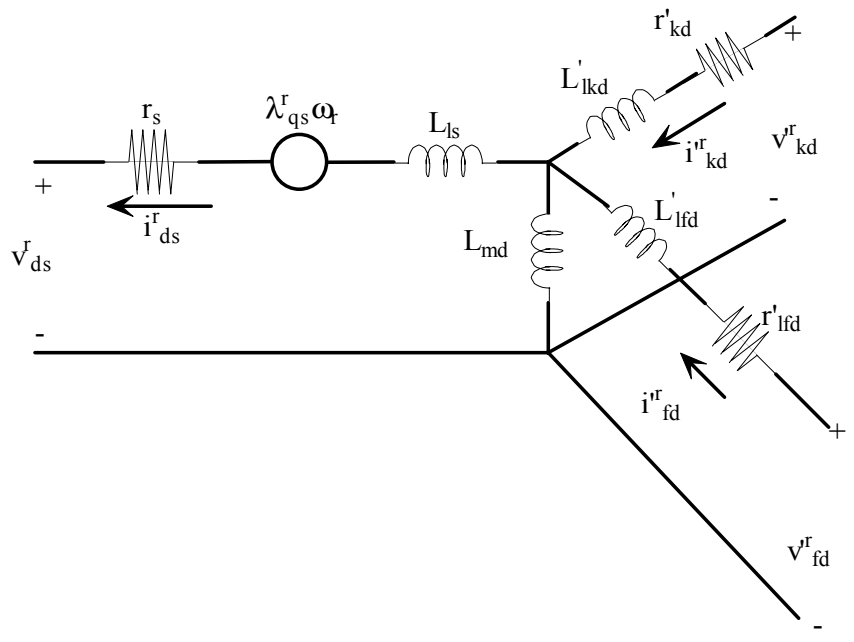

Figure A.2: D-axis equivalent circuit of a synchronous generator.

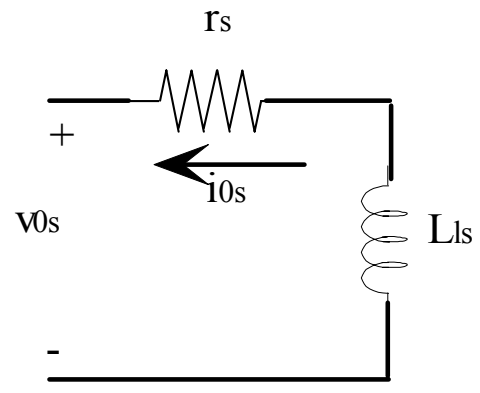

Figure A.3: Zero-axis equivalent circuit of a synchronous generator.

$L_{-}$syn $=\left[\begin{array}{ccccccc}-L_{l s}-L_{m q} & 0 & 0 & 0 & L_{m q} & L_{m q} & 0 \\ 0 & -L_{l s}-L_{m d} & L_{m d} & L_{m d} & 0 & 0 & 0 \\ -L_{m d} & 0 & L_{l f d}^{\prime}+L_{m d} & L_{m d} & 0 & 0 & 0 \\ -L_{m d} & 0 & L_{m d} & L_{l k d}^{\prime}+L_{m d} & 0 & 0 & 0 \\ 0 & -L_{m q} & 0 & 0 & L_{l k q 1}^{\prime}+L_{m q} & L_{m q} & 0 \\ 0 & -L_{m q} & 0 & 0 & L_{m q} & L_{k q 2}^{\prime}+L_{m q} & 0 \\ 0 & 0 & 0 & 0 & 0 & 0 & L_{l s}\end{array}\right]$

The mechanical system is: 

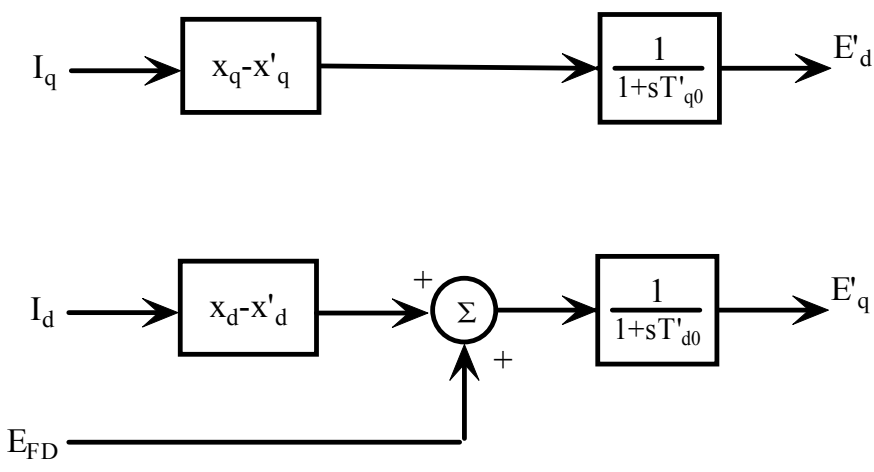

Figure A.4: Diagram of a simplified synchronous generator model.

$$
\begin{gathered}
p \omega_{r}=-\frac{1}{2 H}\left(T_{e}-T_{m}\right) \\
p \theta_{r}=\omega_{r}
\end{gathered}
$$

The torque in per unit is:

$$
T_{e}=\left(\frac{3}{2}\right)\left(\frac{P}{2}\right)\left(\lambda_{d s}^{r} i_{q s}^{r}-\lambda_{q s}^{r} i_{d s}^{r}\right)
$$

\section{A.2 Simplified Synchronous Generator Model}

A simplified [2] synchronous generator model is considered to represent the substation of the distribution system. In this model, the synchronous machine has two stator circuits and two rotor circuit. Figure A.4 shows the two-axis model.

The state equations of the electrical part are:

$$
\begin{gathered}
p E_{d}^{\prime}=\frac{1}{t_{q 0}^{\prime}}\left(-E_{d}^{\prime}+\left(x_{q}-x_{q}^{\prime}\right) I_{q}\right) \\
p E_{q}^{\prime}=\frac{1}{t_{d 0}^{\prime}}\left(-E_{q}^{\prime}+E_{F D}+\left(x_{d}-x_{d}^{\prime}\right) I_{d}\right)
\end{gathered}
$$

The electrical torque output is:

$$
T_{e}=E_{d}^{\prime} I_{d}+E_{q}^{\prime} I_{q}-\left(x_{q}^{\prime}-x_{d}^{\prime}\right) I_{d} I_{q}
$$

The state equations of the mechanical part are: 


$$
\begin{gathered}
p \omega=\frac{1}{t_{j}}\left(T_{m}-D \omega-T_{e}\right) \\
p \delta=\omega
\end{gathered}
$$

\section{A.3 Induction Machine}

A full-order induction machine includes the $4^{\text {th }}$ order DQ-axis state equations (see Figure A.5A.6), $1^{\text {st }}$ order electrical torque and $2^{\text {nd }}$ order zero-axis state equations (see Figure A.7) [69]. In this dissertation research, the induction machine is simulated as a $5^{\text {th }}$ order model and the 2nd order zero-axis equations are ignored. The electrical part is represented as $6^{\text {th }}$ order state space model (see equation A.16-A.21), and the mechanical part is a $1^{\text {st }}$ order model. Also, this model is used to represent the dynamic load model when the mechanical torque is positive.

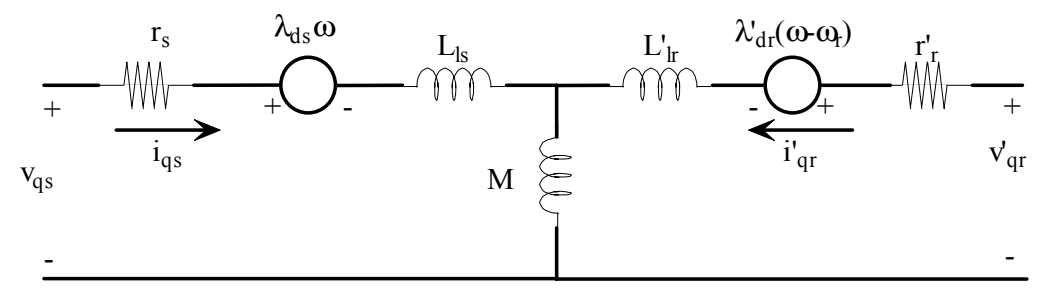

Figure A.5: Q-Axis equivalent circuit of an induction machine.

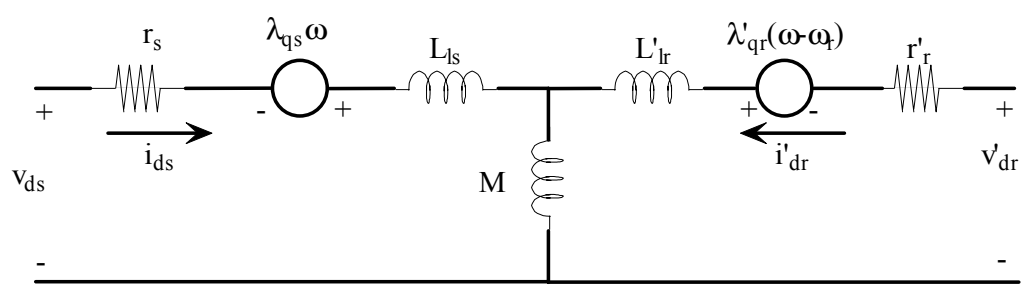

Figure A.6: D-Axis equivalent circuit of an induction machine.

The electrical part equations of the induction machine are:

$$
\begin{aligned}
& v_{q s}=r_{s} i_{q s}+\omega \lambda_{d s}+p \lambda_{q s} \\
& v_{d s}=r_{s} i_{d s}-\omega \lambda_{q s}+p \lambda_{d s}
\end{aligned}
$$



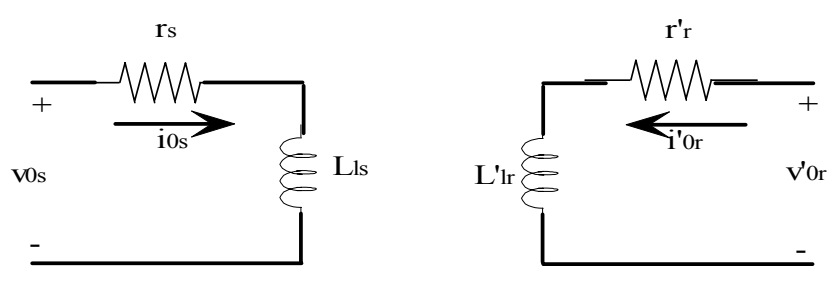

Figure A.7: Zero-axis equivalent circuit of an induction machine.

$$
\begin{gathered}
v_{q r}^{\prime}=r_{r}^{\prime} i_{q r}^{\prime}+\left(\omega-\omega_{r}\right) \lambda_{d r}^{\prime}+p \lambda_{q r}^{\prime} \\
v_{d r}^{\prime}=r_{r}^{\prime} i_{d r}^{\prime}-\left(\omega-\omega_{r}\right) \lambda_{q r}^{\prime}+p \lambda_{d r}^{\prime} \\
v_{o s}=r_{s} i_{0 s}+p \lambda_{0 s} \\
v_{o r}^{\prime}=r_{r}^{\prime} i_{0 r}^{\prime}+p \lambda_{0 r}^{\prime}
\end{gathered}
$$

where $p=\frac{d}{d t}$, and the flux linkage is:

$$
\left[\begin{array}{c}
\lambda_{q s} \\
\lambda_{d s} \\
\lambda_{q r}^{\prime} \\
\lambda_{d r}^{\prime} \\
\lambda_{0 s} \\
\lambda_{0 r}^{\prime}
\end{array}\right]=L_{-} i n d *\left[\begin{array}{c}
i_{q s} \\
i_{d s} \\
i_{q r}^{\prime} \\
i_{d r}^{\prime} \\
i_{0 s} \\
i_{0 r}^{\prime}
\end{array}\right]
$$

and

$$
L_{-} i n d=\left[\begin{array}{cccccc}
L_{l s}+M & 0 & M & 0 & 0 & 0 \\
0 & L_{l s}+M & 0 & M & 0 & 0 \\
M & 0 & L_{l r}^{\prime}+M & 0 & 0 & 0 \\
0 & M & 0 & L_{l r}^{\prime}+M & 0 & 0 \\
0 & 0 & 0 & 0 & L_{l s} & 0 \\
0 & 0 & 0 & 0 & 0 & L_{l r}^{\prime}
\end{array}\right]
$$

$\omega_{b}$ is the base electrical angular velocity used to calculate the inductive reactances. The mechanical part are represented in per unit as:

$$
p \omega_{r}=\frac{\omega_{b}}{2 H}\left(T_{e}-T_{m}\right)
$$


and the torque equation is expressed as:

$$
T_{e}=\lambda_{d s} i_{q s}-\lambda_{q s} i_{d s}
$$

Since machine and power system parameters are nearly always given in ohms or percent or per unit of a base impedance, it is convenient to express the voltage and flux linkage eqations in terms of reactances.

\section{A.4 Voltage Source Inverter}

To connect the fuel cell to the distribution system, the DC/AC inverter is used. The inverter can be a PWM voltage source inverter which uses the hysteretic current control. This controller can regulate the active power and reactive power by tracking the currents at certain references. The general control diagram [6] is shown is Figure A.8.

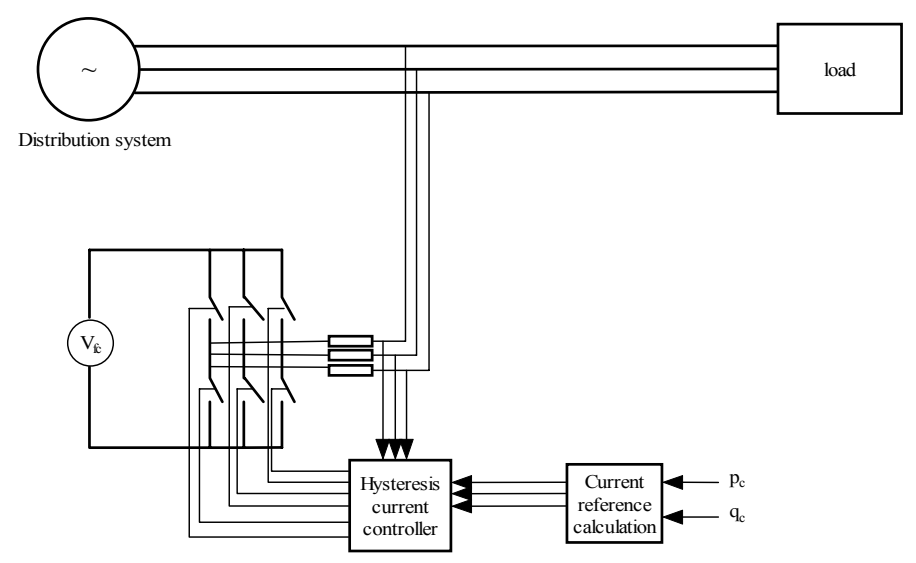

Figure A.8: Diagram of a PWM current source inverter in a distribution system.

\section{A.5 Test Systems}

IEEE-13 node test feeder is used to study the models and controller of the DGs. This system is simulated in Simulink, power system toolbox(PST) and power system blockset (PSB). The model simulated is mainly used to investigate the dynamic characteristics of the DGs and design the dynamic stability controller. The PST model is used to calculate the single phase power flow and 


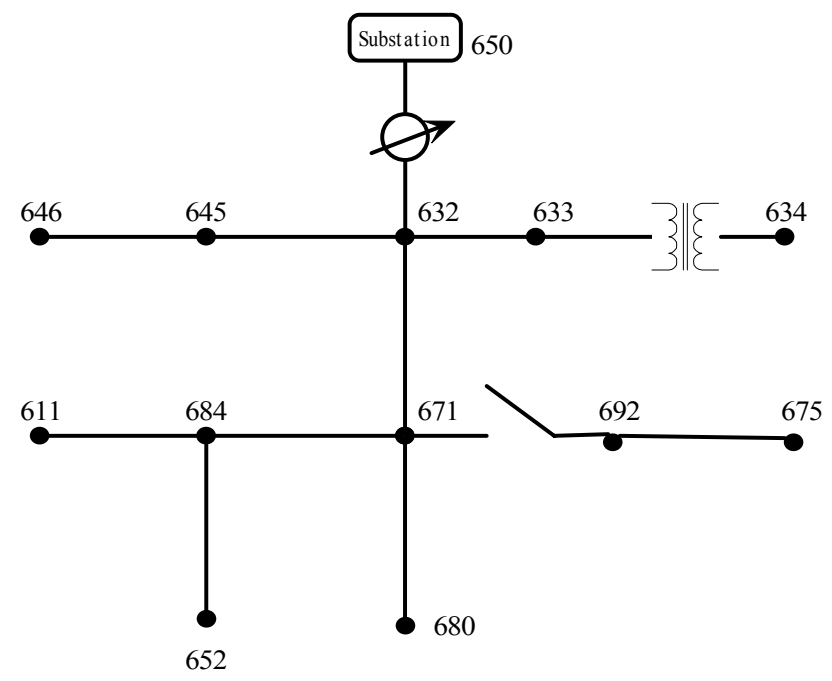

Figure A.9: One line diagram of IEEE-13 node radial feeder.

the values are used to initialize the state variables in Simulink model. The PSB model is used to test three-phase unbalanced and verify the designed controller.

\section{A.5.1 IEEE-13 Node Test Feeder}

The IEEE-13 node test feeder [24] is used as the test system to investigate the dynamic characteristics of the distribution system with DGs. Figure A.9 shows the test system with the two DGs. In the test, the connected transmission system is simulated as $138 \mathrm{kV}$ system, thus the substation transformer is $138 \mathrm{kV} / 4.16 \mathrm{kV}$.

\section{A.5.2 Line Segment Data}

Config. 601:

1. $\mathrm{Z}(\mathrm{R}+\mathrm{j} \mathrm{X})$ in ohms per mile

$$
Z=\left[\begin{array}{ccc}
0.3465+j 1.0179 & 0.1560+j 0.5017 & 0.1580+j 0.4236 \\
& 0.3375+j 1.0478 & 0.1535+j 0.3849 \\
& & 0.3414+j 1.0348
\end{array}\right]
$$

2. B in micro Siemens per mile 
Table A.1: Line segment data of IEEE 13 node test feeder.

\begin{tabular}{|l|l|l|l|}
\hline Node A & Node B & Length(ft.) & Config. \\
\hline 632 & 645 & 500 & 603 \\
\hline 632 & 633 & 500 & 602 \\
\hline 633 & 634 & 0 & XFM-1 \\
\hline 645 & 646 & 300 & 603 \\
\hline 650 & 632 & 2000 & 601 \\
\hline 684 & 652 & 800 & 607 \\
\hline 632 & 671 & 2000 & 601 \\
\hline 671 & 684 & 300 & 604 \\
\hline 671 & 680 & 1000 & 601 \\
\hline 671 & 692 & 0 & Switch \\
\hline 684 & 611 & 300 & 605 \\
\hline 692 & 675 & 500 & 606 \\
\hline
\end{tabular}

$$
B=\left[\begin{array}{ccc}
6.2998 & -1.9958 & -1.2595 \\
& 5.9597 & -0.7417 \\
& & 5.6386
\end{array}\right]
$$

Config. 602:

1. $\mathrm{Z}(\mathrm{R}+\mathrm{j} \mathrm{X})$ in ohms per mile

$$
Z=\left[\begin{array}{ccc}
0.7526+j 1.1814 & 0.1580+j 0.4236 & 0.1560+j 0.5017 \\
& 0.7475+j 1.1983 & 0.1535+j 0.3849 \\
& & 0.7436+j 1.2112
\end{array}\right]
$$

2. B in micro Siemens per mile

$$
B=\left[\begin{array}{ccc}
5.6990 & -1.0817 & -1.6905 \\
& 5.1795 & -0.6588 \\
& & 5.4246
\end{array}\right]
$$

Config. 603:

1. $\mathrm{Z}(\mathrm{R}+\mathrm{jX})$ in ohms per mile

$$
Z=\left[\begin{array}{ccc}
0 & 0 & 0 \\
& 1.3294+j 1.3471 & 0.2066+j 0.4591 \\
& & 1.3238+j 1.3569
\end{array}\right]
$$

2. B in micro Siemens per mile

$$
B=\left[\begin{array}{ccc}
0 & 0 & 0 \\
& 4.7097 & -0.8999 \\
& & 4.6658
\end{array}\right]
$$


Config. 604:

1. $\mathrm{Z}(\mathrm{R}+\mathrm{jX})$ in ohms per mile

$Z=\left[\begin{array}{ccc}1.3238+j 1.3569 & 0 & 0.2066+j 0.4591 \\ & 0 & 0 \\ & & 1.3294+j 1.3471\end{array}\right]$

2. B in micro Siemens per mile

$B=\left[\begin{array}{ccc}4.6658 & 0 & -0.8999 \\ & 0 & 0 \\ & & 4.7097\end{array}\right]$

Config. 605:

1. $\mathrm{Z}(\mathrm{R}+\mathrm{j} \mathrm{X})$ in ohms per mile

$Z=\left[\begin{array}{ccc}0 & 0 & 0 \\ & 0 & 0 \\ & & 1.3292+j 1.3475\end{array}\right]$

2. B in micro Siemens per mile

$B=\left[\begin{array}{ccc}0 & 0 & 0 \\ & 0 & 0 \\ & & 4.5193\end{array}\right]$

Config. 606:

1. $\mathrm{Z}(\mathrm{R}+\mathrm{j} \mathrm{X})$ in ohms per mile

$Z=\left[\begin{array}{ccc}0.7982+j 0.4463 & 0.3192+j 0.0328 & 0.2849-j 0.0143 \\ & 0.7891+j 0.4041 & 0.3192+j 0.0328 \\ & & 0.7982+j 0.4463\end{array}\right]$

2. B in micro Siemens per mile

$B=\left[\begin{array}{ccc}96.8897 & 0 & 0 \\ & 96.8897 & 0 \\ & & 96.8897\end{array}\right]$

Config. 607:

1. $\mathrm{Z}(\mathrm{R}+\mathrm{jX})$ in ohms per mile

$Z=\left[\begin{array}{ccc}1.4925+j 0.6231 & 0 & 0 \\ & 0 & 0 \\ & & 0\end{array}\right]$

2. $\mathrm{B}$ in micro Siemens per mile 


$$
B=\left[\begin{array}{ccc}
97.7806 & 0 & 0 \\
& 0 & 0 \\
& & 0
\end{array}\right]
$$

The system has unbalanced spot and distributed loads. The three-phase power flow is shown in Table A.2.

Table A.2: Three-phase current and voltage of distribution system without DG.

\begin{tabular}{|c|c|c|c|c|c|c|}
\hline Line & V-Phase A & V-Phase B & V-Phase C & I-Phase A & I-Phase B & I-Phase C \\
\hline $650-632$ & $2478 \angle-2.30^{\circ}$ & $2555 \angle-121.19^{\circ}$ & $2433 \angle 117.73^{\circ}$ & $533.4 \angle-22.23^{\circ}$ & $438.7 \angle-138.21^{\circ}$ & $569.8 \angle 95.32^{\circ}$ \\
\hline $632-633$ & $2470 \angle-2.36^{\circ}$ & $2550 \angle-121.23^{\circ}$ & $2426 \angle 117.74^{\circ}$ & $78.92 \angle-35.73^{\circ}$ & $63.5 \angle-156.84^{\circ}$ & $60.11 \angle 82.07^{\circ}$ \\
\hline $633-634$ & $272.8 \angle-2.23^{\circ}$ & $284.4 \angle-121.06^{\circ}$ & $270.6 \angle 117.92^{\circ}$ & $689.6 \angle-36.74^{\circ}$ & $555.4 \angle-157.93^{\circ}$ & $528.6 \angle 81.05^{\circ}$ \\
\hline $632-645$ & 0 & $2552 \angle-121.50^{\circ}$ & $2434 \angle 117.25^{\circ}$ & 0 & $151.8 \angle-142.72^{\circ}$ & $65.19 \angle 58.23^{\circ}$ \\
\hline $645-646$ & 0 & $2555 \angle-121.58^{\circ}$ & $2433 \angle 117.14^{\circ}$ & 0 & $66.49 \angle-122.24^{\circ}$ & $66.08 \angle 57.54^{\circ}$ \\
\hline $632-671$ & $2411 \angle-5.13^{\circ}$ & $2580 \angle-121.77^{\circ}$ & $2340 \angle 116.05^{\circ}$ & $451.8 \angle-20.56^{\circ}$ & $198.3 \angle-128.71^{\circ}$ & $409.4 \angle 103.07^{\circ}$ \\
\hline $671-692$ & $2411 \angle-5.13^{\circ}$ & $2580 \angle-121.77^{\circ}$ & $2340 \angle 116.05^{\circ}$ & $224.7 \angle-17.18^{\circ}$ & $71.63 \angle-57.29^{\circ}$ & $170.7 \angle 111.18^{\circ}$ \\
\hline $692-675$ & $2402 \angle-5.59^{\circ}$ & $2592 \angle-121.79^{\circ}$ & $2328 \angle 116.00^{\circ}$ & $201.9 \angle-4.41^{\circ}$ & $69.94 \angle-57.71^{\circ}$ & $117.1 \angle 113.63^{\circ}$ \\
\hline $671-684$ & $2409 \angle-5.21^{\circ}$ & 0 & $2334 \angle 115.93^{\circ}$ & $53.27 \angle-4.62^{\circ}$ & 0 & $69.14 \angle 123.56^{\circ}$ \\
\hline $684-611$ & 0 & 0 & $2329 \angle 115.78^{\circ}$ & 0 & 0 & $69.18 \angle 122.99^{\circ}$ \\
\hline $684-652$ & $2395 \angle-5.23^{\circ}$ & 0 & 0 & $64.02 \angle-39.13^{\circ}$ & 0 & 0 \\
\hline
\end{tabular}




\section{Appendix B}

\section{Parameters for Simulation}

\section{B.1 Parameters for SI system in Chapter 3}

1) Per unit system

$\mathrm{V}_{\text {base }}=23 \mathrm{kV}, \mathrm{S}_{\text {base }}=20.5 \mathrm{MVA}, \mathrm{Z}_{\text {base }}=25.8049 \mathrm{~W}$

2) Substation

Generator: $\quad \mathrm{S}_{b}=129 \mathrm{MVA}, \mathrm{H}=600 \mathrm{~s}, \mathrm{x}_{d}^{\prime}=0.1, \mathrm{x}_{d}=\mathrm{x}_{q}=\mathrm{x}_{q}^{\prime}=\mathrm{T}_{d 0}^{\prime}=\mathrm{T}_{q 0}^{\prime}=0$.

Transformer: $\mathrm{S}_{b}=42.0 \mathrm{MVA}, \mathrm{Z}_{t}=0.1$ (self base)

3) The distribution line

$\mathrm{R}+\mathrm{jX}=0.149+\mathrm{j} 0.4283 \mathrm{ohm} / \mathrm{mile}$. (Aluminum conductor, hard-drawn, $61 \%$ conductivity)

4) Distributed Generation

Generator: $\quad \mathrm{S}_{b}=4.0 \mathrm{MVA}, \mathrm{H}=9.0 \mathrm{~s}, \mathrm{x}_{d}=2.0, \mathrm{x}_{d}^{\prime}=0.263, \mathrm{x}_{q}=1.6, \mathrm{x}_{q}^{\prime}=0.3, \mathrm{~T}_{d 0}^{\prime}=1.105$, $\mathrm{T}_{q 0}^{\prime}=0.01$.

Exciter: $\mathrm{K}_{A}=38.0, \mathrm{~T}_{A}=0.1, \mathrm{~V}_{R \max }=1.05, \mathrm{~V}_{R \min }=-1.05, \mathrm{~T}_{B}=\mathrm{T}_{C}=0$.

Turbine: $1 / \mathrm{R}=24.5, \mathrm{~T}_{\max }=1.0, \mathrm{~T}_{s}=0.1, \mathrm{~T}_{G}=0.5, \mathrm{~T}_{3}=0$.

DG transformer: $\mathrm{S}_{b}=4.0 \mathrm{MVA}, \mathrm{R}_{t}+\mathrm{j} \mathrm{X}_{t}=0.05+\mathrm{j} 0.05$ (self base)

\section{B.2 Parameters for the Test System in Chapter 4}

Table B.1 shows the parameters for the test system simulation in Chapter 4 . This test system is also used in Chapters 5-10. 
Table B.1: Parameters for the test system simulation.

\begin{tabular}{|l|l|l|l|}
\hline \hline Base values & \multicolumn{2}{|l|}{} \\
\hline$S_{\text {base }}=4.0 M V A$ & $V_{\text {base }}=4.16 k V$ & & \\
\hline Substation & $x_{q}=0.8645$ & $x_{d}^{\prime}=0.1198$ & $x_{q}^{\prime}=0.1198$ \\
\hline$x_{d}=0.8958$ & $T_{d 0}=8.96$ & $T_{q 0}=0.1$ & $H=2364$ \\
\hline$r=0$ & & & \\
\hline$D=0.1$ & \multicolumn{5}{|l|}{} \\
\hline Synchronous generator & $X_{d}=1.8$ \\
\hline$r_{s}=0.003$ & $X_{l s}=0.19$ & $X_{q}=1.8$ & $r_{k d}^{\prime}=0.01334$ \\
\hline$r_{k q 1}^{\prime}=0.00178$ & $X_{l k q 1}^{\prime}=0.8125$ & $r_{f d}^{\prime}=0.000929$ & \\
\hline$X_{l k d}^{\prime}=0.08125$ & $H=5.6$ & & $P_{\min }=-0.1$ \\
\hline Gas Turbine & \multicolumn{5}{|l}{} \\
\hline$K_{d}=25$ & $T_{g}=0.05$ & $P_{\max }=1.2$ & $T_{3}=0.2$ \\
\hline$T_{v}=0.05$ & $T_{f 1}=0.4$ & & $T_{\min }=0$ \\
\hline Diesel Engine & $T_{1}=0.01$ & $T_{2}=0.02$ & $T_{6}=0.0384$ \\
\hline$K=4.0$ & $T_{5}=0.009$ & $T^{\prime}$ & \\
\hline$T_{4}=0.25$ &
\end{tabular}

\section{B.3 Parameters for the SOFC Simulation}

Table B.2 shows the parameters for the SOFC simulation in Chapters $6 \& 7$.

Table B.2: Parameters for the SOFC simulation.

\begin{tabular}{|l|l|l|l|}
\hline \hline SOFC \\
\hline$N_{0}=384$ & $K_{H 2}=8.43 e^{-4}$ & $K_{H 2 O}=2.81 e^{-4}$ & $K_{O 2}=2.52 e^{-3}$ \\
\hline$t_{H 2}=26.1$ & $t_{H 2 O}=78.3$ & $t_{O 2}=2.91$ & $r=0.126$ \\
\hline$R_{s}=0.9$ & $L_{s}=0.01$ & & \\
\hline
\end{tabular}

\section{B.4 Parameters for the Wind Turbine DG}

Table B.3 shows the parameters for the wind turbine DG simulation in Chapters $8 \& 9$.

\section{B.5 Parameters for TCBR Simulation in Chapter 11}

Since the TCBR simulated in power system blockset (PSB), the paramters of a gas turbine DG and a diesel engine DG are based on the $P_{b 1}$ and $P_{b 2}$ respectively. 
Table B.3: Parameters of the wind-turbine DG.

\begin{tabular}{|l|l|l|l|}
\hline \hline \multicolumn{4}{|l|}{ Induction machine } \\
\hline $\mathrm{X}_{l s}=0.135$ & $\mathrm{X}^{\prime}{ }_{l r}=0.075$ & $\mathrm{X}_{M}=4.161$ & $\mathrm{r}_{s}=0.0059$ \\
\hline $\mathrm{r}^{\prime}{ }_{r}=0.0339$ & $\mathrm{H}=0.5$ & & \\
\hline Wind-turbine & \\
\hline $\mathrm{R}=69.96 \mathrm{~m}$ & $\mathrm{~V}_{\text {rated }}=9.3 \mathrm{~m} / \mathrm{s}$ & $\rho_{\text {air }}=1.225$ & \\
\hline $\mathrm{K}_{i}=6.2$ & $\mathrm{~K}_{p}=6.2$ & & \\
\hline $\mathrm{SVC}$ & & \\
\hline $\mathrm{X}_{C}=0.5$ & $\mathrm{X}_{L}=0.476$ & $\mathrm{~T}_{b}=0.00417$ & $\mathrm{~T}_{d}=0.0014$ \\
\hline $\mathrm{K}_{R}=33.3$ & $\mathrm{~T}_{R}=0.1$ & & \\
\hline
\end{tabular}

Table B.4: Parameters for the TCBR simulation.

\begin{tabular}{|l|l|l|l|}
\hline \hline \multicolumn{5}{|l|}{ Synchronous Generator } \\
\hline $\mathrm{P}_{b 1}=2.1 \mathrm{MW}$ & $\mathrm{P}_{b 2}=1.1 \mathrm{MW}$ & $\mathrm{V}_{b}=4160 \mathrm{~V}$ & \\
\hline $\mathrm{X}_{d}=2.03$ & $\mathrm{X}^{\prime}{ }_{d}=0.26$ & $\mathrm{X}^{\prime}{ }_{d}=0.173$ & $\mathrm{X}_{q}=1.6$ \\
\hline $\mathrm{X}^{\prime}{ }_{q}=0.2$ & $\mathrm{X}_{l}=0.18$ & $\mathrm{~T}^{\prime}{ }_{d}=1.105$ & $\mathrm{~T}^{\prime}{ }_{d}=0.035$ \\
\hline $\mathrm{X}^{\prime}{ }^{\prime}{ }_{0}=0.035$ & $\mathrm{R}=2.85 \mathrm{e}-3$ & $\mathrm{H}=2.6$ & \\
\hline Gas Turbine \\
\hline $\mathrm{K}_{d}=25$ & $\mathrm{~T}_{g}=0.05$ & $\mathrm{P}_{\max }=1.2$ & $\mathrm{P}_{\min }=-0.1$ \\
\hline $\mathrm{T}_{v}=0.05$ & $\mathrm{~T}_{f 1}=0.4$ & & \\
\hline Diesel Engine & $\mathrm{T}_{1}=0.01$ & $\mathrm{~T}_{2}=0.02$ & $\mathrm{~T}_{3}=0.2$ \\
\hline $\mathrm{K}=4.0$ & $\mathrm{~T}_{5}=0.009$ & $\mathrm{~T}_{6}=0.0384$ & $\mathrm{~T}_{\min }=0$ \\
\hline $\mathrm{T}_{4}=0.25$ & $\mathrm{~K}_{a 0}=200$ & $\mathrm{~T}_{a}=0.002$ & $\mathrm{~K}_{e 0}=1.0$ \\
\hline Excitation System & $\mathrm{T}_{f 0}=0.001$ \\
\hline $\mathrm{T}_{r}=20 \mathrm{e}-3$ & $\mathrm{~T}_{b}=0$ & $\mathrm{~K}_{p}=0$ \\
\hline $\mathrm{T}_{e}=0$ & $\mathrm{E}_{f \max }=6.0$ & $\mathrm{E}_{f \min }=0$ \\
\hline $\mathrm{T}_{f}=0.1$ & $\mathrm{X}_{0}=1.1 \Omega$ & \\
\hline $\mathrm{TCBR}$ & & \\
\hline $\mathrm{R}_{0}=12 \Omega$ & \multicolumn{5}{|l}{} \\
\hline
\end{tabular}




\section{Appendix C}

\section{Program Structure of Simulation}

In this dissertation research, a software package is developed in Matlab/Simulink. This package includes: DG models, power distribution network models, measurement units and analysis tools.

Figure C.1 shows the general structure of the simulation system. In Figure C.1, the DGi is the distributed generation, $\mathrm{PEj}$ is the power electronics device, and the network includes the distribution lines, transformers and static loads. The dynamic loads are represented as induction motors, so they can be considered as the DGs absorting the real power.

The Simulink workspace is used as running environment. Each of the models are connected in Simulink. The numerical calculation methodologies are also provides by Simulink. During the dynamic simulation procedure, the Matlab functions are called. These functions are written in *.m files.

An example of the general simulation structure in Simulink is shown in Figure C.2. This system is used to study the wind turbine DG in Chapters $8 \& 9$.

The three-phase approach is implemented in power system blockset (PSB). It has a different program structure.

\section{C.1 Models}

The models in this software package include: transient synchronous generator model, full-order synchronous generator model, induction machince model, gas-turbine, diesel engine, wind turbine, solid oxide fuel cell (SOFC) model, phosphoric acid fuel cell (PAFC) model, current source inverter (CSI) model, and static var compensator (SVC) model, etc. As an example, the SOFC model is illustrated in Figure C.3. 


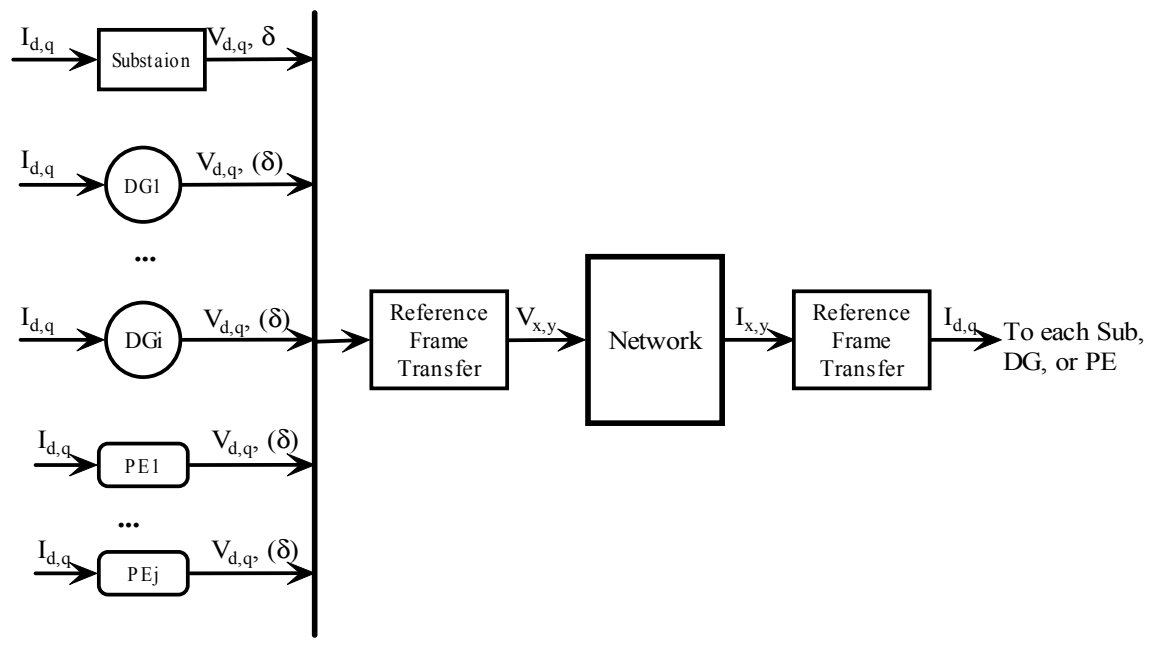

Figure C.1: General structure of the simulation system.

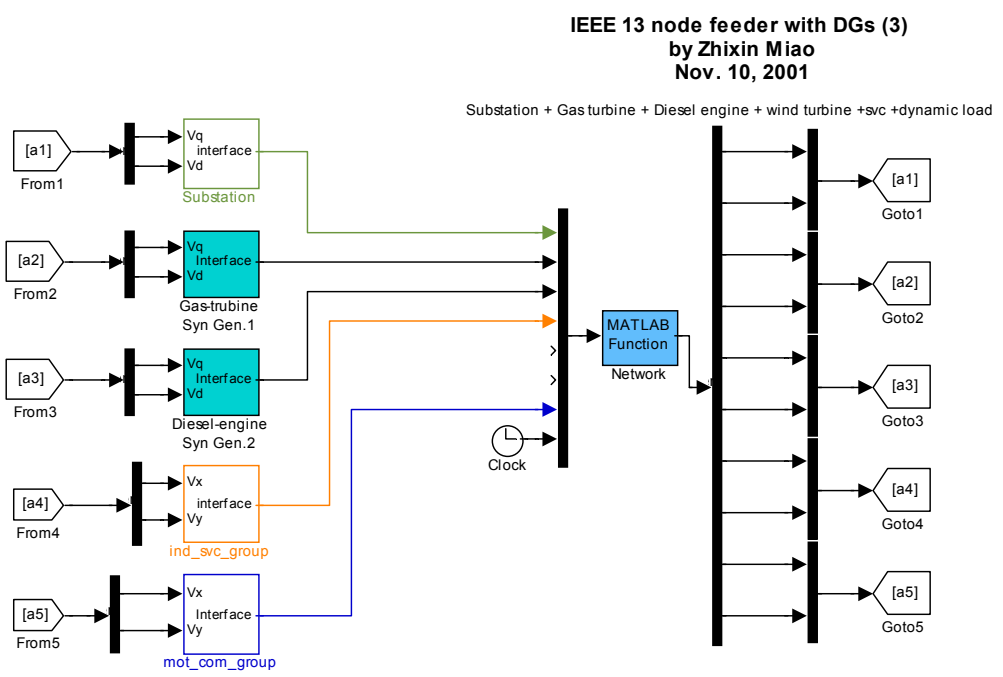

Figure C.2: General structure of the simulation program in Simulink. 


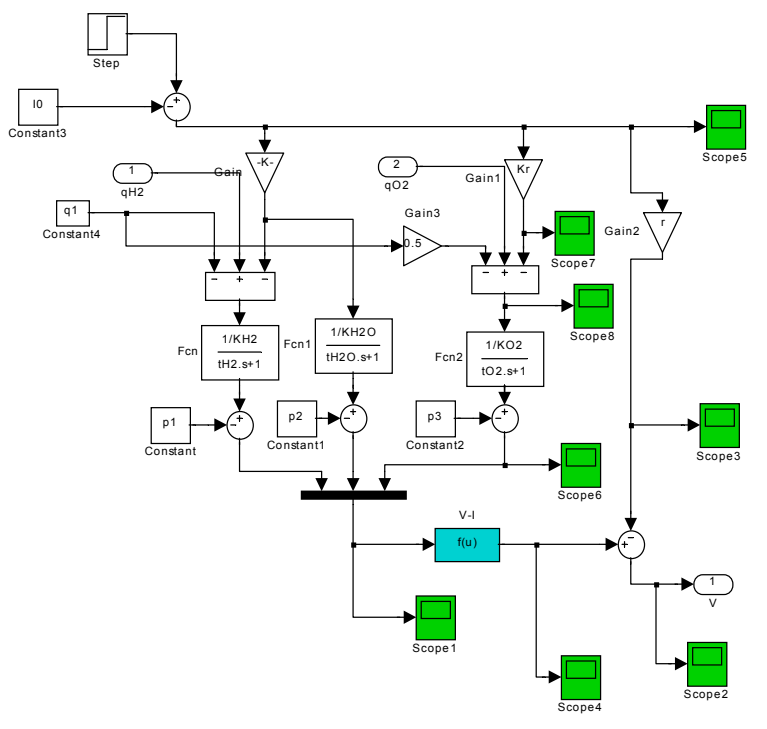

Figure C.3: Simulation of a SOFC in Simulink.

The transient synchronous generator is to represent the substation; the full-order synchonous generator model is connected to gas turbine, diesel engine to represent the gas-turbine, diesel engine DGs; $5^{\text {th }}$ induction machine model is connected to the wind turbine to represent wind turbine DG, it is also used to represent the dynamic load.

All the models are simulated in rotor reference frame $(d, q)$. Output of each model are the voltage and input is the current.

\section{C.2 Network}

The network is represented by algebraic equation.

$$
I=Y V
$$

where $I$ is the input current of each node, $V$ is the voltage of each node. $Y$ is the network matrix.

$I$ and $V$ are complex quantities, in order to make the computation of all real quantities, $I$ and $V$ are seperated as real and image quantities. 


$$
\left[\begin{array}{c}
I_{x 1} \\
I_{y 1} \\
\ldots \\
I_{x i} \\
I_{y i} \\
\ldots \\
I_{x n} \\
I_{y n}
\end{array}\right]=\left[\begin{array}{cccccccc}
G_{11} & B_{11} & & G_{1 i} & B_{1 i} & & G_{1 n} & B_{1 n} \\
B_{11} & -G_{11} & & B_{1 i} & -G_{1 i} & & B_{1 n} & -G_{1 n} \\
& & & \ldots & & & & \\
G_{i 1} & B_{i 1} & \ldots & G_{i i} & B_{i i} & \ldots & G_{i n} & B_{i n} \\
B_{i 1} & -G_{i 1} & & B_{i i} & -G_{i i} & & B_{i n} & -G_{i n} \\
& & & \ldots & & & & \\
G_{n 1} & B_{n 1} & & G_{n i} & B_{n i} & & G_{n n} & B_{n n} \\
B_{n 1} & -G_{n 1} & & B_{n i} & -G_{n i} & & B_{n n} & -G_{n n}
\end{array}\right]\left[\begin{array}{c}
V_{x 1} \\
V_{y 1} \\
\ldots \\
V_{x i} \\
V_{y i} \\
\ldots \\
V_{x n} \\
V_{y n}
\end{array}\right]
$$

A simple example is used in as the network function in Matlab is shown as below:

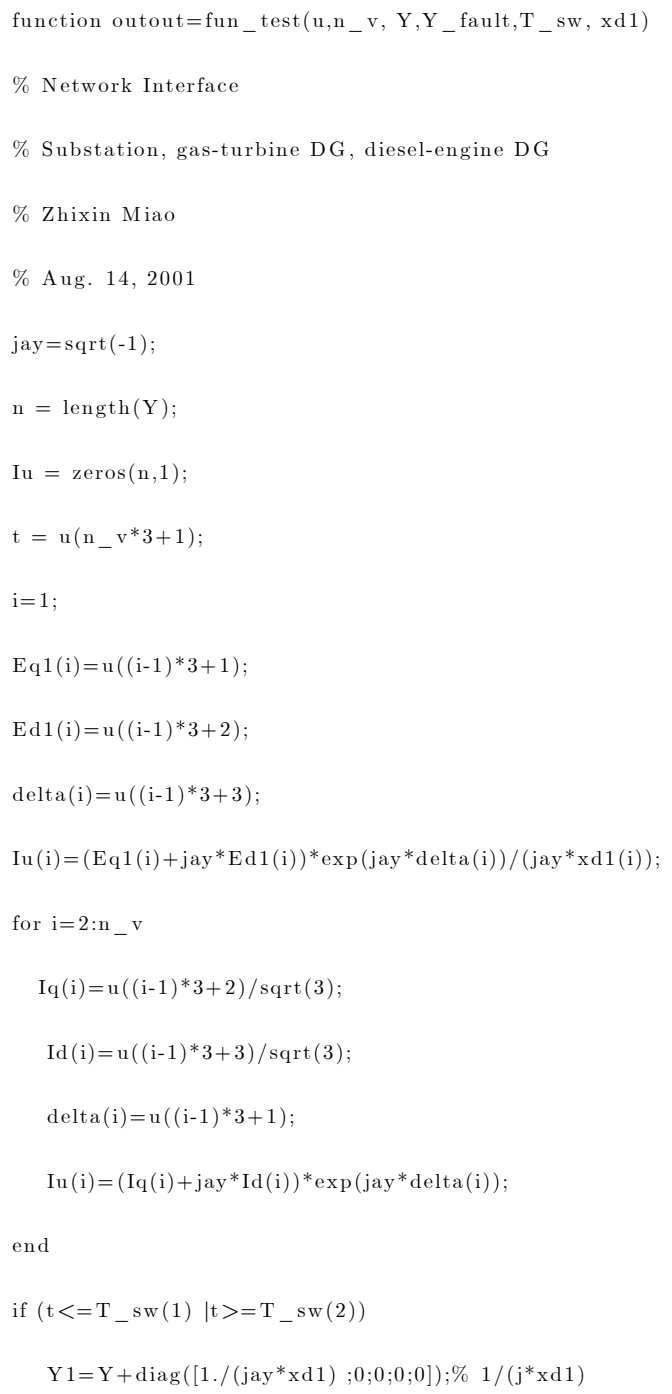




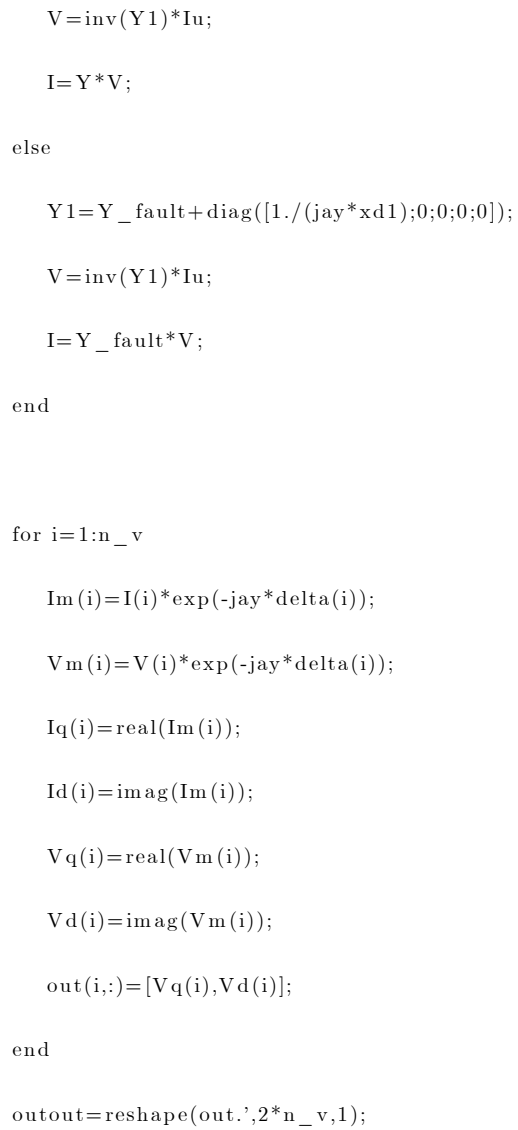

\section{C.3 Analysis Tools}

The analysis tools are developed to evaluate the linearized system model and to design the dynamic stability controller to improve the oscillation damping of the system.

The analysis tools consist of: nonlinear models' linearization in Simulink, eigenvalues and eigensensitivity calculation, participation matrix, residue calculation, critical eigenvalues identification, output feedback optimal control design.

Also, most of the linear system toolbox in MATLAB can be used by the linearized model.

\section{C.4 Features}

This software package setup a platform to study the DG models, the impacts of the DGs on the power distribution system, and to design the controller improve the dynamic stability of the system. The features of the software package can be summarized: 
1) Each DG model is developed independently, so it can be used to investigate the characteristics of each specific DG;

2) The inputs and outputs of each DG model are unified as current (I) and voltage (V) respectively. This unified structure makes it easier to connect multi-DGs to the power distribution system;

3) The Simulink allows all the basic functions of the Simulink such as the numerical calculation methodology, the measurement units;

4) Modular design allows the software is very convenient to be expanded, to include the newly emerged DGs. 


\section{Appendix D}

\section{Robust Analysis Program}

Given linear system $\left(A_{0}, B_{0}, C_{0}\right)$, and the parameter uncertainty $\Delta A=A_{1}-A_{0}$, where $A_{1}$ is the system coefficient matrix when the dynamic load has an increase. $\left(A_{0}, B_{0}, C_{0}\right)$ is obtained from the nonlinear model in Matlab/Simulink.

The robust analysis program is as the following:

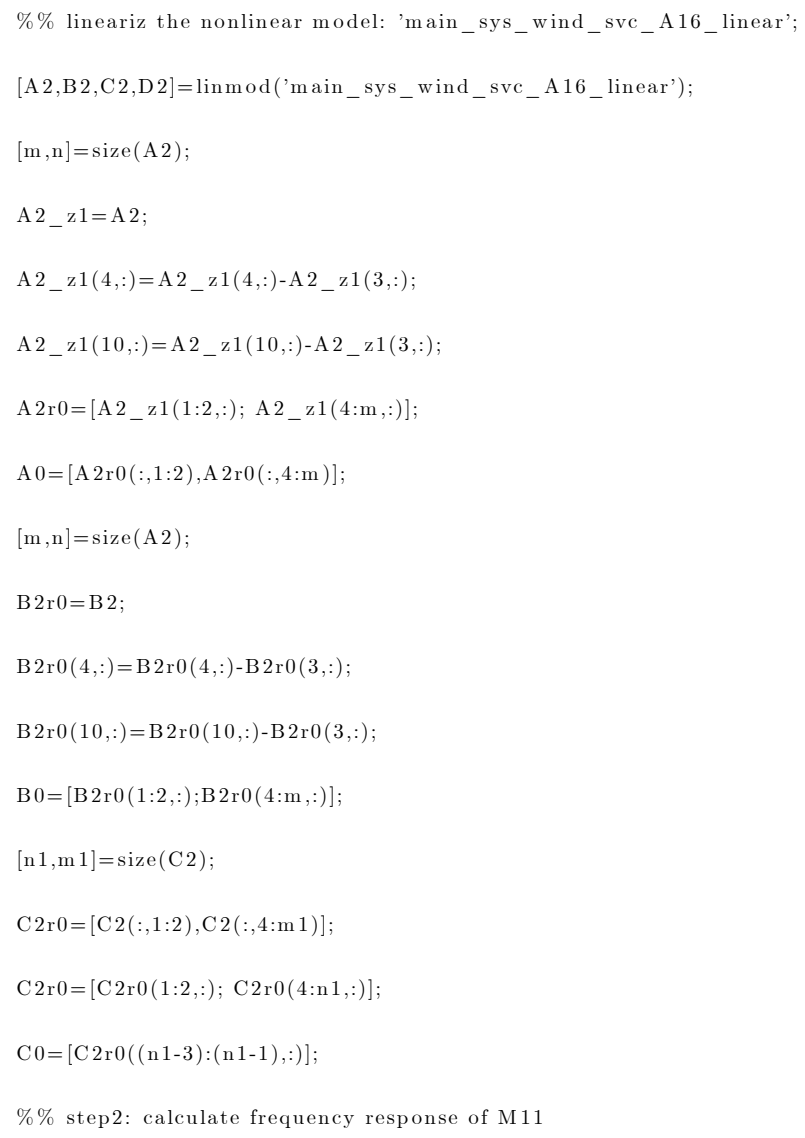




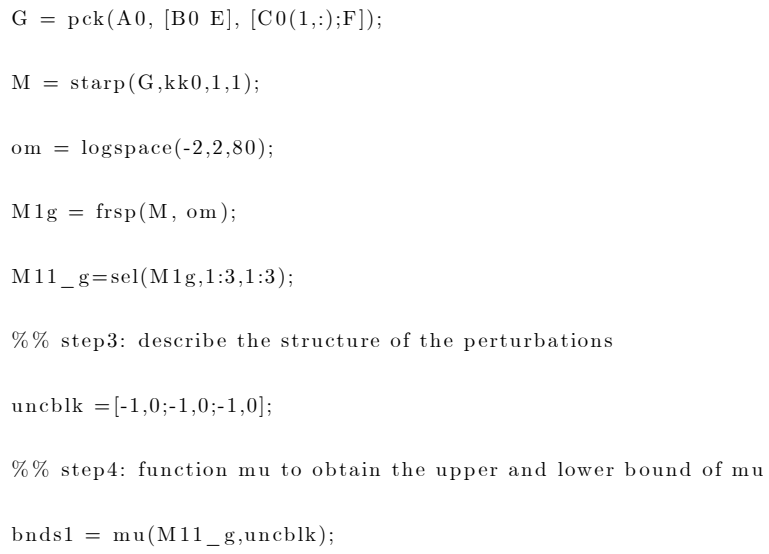




\section{VITA}

Zhixin Miao was born in October 1970 in Nanjing, Jiangsu Province, P.R. China. He entered Huazhong University of Science \& Technology (Wuhan, China) in 1988 and got his Bachelor of Science degree in 1992. In 1994, he entered the graduate school of Nanjing Automation Research Institute, Ministry of Electric Power, P.R. China, and received his Master of Science degree in 1997. Both his B.S. and M.S. degrees are in electrical engineering. From 1992 to 1994 and from 1997 to 1999, he worked as an electrical engineer in power system protection department of Nanjing Automation Research Institute. In 1999, he enrolled West Virginia University as a Ph.D. student. Zhixin Miao worked as a research assistant in Distributed Generation projects in West Virginia University. He was married with Lingling Fan in 1997. 